Cochrane Database of Systematic Reviews

\title{
Olanzapine alone or in combination for acute mania (Review)
}

Rendell JM, Gijsman HJ, Keck PK, Goodwin G, Geddes J

Rendell JM, Gijsman HJ, Keck PK, Goodwin G, Geddes J.

Olanzapine alone or in combination for acute mania.

Cochrane Database of Systematic Reviews 2003, Issue 1. Art. No.: CD004040.

DOI: 10.1002/14651858.CD004040.

www.cochranelibrary.com 
TABLE OF CONTENTS

ABSTRACT

PLAIN LANGUAGE SUMMARY

BACKGROUND

OBJECTIVES

METHODS

RESULTS

DISCUSSION

AUTHORS' CONCLUSIONS

ACKNOWLEDGEMENTS

REFERENCES

CHARACTERISTICS OF STUDIES

DATA AND ANALYSES

Analysis 1.1. Comparison 1 Olanzapine v placebo, Outcome 1 Mean change in YMRS.

Analysis 1.2. Comparison 1 Olanzapine v placebo, Outcome 2 Mean change in CGI-BP mania.

Analysis 1.3. Comparison 1 Olanzapine v placebo, Outcome 3 Failure to respond - YMRS.

Analysis 1.4. Comparison 1 Olanzapine v placebo, Outcome 4 Failure to achieve remission - YMRS.

Analysis 1.5. Comparison 1 Olanzapine v placebo, Outcome 5 Mean Change in 21-item HAMD - all participants. .....................

Analysis 1.6. Comparison 1 Olanzapine v placebo, Outcome 6 Mean change in CGI-BP depression.

Analysis 1.7. Comparison 1 Olanzapine v placebo, Outcome 7 Mean change in PANNS - total symptom score. .........................

Analysis 1.8. Comparison 1 Olanzapine v placebo, Outcome 8 Mean change in PANNS - positive symptom score. ...................

Analysis 1.9. Comparison 1 Olanzapine v placebo, Outcome 9 Mean change in PANNS - negative symptom score. ..................

Analysis 1.10. Comparison 1 Olanzapine v placebo, Outcome 10 Mean change in CGI - BP severity of overall bipolar illness. ....

Analysis 1.11. Comparison 1 Olanzapine v placebo, Outcome 11 Mean dose of anticholinergic medication.

Analysis 1.12. Comparison 1 Olanzapine v placebo, Outcome 12 Use of benzodiazepines.

Analysis 1.13. Comparison 1 Olanzapine v placebo, Outcome 13 Failure to respond - YMRS (excluding early withdrawals). .......

Analysis 1.14. Comparison 1 Olanzapine v placebo, Outcome 14 Failure to remit- YMRS - (excluding early withdrawals). .........

Analysis 1.15. Comparison 1 Olanzapine v placebo, Outcome 15 Failure to complete treatment.

Analysis 1.16. Comparison 1 Olanzapine v placebo, Outcome 16 Treatment emergent depression.

Analysis 1.17. Comparison 1 Olanzapine v placebo, Outcome 17 SAS Scale.

Analysis 1.18. Comparison 1 Olanzapine v placebo, Outcome 18 Barnes Akathisia Scale.

Analysis 1.19. Comparison 1 Olanzapine v placebo, Outcome 19 AIMS.

Analysis 1.20. Comparison 1 Olanzapine v placebo, Outcome 20 Weight Gain (continuous data).

Analysis 1.21. Comparison 1 Olanzapine v placebo, Outcome 21 Somnolence.

Analysis 1.22. Comparison 1 Olanzapine v placebo, Outcome 22 Dry Mouth.

Analysis 1.23. Comparison 1 Olanzapine v placebo, Outcome 23 Dizziness.

Analysis 1.24. Comparison 1 Olanzapine v placebo, Outcome 24 Agitation.

Analysis 1.25. Comparison 1 Olanzapine v placebo, Outcome 25 Asthenia.

Analysis 1.26. Comparison 1 Olanzapine v placebo, Outcome 26 Headache.

Analysis 1.27. Comparison 1 Olanzapine v placebo, Outcome 27 Anxiety.

Analysis 1.28. Comparison 1 Olanzapine v placebo, Outcome 28 Constipation.

Analysis 1.29. Comparison 1 Olanzapine v placebo, Outcome 29 Pain.

Analysis 1.30. Comparison 1 Olanzapine v placebo, Outcome 30 Hostility.

Analysis 1.31. Comparison 1 Olanzapine v placebo, Outcome 31 Nervousness.

Analysis 1.32. Comparison 1 Olanzapine v placebo, Outcome 32 Personality Disorder.

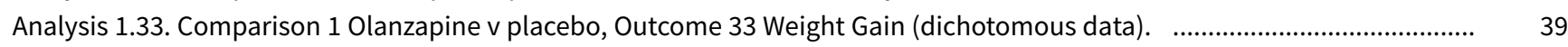

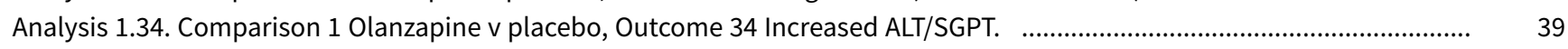

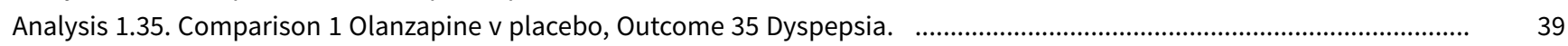

Analysis 1.36. Comparison 1 Olanzapine v placebo, Outcome 36 Mean change in supine systolic blood pressure. ......................... 40

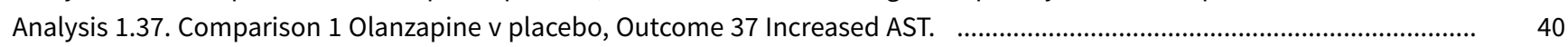

Analysis 1.38. Comparison 1 Olanzapine v placebo, Outcome 38 ECG abnormality. ...................................................................... 41

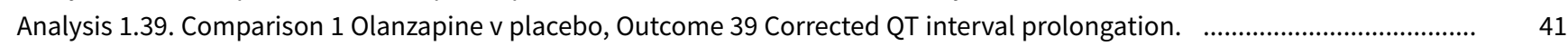


Analysis 1.40. Comparison 1 Olanzapine v placebo, Outcome 40 Prolactin elevation.

Analysis 1.41. Comparison 1 Olanzapine v placebo, Outcome 41 Increased Appetite.

Analysis 1.42. Comparison 1 Olanzapine v placebo, Outcome 42 Tremor.

Analysis 1.43. Comparison 1 Olanzapine v placebo, Outcome 43 Diarrhoea.

Analysis 1.44. Comparison 1 Olanzapine v placebo, Outcome 44 Mean change in 21-item HAMD - depressed participants. ......

Analysis 1.45. Comparison 1 Olanzapine v placebo, Outcome 45 Thirst.

Analysis 1.46. Comparison 1 Olanzapine v placebo, Outcome 46 Speech Disorder.

Analysis 1.47. Comparison 1 Olanzapine v placebo, Outcome 47 Mean change in YMRS for patients not experiencing psychotic symptoms.

Analysis 1.48. Comparison 1 Olanzapine v placebo, Outcome 48 Mean change in YMRS according to mood stabiliser.

Analysis 2.1. Comparison 2 Olanzapine v mood stabiliser, Outcome 1 Mean change in MRS.

Analysis 2.2. Comparison 2 Olanzapine v mood stabiliser, Outcome 2 Failure to respond - YMRS.

Analysis 2.3. Comparison 2 Olanzapine v mood stabiliser, Outcome 3 Failure to achieve remission.

Analysis 2.4. Comparison 2 Olanzapine v mood stabiliser, Outcome 4 Mean Change in 21-item HAMD - all participants. ..........

Analysis 2.5. Comparison 2 Olanzapine v mood stabiliser, Outcome 5 Failure to respond - YMRS (excluding early withdrawals). .

Analysis 2.6. Comparison 2 Olanzapine $v$ mood stabiliser, Outcome 6 Failure to achieve remission (excluding early withdrawals).

Analysis 2.7. Comparison 2 Olanzapine v mood stabiliser, Outcome 7 Mean change in MRS and presence of psychotic features.

Analysis 2.8. Comparison 2 Olanzapine v mood stabiliser, Outcome 8 Mean change in 21-item HAMD - depressed participants.

Analysis 2.9. Comparison 2 Olanzapine v mood stabiliser, Outcome 9 Failure to complete treatment.

Analysis 2.10. Comparison 2 Olanzapine v mood stabiliser, Outcome 10 Somnolence.

Analysis 2.11. Comparison 2 Olanzapine v mood stabiliser, Outcome 11 Dry mouth.

Analysis 2.12. Comparison 2 Olanzapine v mood stabiliser, Outcome 12 Increased appetite.

Analysis 2.13. Comparison 2 Olanzapine v mood stabiliser, Outcome 13 Nausea.

Analysis 2.14. Comparison 2 Olanzapine v mood stabiliser, Outcome 14 SAS Scale.

Analysis 2.15. Comparison 2 Olanzapine v mood stabiliser, Outcome 15 Barnes Akathisia Scale.

Analysis 2.16. Comparison 2 Olanzapine v mood stabiliser, Outcome 16 AIMS.

Analysis 2.17. Comparison 2 Olanzapine v mood stabiliser, Outcome 17 Weight change (continuous data).

Analysis 2.18. Comparison 2 Olanzapine v mood stabiliser, Outcome 18 Raised ALT/SGPT.

Analysis 2.19. Comparison 2 Olanzapine v mood stabiliser, Outcome 19 Lowered platelet count.

Analysis 2.20. Comparison 2 Olanzapine v mood stabiliser, Outcome 20 Oedema.

Analysis 2.21. Comparison 2 Olanzapine v mood stabiliser, Outcome 21 Rhinitis.

Analysis 2.22. Comparison 2 Olanzapine v mood stabiliser, Outcome 22 Headache.

Analysis 2.23. Comparison 2 Olanzapine v mood stabiliser, Outcome 23 Asthenia.

Analysis 2.24. Comparison 2 Olanzapine v mood stabiliser, Outcome 24 Dizziness.

Analysis 2.25. Comparison 2 Olanzapine v mood stabiliser, Outcome 25 Constipation.

Analysis 2.26. Comparison 2 Olanzapine v mood stabiliser, Outcome 26 Dyspepsia.

Analysis 2.27. Comparison 2 Olanzapine v mood stabiliser, Outcome 27 Pain.

Analysis 2.28. Comparison 2 Olanzapine v mood stabiliser, Outcome 28 Weight Gain (dichotomous data).

Analysis 2.29. Comparison 2 Olanzapine v mood stabiliser, Outcome 29 Agitation.

Analysis 2.30. Comparison 2 Olanzapine v mood stabiliser, Outcome 30 Nervouseness.

Analysis 2.31. Comparison 2 Olanzapine v mood stabiliser, Outcome 31 Tremor.

Analysis 2.32. Comparison 2 Olanzapine v mood stabiliser, Outcome 32 Vomiting.

Analysis 2.33. Comparison 2 Olanzapine v mood stabiliser, Outcome 33 Speech Disorder.

Analysis 2.34. Comparison 2 Olanzapine v mood stabiliser, Outcome 34 Neck Rigidity.

Analysis 2.35. Comparison 2 Olanzapine v mood stabiliser, Outcome 35 Diarrhoea.

Analysis 2.36. Comparison 2 Olanzapine v mood stabiliser, Outcome 36 Sleep disorder.

Analysis 2.37. Comparison 2 Olanzapine v mood stabiliser, Outcome 37 Tongue Oedema.

Analysis 3.1. Comparison 3 Olanzapine v other antipsychotic, Outcome 1 Failure to respond - (at least 50\% reduction in YMRS).

Analysis 3.2. Comparison 3 Olanzapine v other antipsychotic, Outcome 2 Failure to achieve remission - YMRS $<=12$ and HAMD-21 $<=8$.

Analysis 3.3. Comparison 3 Olanzapine v other antipsychotic, Outcome 3 Failure to respond - excluding withdrawals (at least $50 \%$ reduction in YMRS). 

Analysis 3.5. Comparison 3 Olanzapine v other antipsychotic, Outcome 5 Treatment emergent depression. ..................................66

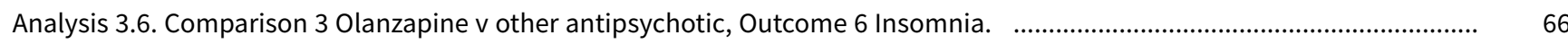

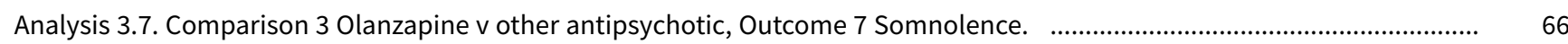
Analysis 3.8. Comparison 3 Olanzapine v other antipsychotic, Outcome 8 Weight Gain (dichotomous data). .............................. 67

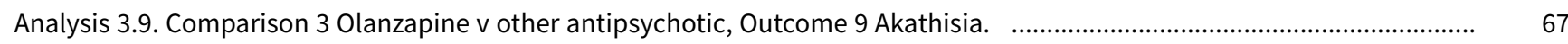

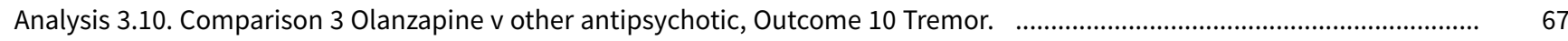

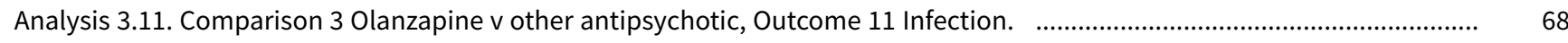

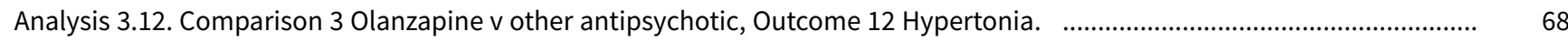

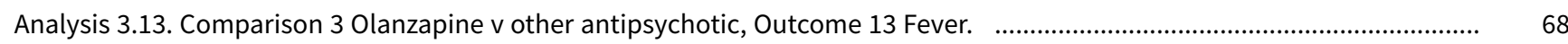

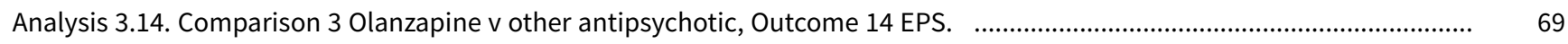

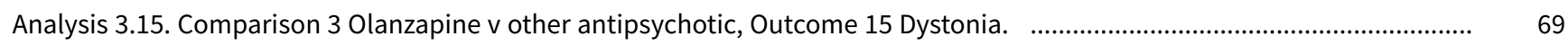

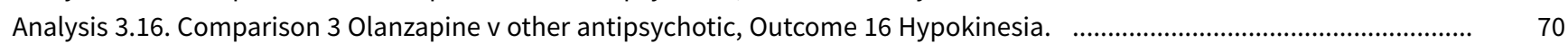

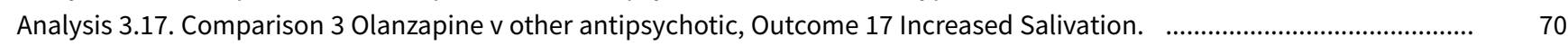
Analysis 3.18. Comparison 3 Olanzapine v other antipsychotic, Outcome 18 Dyskinesia. ............................................................... 70 Analysis 3.19. Comparison 3 Olanzapine v other antipsychotic, Outcome 19 Failure to complete treatment due to adverse 71 effects.

Analysis 3.20. Comparison 3 Olanzapine v other antipsychotic, Outcome 20 Failure to respond - (at least $70 \%$ reduction in YMRS).

Analysis 3.21. Comparison 3 Olanzapine v other antipsychotic, Outcome 21 Failure to respond - excluding withdrawals (at least $70 \%$ reduction in YMRS).

Analysis 3.22. Comparison 3 Olanzapine v other antipsychotic, Outcome 22 Failure to respond - (at least $80 \%$ reduction in YMRS).

Analysis 3.23. Comparison 3 Olanzapine v other antipsychotic, Outcome 23 Failure to respond - excluding withdrawals (at least $80 \%$ reduction in YMRS).

FEEDBACK

WHAT'S NEW

HISTORY (6)

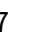

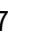

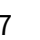

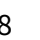

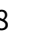

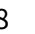

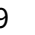
.

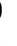
\% 
[Intervention Review]

\section{Olanzapine alone or in combination for acute mania}

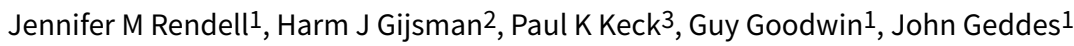

1Department of Psychiatry, University of Oxford, Oxford, UK. 2Stichting Forum GGZ Nijmegen, 6525 DX Nijmegen, Netherlands.

${ }^{3}$ Department of Psychiatry, University of Cincinnati College of Medicine, Cincinnati, $\mathrm{OH}$, USA

Contact: John Geddes, Department of Psychiatry, University of Oxford, Warneford Hospital, Oxford, OX3 7JX, UK.

john.geddes@psych.ox.ac.uk.

Editorial group: Cochrane Common Mental Disorders Group.

Publication status and date: Edited (no change to conclusions), published in Issue 1, 2010.

Citation: Rendell JM, Gijsman HJ, Keck PK, Goodwin G, Geddes J. Olanzapine alone or in combination for acute mania. Cochrane Database of Systematic Reviews 2003, Issue 1. Art. No.: CD004040. DOI: 10.1002/14651858.CD004040.

Copyright @ 2010 The Cochrane Collaboration. Published by John Wiley \& Sons, Ltd.

\section{A B S T R A C T}

\section{Background}

Olanzapine, an atypical antipsychotic, is used in the treatment of mania both as monotherapy and combined with other medicines.

\section{Objectives}

To review the efficacy and tolerability of olanzapine in the treatment of mania

\section{Search methods}

The Cochrane Collaboration Depression, Anxiety and Neurosis Controlled Trials Register (CCDANCTR), The Cochrane Central Register of Controlled Trials (CENTRAL), EMBASE, MEDLINE, CINAHL and PsycINFO were searched.

\section{Selection criteria}

Randomised trials comparing olanzapine with placebo or other drug in acute manic or mixed episodes.

\section{Data collection and analysis}

Two reviewers independently extracted data from trial reports

\section{Main results}

Six trials (1422 participants) were included in the review. There was a high rate of failure to complete treatment on all treatments which may have biased the estimates of relative efficacy. Olanzapine was superior to placebo at reducing manic symptoms as monotherapy (Young Mania Rating Scale (YMRS) - weighted mean difference (WMD): $-5.94,95 \% \mathrm{Cl}-9.09$ to -2.80 ) and in combination with lithium/valproate (YMRS) (WMD -4.01, 95\% confidence interval -6.06 to -1.96). Olanzapine monotherapy was superior at reducing psychotic symptoms (PANSS positive symptoms subscale WMD: $-3.54,95 \% \mathrm{Cl}-5.28$ to -1.80$)$. Olanzapine was superior to divalproex at reducing manic symptoms (standardised mean difference (SMD): $-0.29,95 \% \mathrm{Cl}-0.50$ to -0.08 ). Olanzapine did not lead to a statistically higher rate of clinical response than haloperidol (RR: $1.03,95 \% \mathrm{Cl} 0.77$ to 1.38). Fewer patients discontinued treatment on olanzapine than placebo (RR: $0.62,95 \% \mathrm{Cl} 0.48$ to 0.80 ). Olanzapine caused greater weight gain than placebo (WMD $1.91 \mathrm{Kg}, 95 \% \mathrm{Cl} 1.29$ to 2.53 ) and somnolence (RR: $2.1395 \% \mathrm{Cl} 1.62$ to 2.79) but not more depressive symptoms (RR: $0.95,95 \% \mathrm{Cl} 0.65$ to 1.40 ) or movement disorder (WMD: $-0.33,95 \% \mathrm{Cl}-0.74$ to 0.09 ). Olanzapine caused more prolactin elevation than placebo (RR: $4.3595 \% \mathrm{Cl} 1.77$ to 10.70 ). Olanzapine caused greater weight gain (WMD: 1.54 , $95 \% \mathrm{Cl}$ 1.02 to 2.05); somnolence (RR: $1.8095 \% \mathrm{Cl} 1.32$ to 2.46 ) and movement disorders (SAS - WMD: $0.7295 \% \mathrm{Cl} 0.11$ to 1.33 ) than divalproex but less nausea ( RR: $0.3695 \% \mathrm{Cl} 0.20$ to 0.65 ). Olanzapine caused more weight gain than haloperidol (RR: $3.59,95 \% \mathrm{Cl} 1.49$ to 8.64 ) but less movement disorder (EPS RR: $0.10,95 \% \mathrm{Cl} 0.04$ to 0.24 ). 


\section{Authors' conclusions}

Olanzapine is an effective treatment for mania and may be more efficacious than divalproex, though leads to more weight gain. Clinicians should consider both the relative efficacy and the different incidence of specific adverse effects of available drugs.

\section{PLAIN LANGUAGE SUMMARY}

\section{Olanzapine compared to placebo or other medicine as treatment for mania}

High withdrawal rates from the trials limit the confidence that can be placed on the results. Olanzapine was superior to placebo in reduction of manic symptoms both as monotherapy and combined with mood stabilizers, though caused weight gain. Olanzapine was more efficacious than divalproex and caused less nausea but more weight gain, somnolence and movement disorders. Olanzapine was comparable to haloperidol in efficacy, caused less movement disorders but greater weight gain. 


\section{B A C K G R O U N D}

Bipolar disorder is a mental disorder characterised by episodes of elevated or irritable mood (manic or hypomanic episodes) and episodes of low mood, loss of energy and sadness (depressive episodes). Some people also experience mixed episodes in which manic and depressive symptoms are present at the same time. Psychotic symptoms may occur in mania and are called moodcongruent when they occur during a manic episode and are consistent with the mood disturbance. Manic episodes may also occur in patients who have symptoms of both schizophrenia and mood disorder (schizoaffective disorder).

The costs of manic episodes are high both for patients and for health services. For patients, in addition to the period of acute illness, manic episodes often leave an aftermath of psychological, social and financial problems. Direct medical costs are high because admission to a psychiatric intensive care unit is often necessary.

Drugs are the first line treatment for acute mania. The main objectives in treating mania are to control dangerous behaviour, produce appropriate acute sedation and shorten the episode of mood disturbance. A number of different drugs are used in the treatment of mania - either as monotherapy or in combination. Lithium has been used to treat mania for many years and has been shown to be effective (Goodwin 1990). Antipsychotics (also called neuroleptics, major tranquilisers) have been used for many years, particularly when mania is accompanied by psychosis. In North America, antipsychotics have mainly been considered as adjunctive to primary therapy with a "mood stabiliser" such as lithium or valproate. By contrast, in Europe, antipsychotics are usually themselves considered as a primary therapy for mania, either alone or in combination with mood stabilisers.

All drug treatments for mania are potentially associated with serious adverse effects and with a risk of precipitating depression. The recognised adverse effects of conventional antipsychotics include movement disorders (EPS; parkinsonian symptoms, dystonia, akathisia, tardive dyskinesia), neuroleptic malignant syndrome, EEG changes, cardiovascular problems (hypotension, tachycardia, arrhythmias) and alterations in liver function. Nevertheless, compared to lithium, antipsychotics are sometimes considered to possess a wider ratio between doses that possess efficacy and those that induce adverse effects and this is important in the treatment of patients with mania. The rapid control of agitation and overactivity may be offset by the risks of serious adverse effects and poor tolerability. Newer "atypical antipsychotics" (olanzapine, risperidone, ziprasidone, quetiapine, clozapine, amisulpiride, sertindole, zotepine and aripiprazole) may be an important advance if they share the advantages of the older antipsychotics in mania, but have fewer adverse effects.

Olanzapine is an atypical antipsychotic that is more effective than placebo, and comparable to conventional antipsychotics, in the treatment of schizophrenia (Duggan 2002). Olanzapine causes fewer movement disorders but greater weight gain than conventional antipsychotics and it may increase the risk of diabetes (Koro 2002).

This systematic review assessed the evidence for the efficacy and tolerability of olanzapine compared with placebo or other active treatments.

\section{OB JECTIVES}

1.To determine the efficacy of olanzapine compared with placebo or other active treatment in alleviating the acute symptoms of manic or mixed episodes.

2. To review the effect of olanzapine on general health and social functioning.

3.To review acceptability of treatment with olanzapine.

4. To investigate the adverse effects of treatment with olanzapine.

5.To determine overall mortality rates on treatment with olanzapine.

\section{METHODS}

\section{Criteria for considering studies for this review Types of studies}

Randomised controlled trials which compared olanzapine with placebo or other active treatments. For trials with a crossover design only results from the first randomisation period were considered.

\section{Types of participants}

Patients of both sexes and all ages with a diagnosis of bipolar or schizoaffective disorder: manic or mixed episode, however diagnosed, with or without psychotic symptoms. Most recent studies were likely to have used DSMIV or ICD10 criteria. Older studies may have used ICD9, DSM III / DSM IIIR of other diagnostic systems.

Studies of acute treatment with olanzapine which recruited patients with diagnoses other than bipolar disorder or schizoaffective disorder and did not stratify randomisation according to diagnosis were not included in this review.

\section{Types of interventions}

Olanzapine in comparison with placebo or other antimanic treatment either as monotherapy or adjunctive treatment in the treatment of an acute manic or mixed episode.

\section{Types of outcome measures}

1. Efficacy in the treatment of manic or mixed episode

The primary measure of efficacy for this review was changes in manic symptom ratings.

Secondary measures of efficacy included were:-

a. achievement of response or remission of manic symptoms

b. change in depression rating scales and achievement of response or remission of depressive symptoms for patients experiencing a mixed episode

c. change in psychotic symptom rating scales

d. change in rating scales of severity of psychiatric symptoms

e. use of rescue medication

f. time to onset of symptom reduction or response

g. requirement for inpatient care e.g. length of stay

2. General health and social functioning, measured by quality of life scales. 
3. Acceptability of treatment

Completion of trial treatment, which includes elements of tolerability and efficacy, was used as an indicator of the overall acceptability of treatments.

4. Specific adverse effects, measured by patients experiencing:-

a. movement disorders - parkinsonian symptoms, dystonia, akathisia, tardive dyskinesia

b. cardiovascular effects - hypotension, tachycardia, arrhythmias and ECG changes

c. switch to depression for patients experiencing a manic episode

d. weight gain

e. sedation

f. GI disturbance - nausea, vomiting, constipation

g. haematological changes

h. diabetes

i. alopecia

and by requirement for medication for treatment emergent adverse effects.

5. Mortality rates during treatment.

\section{Search methods for identification of studies}

\section{Electronic searches:}

a/ The following specified electronic databases were searched with subject headings (psychotic affective disorders, bipolar disorder, mania, olanzapine) and text words (mania*, manic*, olanzapine)

The Cochrane Collaboration Depression, Anxiety and Neurosis Controlled Trials Register (CCDANCTR-Studies)

The Cochrane Central Register of Controlled Trials (CENTRAL)

b/ The following additional databases were searched to check the completeness of the CCDANCTR and CENTRAL using terms as above.

EMBASE (1980-2002)

MEDLINE (1966-2002)

CINAHL (1982-2002)

PsycINFO (1872-2002)

\section{Reference Checking:}

The reference lists of all identified randomised controlled trials, other relevant papers and major textbooks of affective disorder written in English were checked.

Personal Communication:

The authors of significant papers were identified from authorship lists over the last five years. They, and other experts in the field, were contacted and asked of their knowledge of other studies, published or unpublished, relevant to the review article.

Eli Lilly (pharmaceutical company that manufactures olanzapine) was requested to provide relevant published and unpublished data.

\section{Data collection and analysis}

a) Selection of trials and data extraction. Studies relating to olanzapine generated by the search strategies were checked to ensure they met the previously defined inclusion criteria. Two reviewers independently extracted data concerning participant characteristics, intervention details and outcome measures from the included studies. Subgroup analyses were recorded where the subgroups were defined a priori; if appropriate, the results were included in the meta-analysis. All disagreements were resolved by discussion.

b) Quality assessment. Quality was assessed according to the Cochrane criteria for quality assessment (Sackett 1997). This pays particular attention to the adequacy of the randomisation procedure. On this basis, studies were given a quality rating of $A$ (adequate), B (unclear), and C (inadequate). If the raters disagreed the final rating was made by consensus with the involvement (if necessary) of another member of the review group. In addition, a general appraisal of study quality was made by assessing key methodological issues such as blinding, completeness of follow-up and reporting of study withdrawals. Where inadequate details of randomisation and other characteristics of trials were provided, the authors were contacted in order to obtain further information.

Non-concurrence in selection and quality assessment was reported as appropriate.

c) Data Analysis. Data were entered into Revman 4.2 software by one reviewer.

Intention to Treat data (ITT) data were used when available. Where ITT data were not available, end-point data for trial completers were used.

Continuous data were analysed using weighted mean differences (with 95\% confidence intervals) or standardised mean differences (where different measurement scales were used). Where standard deviations were not recorded, authors were asked to supply the data. In the absence of data from the authors the mean standard deviation from other studies was used. When there were missing data and the method of "last observation carried forward " was used to do an ITT analysis, then the LOCF data were used, with due consideration of the potential bias and uncertainty introduced.

For dichotomous, or event-like, data, relative risks were calculated with $95 \%$ confidence intervals. Where participants withdrew from a trial before the endpoint, it was assumed they would have experienced the negative outcome by the end of the trial (e.g. failure to respond to treatment). Where the proportion of participants withdrawing from treatment was substantial (more than $20 \%$ ), sensitivity analyses were performed to investigate the effect of the possible different outcomes of those participants who withdrew in each group (for example, all the patients in the experimental group experience the negative outcome and all those allocated to the comparison group experience the positive outcome).

Heterogeneity between studies was assessed using the chi-square test with a p-value of less than or equal to 0.1 being taken to indicate heterogeneity. If significant heterogeneity was identified, potential sources were considered. Fixed and random effects analyses were done routinely to investigate the effect of the choice of method on the estimates. Material differences between the models were reported.

Skewed data and non-quantitative data were presented descriptively.

Monotherapy and adjunctive treatment trials were analysed separately and, where appropriate, combined results were also reported.

Where data were reported, subgroup analyses were performed to assess the possibility of differences in the efficacy of olanzapine 
in the treatment of psychotic and non-psychotic mania. If data were available, analysis by length of treatment was performed to ascertain whether any treatment differences detected varied with time.

\section{RES U L T S}

\section{Description of studies}

The search for randomised controlled trials of antipsychotics identified 26 papers relating to trials of olanzapine for indications other than mania (schizophrenia, major depressive disorder, anorexia nervosa and anxiety in Alzheimer's disease) which have not been included. From the remaining references, eight randomised controlled trials of olanzapine in mania were identified. (Several of the trials were presented at a number of conferences and subgroup analyses have been published. In this review only the main publications have been included in the list of references.)

Three of the eight trials were placebo-controlled trials, two of olanzapine monotherapy versus placebo (HGEH Trial, 1999*; HGGW Trial $2000^{\star}$ ) and one of olanzapine versus placebo as adjunctive treatment to lithium or valproate (HGFU Trial 2002*). Three trials were comparisons of olanzapine with mood stabilisers (lithium and lamotrigine - Berk 1999; divalproex ( HGHQ Trial 2002*; Zajecka 2000). One trial compared olanzapine with haloperidol (HGHD Trial 2002*). Zajecka 2000 and HGHD Trial 2002 have not yet been published but some data from conference posters were available. The authors have been asked to supply the data for these trials. One trial, which compared intramuscular injections of olanzapine, lorazepam and placebo, was excluded from the analysis because response was defined as a rapid reduction in agitation (i.e. within 2 hours of treatment) rather than reduction of manic symptoms (Meehan 2001). Seven trials reporting eight comparisons with olanzapine (1467 participants) are therefore included in this review.

For one trial (Zajecka 2000) efficacy data was reported after three weeks randomised treatment and adverse event data after twelve weeks and in two trials (HGHD Trial 2002, HGFU Trial 2002) the acute treatment phase was followed by a continuation phase.

* Studies by Tohen et al have been identified by Olanzapine Study Group initials.

\section{Risk of bias in included studies}

1. Randomisation / concealment of allocation

All trials were described as randomised, but none gave details of the method used to achieve random allocation or allocation concealment. All trials were therefore rated "B" (unclear) for allocation concealment according to Cochrane criteria (Sackett 1997). Additional information has been requested from the authors.

\section{Intention to treat analysis.}

Five trials reported a modified intention-to-treat analysis using the last observation carried forward (LOCF) to deal with missing continuous data and excluding participants for whom there were no post-baseline measures from analyses of efficacy measures. When withdrawal from the trial is random and not associated with the trial intervention, the LOCF approach is usually assumed to give a conservative estimate of the effectiveness of a treatment in an acute illness. When withdrawal is non-random (i.e. associated with one of the treatments) it can give a biased estimate of that treatment effect. For dichotomous data we imputed an ITT analysis by assuming that all trial withdrawals failed to respond.

Two trials (HGHD Trial 2002; Zajecka 2000) did not give details of how data on patients who withdrew from the trial prematurely were handled.

\section{Blinding}

All trials were reported to have been double-blind, in which the treatment allocation was masked from both the clinicians and patients.

\section{Numbers of participants}

The number of randomised participants was 45 (Berk 1999), 115 (HGGW Trial 2000), 120 (Zajecka 2000), 139 (HGEH Trial, 1999), 251 (HGHQ Trial 2002), 344 (HGFU Trial 2002) and 453 (HGHD Trial 2002).

\section{Selection of participants}

Six trials were multi-centre recruiting patients from sites in the USA and Canada (HGEH Trial, 1999; HGGW Trial 2000; HGFU Trial 2002; HGHQ Trial 2002; HGHD Trial 2002; Zajecka 2000). The fifth trial (Berk 1999) was a single centre study and recruited inpatients. The four trials that reported exclusion criteria all excluded patients with a recent history of substance abuse / dependence (Berk 1999; HGEH Trial, 1999; HGGW Trial 2000; HGHQ Trial 2002).

\section{Diagnosis of Mania}

In six trials mania was diagnosed according to DSM-IV criteria - for 5 trials criteria for bipolar disorder manic or mixed episode were used (HGEH Trial, 1999; HGGW Trial 2000; HGFU Trial 2002; HGHQ Trial 2002; HGHD Trial 2002) and in 1 trial (Berk 1999) criteria for manic episode only were used. In 4 trials the inclusion criteria included a minimum score of 20 on the Young Mania Rating (YMRS) (HGEH Trial, 1999; HGGW Trial 2000; HGHQ Trial 2002; HGHD Trial 2002). In 1 trial, patients were treated with lithium or valproate for 2 weeks and were then required to have a minimum score on the YMRS of 16 on two consecutive measurements between 2 and 7 days apart (HGFU Trial 2002). One trial did not specify a minimum YMRS score (Berk 1999). One trial did not report the basis for a diagnosis of mania (Zajecka 2000).

\section{Effects of interventions}

The only data for Berk 1999 which were presented in a form that could be included were on withdrawal from treatment. Since this alone is not very informative, this trial has been excluded from the analysis. The authors have been asked to provide additional data.

\section{EFFICACY OF OLANZAPINE IN THE TREATMENT OF MANIA}

The proportion of participants who withdrew from treatment exceeded $20 \%$ for each intervention in all trials. However it was not possible to do the planned sensitivity analyses for because dichotomous data on responders included LOCF data for some participants.

\section{a) Olanzapine versus placebo}

i) Response or remission of manic symptoms

The trials used a number of measures of reduction of manic symptoms but each trial report defined, a priori, the mean change on the Young Mania Rating Scale (YMRS) total score from baseline to endpoint as the primary outcome measure. On this measure, there was evidence that olanzapine was more efficacious than placebo both as monotherapy (fixed effects weighted mean difference 
(WMD): $-5.94,95 \%$ confidence interval -9.09 to $-2.80 ; p=0.0002$, chi-square for heterogeneity $0.15, \mathrm{df}=1, \mathrm{p}=0.69 ; 2$ trials, 246 participants) and as adjunctive treatment to lithium or valproate (WMD: $-4.01,95 \%$ confidence interval -6.06 to $-1.96, p=0.0001,2$ trials, 334 participants). Meta-analysis of these results did not reveal significant heterogeneity between the monotherapy trials and the adjunctive treatment trial (fixed effects WMD: $-4.59,95 \%$ confidence interval -6.31 to $-2.87 ; p<0.00001$, chi-square for heterogeneity 1.18 , $\mathrm{df}=2, \mathrm{p}=0.56 ; 3$ trials, 580 participants).

There was also evidence that olanzapine was more efficacious than placebo when manic symptoms were measured in terms of mean change in CGI-BP mania score - monotherapy (fixed effects WMD: $-0.75,95 \%$ confidence interval -1.12 to $-0.38 ; p<0.0 .0001$, chi-square for heterogeneity $0.89, \mathrm{df}=1, \mathrm{p}=0.35 ; 2$ trials, 246 participants); adjunctive treatment (WMD: $-0.3295 \%$ confidence interval -0.62 to $-0.02, p=0.04,1$ trial, 334 participants) and meta-analysis (fixed effects WMD: $-0.49,95 \%$ confidence interval -0.73 to -0.26 ; $p<0.0001$, chi-square for heterogeneity $3.96, d f=2, p=0.14 ; 3$ trials, 580 participants).

Olanzapine was found to be superior to placebo on dichotomous measures. A smaller proportion of patients on olanzapine failed to respond to treatment at endpoint (defined a priori as 50\% or more reduction in YMRS between baseline and endpoint) monotherapy (fixed effects RR: $0.64,95 \%$ confidence interval 0.52 to $0.81 ; p=0.0001$, chi-square for heterogeneity $0.17, d f=1, p=0.68$; 2 trials, 254 participants), adjunctive treatment (RR: 0.63, 95\% confidence interval 0.49 to $0.80, p=0.0001,1$ trial, 344 participants) and meta-analysis (fixed effects RR: $0.64,95 \%$ confidence interval 0.54 to $0.75 ; p<0.00001$, chi-square for heterogeneity $0.21, d f=2$, $\mathrm{p}=0.9 ; 3$ trials, 598 participants). The relative risk reduction for olanzapine monotherapy (RRR: 0.36 ) is comparable with that for adding olanzapine to a mood stabiliser (RRR: 0.37). There was evidence from 2 trials (HGGW Trial 2000; HGFU Trial 2002) that olanzapine was more likely than placebo to produce remission of symptoms (defined as YMRS of 12 or less at end point) monotherapy (RR: $0.60,95 \%$ confidence interval 0.41 to 0.87 , $\mathrm{p}=0.007,1$ trial, 115 participants), adjunctive treatment (RR: 0.70, $95 \%$ confidence interval 0.50 to $0.99, p=0.04,1$ trial, 344 participants and meta-analysis (fixed effects RR: $0.66,95 \% \mathrm{Cl} 0.51$ to 0.85 ; $p=0.001$, chi-square for heterogeneity $0.39 \mathrm{df}=1, \mathrm{p}=0.53 ; 2$ trials; 459 participants).

The difference between olanzapine and placebo in terms of failure to respond and failure to achieve remission remained statistically significant when patients for whom there were no post baseline measurements were excluded from the analyses (see figures).

One trial reported an analysis of the subgroup of patients not experiencing psychotic symptoms at baseline. Olanzapine as adjunctive treatment to mood stabiliser was more efficacious than placebo in terms of mean change on the YMRS both as monotherapy (WMD: $-4.93,95 \%$ confidence interval -7.24 to $-2.62, p<0 . .0001$, 1 trial, 226 participants). Data for the subgroup of patients with psychotic symptoms could not be analysed.

ii) Change in depressive symptoms

The trials all reported mean change in depressive symptoms as measured by the 21-item Hamilton Depression Rating Scale (HAMD-21) and the CGI -BP depression scale for all participants. No statistically significant difference was found between olanzapine monotherapy and placebo in terms of reduction of depressive symptoms on the HAMD-21 (random effects WMD: -1.53 , 95\% confidence interval -4.93 to $1.87 ; p=0.38$, chi-square for heterogeneity 3.79, $\mathrm{df}=1 \mathrm{p}=0.05 ; 2$ trials, 244 participants) or the CGI-BP depression scale (random effects WMD: $0.05,95 \%$ confidence interval -0.59 to $0.69 ; p=0.87$, chi-square for heterogeneity $4.22, \mathrm{df}=1, \mathrm{p}=0.04 ; 2$ trials, 244 participants). Random effects analyses have been used to allow for the observed heterogeneity between the trials however, fixed effects analyses also failed to find a difference between interventions. In contrast, olanzapine as adjunctive treatment to lithium or valproate was found to be more efficacious than placebo on both the HAMD-21 (WMD: $-4.09,95 \%$ confidence interval -5.71 to $-2.47, p<0.00001$, 1 trial, 334 participants) and GGI-BP depression (WMD: -0.62, $95 \%$ confidence interval -0.94 to $-0.30, p=0.0001,1$ trial, 334 participants). Meta-analysis did not find a difference between olanzapine and placebo using the random effects analyses HAMD-21 (random effects WMD: $-2.48,95 \%$ confidence interval -5.18 to $0.23 ; p=0.07$, chi-square for heterogeneity $9.54, d f=2, p=$ 0.008 ; 3 trials, 578 participants) and CGI-BP depression (random effects WMD: $-0.19,95 \%$ confidence interval -0.80 to $0.42 ; p=0.55$, chi-square for heterogeneity $14.59, \mathrm{df}=2, \mathrm{p}=0.0007 ; 3$ trials, 580 participants). Using the fixed effects meta-analyses, olanzapine was found to be more efficacious than placebo - HAMD-21 (fixed effects WMD: $-2.7395 \%$ confidence interval -3.90 to -1.55 ) and CGI-BP depression (fixed effects WMD: $-0.24,95 \%$ confidence interval -0.46 to -0.02). The proportion of participants in one trial (HGEH Trial, 1999) with a mixed episode at baseline was $17.3 \%$ compared to over $40 \%$ in the other two trials and it is possible that this is the cause of the observed heterogeneity.

Two trials (HGGW Trial 2000; HGFU Trial 2002) reported reduction in HAMD-21 score for patients with moderate to severe depression at baseline (HAMD-21 at least 20). There was evidence that olanzapine was more efficacious than placebo at reducing depressive symptoms both as monotherapy (WMD: -5.98, 95\% confidence interval -11.19 to $-0.77, p=0.02,1$ trial, 42 participants), as adjunctive treatment (WMD: -8.74 , 95\% confidence interval -12.74 to $-4.74, p<0.0001,1$ trial, 72 participants) and as metaanalysis (fixed effects WMD: $-7.72,95 \%$ confidence interval -10.89 to $-4.55 ; p<0.00001$, chi-square for heterogeneity $0.68, \mathrm{df}=1, \mathrm{p}=0.41 ; 2$ trials, 114 participants).

\section{iii) Change in psychotic symptom rating scales}

Olanzapine monotherapy was more efficacious than placebo in reduction of positive symptoms, measured as the mean reduction on PANSS positive symptoms subscale fixed effects WMD: -3.54, $95 \%$ confidence interval -5.28 to $-1.80 ; p<0.0001$, chi-square for heterogeneity $1.39, \mathrm{df}=1, \mathrm{p}=0.24 ; 2$ trials, 244 participants).

Olanzapine was also found to cause a greater reduction in PANSS total score both as monotherapy fixed effects WMD: -10.00 , 95\% confidence interval -14.84 to $-5.16 ; p<0.0001$, chi-square for heterogeneity $1.25, \mathrm{df}=1, \mathrm{p}=0.26 ; 2$ trials, 244 participants) and as adjunctive treatment (WMD: -5.94 , 95\% confidence interval -9.60 to $-2.28, p=0.001,1$ trial, 344 participants) and when combined (fixed effects WMD: -7.42 , 95\% confidence interval -10.33 to -4.50 ; $p<0.00001$, chi-square for heterogeneity $2.97, d f=2, p=0.23 ; 3$ trials, 578 participants).

iv) Change in severity of psychiatric symptoms rating scales There was evidence that olanzapine was more efficacious than placebo in improvement in overall severity of bipolar illness measured on the Clinical Global Impression (CGI) bipolar scale 
for severity of overall illness although this was not significant for olanzapine monotherapy when the random effects analysis was used to allow for heterogeneity between trials - monotherapy (random effects WMD: -0.63 , 95\% confidence interval -1.30 to $0.05 ; p=0.07$, chi-square for heterogeneity 3.69, $d f=1, p=0.05 ; 2$ trials, 246 participants), adjunctive treatment (WMD: $-0.31,95 \%$ confidence interval -0.60 to $-0.02, p=0.03,1$ trial, 334 participants) and combined (random effects WMD: $-0.49,95 \%$ confidence interval -0.87 to $-0.10 ; p=0.01$, chi-square for heterogeneity $5.12, d f=2$, $p=0.08 ; 3$ trials, 580 participants). The reason for the observed heterogeneity is unclear but may in part be due to the differences in depressive symptoms at baseline.

\section{v) Use of rescue medication}

No statistically significant difference was found between olanzapine and placebo in the number of patients that took one or more doses of a benzodiazepine - as monotherapy (RR: 0.89, 95\% confidence interval 0.70 to $1.14, \mathrm{p}=0.36,1$ trial, 115 participants), as adjunctive treatment (RR: $0.85,95 \%$ confidence interval 0.61 to $1.18, \mathrm{p}=0.33,1$ trial, 344 participants) and combined (fixed effects RR: $0.87,95 \%$ confidence interval 0.70 to $1.07 ; p=0.19$, chi-square for heterogeneity $0.06, d f=1, p=0.80 ; 2$ trials, 459 participants).

vi) Time to onset of symptom reduction or response No data were reported

vii) Requirement for inpatient care e.g. length of stay. No data were reported.

b) Olanzapine versus mood stabiliser

For Zajecka 2000 efficacy was assessed 3 weeks after randomization.

Notes re continuous data: Zajecka 2000 did not record standard deviations for mean changes and so values from HGHQ Trial 2002, where available, have been used.

i) Response or remission of manic symptoms

Olanzapine was more efficacious than divalproex on the primary measure of response, mean change on the Young Mania Rating Scale (HGHQ Trial 2002) and the Mania Rating Scale (Zajecka 2000), (fixed effects standardised mean difference SMD: -0.29 , $95 \%$ confidence interval -0.50 to $-0.08 ; p=0.006$, chi-square for heterogeneity $0.08, \mathrm{df}=1, \mathrm{p}=0.78 ; 2$ trials, 363 participants) and in the proportion of patients who failed to respond to treatment at endpoint where response was defined a priori as $50 \%$ or more reduction in YMRS between baseline and endpoint (RR: $0.78,95 \%$ confidence interval 0.61 to $0.99, p=0.04,1$ trial, 251 participants). However, when participants for whom there were no post-baseline measurements were excluded from this analysis of failure to respond to treatment the difference between olanzapine and divalproex was no longer significant (RR: $0.79,95 \%$ confidence interval 0.62 to $1.01, \mathrm{p}=0.06,1$ trial, 248 participants). There was evidence that olanzapine was more efficacious than divalproex in terms of the proportion of patients who failed to achieve remission (defined a priori as YMRS at end point of 12 or less) (RR: $0.79,95 \%$ confidence interval 0.64 to $0.97, p=0.03,1$ trial, 251participants). (Standardised mean difference (SMD) has been used because the trials used different mania rating scales).

One trial reported analyses of subgroups of patients according to the presence or absence of psychotic symptoms at baseline. Olanzapine was more efficacious than divalproex in terms of mean change on the YMRS for patients not experiencing psychotic symptoms (WMD: $-0.63,95 \%$ confidence interval -0.97 to -0.28 , $\mathrm{p}=0.0003,1$ trial, 137 participants) but not for patients experiencing psychotic symptoms (WMD: 0.01, 95\% confidence interval -0.36 to $0.38, p=0.96,1$ trial, 114 participants). There is no indication that randomisation was stratified according to presence of psychotic features and so that it is possible that other nonrandom differences between the groups account for the observed difference.

ii) Change in depressive symptoms

There was no evidence that olanzapine was more efficacious than divalproex in reducing depressive symptoms (fixed effect WMD: $-1.01,95 \%$ confidence interval -2.43 to $0.41 ; p=0.16$, chi-square for heterogeneity $0.86, \mathrm{df}=1, \mathrm{p}=0.35 ; 2$ trials, 355 participants). Not all patients had depressive symptoms at baseline, but there was no evidence that olanzapine was more efficacious than divalproex for participants moderate to severe depression at baseline (HAMD-21 at least 20) (WMD; -2.20, 95\% confidence interval -6.40 to 2.00 , $\mathrm{p}=0.31,1$ trial, 53 participants).

iii) Change in psychotic symptom rating scales No data were reported on change in psychotic symptoms.

iv) Change in severity of psychiatric symptoms rating scales Data reported on change in BPRS for one trial could not be analysed because it was not possible to estimate standard deviations (Zajecka 2000).

v) Use of rescue medication

No data that could be analysed were reported.

vi) Time to onset of symptom reduction or response No data were reported.

vii) Requirement for inpatient care e.g. length of stay. No data were reported.

c) Olanzapine versus other antipsychotics

i) Response or remission of manic symptoms

Continuous data on reduction of manic symptoms was not reported.

No statistically significant difference was found between olanzapine and haloperidol in terms of the proportion of participants who failed to respond (defined as reduction in YMRS of at least $50 \%$ between baseline and endpoint) either when withdrawals were included as non responders (RR: 1.03, 95\% confidence interval 0.77 to $1.38, p=0.85,1$ trial, 453 participants) or when they were excluded from the analysis (RR: $1.07,95 \%$ confidence interval 0.79 to $1.46, \mathrm{p}=0.65,1$ trial, 444 participants). No statistically significant difference was seen between olanzapine and haloperidol when response was defined in terms of a reduction in YMRS of at least $70 \%$ or at least $80 \%$ (see figures).

The primary measure of efficacy, defined a priori, was the proportion of patients in remission at 6 weeks where remission was defined as Young Mania Rating Scale (YMRS) of 12 or less and Hamilton Depression Rating Scale (HAMD-21) of 8 or less. There was no statistically significant difference between olanzapine and haloperidol on this measure (RR: $0.89,95 \%$ confidence interval 0.74 to $1.06, \mathrm{p}=0.2,1$ trial, 453 participants).

ii) Change in depressive symptoms 
Data for mean change on HAMD-21and MADRS were reported but no standard deviations were given so the data could not be analysed.

iii) Change in psychotic symptom rating scales

No data were reported

iv) Change in severity of psychiatric symptoms rating scales No data were reported

v) Use of rescue medication

No data were reported

vi) Time to onset of symptom reduction or response

No data were reported

vii) Requirement for inpatient care e.g. length of stay.

No data were reported.

\section{GENERAL HEALTH AND SOCIAL FUNCTIONING}

a) Olanzapine versus placebo

i) Quality of life scales

One trial (HGEH Trial, 1999) measured quality of life using the SF-36 but did not report the results for the total score.

b) Olanzapine versus mood stabilizer

i) Quality of life scales

One trial (Zajecka 2000) measured quality of life using the Quality of Life Enjoyment and Satisfaction Scale (Q-LES-Q) but did not report the results for the total score.

\section{c) Olanzapine versus other antipsychotics}

No data were reported.

\section{ACCEPTABILITY OF TREATMENT AS MEASURED BY COMPLETION OF THE TRIAL}

a) Olanzapine versus placebo

i) Failure to complete treatment

The proportion of participants who failed to complete treatment ranged from $29 \%$ for the placebo group in the adjunctive treatment trial (HGFU Trial 2002) to $65 \%$ for the placebo group in one monotherapy trial (HGEH Trial, 1999). A smaller proportion of participants failed to complete treatment in the olanzapine monotherapy group than in the placebo treated group (RR: 0.62 , $95 \%$ confidence interval 0.48 to $0.80 ; p=0.0003$, chi-square for heterogeneity $0.14, \mathrm{df}=1, \mathrm{p}=0.71 ; 2$ trials, 254 participants). In contrast no statistically significant difference was found between the proportion of patients that completed treatment in the olanzapine plus mood stabiliser and the placebo plus mood stabiliser groups (R: $1.05,95 \%$ confidence interval 0.74 to 1.49 , $\mathrm{p}=0.78,1$ trial, 344 participants).

It was not possible to assess the extent to which failure to complete treatment was caused by lack of efficacy or adverse effects because reasons cited included patient or physician decisions which are likely to be related to efficacy and/or adverse effects.

b) Olanzapine versus mood stabiliser

i) Failure to complete treatment.
Zajecka 2000 reported data on failure to complete treatment at 12 weeks.

No statistically significant difference was found between olanzapine divalproex in terms of the proportion of patients who failed to complete treatment (RR: $0.90,95 \%$ confidence interval 0.73 to $1.12, p=0.35$, chi-square for heterogeneity $0.11, d f=1, p=0.74 ; 2$ trials, 371 participants).

c) Olanzapine versus other antipsychotic

i) Failure to complete treatment.

In the olanzapine group $29 \%$ of participants failed to complete treatment compared to $36 \%$ in the haloperidol group. This difference was not significant (fixed effects RR: 0.82, 95\% confidence interval 0.62 to $1.07, \mathrm{p}=0.14,1$ trial, 453 participants).

\section{ADVERSE EFFECTS}

a) Olanzapine versus placebo

The trials reported dichotomous data for a number of treatment emergent adverse effects. It was unclear how these adverse effects were measured both in terms of severity and duration and further information on these is being sought from the authors.

i) Weight gain

For all three trials olanzapine was associated with significantly greater weight gain than placebo when measured as mean change in weight - monotherapy (fixed effects WMD 1.91, 95\% confidence interval 1.29 to $2.53, p<0.00001$, chi- square for heterogeneity $0.44, \mathrm{df}=1 \mathrm{p}=0.5,2$ trials, 249 participants), adjunctive treatment (WMD 2.85, 95\% confidence interval 2.24 to $3.46, p<0.00001,1$ trial; 332 participants) and when combined (random effects WMD $2.27,95 \%$ confidence interval 1.56 to $2.99, \mathrm{p}<0.00001$, chi- square for heterogeneity $4.90, \mathrm{df}=2 \mathrm{p}=0.09,3$ trials; 581 participants). The mean weight change on olanzapine ranged from $+1.65 \mathrm{Kg}$ on monotherapy (HGEH Trial, 1999) to $+3.08 \mathrm{Kg}$ on adjunctive treatment and on placebo from $-0.44 \mathrm{Kg}$ on monotherapy (HGEH Trial, 1999) to $+0.23 \mathrm{Kg}$ as adjunctive treatment. Two trials also reported weight gain in terms of the proportion of patients who gained weight. These trials also showed that olanzapine was associated with a higher incidence of weight gain - monotherapy (RR 7.89, 95\% confidence interval 1.01 to $61.39, p=0.05,1$ trial, 139 participants), adjunctive treatment (RR $3.77,95 \%$ confidence interval 1.86 to $7.61, p=0.0002,1$ trial, 344 participants) and when combined (fixed effects RR 4.12, 95\% confidence interval 2.13 to 7.98, $p<0.0001$, chi- square for heterogeneity $0.45 \mathrm{df}=1 \mathrm{p}=0.5,2$ trials, 483 participants). Heterogeneity was observed between the monotherapy trials and the adjunctive treatment trial for mean change in weight but not for the proportion of patients who gained weight. One possible reason for this is the longer duration of the adjunctive treatment trial.

\section{ii) Movement disorders}

No statistically significant difference was found between olanzapine monotherapy and placebo in terms of movement disorders measured on the Simpson-Angus Scale (fixed effects WMD- $0.33,95 \%$ confidence interval -0.74 to $0.09, p=0.12$, chi-square for heterogeneity $0.21, \mathrm{df}=1, \mathrm{p}=0.65 ; 2$ trials, 241 participants), the Barnes Akathisia Scale (fixed effects WMD - 0.13 , 95\% confidence interval -0.32 to $0.06, p=0.17$, chi-square for heterogeneity 0.84 , $\mathrm{df}=1, \mathrm{p}=0.36 ; 2$ trials, 246 participants) and the Abnormal Involuntary Movement Scale (AIMS) (WMD - 0.25 , 95\% confidence interval -0.58 to $0.08, p=0.14,1$ trial, 135 participants). 
One trial reported use of medication to treat movement disorders. The mean dose of anticholinergic medication (benztropine) taken by participants in the olanzapine monotherapy group was significantly greater than that taken by participants in the placebo group (WMD: $0.11,95 \%$ confidence interval 0.03 to $0.19, p=0.008,1$ trial, 115 participants). However usage in both groups was low with approximately $60 \%$ of patients treated with olanzapine on $0.6 \mathrm{mg} /$ day or less compared to a usual maintenance dose of $1-4 \mathrm{mg} /$ day. Compared to placebo, olanzapine as adjunctive treatment was found to cause more tremor (RR 1.77, 95\% confidence interval 1.05 to $3.01, \mathrm{p}=0.03,1$ trial, 344 participants).

\section{iii) Depression}

No statistically significant difference was found between olanzapine and placebo in terms of treatment emergent depression as monotherapy (fixed effects RR $0.84,95 \%$ confidence interval 0.44 to $1.60, p=0.6$, chi-square for heterogeneity $0.76 \mathrm{df}=1 \mathrm{p}=0.38,2$ trials, 249 participants), as adjunctive treatment (RR 1.03, 95\% confidence interval 0.63 to $1.67, p=0.91,1$ trial, 344 participants) or when the results were combined (RR $0.95,95 \%$ confidence interval 0.65 to $1.40, p=0.81$, chi-square for heterogeneity $1.00 \mathrm{df}=2 \mathrm{p}=0.61,3$ trials, 593 participants).

\section{iv) Other adverse effects}

Olanzapine was found to be associated with higher incidence than placebo of 7 adverse effects. Four adverse effects were reported for all 3 trials, 598 participants - somnolence (RR $2.1395 \% \mathrm{Cl} 1.62$ to $2.79, \mathrm{p}<0.0001$ ), dry mouth (RR $3.6495 \% \mathrm{Cl} 2.24$ to 5.91 , $\mathrm{p}<0.00001$ ), dizziness (RR $2.3795 \% \mathrm{Cl} 1.39$ to 4.04, $\mathrm{p}=0.001$ ) and asthenia (RR $1.6995 \% \mathrm{Cl} 1.09$ to 2.64, $\mathrm{p}=0.02$ ). Three were reported for the adjunctive treatment trial (HGFU Trial 2002), increased appetite (RR $3.0195 \% \mathrm{Cl} 1.54$ to $5.88, \mathrm{p}=0.001,344$ participants), speech disorder (RR $7.5395 \% \mathrm{Cl} 1.01$ to 56.32, $\mathrm{p}=0.05,344$ participants), and raised prolactin (RR $4.3595 \% \mathrm{Cl} 1.77$ to $10.70, \mathrm{p}=0.001$, 334 participants).

Compared to placebo, olanzapine monotherapy was also found to be associated with increased levels on two liver functions tests - raised ALT (RR 10.32 95\% Cl 2.85 to 37.35, p=0.0004, 2 trials, 254 participants) and raised AST (RR $22.8895 \% \mathrm{Cl} 1.37$ to $381.40, p=0.03,1$ trial, 115 participants). However in the trial which reported both tests (HGGW Trial 2000) only one participant (treated with olanzapine) met predefined criteria for clinically significant abnormality and for the other trial it was reported that ALT levels returned to normal during continued treatment. Both trials reported that no patient displayed symptoms of hepatic dysfunction. Olanzapine was associated with greater increase in supine systolic blood pressure than placebo (WMD $8.9095 \% \mathrm{Cl} 2.70$ to $15.10, p=0.005$ ).

Olanzapine was found to be associated with lower incidence of 3 adverse effects - nervousness reported in all three trials, 598 participants (RR $0.6395 \% \mathrm{Cl} 0.40$ to $0.98, \mathrm{p}=0.04$ ); agitation reported for two monotherapy trials (HGEH Trial, 1999; HGGW Trial 2000), 254 participants (RR $0.5995 \% \mathrm{Cl} 0.35$ to $1.01, \mathrm{p}=0.05$ ) and ECG abnormality reported in one monotherapy trial (HGGW Trial 2000), 115 participants ( $R R 0.3895 \% \mathrm{Cl} 0.18$ to $0.83, \mathrm{p}=0.02$ ).

No statistically significant difference was found between olanzapine and placebo in incidence of 10 adverse effects. One was reported for all three trials - headache, 598 participants (RR $0.9095 \% \mathrm{Cl} 0.63$ to $1.29, \mathrm{p}=0.57$ ). Four were reported for the two monotherapy trials (HGEH Trial, 1999; HGGW Trial 2000), 254 participants - constipation (RR $2.0995 \% \mathrm{Cl} 0.87$ to $5.04, \mathrm{p}=0.1$ ); hostility (RR $0.5195 \% \mathrm{Cl} 0.21$ to $1.22, \mathrm{p}=0.13$ ); personality disorder (RR $0.4195 \% \mathrm{Cl} 0.16$ to $1.02, \mathrm{p}=0.06$ ) and anxiety (RR $0.6595 \%$ $\mathrm{Cl} 0.11$ to $3.67, \mathrm{p}=0.62$ ). Two were reported only in the adjunctive treatment trial (HGFU Trial 2002), 344 participants - diarrhoea (RR $0.8095 \% \mathrm{Cl} 0.45$ to $1.40, \mathrm{p}=0.43$ ) and thirst (RR $1.6595 \% \mathrm{Cl} 0.73$ to $3.73, p=0.23$ ), one only in the 3-week monotherapy trial (HGEH Trial, 1999; HGEH Trial, 1999), 139 participants - pain (RR $2.6395 \%$ $\mathrm{Cl} 0.73$ to $9.50, \mathrm{p}=0.14)$ and two only in the 4 week monotherapy trial (HGGW Trial 2000), 115 participants - dyspepsia (RR $2.5595 \%$ $\mathrm{Cl} 0.69$ to 9.36, $\mathrm{p}=0.16$ ) and QT interval prolongation (RR $0.7395 \%$ $\mathrm{Cl} 0.13$ to $4.19, \mathrm{p}=0.72$ ).

\section{b) Olanzapine versus mood stabiliser}

Zajecka 2000 reported adverse event data at 12 weeks.

\section{i) Weight gain}

Olanzapine was associated with significantly greater weight gain than divalproex (fixed effects WMD: 1.54, 95\% confidence interval 1.02 to $2.05 ; p<0.0001$; chi-square for heterogeneity $0.03, \mathrm{df}=1, \mathrm{p}=$ $0.86 ; 2$ trials, 366 participants) and a higher proportion of patients on olanzapine than on divalproex gained weight (fixed effects RR: $1.90,95 \%$ confidence interval 1.07 to $3.37 ; p=0.03$, chi-square for heterogeneity $0.80, \mathrm{df}=1, \mathrm{p}=0.37,2$ trials, 371 participants).

\section{ii) Movement disorders}

Olanzapine was associated with more movement disorders than divalproex measured on the Simpson-Angus Scale (WMD: 0.72, 95\% confidence interval 0.11 to $1.33, \mathrm{p}=0.02,1$ trial, 241 participants). Olanzapine was also associated with a higher incidence of neck rigidity (RR: $4.54,95 \% \mathrm{Cl} 1.00$ to $20.58, \mathrm{p}=0.05,1$ trial, 251 participants). No statistically significant difference was found between olanzapine and divalproex on the Barnes Akathisia Scale (WMD: $0.02,95 \%$ confidence interval -0.23 to $0.27, p=0.87,1$ trial, 241 participants) or the Abnormal Involuntary Movement Scale (AIMS) (WMD: - $-1.17,95 \%$ confidence interval -0.61 to $0.27, p=0.45,1$ trial, 247 participants).

Olanzapine was found to cause more tremor than divalproex (RR: $3.02,95 \%$ confidence interval 1.00 to $9.12, p=0.05,1$ trial, 251 participants).

\section{iii) Other adverse effects}

Olanzapine was found to be associated with higher incidence than divalproex of 5 adverse effects - somnolence (RR: $1.80,95 \% \mathrm{Cl} 1.32$ to 2.46, $p=0.0002$, chi-square for heterogeneity $0.18, d f=1, p=0.67$; 2 trials, 371 participants), dry mouth (RR: $5.29, \mathrm{Cl} 2.59$ to 10.81 , p $<0.00001,1$ trial, 251 participants), increased appetite (RR: 5.04, $95 \% \mathrm{Cl} 1.50$ to $16.98, \mathrm{p}=0.009,1$ trials, 251 participants), speech disorder (RR: $10.03,95 \% \mathrm{Cl} 1.89$ to $53.25, \mathrm{p}=0.007$, chi-square for heterogeneity $0.00, \mathrm{df}=1, \mathrm{p}=0.99,2$ trials, 371 participants) and oedema (RR: $18.76,95 \% \mathrm{Cl} 1.11$ to $317.87, \mathrm{p}=0.04,1$ trial, 120 participants).

Olanzapine was found to be associated with lower incidence than divalproex of two adverse effects - nausea (RR: $0.36,95 \% \mathrm{Cl} 0.20$ to $0.65, p=0.0007,1$ trial, 251 participants) and lowered platelet count (RR: $0.05,95 \% \mathrm{Cl} 0.00$ to $0.87, \mathrm{p}=0.04,1$ trial, 227 participants).

No statistically significant difference was found between olanzapine and divalproex for fourteen adverse effects - headache (RR: $0.97,95 \% \mathrm{Cl} 0.62$ to $1.54, \mathrm{p}=0.91,1$ trial, 251 participants), pain (RR: $0.95,95 \% \mathrm{Cl} 0.51$ to $1.76, \mathrm{p}=0.88,1$ trial, 251 participants), asthenia (RR: $1.19,95 \% \mathrm{Cl} 0.65$ to $2.16, p=0.58,1$ trial, 251 
participants), dizziness (RR: $1.34,95 \% \mathrm{Cl} 0.72$ to $2.50, \mathrm{p}=0.35,1$ trial, 251 participants), agitation (RR: $1.01,95 \% \mathrm{Cl} 0.50$ to $2.03, \mathrm{p}=0.93,1$ trial, 251 participants), nervousness (RR: $0.62,95 \% \mathrm{Cl} 0.33$ to 1.19 , $\mathrm{p}=0.15,1$ trial, 251 participants), constipation (RR: 1.21, 95\% Cl 0.64 to $2.29, p=0.58,1$ trial, 251 participants), dyspepsia (RR: 1.30, 95\% $\mathrm{Cl} 0.67$ to 2.49, $\mathrm{p}=0.44,1$ trial, 251 participants), vomiting (RR: 0.56, $95 \% \mathrm{Cl} 0.27$ to $1.16, \mathrm{p}=0.12$, 1 trial, 251 participants), diarrhoea (RR: $0.47,95 \% \mathrm{Cl} 0.21$ to $1.06, \mathrm{p}=0.07,1$ trial, 251 participants) sleep disorder (RR: $7.06,95 \% \mathrm{Cl} 0.88$ to $56.52, \mathrm{p}=0.07,1$ trial, 251 participants), tongue oedema (RR: $13.10,95 \% \mathrm{Cl} 0.75$ to 230.15 , $\mathrm{p}=0.08,1$ trial, 251 participants), rhinitis ((RR: $4.42,95 \% \mathrm{Cl} 0.98$ to 19.96, $\mathrm{p}=0.05,1$ trial, 120 participants) and raised ALT/SGPT (RR: $12.56,95 \% \mathrm{Cl} 0.72$ to $220.38, \mathrm{p}=0.08,1$ trial, 230 participants).

c) Olanzapine versus other antipsychotic

Treatment emergent adverse events that were common (incidence of $10 \%$ or greater) or significant were reported.

\section{i) Weight gain}

Olanzapine was associated with weight gain in a higher proportion of participants than haloperidol (RR: $3.59,95 \%$ confidence interval 1.49 to $8.64, \mathrm{p}=0.004,1$ trial, 453 participants).

\section{ii) Movement disorders}

A smaller proportion of participants on olanzapine than on haloperidol experienced movement disorders - EPS (RR: 0.10, $95 \%$ confidence interval 0.04 to $0.24, p<0.00001,1$ trial, 453 participants). Olanzapine was associated with a lower incidence than haloperidol of 6 adverse effects - akathisia (RR: 0.21, 95\% $\mathrm{Cl} 0.12$ to $0.38, \mathrm{p}<0.00001,1$ trial, 453 participants), tremor (RR: $0.33,95 \% \mathrm{Cl} 0.17$ to $0.64, \mathrm{p}=0.001,1$ trial, 453 participants), hypertonia (RR: $0.22,95 \% \mathrm{Cl} 0.11$ to $0.45, \mathrm{p}<0.0001,1$ trial, 453 participants), dystonia (RR: $0.20,95 \% \mathrm{Cl} 0.06$ to $0.69, \mathrm{p}=0.01,1$ trial, 453 participants), hypokinesia (RR: $0.12,95 \% \mathrm{Cl} 0.01$ to $0.93, \mathrm{p}=0.04$, 1 trial, 453 participants) and increased salivation (RR: 0.06, 95\% $\mathrm{Cl} 0.01$ to $0.47, \mathrm{p}=0.007,1$ trial, 453 participants). Olanzapine may cause less tardive dyskinesia than haloperidol although difference just failed to reach statistical significance - probably due to the low incidence of this event (RR: $0.07,95 \% \mathrm{Cl} 0.00$ to $1.27, \mathrm{p}=0.07,1$ trial, 453 participants).

\section{iii) Depression}

A smaller proportion of participants on olanzapine than on haloperidol who had a baseline HAMD-21 of 8 or less experienced treatment emergent depression (defined as HAMD-21 of 15 or greater at anytime during the 6 week acute treatment phase (RR: $0.38,95 \%$ confidence interval 0.16 to $0.95, p=0.04,1$ trial, 453 participants).

\section{iii) Other adverse effects}

No statistically significant difference was found between olanzapine and haloperidol in terms of the proportion of participants who withdrew from treatment due to adverse effects (RR: $0.66,95 \% \mathrm{Cl} 0.34$ to $1.26, \mathrm{p}=0.2,1$ trial, 453 participants).

Olanzapine was associated with a higher incidence than haloperidol of 1 adverse effect - infection (RR: 9.36, 95\% Cl 1.21 to $72.51, \mathrm{p}=0.03,1$ trial, 453 participants).

No statistically significant difference was found between olanzapine and haloperidol in terms of the proportion of patients experiencing 3 adverse effects - insomnia (RR: $0.78,95 \% \mathrm{Cl} 0.47$ to 1.28, $p=0.33$, 1 trial, 453 participants), somnolence (RR: $1.50,95 \%$
$\mathrm{Cl} 0.81$ to 2.78, $\mathrm{p}=0.2,1$ trial, 453 participants) and fever (RR: 15.91, $95 \% \mathrm{Cl} 0.92$ to $274.10, \mathrm{p}=0.06,1$ trial, 453 participants).

\section{MORTALITY RATES}

a) Olanzapine versus placebo

No deaths were reported.

\section{b) Olanzapine versus mood stabiliser}

One patient randomised to olanzapine died of diabetic ketoacidosis. The patient had no personal or family history of diabetes and had a glucose level on entry to the trial of $86 \mathrm{mg} /$ $\mathrm{dL}$ which is within the normal range but the level at autopsy was $843 \mathrm{mg} / \mathrm{dL}$.

\section{c) Olanzapine versus haloperidol}

No deaths were reported.

\section{DISCUSSION}

Results from six trials were included in this review. All were undertaken by the manufacturers of one of the interventions and all assessed efficacy in patients with well defined clinical presentation rather than effectiveness in the more diverse patient population seen in routine clinical practice. None of the trials reported the design in sufficient detail in terms of allocation concealment and maintenance of blinding, for an accurate assessment of quality to be made. Although the search was thorough it is still possible that there are unpublished trials which have not been identified but the small number of trials identified hinders the detection of any publication bias.

The main feature of all the trials was the high rate of failure to complete treatment according to the trial protocol. This is similar to the findings in acute schizophrenia in which it has been reported that about a third of participants failed to complete treatment. (Wahlbeck 2001). High withdrawal rates reduce the reliability of the assessment of other outcomes. The five trials that gave details of the analyses reported using last observation carried forward (LOCF) in assessments of efficacy. For trials of treatment for mania there is reason to suppose that the greater the proportion of patients who fail to complete treatment and the shorter the average time on randomised treatment the more conservative the resultant estimates of efficacy. This is because the natural course of a manic episode is to remit over time and, for each individual, this effect of improvement over time will be lost to the analysis from the time that the patient stops trial treatment and the last observation is taken. There is, however, no way to tell precisely what effect failure to complete treatment has on the assessment of efficacy for any individual trial. In the trials of olanzapine monotherapy versus placebo there a further concern that the rates for olanzapine, though still high, are significantly less than for placebo and it is possible that this differential rate was caused by some non random effect, i.e. related to one or other of the study treatments and this might bias the estimates of the effects of the treatments. Results reported for efficacy must therefore be viewed with caution.

There was evidence that olanzapine reduces the symptoms of mania as measured by clinician administered mania rating scales. Olanzapine was found to be more efficacious than placebo both as monotherapy and as adjunctive treatment to lithium or valproate. 
There was no evidence for a difference in effect size between monotherapy and adjunctive treatment so it is possible that the effects of the mood stabiliser and olanzapine may be additive.

The only difference in terms of reduction of mania identified between olanzapine and other active treatments was that there was some evidence that olanzapine was more efficacious than divalproex in reduction of manic symptoms. There was also some evidence that olanzapine may be more effective than placebo in reducing the depressive symptoms that occur in mania and in reducing psychotic symptoms.

Mania rating scales measure the severity of a number of core symptoms of the manic phase of bipolar disorder. These measures provide a useful way to assess change in severity over time. They do not necessarily correlate precisely with more pragmatic measures of mental health such as duration of hospital admission and time to return to normal functioning which are likely to be of more interest to both patients and clinicians.

No details were given of the criteria used to assess the incidence of treatment-emergent adverse effects so the clinical significance is unclear but the data reported indicate that olanzapine causes more somnolence than placebo or divalproex but the same as haloperidol. The only significant difference in terms of gastrointestinal adverse effects was that olanzapine caused less nausea than divalproex. In terms of movement disorders there was some evidence that olanzapine was associated with more symptoms than placebo and divalproex but less than haloperidol. None of the trials reported usable data on general health and social functioning and therefore no assessment could be made of which adverse effects were most troublesome.

Olanzapine produced significantly greater weight gain than placebo, mood stabilisers and haloperidol. This is of particular concern because of the possibility that weight gain interferes with glucose metabolism by causing decreased insulin sensitivity. None of the trials reported changes in blood glucose levels so no data were available on incidence of treatment-emergent hyperglycaemia.

\section{AUTHORS' CONCLUSIONS}

\section{Implications for practice}

There is some evidence that olanzapine is an effective treatment for mania and it reduces psychotic symptoms when present and overall severity of psychiatric illness. Olanzapine may be superior to divalproex in acute mania in terms of symptom reduction but clinicians and patients will need to consider the possible increased risk of adverse effects - particularly weight gain and somnolence. Clinicians need also to be alert to the possibility of alterations in glucose metabolism in patients treated with olanzapine. There was no clear difference in overall acceptability of treatment (as measured by failure to complete the trial) between olanzapine and divalproex. It remains unclear how olanzapine compares to other mood stabilisers such as lithium. On the limited data available, olanzapine was comparable to haloperidol in terms of reduction of mania and remission of mood symptoms. Olanzapine was associated with a higher incidence of weight gain than haloperidol but lower incidence of extra-pyramidal symptoms.

Since the choice of acute treatment may also determine maintenance treatment, clinicians may also want to consider the long term evidence for the safety and/or efficacy of olanzapine in relapse prevention in bipolar disorder (a systematic review of olanzapine as treatment for relapse prevention is currently being undertaken Cipriani 2003).

\section{Implications for research}

Adequately sized randomised trials are needed comparing olanzapine with mood stabilisers and other antipsychotic drugs in the treatment of mania and in the subsequent prevention of manic and depressive relapse. The trials need to be designed to inform prescribing policy rather than assess safety and efficacy for licensing purposes. They should be open to a heterogeneous patient population and should include outcome measures of more relevance to clinicians and patients such as rate of return to normal functioning and quality of life and should record changes in blood glucose levels and onset of diabetes.

\section{ACKNOWLEDGEMENTS}

We thank Heather Wilder, Information Scientist, Centre for Evidence Based Mental Health and the Cochrane Depression, Anxiety and Neurosis Group editorial staff for assistance in developing the search strategy for the review and for conducting several of the database searches. 


\section{RE F E R E N C E S}

\section{References to studies included in this review}

Berk 1999 \{published data only\}

Berk M. Lamotrigine and the treatment of mania in bipolar disorder. European Neuropsychopharmacology 1999;9(Suppl 4):119-23.

* Berk M, Ichim M, Brook J. Olanzapine compared to lithium in mania: a double-blind randomized controlled trial. International Clinical Psychopharmacology 1999;14(6):339-43.

Ichim L, Berk M, Brook S. Lamotrigine compared to lithium in mania: a double-blind randomized controlled trial. Annals of Clinical Psychiatry. 2000;12(1):5-10.

HGEH Trial, 1999 \{published data only\}

* Tohen M, Sanger T, McElroy S, Tollefson GD, Chengappa KN, Daniel DG, et al. Olanzapine versus placebo in the treatment of acute mania. American Journal of Psychiatry 1999;156(5):702-9.

HGFU Trial 2002 \{published data only\}

* Tohen M, Chengappa R, Suppes T, Zarate CA Jr, Calabrese JR, Bowden $\mathrm{CL}$, et al. Efficacy of olanzapine in combination with valproate or lithium in the treatment of mania in patients partially non-responsive to valproate or lithium monotherapy. Archives of General Psychiatry 2002;59(1):62-9.

HGGW Trial 2000 \{published data only\}

* Tohen M, Jacobs T, Grundy S. McElroy SL, Banov MC, Janicak PG, et al. Efficacy of olanzapine in acute bipolar mania. Archives of General Psychiatry 2000;57(9):841-9.

\section{HGHD Trial 2002 \{published data only\}}

Tohen M, Zhang F, Feldman P, et al. Olanzapine versus haloperidol in the treatment of acute mania. British Association of Psychopharmacologicum, Harrogate, UK. 2002.

* Tohen M, Zhang F, Feldman PD, Evans AR, Breier AF. . Olanzapine versus haloperidol treatment of acute maniaAnnual Meeting of the Amedican Psychiatric Association, New Orleans. 2001.

\section{HGHQ Trial 2002 \{published data only\}}

* Tohen M, Baker RW, Altshuler LL, Zarate CA, Suppes T, Ketter TA, et al. Olanzapine versus divalproex in the treatment of acute mania. American Journal of Psychiatry 2002;159(6):1011-7.
Zajecka 2000 \{published data only\}

* Zajecka JM, Weisler, Swann A, et al. Divalproex sodium vs. olanzapine for the treatment of mania in bipolar disorder. 39th ACNP Annual Meeting, San Juan, Puerto Rico. 2000.

\section{References to studies excluded from this review}

Meehan 2001 \{published data only\}

Meehan K, Zhang F, Stacy D, Tohen M, Janicak P, Small J, et al. A double-blind, randomized comparison of the efficacy and safety of intramuscular injections of olanzapine, lorazepam, or placebo in treating acutely agitated patients diagnosed with bipolar disorder. Journal of Clinical Psychopharmacology. 2001;21(4):389-97.

\section{Additional references}

\section{Cipriani 2003}

Cipriani A, Rendell J, Geddes J. Olanzapine in long-term treatment for bipolar disorder (Cochrane Protocol). Cochrane Database of Systematic Reviews 2003, Issue 3.

\section{Duggan 2002}

Duggan L, Fenton M, Dardennes RM, El-Dosoky A, Indran S. Olanzapine for schizophrenia. Cochrane Database of Systematic Reviews 2002, Issue 4.

\section{Goodwin 1990}

Goodwin FK, Jamison KR. Manic-Depressive Illness. Oxford: Oxford University Press, 1990.

\section{Koro 2002}

Koro CE, Fedder DO, L'Italien GJ, Weiss SS, Magder LS, Kreyenbuhl J, et al. Assessment of independent effect of olanzapine and risperidone on risk of diabetes among patients with schizophrenia: population based nested case-control study. BMJ 2002;325(7258):243-7.

\section{Sackett 1997}

Sackett D. The Cochrane Collaboration Handbook. Oxford: Update Software, 1997.

\section{Wahlbeck 2001}

Wahlbeck K, Tuunainen A, Ahokas A, Leucht S. Dropout rates in randomised antipsychotic drug trials. Psychopharmacologia 2001;155(3):230-3.

* Indicates the major publication for the study

\section{CHARACTERISTICS OF STUDIES}

Characteristics of included studies [ordered by study ID]

Berk 1999

Methods

Double-blind randomised controlled trial.

Trial duration - 4 weeks. 
Berk 1999 (Continued)

Single centre trial.

Washout period for other psychotropic medicines of 1 day.

Participants
Age range 20 - 59.
Inclusion criteria: DSM-IV criteria for bipolar disorder, manic episode. Exclusion criteria: Neuroleptic
depot in previous month; fluoxetine in previous 5 weeks; history of recent drug or alcohol abuse; se-
vere disturbance affecting ability to consent and to adhere to the trial protocol; abnormal liver func-
tion or haematological findings; acute medical disorder; medical disorder requiring frequent changes
of medication; cardiac disease.

Interventions Olanzapine versus lithium and versus lamotrigine.

Olanzapine $10 \mathrm{mg} /$ day. Lithium $800 \mathrm{mg} /$ day mean lithium level $0.74 \mathrm{mmol} / \mathrm{l}$. Lamotrigine starting dose $25 \mathrm{mg}$ in week $1,50 \mathrm{mg}$ in week 2 then $100 \mathrm{mg}$. Rescue medication: lorazepam for control of aggression and antiparkinsonian medication as needed.

Outcomes

Mania Scale (MAS), Brief Psychiatric Rating Scale (BPRS), Clinical Global Impression (CGI) severity and improvement scales, Global Assessment of Functioning (GAF). Extra-pyramidal symptoms were measured using the Simpson Angus Scale (SAS) and the Barnes Akathisia Scale. Laboratory tests.

\section{Notes}

\section{Risk of bias}

\begin{tabular}{lll}
\hline Bias & Authors' judgement & Support for judgement \\
\hline Allocation concealment? & Unclear risk & B - Unclear \\
\hline
\end{tabular}

\section{HGEH Trial, 1999}

\begin{tabular}{ll}
\hline Methods & $\begin{array}{l}\text { Double-blind randomised controlled trial. } \\
\text { Trial duration - } 3 \text { weeks. Multi-centre trial. } \\
\text { Washout period for all medications except benzodiazepines of 2-4 days. }\end{array}$ \\
\hline Participants & $\begin{array}{l}\text { Age participants. } \\
\text { Inclusion criteria: DSM-IV criteria for bipolar disorder manic or mixed episode (with or without psychot- } \\
\text { ic features) of at least } 2 \text { weeks duration. Minimum of } 20 \text { on YMRS. } \\
\text { Exclusion criteria: serious, unstable illness, DSM-IV defined substance dependence within the last } 3 \\
\text { months, serious risk of suicide. }\end{array}$ \\
\hline
\end{tabular}

Interventions

Olanzapine versus placebo.

Olanzapine starting dose $10 \mathrm{mg} /$ day adjusted as clinically indicated to $5-20 \mathrm{mg} /$ day - mean modal dose $14.9 \mathrm{mg} /$ day.

Rescue medication - limited use if lorazepam for first 10 days and antiparkinsonian medication as needed.

$\begin{array}{ll}\text { Outcomes } & \text { Primary outcome - change from baseline to endpoint score on Young Mania Rating Scale (YMRS). } \\ & \text { Response defined as } 50 \% \text { reduction in YMRS; Other rating scales - 21-item Hamilton Depression Rat- } \\ \text { ing Scale, Positive and Negative Syndrome Scale (PANSS), Clincial Global Rating (CGI) -Bipolar Version. } \\ \text { Quality of life assessed using the Medical Outcomes Study SF36. Extrapyramidal symptoms assessed } \\ \text { using the Simpson Angus Rating Scale (SAS), the Barnes Akathisia Scale and the Abnormal Involuntary } \\ \text { Movement Scale (AIMS). }\end{array}$

\section{Notes}


HGEH Trial, 1999 (Continued)

Risk of bias

\begin{tabular}{lll}
\hline Bias & Authors' judgement & Support for judgement \\
\hline Allocation concealment? & Unclear risk & B - Unclear \\
\hline
\end{tabular}

HGFU Trial 2002

$\begin{array}{ll}\text { Methods } & \text { Double-blind randomised controlled trial. } \\ \text { Trial duration }-6 \text { weeks. Multi-centre trial. } \\ \text { Patients on mood stabiliser for } 2 \text { weeks prior to randomisation, no other psychotropic medication al- } \\ \text { lowed. }\end{array}$

Participants
Mean Age 40.6 years.
Inclusion Criteria: DSM-IV criteria for bipolar disorder manic or mixed episode (with or without psy-
chotic features); at least 2 previous depressed, manic or mixed episodes; documented trial of two
weeks on lithium ( 0.6 to $1.2 \mathrm{mmol} / \mathrm{l})$ or valproate $(50-125 \mathrm{microg} / \mathrm{ml})$. Minimum 16 on YMRS on 2 assess-
ments 2 - 7 days apart.
Interventions Olanzapine versus placebo as adjunct to lithium or valproate. Olanzapine starting dose $10 \mathrm{mg} / \mathrm{day}$ in- creased according to tolerability up to $20 \mathrm{mg} /$ day. Mean modal dose $10.4 \mathrm{mg} /$ day.
Lithium and valproate doses continued. Rescue medication - benzodiazepine for up to 14 days in total and benztropine mesylate as needed.
Lithium serum level

$\begin{array}{ll}\text { Outcomes } & \text { Primary outcome - change from baseline to endpoint score on Young Mania Rating Scale (YMRS). } \\ & \text { Response defined as } 50 \% \text { reduction in YMRS; Other rating scales for severity of psychiatric illness - 21- } \\ & \text { item Hamilton Depression Rating Scale, Positive and Negative Syndrome Scale (PANSS), Clincial Glob- } \\ & \text { al Rating (CGI) -Bipolar Version. Extrapyramidal symptoms assessed using the Simpson Angus Rating } \\ \text { Scale (SAS), the Barnes Akathisia Scale and the Abnormal Involuntary Movement Scale (AIMS). } \\ \text { Laboratory tests. }\end{array}$

Notes

\section{Risk of bias}

\begin{tabular}{lll}
\hline Bias & Authors' judgement & Support for judgement \\
\hline Allocation concealment? & Unclear risk & B - Unclear \\
\hline
\end{tabular}

HGGW Trial 2000

$\begin{array}{ll}\text { Methods } & \text { Double-blind randomised controlled trial. } \\ \text { Trial duration }-4 \text { weeks. Multi-centre trial. } \\ \text { All psychotropic medication except benzodiazepines tapered during screening period and discontin- } \\ \text { ued at least } 1 \text { day before randomisation. }\end{array}$

Participants

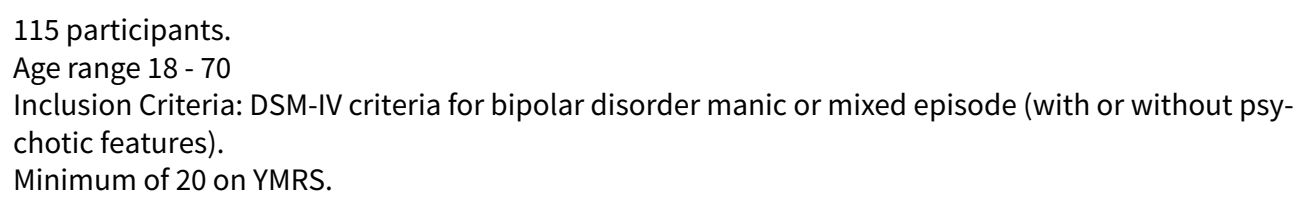


HGGW Trial 2000 (Continued)

Exclusion criteria: serious, unstable illness, DSM-IV defined substance dependence within the last 3 months, serious risk of suicide.

\begin{tabular}{ll}
\hline Interventions & Olanzapine versus placebo. \\
& Olanzapine starting dose $15 \mathrm{mg} /$ day adjusted as clinically indicated to $5-20 \mathrm{mg} / \mathrm{day}-\mathrm{mean}$ modal dos \\
& $16.4 \mathrm{mg} /$ day. \\
& Rescue medication - limited use of lorazepam for first 10 days and antiparkinsonian medication as \\
& needed.
\end{tabular}

\begin{tabular}{ll}
\hline Outcomes & Young Mania Rating Scale, CGI - BP mania scale, CGI - BD scale, 21-item Hamilton Depression Rating \\
Scale, Positive and Negative Syndrome Scale (PANSS). Extrapyramidal symptoms assessed using the \\
Simpson Angus Rating Scale (SAS) and the Barnes Akathisia Scale
\end{tabular}

Notes

\section{Risk of bias}

\begin{tabular}{lll}
\hline Bias & Authors' judgement & Support for judgement \\
\hline Allocation concealment? & Unclear risk & B - Unclear \\
\hline
\end{tabular}

\section{HGHD Trial 2002}

\begin{tabular}{|c|c|}
\hline Methods & $\begin{array}{l}\text { Double-blind randomised controlled trial } \\
\text { Trial duration - acute phase } 6 \text { weeks followed by } 6 \text { weeks' continuation phase. } \\
\text { Multi-centre trial }\end{array}$ \\
\hline Participants & $\begin{array}{l}453 \text { participants. } \\
\text { Age range } 18 \text { - } 86 . \\
\text { Acute phase: Inclusion Criteria: DSM-IV criteria for bipolar disorder manic or mixed episode (with or } \\
\text { without psychotic features). Minimum of } 20 \text { on YMRS. } \\
\text { Continuation Phase: Inclusion criterion: improvement from baseline on CGI-BP severity of overall ill- } \\
\text { ness score. }\end{array}$ \\
\hline Interventions & $\begin{array}{l}\text { Olanzapine versus haloperidol. Olanzapine dose } 15 \mathrm{mg} \text { on day } 1 \text { then } 5-20 \mathrm{mg} / \text { day. Haloperidol } 10 \mathrm{mg} \\
\text { on day } 1 \text { then } 3-15 \mathrm{mg} / \text { day. } \\
\text { Rescue medication - limited use of lorazepam. }\end{array}$ \\
\hline Outcomes & $\begin{array}{l}\text { Primary outcome - remission defined as Young Mania Scale (YMRS) rating of } 12 \text { or less and Hamilton De- } \\
\text { pression Rating Scale (HAMD-21) of } 8 \text { or less at week } 6 . \\
\text { Secondary outcomes - Response (reduction in YMRS of at least 50\%), Montgomery-Asberg Depression } \\
\text { Rating Scale (MADRS), Positive and Negative Syndrome Scale (PANSS), Clincial Global Rating (CGI) - } \\
\text { Bipolar Version. } \\
\text { Extra-pyramidal symptoms were measured using the Simpson Angus Scale (SAS) and the Barnes } \\
\text { Akathisia Scale. Laboratory tests and adverse effects. }\end{array}$ \\
\hline
\end{tabular}

Notes

\section{Risk of bias}

\begin{tabular}{lll}
\hline Bias & Authors' judgement & Support for judgement \\
\hline Allocation concealment? & Unclear risk & B - Unclear \\
\hline
\end{tabular}




\title{
HGHQ Trial 2002
}

\section{Methods}

Double-blind randomised controlled trial.

Trial duration - 3 weeks followed by 44 week continuation phase. Multi-centre trial.

\author{
Participants \\ 251 participants. \\ Age range $18-75$. \\ Inclusion criteria: DSM-IV criteria for bipolar I disorder manic or mixed episode. Currently hospitalised. \\ Minimum of 20 on YMRS. \\ Exclusion criteria: serious and unstable medical illness, DSM-IV substance abuse in past 30 days, doc- \\ umented history of intolerance to olanzapine or divalproex and treatment with lithium, an anticonvul- \\ sant or an antipsychotic within 24 hours of randomisation.
}
Interventions Olanzapine versus divalproex. Olanzapine starting dose $15 \mathrm{mg} /$ day adjusted after day 2 as clinically in- dicated wthin the range 5 and $20 \mathrm{mg} /$ day. Mean modal dose $17 \mathrm{mg} /$ day.
Divalproex starting dose $750 \mathrm{mg} /$ day adjusted after day 2 within the range $500-2500 \mathrm{mg} /$ day accord- ing to clinical response and to maintain plasma level within the range $50-125 \mathrm{microg} / \mathrm{ml}$. Mean modal dose $1401 \mathrm{mg} /$ day.
Rescue medication - limited use of lorazepam and of benztropine to treat EPS.

\begin{abstract}
Outcomes
Primary outcome - change from baseline to endpoint score on Young Mania Rating Scale (YMRS). Response defined as 50\% reduction in YMRS; remission defined as YMRS of 12 or less at endpoint. Other rating scales for severity of psychiatric illness -

21 item Hamilton Depression Rating Scale. Extrapyramidal symptoms assessed using the Simpson Angus Rating Scale (SAS), the Barnes Akathisia Scale and the Abnormal Involuntary Movement Scale AIMS).
\end{abstract}

\section{Notes}

\section{Risk of bias}

\begin{tabular}{lll}
\hline Bias & Authors' judgement & Support for judgement \\
\hline Allocation concealment? & Unclear risk & B - Unclear \\
\hline
\end{tabular}

\section{Zajecka 2000}

Methods Double-blind randomised controlled trial.

Trial duration - 12 weeks with assessment of efficacy at 3 weeks with patients not meeting improvement criteria withdrawn. Multi-centre trial. Participants who did not meet criteria for improvement after 21 days were discontinued.

Washout period 1 - 3 days

\begin{tabular}{ll}
\hline Participants & $\begin{array}{l}120 \text { participants. } \\
\text { Age range } 18-65\end{array}$ \\
\hline Interventions & $\begin{array}{l}\text { Olanzapine versus divalproex. Olanzapine starting dose } 10 \mathrm{mg} / \text { day. Dose increased by } 500 \text { mg on days } \\
3 \text { abd } 6 \text { if clinical symptoms of mania persisted. Mean maximum dose } 14.7 \mathrm{mg} \text { day (range } 2-25 \mathrm{mg} / \text { day). } \\
\text { Divalproex starting dose } 20 \mathrm{mg} / \mathrm{kg} / \text { day. Dose increased by } 5 \mathrm{mg} \text { on days } 3 \text { abd } 6 \text { if clinical symptoms of } \\
\text { mania persisted. Mean maximum dose } 2115 \mathrm{mg} \text { day (range } 750 \text { - 3250mg/day). }\end{array}$ \\
\hline Outcomes & $\begin{array}{l}\text { Primary outcome - Mania Rating Scale (MRS). Secondary outcomes - Manic Syndrome Scale (MSS), } \\
\text { Behaviour and Ideation Scale (BIS), Brief Psychiatric Rating Scale (BPRS), Hamilton Depression Scale } \\
\text { (HAMD), Clinical Global Improvement Scale (CGI) and Quality of life enjoyment and satisfaction ques- } \\
\text { tionnaire (Q-LES-Q) }\end{array}$
\end{tabular}

\section{Notes}


Zajecka 2000 (Continued)

Risk of bias

\begin{tabular}{lll}
\hline Bias & Authors' judgement & Support for judgement \\
\hline Allocation concealment? & Unclear risk & B - Unclear \\
\hline
\end{tabular}

Characteristics of excluded studies [ordered by study ID]

Study Reason for exclusion

Meehan 2001

Trial comparing intramuscular formulations of olanzapine, lorazepam and placebo in terms of short term reduction of agitation rather than reduction in manic symptoms.

\section{DATA AND ANALYSES}

\section{Comparison 1. Olanzapine v placebo}

\begin{tabular}{|c|c|c|c|c|}
\hline Outcome or subgroup title & No. of studies & $\begin{array}{l}\text { No. of partici- } \\
\text { pants }\end{array}$ & Statistical method & Effect size \\
\hline 1 Mean change in YMRS & 3 & 580 & $\begin{array}{l}\text { Mean Difference (IV, Fixed, } \\
95 \% \mathrm{Cl} \text { ) }\end{array}$ & $-4.59[-6.31,-2.87]$ \\
\hline $\begin{array}{l}1.1 \text { Olanzapine v. placebo as } \\
\text { monotherapy }\end{array}$ & 2 & 246 & $\begin{array}{l}\text { Mean Difference (IV, Fixed, } \\
95 \% \mathrm{Cl} \text { ) }\end{array}$ & $-5.94[-9.09,-2.80]$ \\
\hline $\begin{array}{l}1.2 \text { Olanzapine v. placebo as add-on } \\
\text { to mood stabilizer }\end{array}$ & 1 & 334 & $\begin{array}{l}\text { Mean Difference (IV, Fixed, } \\
95 \% \mathrm{CI})\end{array}$ & $-4.01[-6.06,-1.96]$ \\
\hline 2 Mean change in CGI-BP mania & 3 & 580 & $\begin{array}{l}\text { Mean Difference (IV, Fixed, } \\
95 \% \mathrm{Cl} \text { ) }\end{array}$ & $-0.49[-0.73,-0.26]$ \\
\hline $\begin{array}{l}2.1 \text { Olanzapine v. placebo as } \\
\text { monotherapy }\end{array}$ & 2 & 246 & $\begin{array}{l}\text { Mean Difference (IV, Fixed, } \\
95 \% \mathrm{Cl})\end{array}$ & $-0.75[-1.12,-0.38]$ \\
\hline $\begin{array}{l}2.2 \text { Olanzapine v. placebo as add-on } \\
\text { to mood stabilizer }\end{array}$ & 1 & 334 & $\begin{array}{l}\text { Mean Difference (IV, Fixed, } \\
95 \% \mathrm{Cl})\end{array}$ & $-0.32[-0.62,-0.02]$ \\
\hline 3 Failure to respond - YMRS & 3 & 598 & $\begin{array}{l}\text { Risk Ratio (M-H, Fixed, 95\% } \\
\mathrm{Cl} \text { ) }\end{array}$ & $0.64[0.54,0.75]$ \\
\hline $\begin{array}{l}3.1 \text { Olanzapine v. placebo as } \\
\text { monotherapy }\end{array}$ & 2 & 254 & $\begin{array}{l}\text { Risk Ratio (M-H, Fixed, 95\% } \\
\mathrm{Cl} \text { ) }\end{array}$ & $0.64[0.52,0.81]$ \\
\hline $\begin{array}{l}3.2 \text { Olanzapine v. placebo as add-on } \\
\text { to mood stabilizer }\end{array}$ & 1 & 344 & $\begin{array}{l}\text { Risk Ratio (M-H, Fixed, 95\% } \\
\mathrm{Cl})\end{array}$ & $0.63[0.49,0.80]$ \\
\hline 4 Failure to achieve remission - YMRS & 2 & 459 & $\begin{array}{l}\text { Risk Ratio (M-H, Fixed, 95\% } \\
\mathrm{Cl} \text { ) }\end{array}$ & $0.66[0.51,0.85]$ \\
\hline
\end{tabular}




\begin{tabular}{|c|c|c|c|c|}
\hline Outcome or subgroup title & No. of studies & $\begin{array}{l}\text { No. of partici- } \\
\text { pants }\end{array}$ & Statistical method & Effect size \\
\hline $\begin{array}{l}4.1 \text { Olanzapine v. placebo as } \\
\text { monotherapy }\end{array}$ & 1 & 115 & $\begin{array}{l}\text { Risk Ratio (M-H, Fixed, 95\% } \\
\mathrm{Cl} \text { ) }\end{array}$ & $0.6[0.41,0.87]$ \\
\hline $\begin{array}{l}4.2 \text { Olanzapine v. placebo as add-on } \\
\text { to mood stabilizer }\end{array}$ & 1 & 344 & $\begin{array}{l}\text { Risk Ratio (M-H, Fixed, 95\% } \\
\mathrm{Cl} \text { ) }\end{array}$ & $0.70[0.50,0.99]$ \\
\hline $\begin{array}{l}5 \text { Mean Change in 21-item HAMD - all } \\
\text { participants }\end{array}$ & 3 & 578 & $\begin{array}{l}\text { Mean Difference (IV, Fixed, } \\
95 \% \mathrm{Cl} \text { ) }\end{array}$ & $-2.73[-3.90,-1.55]$ \\
\hline $\begin{array}{l}5.1 \text { Olanzapine v. placebo as } \\
\text { monotherapy }\end{array}$ & 2 & 244 & $\begin{array}{l}\text { Mean Difference (IV, Fixed, } \\
95 \% \mathrm{CI})\end{array}$ & $-1.22[-2.92,0.48]$ \\
\hline $\begin{array}{l}5.2 \text { Olanzapine v. placebo as add-on } \\
\text { to mood stabilizer }\end{array}$ & 1 & 334 & $\begin{array}{l}\text { Mean Difference (IV, Fixed, } \\
95 \% \mathrm{CI} \text { ) }\end{array}$ & $-4.09[-5.71,-2.47]$ \\
\hline 6 Mean change in CGI-BP depression & 3 & 580 & $\begin{array}{l}\text { Mean Difference (IV, Fixed, } \\
95 \% \mathrm{CI} \text { ) }\end{array}$ & $-0.24[-0.46,-0.02]$ \\
\hline $\begin{array}{l}6.1 \text { Olanzapine v. placebo as } \\
\text { monotherapy }\end{array}$ & 2 & 246 & $\begin{array}{l}\text { Mean Difference (IV, Fixed, } \\
95 \% \mathrm{CI} \text { ) }\end{array}$ & $0.10[-0.20,0.41]$ \\
\hline $\begin{array}{l}6.2 \text { Olanzapine v. placebo as add-on } \\
\text { to mood stabilizer }\end{array}$ & 1 & 334 & $\begin{array}{l}\text { Mean Difference (IV, Fixed, } \\
95 \% \mathrm{Cl} \text { ) }\end{array}$ & $-0.62[-0.94,-0.30]$ \\
\hline $\begin{array}{l}7 \text { Mean change in PANNS - total } \\
\text { symptom score }\end{array}$ & 3 & 578 & $\begin{array}{l}\text { Mean Difference (IV, Fixed, } \\
95 \% \mathrm{CI})\end{array}$ & $\begin{array}{l}-7.42[-10.33 \\
-4.50]\end{array}$ \\
\hline $\begin{array}{l}7.1 \text { Olanzapine v. placebo as } \\
\text { monotherapy }\end{array}$ & 2 & 244 & $\begin{array}{l}\text { Mean Difference (IV, Fixed, } \\
95 \% \mathrm{CI})\end{array}$ & $\begin{array}{l}-10.00[-14.84 \\
-5.16]\end{array}$ \\
\hline $\begin{array}{l}7.2 \text { Olanzapine v. placebo as add-on } \\
\text { to mood stabilizer }\end{array}$ & 1 & 334 & $\begin{array}{l}\text { Mean Difference (IV, Fixed, } \\
95 \% \mathrm{CI})\end{array}$ & $-5.94[-9.60,-2.28]$ \\
\hline $\begin{array}{l}8 \text { Mean change in PANNS - positive } \\
\text { symptom score }\end{array}$ & 2 & 250 & $\begin{array}{l}\text { Mean Difference (IV, Fixed, } \\
95 \% \mathrm{CI})\end{array}$ & $-3.54[-5.28,-1.80]$ \\
\hline $\begin{array}{l}8.1 \text { Olanzapine v. placebo as } \\
\text { monotherapy }\end{array}$ & 2 & 250 & $\begin{array}{l}\text { Mean Difference (IV, Fixed, } \\
95 \% \mathrm{Cl})\end{array}$ & $-3.54[-5.28,-1.80]$ \\
\hline $\begin{array}{l}9 \text { Mean change in PANNS - negative } \\
\text { symptom score }\end{array}$ & 2 & 244 & $\begin{array}{l}\text { Mean Difference (IV, Fixed, } \\
95 \% \mathrm{CI})\end{array}$ & $-1.18[-2.36,0.01]$ \\
\hline $\begin{array}{l}9.1 \text { Olanzapine v. placebo as } \\
\text { monotherapy }\end{array}$ & 2 & 244 & $\begin{array}{l}\text { Mean Difference (IV, Fixed, } \\
95 \% \mathrm{CI})\end{array}$ & $-1.18[-2.36,0.01]$ \\
\hline $\begin{array}{l}10 \text { Mean change in CGI - BP severity of } \\
\text { overall bipolar illness }\end{array}$ & 3 & 580 & $\begin{array}{l}\text { Mean Difference (IV, Fixed, } \\
95 \% \mathrm{Cl} \text { ) }\end{array}$ & $-0.42[-0.64,-0.20]$ \\
\hline $\begin{array}{l}10.1 \text { Olanzapine v. placebo as } \\
\text { monotherapy }\end{array}$ & 2 & 246 & $\begin{array}{l}\text { Mean Difference (IV, Fixed, } \\
95 \% \mathrm{Cl} \text { ) }\end{array}$ & $-0.58[-0.93,-0.24]$ \\
\hline $\begin{array}{l}10.2 \text { Olanzapine v. placebo as add-on } \\
\text { to mood stabilizer }\end{array}$ & 1 & 334 & $\begin{array}{l}\text { Mean Difference (IV, Fixed, } \\
95 \% \mathrm{Cl})\end{array}$ & $-0.31[-0.60,-0.02]$ \\
\hline
\end{tabular}




\begin{tabular}{|c|c|c|c|c|}
\hline Outcome or subgroup title & No. of studies & $\begin{array}{l}\text { No. of partici- } \\
\text { pants }\end{array}$ & Statistical method & Effect size \\
\hline $\begin{array}{l}11 \text { Mean dose of anticholinergic med- } \\
\text { ication }\end{array}$ & 1 & 115 & $\begin{array}{l}\text { Mean Difference (IV, Fixed, } \\
95 \% \mathrm{CI})\end{array}$ & $0.11[0.03,0.19]$ \\
\hline $\begin{array}{l}11.1 \text { Olanzapine v. placebo as } \\
\text { monotherapy }\end{array}$ & 1 & 115 & $\begin{array}{l}\text { Mean Difference (IV, Fixed, } \\
95 \% \mathrm{CI})\end{array}$ & $0.11[0.03,0.19]$ \\
\hline 12 Use of benzodiazepines & 2 & 459 & $\begin{array}{l}\text { Risk Ratio (M-H, Fixed, 95\% } \\
\mathrm{Cl} \text { ) }\end{array}$ & $0.87[0.70,1.07]$ \\
\hline $\begin{array}{l}12.1 \text { Olanzapine v. placebo as } \\
\text { monotherapy }\end{array}$ & 1 & 115 & $\begin{array}{l}\text { Risk Ratio (M-H, Fixed, 95\% } \\
\mathrm{Cl} \text { ) }\end{array}$ & $0.89[0.70,1.14]$ \\
\hline $\begin{array}{l}12.2 \text { Olanzapine } v \text {. placebo as add-on } \\
\text { to mood stabilizer }\end{array}$ & 1 & 344 & $\begin{array}{l}\text { Risk Ratio (M-H, Fixed, 95\% } \\
\mathrm{Cl} \text { ) }\end{array}$ & $0.85[0.61,1.18]$ \\
\hline $\begin{array}{l}13 \text { Failure to respond - YMRS (exclud- } \\
\text { ing early withdrawals) }\end{array}$ & 3 & 580 & $\begin{array}{l}\text { Risk Ratio (M-H, Fixed, 95\% } \\
\text { Cl) }\end{array}$ & $0.62[0.52,0.73]$ \\
\hline $\begin{array}{l}13.1 \text { Olanzapine v. placebo as } \\
\text { monotherapy }\end{array}$ & 2 & 246 & $\begin{array}{l}\text { Risk Ratio (M-H, Fixed, 95\% } \\
\mathrm{Cl})\end{array}$ & $0.65[0.52,0.82]$ \\
\hline $\begin{array}{l}13.2 \text { Olanzapine v. placebo as add-on } \\
\text { to mood stabilizer }\end{array}$ & 1 & 334 & $\begin{array}{l}\text { Risk Ratio (M-H, Fixed, 95\% } \\
\mathrm{Cl})\end{array}$ & $0.58[0.45,0.75]$ \\
\hline $\begin{array}{l}14 \text { Failure to remit- YMRS - (excluding } \\
\text { early withdrawals) }\end{array}$ & 2 & 444 & $\begin{array}{l}\text { Risk Ratio (M-H, Fixed, 95\% } \\
\mathrm{Cl} \text { ) }\end{array}$ & $0.62[0.47,0.80]$ \\
\hline $\begin{array}{l}14.1 \text { Olanzapine v. placebo as } \\
\text { monotherapy }\end{array}$ & 1 & 110 & $\begin{array}{l}\text { Risk Ratio (M-H, Fixed, 95\% } \\
\mathrm{Cl})\end{array}$ & $0.60[0.41,0.89]$ \\
\hline $\begin{array}{l}14.2 \text { Olanzapine v. placebo as add-on } \\
\text { to mood stabilizer }\end{array}$ & 1 & 334 & $\begin{array}{l}\text { Risk Ratio (M-H, Fixed, 95\% } \\
\mathrm{Cl})\end{array}$ & $0.62[0.44,0.89]$ \\
\hline 15 Failure to complete treatment & 3 & 598 & $\begin{array}{l}\text { Risk Ratio (M-H, Fixed, 95\% } \\
\mathrm{Cl} \text { ) }\end{array}$ & $0.77[0.63,0.95]$ \\
\hline $\begin{array}{l}15.1 \text { Olanzapine v. placebo as } \\
\text { monotherapy }\end{array}$ & 2 & 254 & $\begin{array}{l}\text { Risk Ratio (M-H, Fixed, 95\% } \\
\mathrm{Cl})\end{array}$ & $0.62[0.48,0.80]$ \\
\hline $\begin{array}{l}15.2 \text { Olanzapine v. placebo as add-on } \\
\text { to mood stabilizer }\end{array}$ & 1 & 344 & $\begin{array}{l}\text { Risk Ratio (M-H, Fixed, 95\% } \\
\mathrm{Cl} \text { ) }\end{array}$ & $1.05[0.74,1.49]$ \\
\hline 16 Treatment emergent depression & 3 & 593 & $\begin{array}{l}\text { Risk Ratio (M-H, Fixed, 95\% } \\
\mathrm{Cl} \text { ) }\end{array}$ & $0.95[0.65,1.40]$ \\
\hline $\begin{array}{l}16.1 \text { Olanzapine v. placebo as } \\
\text { monotherapy }\end{array}$ & 2 & 249 & $\begin{array}{l}\text { Risk Ratio (M-H, Fixed, 95\% } \\
\mathrm{Cl} \text { ) }\end{array}$ & $0.84[0.44,1.60]$ \\
\hline $\begin{array}{l}16.2 \text { Olanzapine v. placebo as add-on } \\
\text { to mood stabilizer }\end{array}$ & 1 & 344 & $\begin{array}{l}\text { Risk Ratio (M-H, Fixed, 95\% } \\
\mathrm{Cl} \text { ) }\end{array}$ & $1.03[0.63,1.67]$ \\
\hline 17 SAS Scale & 2 & 241 & $\begin{array}{l}\text { Mean Difference (IV, Fixed, } \\
95 \% \mathrm{Cl})\end{array}$ & $-0.33[-0.74,0.09]$ \\
\hline
\end{tabular}




\begin{tabular}{|c|c|c|c|c|}
\hline Outcome or subgroup title & No. of studies & $\begin{array}{l}\text { No. of partici- } \\
\text { pants }\end{array}$ & Statistical method & Effect size \\
\hline $\begin{array}{l}17.1 \text { Olanzapine v. placebo as } \\
\text { monotherapy }\end{array}$ & 2 & 241 & $\begin{array}{l}\text { Mean Difference (IV, Fixed, } \\
95 \% \mathrm{Cl})\end{array}$ & $-0.33[-0.74,0.09]$ \\
\hline 18 Barnes Akathisia Scale & 2 & 246 & $\begin{array}{l}\text { Mean Difference (IV, Fixed, } \\
95 \% \mathrm{CI})\end{array}$ & $-0.13[-0.32,0.06]$ \\
\hline $\begin{array}{l}18.1 \text { Olanzapine v. placebo as } \\
\text { monotherapy }\end{array}$ & 2 & 246 & $\begin{array}{l}\text { Mean Difference (IV, Fixed, } \\
95 \% \mathrm{Cl} \text { ) }\end{array}$ & $-0.13[-0.32,0.06]$ \\
\hline 19 AIMS & 1 & 135 & $\begin{array}{l}\text { Mean Difference (IV, Fixed, } \\
95 \% \mathrm{CI})\end{array}$ & $-0.25[-0.58,0.08]$ \\
\hline $\begin{array}{l}\text { 19.1 Olanzapine v. placebo as } \\
\text { monotherapy }\end{array}$ & 1 & 135 & $\begin{array}{l}\text { Mean Difference (IV, Fixed, } \\
95 \% \mathrm{Cl} \text { ) }\end{array}$ & $-0.25[-0.58,0.08]$ \\
\hline 20 Weight Gain (continuous data) & 3 & 581 & $\begin{array}{l}\text { Mean Difference (IV, Fixed, } \\
95 \% \mathrm{CI})\end{array}$ & $2.39[1.96,2.83]$ \\
\hline $\begin{array}{l}20.1 \text { Olanzapine v. placebo as } \\
\text { monotherapy }\end{array}$ & 2 & 249 & $\begin{array}{l}\text { Mean Difference (IV, Fixed, } \\
95 \% \mathrm{Cl} \text { ) }\end{array}$ & $1.91[1.29,2.53]$ \\
\hline $\begin{array}{l}20.2 \text { Olanzapine v. placebo as add-on } \\
\text { to mood stabilizer }\end{array}$ & 1 & 332 & $\begin{array}{l}\text { Mean Difference (IV, Fixed, } \\
95 \% \mathrm{Cl} \text { ) }\end{array}$ & $2.85[2.24,3.46]$ \\
\hline 21 Somnolence & 3 & 598 & $\begin{array}{l}\text { Risk Ratio (M-H, Fixed, 95\% } \\
\mathrm{Cl})\end{array}$ & $2.13[1.62,2.79]$ \\
\hline $\begin{array}{l}21.1 \text { Olanzapine v. placebo as } \\
\text { monotherapy }\end{array}$ & 2 & 254 & $\begin{array}{l}\text { Risk Ratio (M-H, Fixed, 95\% } \\
\mathrm{Cl})\end{array}$ & $2.65[1.61,4.38]$ \\
\hline $\begin{array}{l}21.2 \text { Olanzapine v. placebo as add-on } \\
\text { to mood stabilizer }\end{array}$ & 1 & 344 & $\begin{array}{l}\text { Risk Ratio (M-H, Fixed, 95\% } \\
\mathrm{Cl})\end{array}$ & $1.91[1.38,2.65]$ \\
\hline 22 Dry Mouth & 3 & 598 & $\begin{array}{l}\text { Risk Ratio (M-H, Fixed, 95\% } \\
\mathrm{Cl} \text { ) }\end{array}$ & $3.64[2.24,5.91]$ \\
\hline $\begin{array}{l}22.1 \text { Olanzapine v. placebo as } \\
\text { monotherapy }\end{array}$ & 2 & 254 & $\begin{array}{l}\text { Risk Ratio (M-H, Fixed, 95\% } \\
\mathrm{Cl})\end{array}$ & $3.06[1.50,6.22]$ \\
\hline $\begin{array}{l}22.2 \text { Olanzapine v. placebo as add-on } \\
\text { to mood stabilizer }\end{array}$ & 1 & 344 & $\begin{array}{l}\text { Risk Ratio (M-H, Fixed, 95\% } \\
\mathrm{Cl})\end{array}$ & $4.07[2.12,7.84]$ \\
\hline 23 Dizziness & 3 & 598 & $\begin{array}{l}\text { Risk Ratio (M-H, Fixed, 95\% } \\
\mathrm{Cl} \text { ) }\end{array}$ & $2.37[1.39,4.04]$ \\
\hline $\begin{array}{l}23.1 \text { Olanzapine v. placebo as } \\
\text { monotherapy }\end{array}$ & 2 & 254 & $\begin{array}{l}\text { Risk Ratio (M-H, Fixed, 95\% } \\
\mathrm{Cl} \text { ) }\end{array}$ & $2.95[1.37,6.38]$ \\
\hline $\begin{array}{l}23.2 \text { Olanzapine v. placebo as add-on } \\
\text { to mood stabilizer }\end{array}$ & 1 & 344 & $\begin{array}{l}\text { Risk Ratio (M-H, Fixed, 95\% } \\
\mathrm{Cl} \text { ) }\end{array}$ & $1.95[0.92,4.10]$ \\
\hline 24 Agitation & 2 & 254 & $\begin{array}{l}\text { Risk Ratio (M-H, Fixed, 95\% } \\
\mathrm{Cl})\end{array}$ & $0.59[0.35,1.01]$ \\
\hline
\end{tabular}




\begin{tabular}{|c|c|c|c|c|}
\hline Outcome or subgroup title & No. of studies & $\begin{array}{l}\text { No. of partici- } \\
\text { pants }\end{array}$ & Statistical method & Effect size \\
\hline $\begin{array}{l}24.1 \text { Olanzapine v. placebo as } \\
\text { monotherapy }\end{array}$ & 2 & 254 & $\begin{array}{l}\text { Risk Ratio (M-H, Fixed, 95\% } \\
\mathrm{Cl})\end{array}$ & $0.59[0.35,1.01]$ \\
\hline 25 Asthenia & 3 & 598 & $\begin{array}{l}\text { Risk Ratio (M-H, Fixed, 95\% } \\
\mathrm{Cl} \text { ) }\end{array}$ & $1.69[1.09,2.64]$ \\
\hline $\begin{array}{l}25.1 \text { Olanzapine v. placebo as } \\
\text { monotherapy }\end{array}$ & 2 & 254 & $\begin{array}{l}\text { Risk Ratio (M-H, Fixed, 95\% } \\
\mathrm{Cl} \text { ) }\end{array}$ & $2.42[1.10,5.33]$ \\
\hline $\begin{array}{l}25.2 \text { Olanzapine v. placebo as add-on } \\
\text { to mood stabilizer }\end{array}$ & 1 & 344 & $\begin{array}{l}\text { Risk Ratio (M-H, Fixed, 95\% } \\
\mathrm{Cl})\end{array}$ & $1.41[0.82,2.43]$ \\
\hline 26 Headache & 3 & 598 & $\begin{array}{l}\text { Risk Ratio (M-H, Fixed, 95\% } \\
\mathrm{Cl})\end{array}$ & $0.90[0.63,1.29]$ \\
\hline $\begin{array}{l}26.1 \text { Olanzapine v. placebo as } \\
\text { monotherapy }\end{array}$ & 2 & 254 & $\begin{array}{l}\text { Risk Ratio (M-H, Fixed, 95\% } \\
\mathrm{Cl} \text { ) }\end{array}$ & $0.95[0.56,1.61]$ \\
\hline $\begin{array}{l}26.2 \text { Olanzapine v. placebo as add-on } \\
\text { to mood stabilizer }\end{array}$ & 1 & 344 & $\begin{array}{l}\text { Risk Ratio (M-H, Fixed, 95\% } \\
\mathrm{Cl})\end{array}$ & $0.86[0.53,1.40]$ \\
\hline 27 Anxiety & 2 & 254 & $\begin{array}{l}\text { Risk Ratio (M-H, Random, } \\
95 \% \mathrm{Cl})\end{array}$ & $0.65[0.11,3.67]$ \\
\hline $\begin{array}{l}27.1 \text { Olanzapine v. placebo as } \\
\text { monotherapy }\end{array}$ & 2 & 254 & $\begin{array}{l}\text { Risk Ratio (M-H, Random, } \\
95 \% \mathrm{Cl} \text { ) }\end{array}$ & $0.65[0.11,3.67]$ \\
\hline 28 Constipation & 2 & 254 & $\begin{array}{l}\text { Risk Ratio (M-H, Fixed, 95\% } \\
\mathrm{Cl} \text { ) }\end{array}$ & $2.09[0.87,5.04]$ \\
\hline $\begin{array}{l}28.1 \text { Olanzapine v. placebo as } \\
\text { monotherapy }\end{array}$ & 2 & 254 & $\begin{array}{l}\text { Risk Ratio (M-H, Fixed, 95\% } \\
\mathrm{Cl} \text { ) }\end{array}$ & $2.09[0.87,5.04]$ \\
\hline 29 Pain & 1 & 139 & $\begin{array}{l}\text { Risk Ratio (M-H, Fixed, 95\% } \\
\mathrm{Cl} \text { ) }\end{array}$ & $2.63[0.73,9.50]$ \\
\hline $\begin{array}{l}29.1 \text { Olanzapine v. placebo as } \\
\text { monotherapy }\end{array}$ & 1 & 139 & $\begin{array}{l}\text { Risk Ratio (M-H, Fixed, 95\% } \\
\mathrm{Cl} \text { ) }\end{array}$ & $2.63[0.73,9.50]$ \\
\hline 30 Hostility & 2 & 254 & $\begin{array}{l}\text { Risk Ratio (M-H, Fixed, 95\% } \\
\mathrm{Cl} \text { ) }\end{array}$ & $0.51[0.21,1.22]$ \\
\hline $\begin{array}{l}30.1 \text { Olanzapine v. placebo as } \\
\text { monotherapy }\end{array}$ & 2 & 254 & $\begin{array}{l}\text { Risk Ratio (M-H, Fixed, 95\% } \\
\mathrm{Cl} \text { ) }\end{array}$ & $0.51[0.21,1.22]$ \\
\hline 31 Nervousness & 3 & 598 & $\begin{array}{l}\text { Risk Ratio (M-H, Fixed, 95\% } \\
\mathrm{Cl})\end{array}$ & $0.63[0.40,0.98]$ \\
\hline $\begin{array}{l}31.1 \text { Olanzapine v. placebo as } \\
\text { monotherapy }\end{array}$ & 2 & 254 & $\begin{array}{l}\text { Risk Ratio (M-H, Fixed, 95\% } \\
\mathrm{Cl})\end{array}$ & $0.54[0.27,1.08]$ \\
\hline $\begin{array}{l}31.2 \text { Olanzapine v. placebo as add-on } \\
\text { to mood stabilizer }\end{array}$ & 1 & 344 & $\begin{array}{l}\text { Risk Ratio (M-H, Fixed, 95\% } \\
\mathrm{Cl})\end{array}$ & $0.71[0.40,1.27]$ \\
\hline
\end{tabular}




\begin{tabular}{|c|c|c|c|c|}
\hline Outcome or subgroup title & No. of studies & $\begin{array}{l}\text { No. of partici- } \\
\text { pants }\end{array}$ & Statistical method & Effect size \\
\hline 32 Personality Disorder & 2 & 254 & $\begin{array}{l}\text { Risk Ratio (M-H, Fixed, 95\% } \\
\mathrm{Cl})\end{array}$ & $0.41[0.16,1.02]$ \\
\hline $\begin{array}{l}32.1 \text { Olanzapine v. placebo as } \\
\text { monotherapy }\end{array}$ & 2 & 254 & $\begin{array}{l}\text { Risk Ratio (M-H, Fixed, 95\% } \\
\mathrm{Cl})\end{array}$ & $0.41[0.16,1.02]$ \\
\hline 33 Weight Gain (dichotomous data) & 2 & 483 & $\begin{array}{l}\text { Risk Ratio (M-H, Fixed, 95\% } \\
\mathrm{Cl})\end{array}$ & $4.12[2.13,7.98]$ \\
\hline $\begin{array}{l}33.1 \text { Olanzapine v. placebo as } \\
\text { monotherapy }\end{array}$ & 1 & 139 & $\begin{array}{l}\text { Risk Ratio (M-H, Fixed, 95\% } \\
\mathrm{Cl})\end{array}$ & $7.89[1.01,61.38]$ \\
\hline $\begin{array}{l}33.2 \text { Olanzapine v. placebo as add-on } \\
\text { to mood stabilizer }\end{array}$ & 1 & 344 & $\begin{array}{l}\text { Risk Ratio (M-H, Fixed, 95\% } \\
\mathrm{Cl})\end{array}$ & $3.77[1.86,7.61]$ \\
\hline 34 Increased ALT/SGPT & 2 & 254 & $\begin{array}{l}\text { Risk Ratio (M-H, Fixed, 95\% } \\
\mathrm{Cl})\end{array}$ & $10.32[2.85,37.35]$ \\
\hline $\begin{array}{l}34.1 \text { Olanzapine v. placebo as } \\
\text { monotherapy }\end{array}$ & 2 & 254 & $\begin{array}{l}\text { Risk Ratio (M-H, Fixed, 95\% } \\
\mathrm{Cl})\end{array}$ & $10.32[2.85,37.35]$ \\
\hline 35 Dyspepsia & 1 & 115 & $\begin{array}{l}\text { Risk Ratio (M-H, Fixed, 95\% } \\
\mathrm{CI})\end{array}$ & $2.55[0.69,9.36]$ \\
\hline $\begin{array}{l}35.1 \text { Olanzapine v. placebo as } \\
\text { monotherapy }\end{array}$ & 1 & 115 & $\begin{array}{l}\text { Risk Ratio (M-H, Fixed, 95\% } \\
\mathrm{Cl})\end{array}$ & $2.55[0.69,9.36]$ \\
\hline $\begin{array}{l}36 \text { Mean change in supine systolic } \\
\text { blood pressure }\end{array}$ & 1 & 115 & $\begin{array}{l}\text { Mean Difference (IV, Fixed, } \\
95 \% \mathrm{CI})\end{array}$ & $8.9[2.70,15.10]$ \\
\hline $\begin{array}{l}36.1 \text { Olanzapine v. placebo as } \\
\text { monotherapy }\end{array}$ & 1 & 115 & $\begin{array}{l}\text { Mean Difference (IV, Fixed, } \\
95 \% \mathrm{Cl})\end{array}$ & $8.9[2.70,15.10]$ \\
\hline 37 Increased AST & 1 & 115 & $\begin{array}{l}\text { Risk Ratio (M-H, Fixed, 95\% } \\
\mathrm{Cl} \text { ) }\end{array}$ & $\begin{array}{l}22.88[1.37 \\
381.38]\end{array}$ \\
\hline $\begin{array}{l}37.1 \text { Olanzapine v. placebo as } \\
\text { monotherapy }\end{array}$ & 1 & 115 & $\begin{array}{l}\text { Risk Ratio (M-H, Fixed, 95\% } \\
\mathrm{Cl} \text { ) }\end{array}$ & $\begin{array}{l}22.88[1.37 \\
381.38]\end{array}$ \\
\hline 38 ECG abnormality & 1 & 115 & $\begin{array}{l}\text { Risk Ratio (M-H, Fixed, 95\% } \\
\mathrm{Cl})\end{array}$ & $0.38[0.18,0.83]$ \\
\hline $\begin{array}{l}38.1 \text { Olanzapine v. placebo as } \\
\text { monotherapy }\end{array}$ & 1 & 115 & $\begin{array}{l}\text { Risk Ratio (M-H, Fixed, 95\% } \\
\mathrm{Cl})\end{array}$ & $0.38[0.18,0.83]$ \\
\hline $\begin{array}{l}39 \text { Corrected QT interval prolonga- } \\
\text { tion }\end{array}$ & 1 & 115 & $\begin{array}{l}\text { Risk Ratio (M-H, Fixed, 95\% } \\
\mathrm{Cl})\end{array}$ & $0.73[0.13,4.19]$ \\
\hline $\begin{array}{l}39.1 \text { Olanzapine v. placebo as } \\
\text { monotherapy }\end{array}$ & 1 & 115 & $\begin{array}{l}\text { Risk Ratio (M-H, Fixed, 95\% } \\
\mathrm{Cl})\end{array}$ & $0.73[0.13,4.19]$ \\
\hline 40 Prolactin elevation & 1 & 334 & $\begin{array}{l}\text { Risk Ratio (M-H, Fixed, 95\% } \\
\mathrm{Cl} \text { ) }\end{array}$ & $4.35[1.77,10.70]$ \\
\hline
\end{tabular}




\begin{tabular}{|c|c|c|c|c|}
\hline Outcome or subgroup title & No. of studies & $\begin{array}{l}\text { No. of partici- } \\
\text { pants }\end{array}$ & Statistical method & Effect size \\
\hline $\begin{array}{l}40.2 \text { Olanzapine v. placebo as add-on } \\
\text { to mood stabilizer }\end{array}$ & 1 & 334 & $\begin{array}{l}\text { Risk Ratio (M-H, Fixed, 95\% } \\
\mathrm{Cl})\end{array}$ & $4.35[1.77,10.70]$ \\
\hline 41 Increased Appetite & 1 & 344 & $\begin{array}{l}\text { Risk Ratio (M-H, Fixed, 95\% } \\
\mathrm{Cl})\end{array}$ & $3.01[1.54,5.88]$ \\
\hline $\begin{array}{l}41.2 \text { Olanzapine v. placebo as add-on } \\
\text { to mood stabilizer }\end{array}$ & 1 & 344 & $\begin{array}{l}\text { Risk Ratio (M-H, Fixed, 95\% } \\
\mathrm{Cl})\end{array}$ & $3.01[1.54,5.88]$ \\
\hline 42 Tremor & 1 & 344 & $\begin{array}{l}\text { Risk Ratio (M-H, Fixed, 95\% } \\
\mathrm{Cl})\end{array}$ & $1.77[1.05,3.01]$ \\
\hline $\begin{array}{l}42.2 \text { Olanzapine v. placebo as add-on } \\
\text { to mood stabilizer }\end{array}$ & 1 & 344 & $\begin{array}{l}\text { Risk Ratio (M-H, Fixed, 95\% } \\
\mathrm{Cl})\end{array}$ & $1.77[1.05,3.01]$ \\
\hline 43 Diarrhoea & 1 & 344 & $\begin{array}{l}\text { Risk Ratio (M-H, Fixed, 95\% } \\
\mathrm{Cl})\end{array}$ & $0.80[0.45,1.40]$ \\
\hline $\begin{array}{l}43.2 \text { Olanzapine v. placebo as add-on } \\
\text { to mood stabilizer }\end{array}$ & 1 & 344 & $\begin{array}{l}\text { Risk Ratio (M-H, Fixed, 95\% } \\
\mathrm{Cl})\end{array}$ & $0.80[0.45,1.40]$ \\
\hline $\begin{array}{l}44 \text { Mean change in } 21 \text {-item HAMD - } \\
\text { depressed participants }\end{array}$ & 2 & 114 & $\begin{array}{l}\text { Mean Difference (IV, Fixed, } \\
95 \% \mathrm{CI})\end{array}$ & $\begin{array}{l}-7.72[-10.89 \\
-4.55]\end{array}$ \\
\hline $\begin{array}{l}44.1 \text { Olanzapine v. placebo as } \\
\text { monotherapy }\end{array}$ & 1 & 42 & $\begin{array}{l}\text { Mean Difference (IV, Fixed, } \\
95 \% \mathrm{Cl} \text { ) }\end{array}$ & $\begin{array}{l}-5.98[-11.19 \\
-0.77]\end{array}$ \\
\hline $\begin{array}{l}44.2 \text { Olanzapine v. placebo as add-on } \\
\text { to mood stabilizer }\end{array}$ & 1 & 72 & $\begin{array}{l}\text { Mean Difference (IV, Fixed, } \\
95 \% \mathrm{CI})\end{array}$ & $\begin{array}{l}-8.74[-12.74 \\
-4.74]\end{array}$ \\
\hline 45 Thirst & 1 & 344 & $\begin{array}{l}\text { Risk Ratio (M-H, Fixed, 95\% } \\
\mathrm{Cl})\end{array}$ & $1.65[0.73,3.73]$ \\
\hline $\begin{array}{l}45.2 \text { Olanzapine v. placebo as add-on } \\
\text { to mood stabilizer }\end{array}$ & 1 & 344 & $\begin{array}{l}\text { Risk Ratio (M-H, Fixed, 95\% } \\
\mathrm{Cl})\end{array}$ & $1.65[0.73,3.73]$ \\
\hline 46 Speech Disorder & 1 & 344 & $\begin{array}{l}\text { Risk Ratio (M-H, Fixed, 95\% } \\
\mathrm{Cl})\end{array}$ & $7.53[1.01,56.32]$ \\
\hline $\begin{array}{l}46.2 \text { Olanzapine v. placebo as add-on } \\
\text { to mood stabilizer }\end{array}$ & 1 & 344 & $\begin{array}{l}\text { Risk Ratio (M-H, Fixed, 95\% } \\
\mathrm{Cl})\end{array}$ & $7.53[1.01,56.32]$ \\
\hline $\begin{array}{l}47 \text { Mean change in YMRS for patients } \\
\text { not experiencing psychotic symp- } \\
\text { toms }\end{array}$ & 1 & 226 & $\begin{array}{l}\text { Mean Difference (IV, Fixed, } \\
95 \% \mathrm{Cl} \text { ) }\end{array}$ & $-4.93[-7.24,-2.62]$ \\
\hline $\begin{array}{l}47.2 \text { Olanzapine v. placebo as add-on } \\
\text { to mood stabilizer }\end{array}$ & 1 & 226 & $\begin{array}{l}\text { Mean Difference (IV, Fixed, } \\
95 \% \mathrm{CI})\end{array}$ & $-4.93[-7.24,-2.62]$ \\
\hline $\begin{array}{l}48 \text { Mean change in YMRS according to } \\
\text { mood stabiliser }\end{array}$ & 1 & 351 & $\begin{array}{l}\text { Mean Difference (IV, Fixed, } \\
95 \% \mathrm{CI})\end{array}$ & $-3.98[-6.02,-1.94]$ \\
\hline $\begin{array}{l}48.1 \text { Olanzapine v. placebo as add-on } \\
\text { to lithium }\end{array}$ & 1 & 115 & $\begin{array}{l}\text { Mean Difference (IV, Fixed, } \\
95 \% \mathrm{CI} \text { ) }\end{array}$ & $-3.23[-6.50,0.04]$ \\
\hline
\end{tabular}




\begin{tabular}{lllll}
\hline Outcome or subgroup title & No. of studies & $\begin{array}{l}\text { No. of partici- } \\
\text { pants }\end{array}$ & Statistical method & Effect size \\
\hline $\begin{array}{l}\text { 48.2 Olanzapine v. placebo as add-on } \\
\text { to valproate }\end{array}$ & 1 & 236 & $\begin{array}{l}\text { Mean Difference (IV, Fixed, } \\
95 \% \mathrm{Cl})\end{array}$ & $-4.46[-7.07,-1.85]$ \\
\hline $\begin{array}{l}49 \text { Failure to respond - YMRS (excl } \\
\text { withdrawals) }\end{array}$ & 0 & 0 & Risk Ratio (M-H, Fixed, 95\% & $0.0[0.0,0.0]$ \\
\hline $\begin{array}{l}\text { 49.1 Olanzapine v. placebo as } \\
\text { monotherapy }\end{array}$ & 0 & 0 & Risk Ratio (M-H, Fixed, 95\% & $0.0[0.0,0.0]$ \\
\hline $\begin{array}{l}\text { 49.2 Olanzapine v. placebo as add-on } \\
\text { to mood stabilizer }\end{array}$ & 0 & 0 & Cl) & $\begin{array}{l}\text { Risk Ratio (M-H, Fixed, 95\% } \\
\text { Cl) }\end{array}$ \\
\hline
\end{tabular}

Analysis 1.1. Comparison 1 Olanzapine v placebo, Outcome 1 Mean change in YMRS.

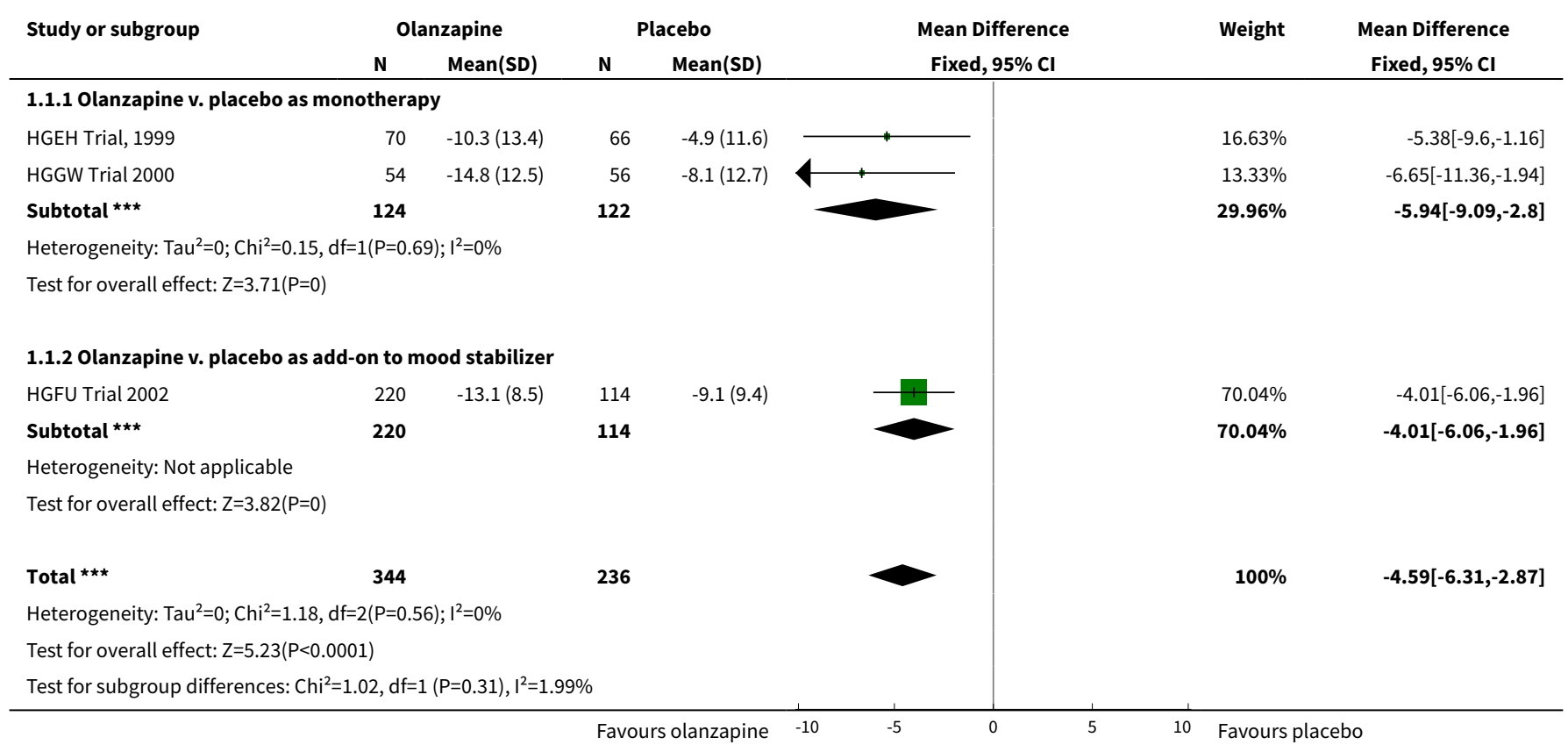

Analysis 1.2. Comparison 1 Olanzapine v placebo, Outcome 2 Mean change in CGI-BP mania.

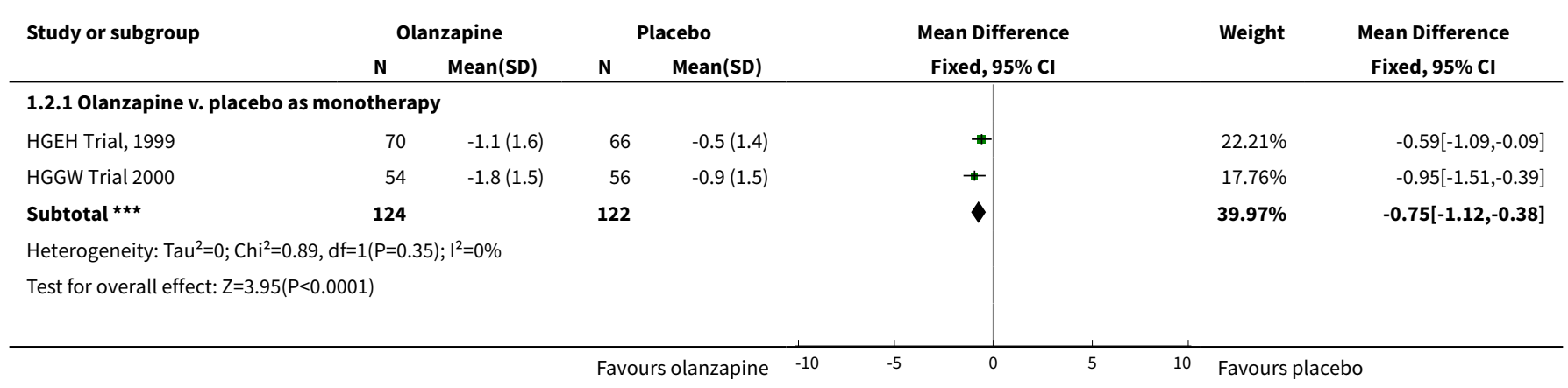




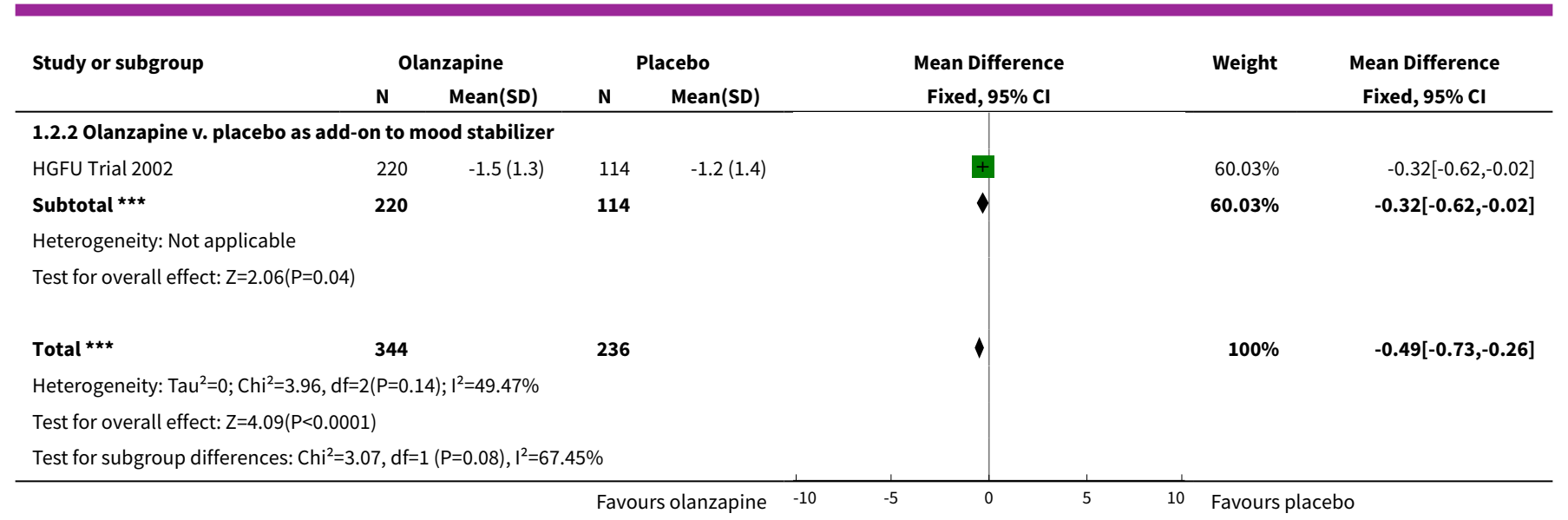

Analysis 1.3. Comparison 1 Olanzapine v placebo, Outcome 3 Failure to respond - YMRS.

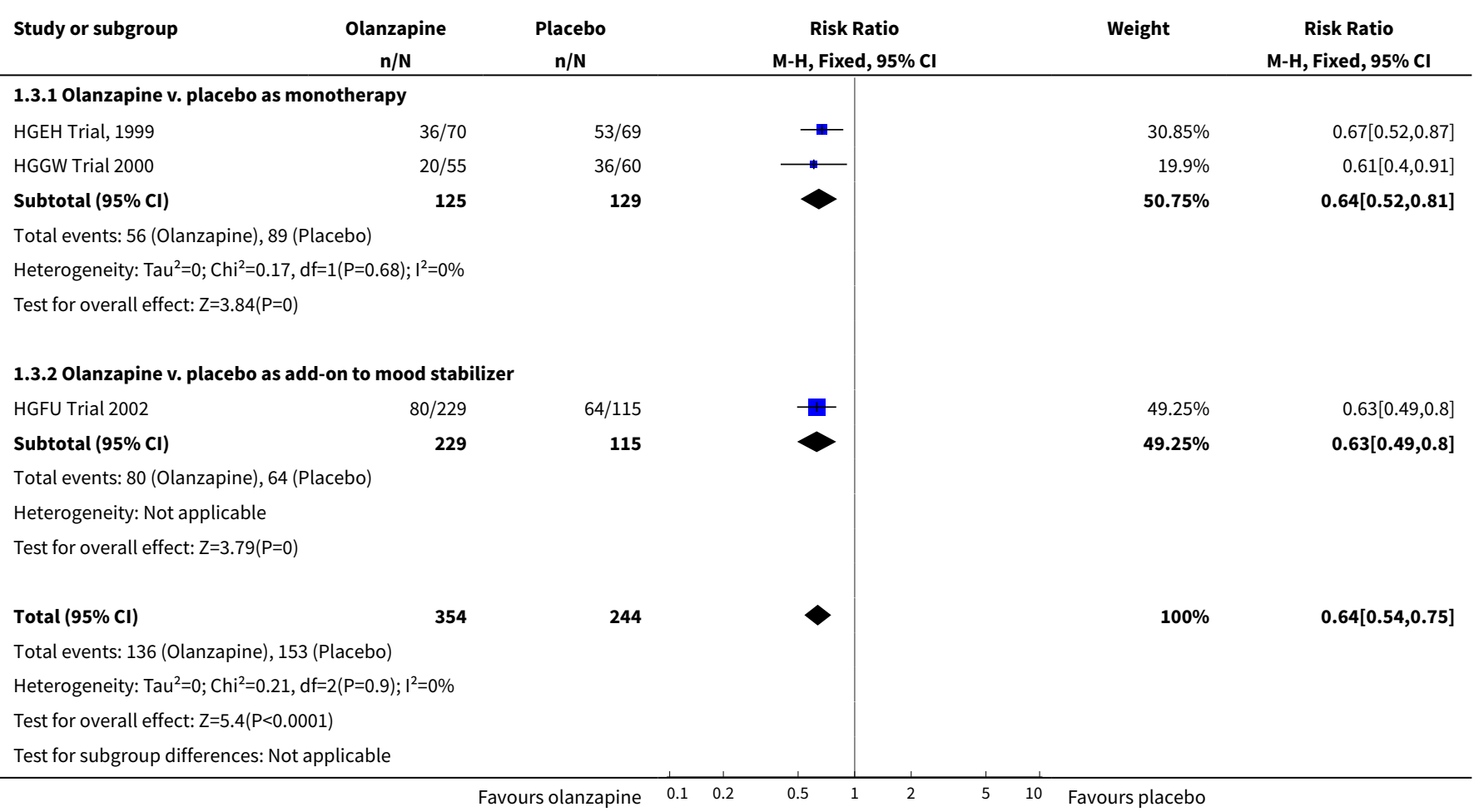

\section{Analysis 1.4. Comparison 1 Olanzapine v placebo, Outcome 4 Failure to achieve remission - YMRS.}

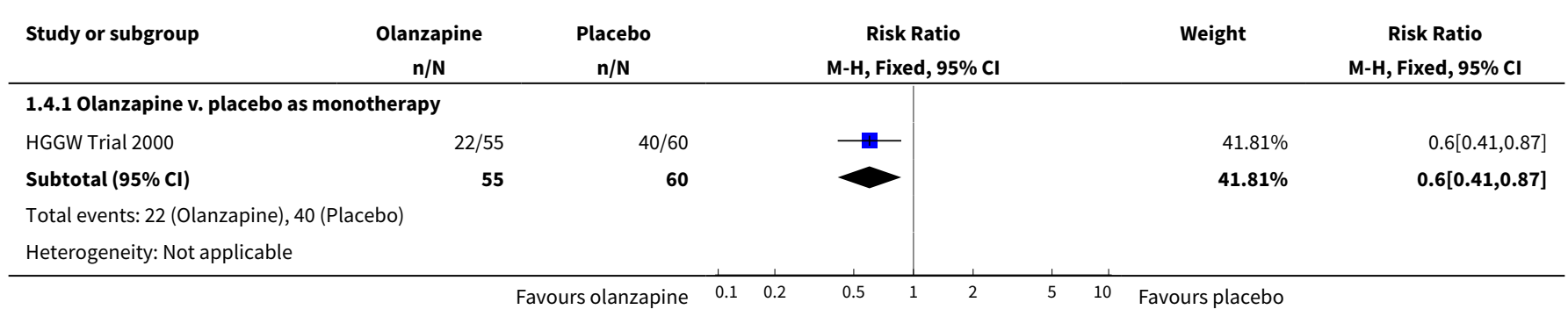




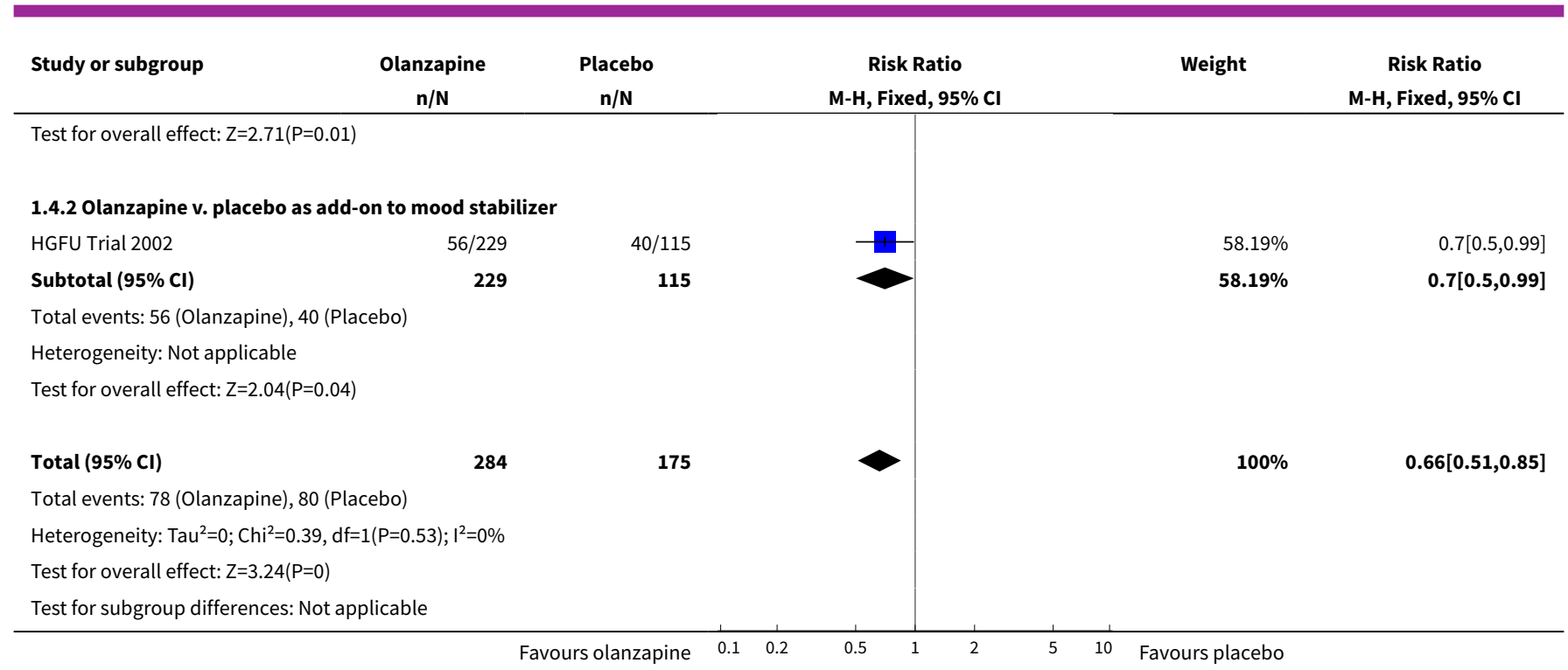

Analysis 1.5. Comparison 1 Olanzapine v placebo, Outcome 5 Mean Change in 21-item HAMD - all participants.

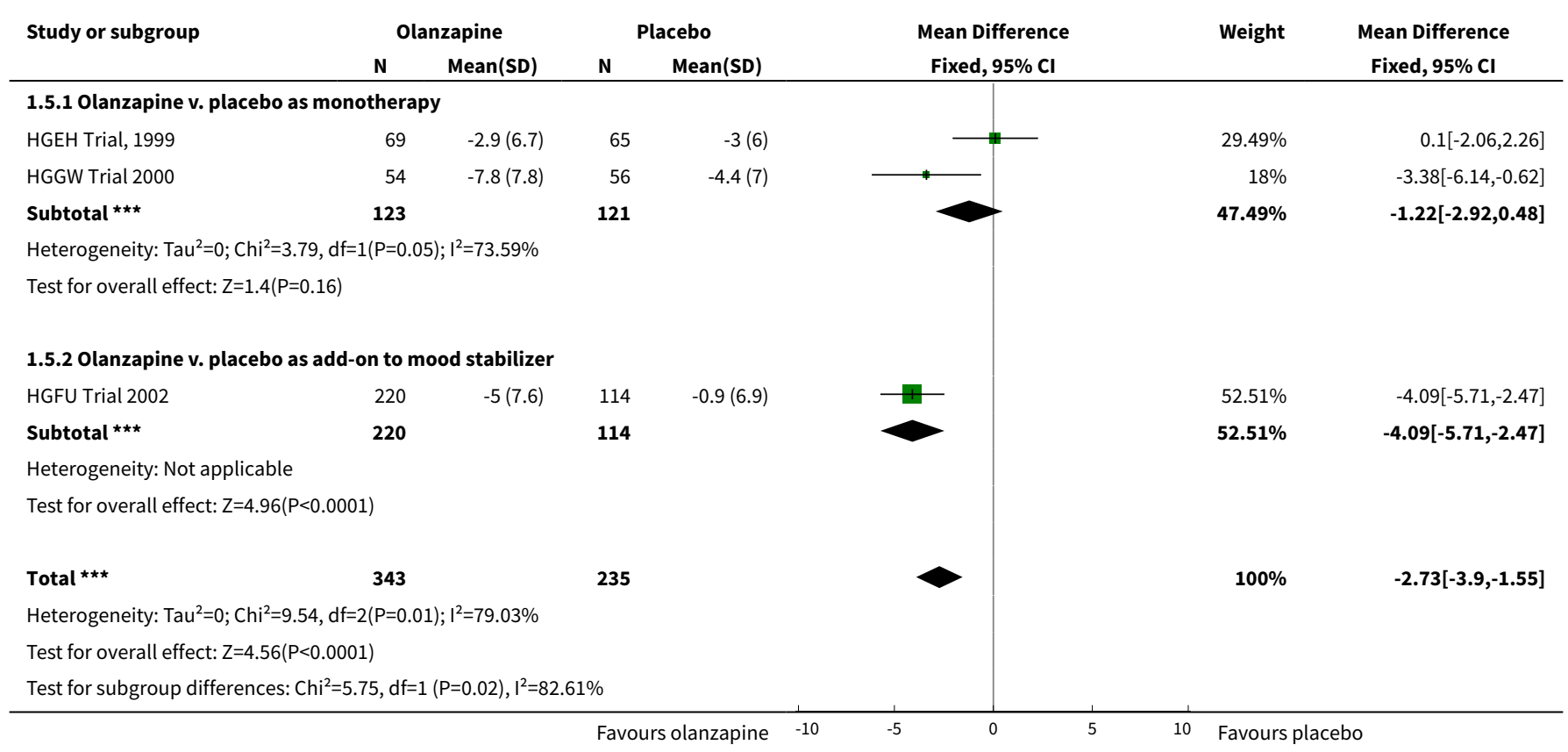

Analysis 1.6. Comparison 1 Olanzapine v placebo, Outcome 6 Mean change in CGI-BP depression.

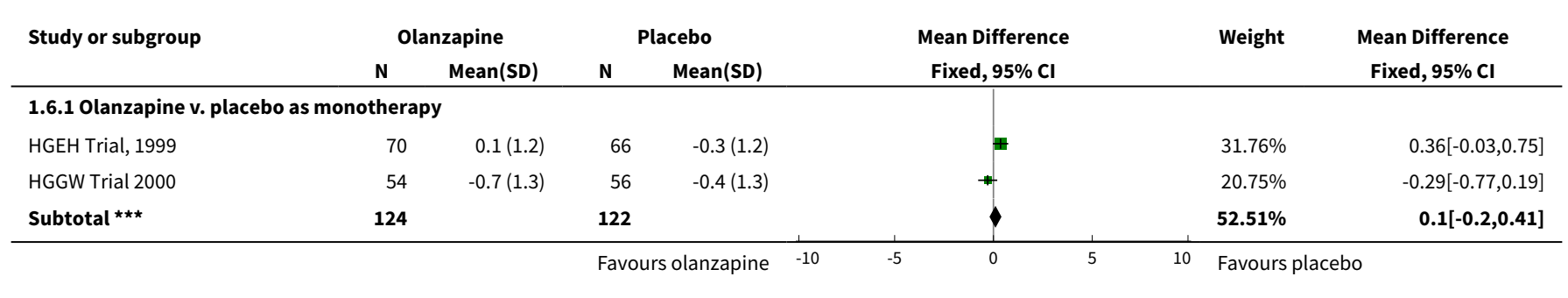




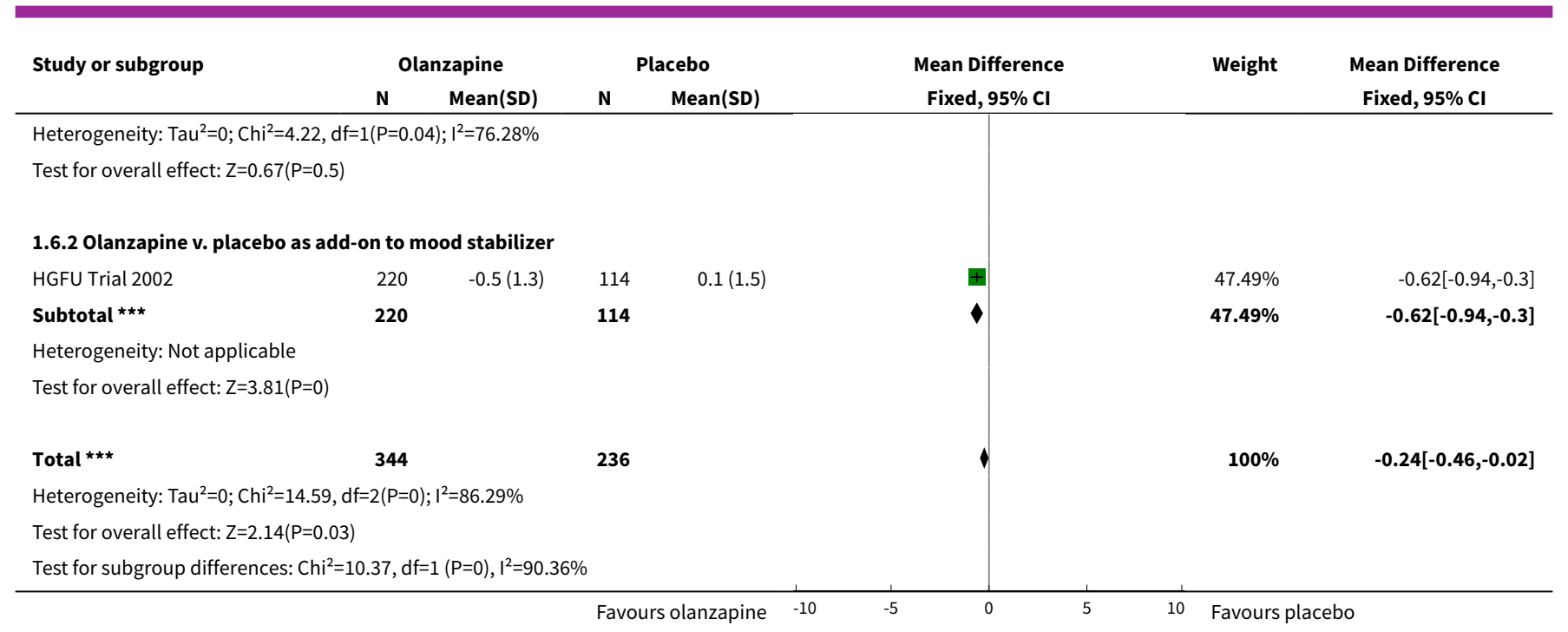

\section{Analysis 1.7. Comparison 1 Olanzapine v placebo, Outcome 7 Mean change in PANNS - total symptom score.}

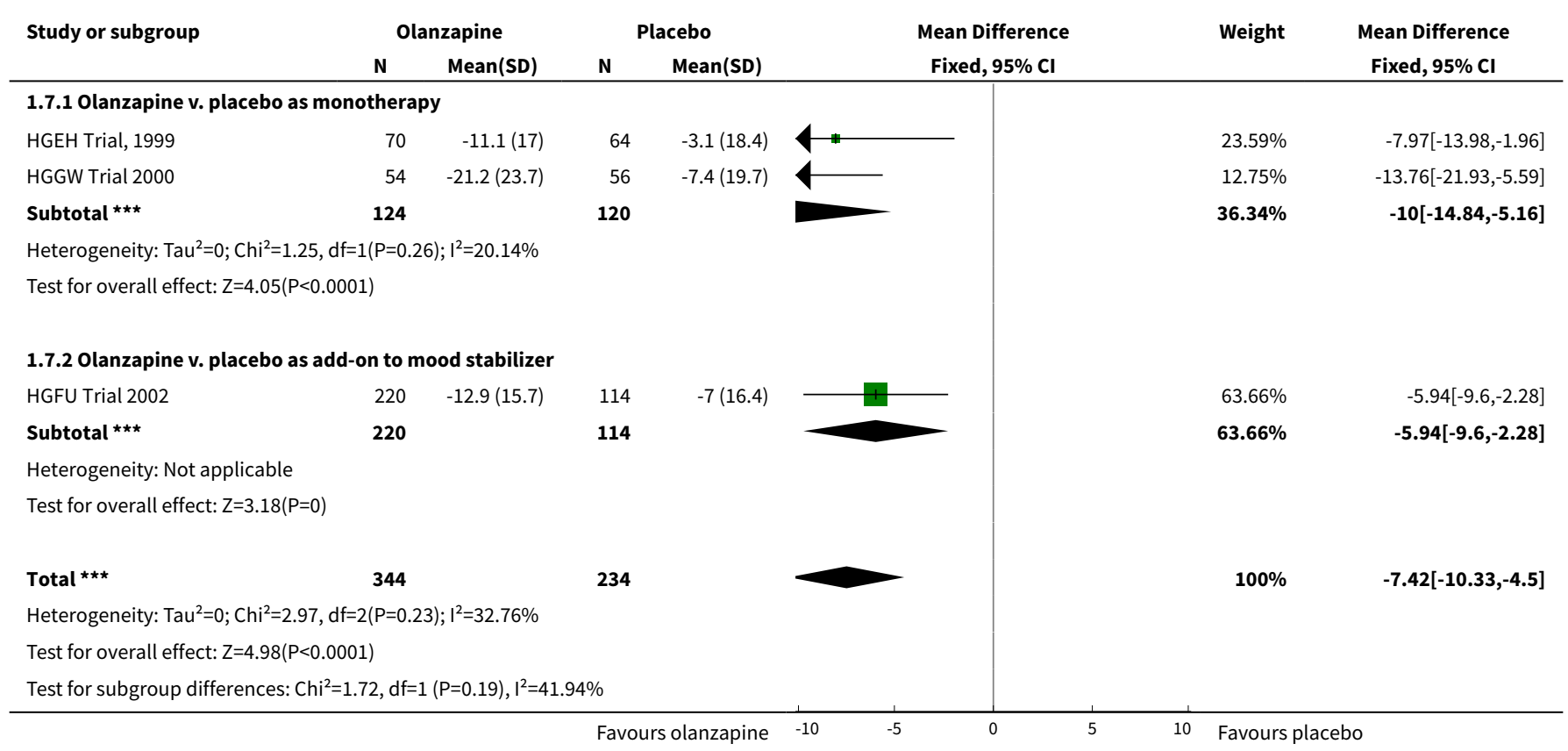

Analysis 1.8. Comparison 1 Olanzapine v placebo, Outcome 8 Mean change in PANNS - positive symptom score.

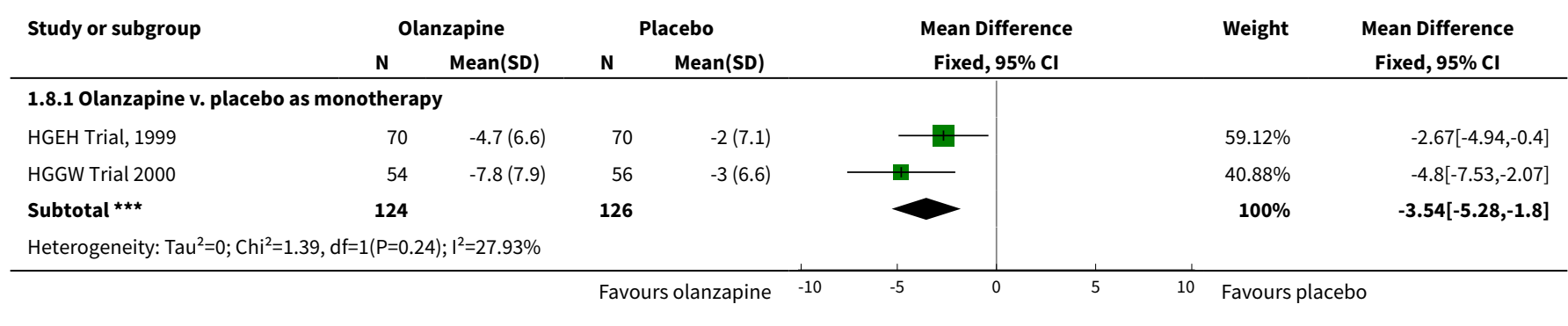




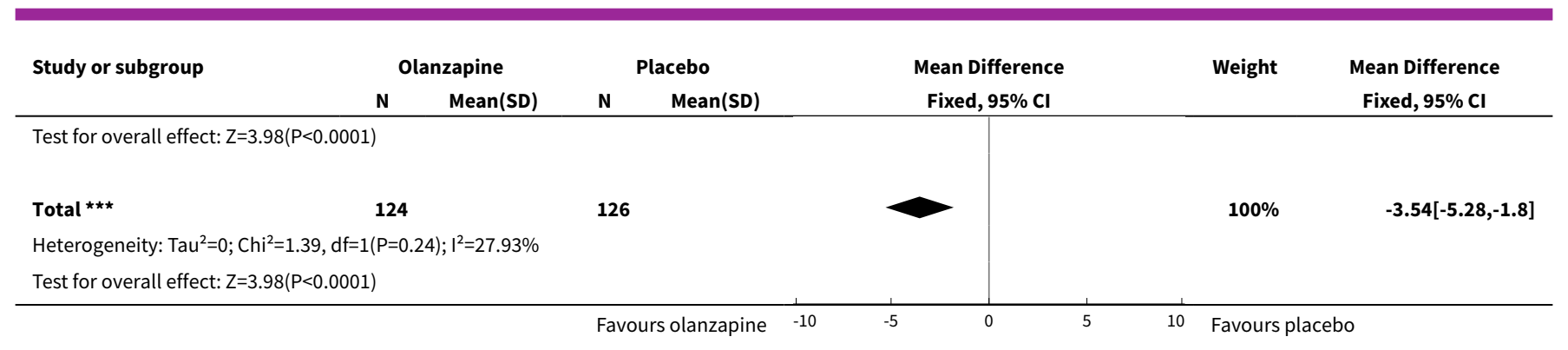

Analysis 1.9. Comparison 1 Olanzapine v placebo, Outcome 9 Mean change in PANNS - negative symptom score.

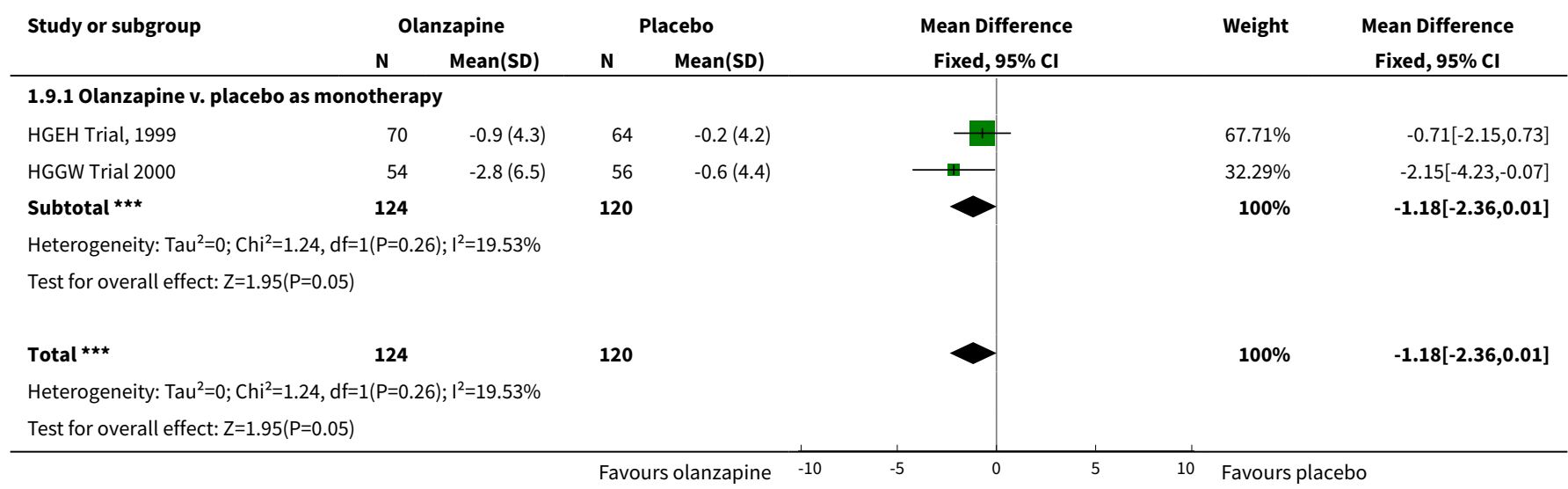

Analysis 1.10. Comparison 1 Olanzapine v placebo, Outcome 10 Mean change in CGI - BP severity of overall bipolar illness.

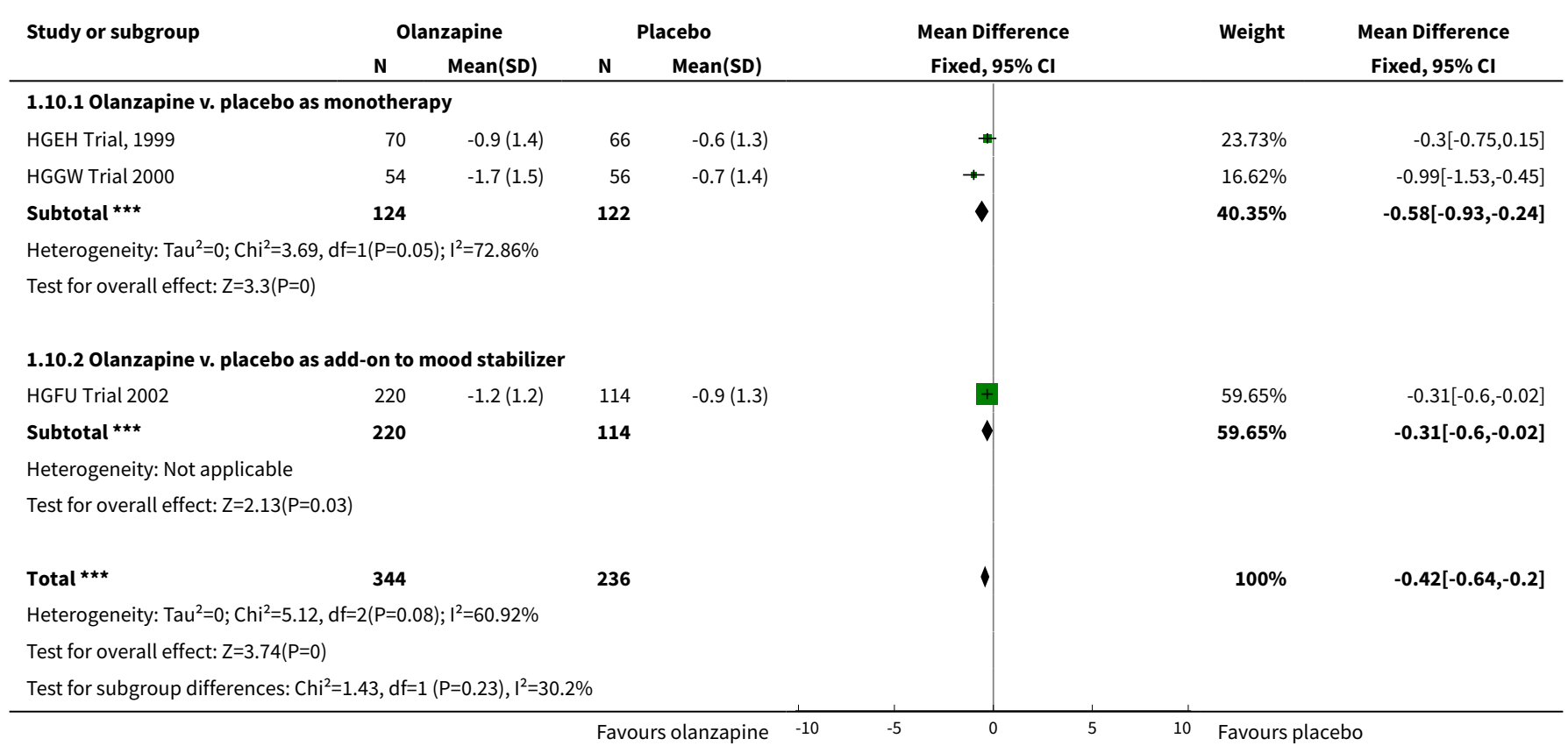


Analysis 1.11. Comparison 1 Olanzapine v placebo, Outcome 11 Mean dose of anticholinergic medication.

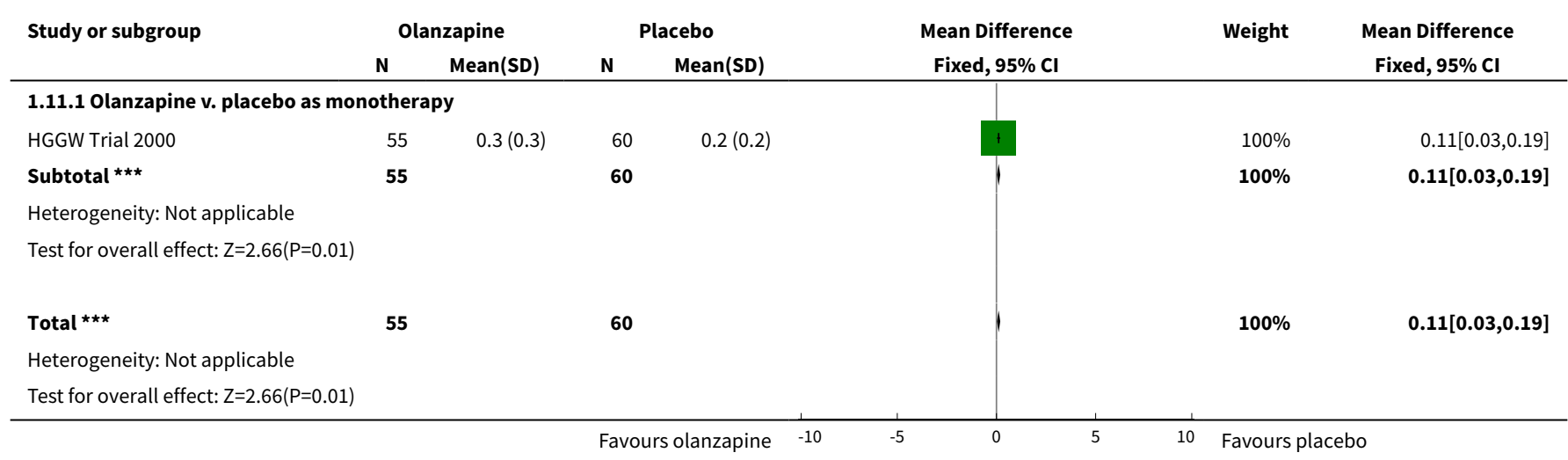

Analysis 1.12. Comparison 1 Olanzapine v placebo, Outcome 12 Use of benzodiazepines.

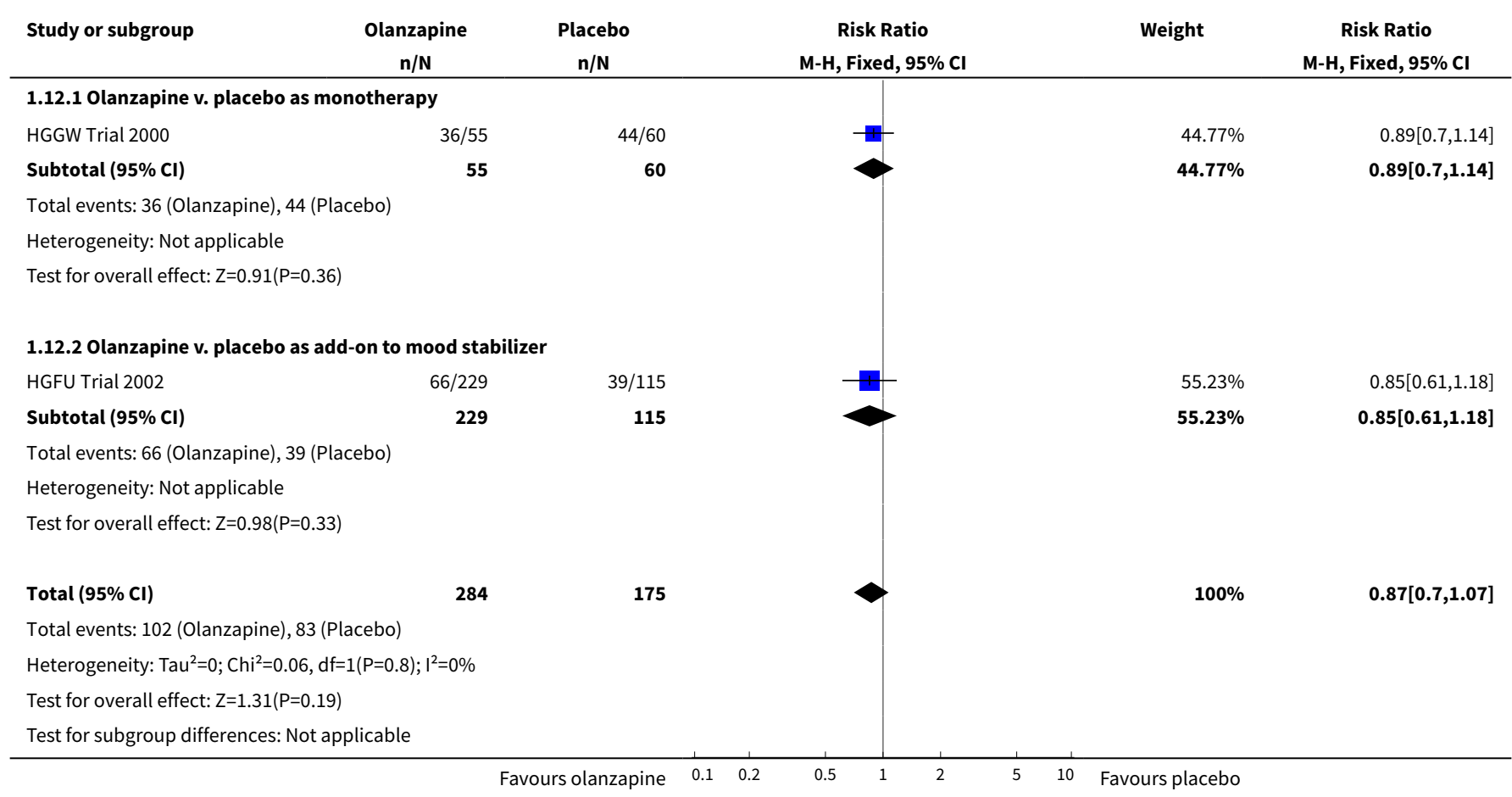

Analysis 1.13. Comparison 1 Olanzapine v placebo, Outcome 13 Failure to respond - YMRS (excluding early withdrawals).

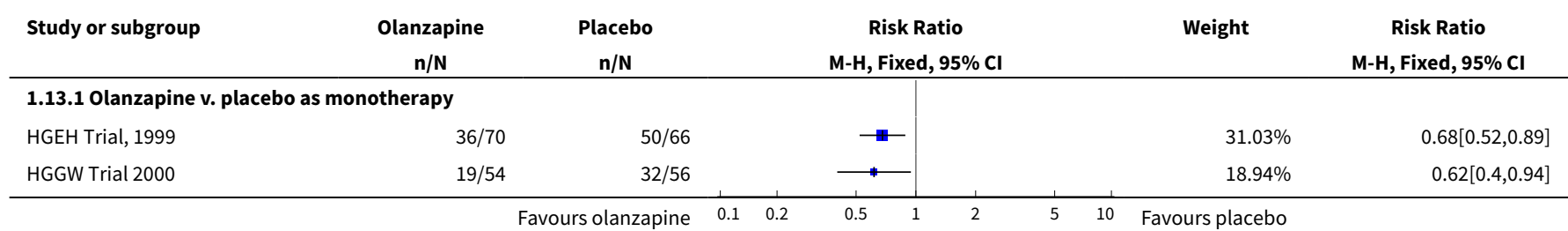




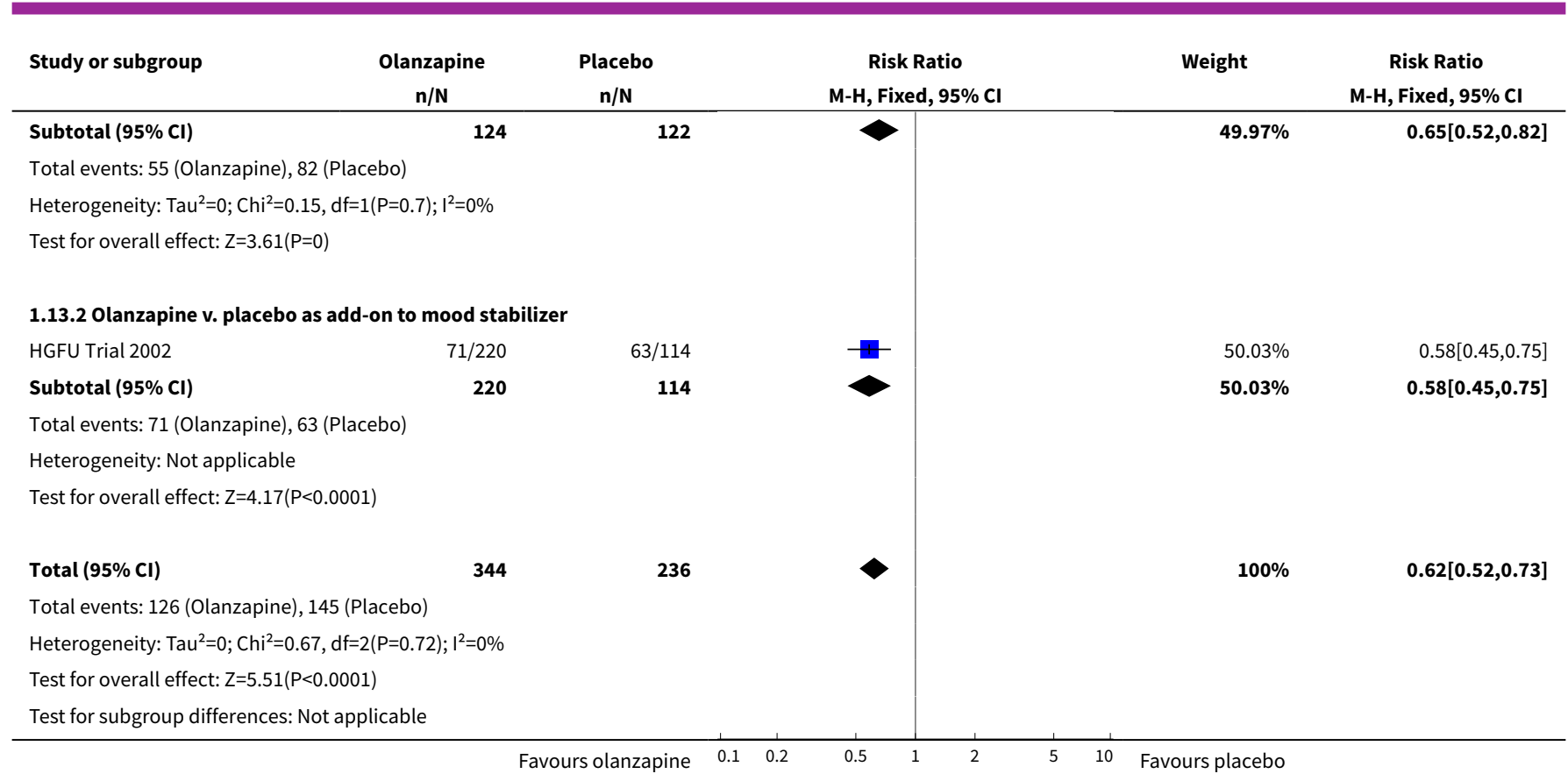

Analysis 1.14. Comparison 1 Olanzapine v placebo, Outcome

14 Failure to remit- YMRS - (excluding early withdrawals).

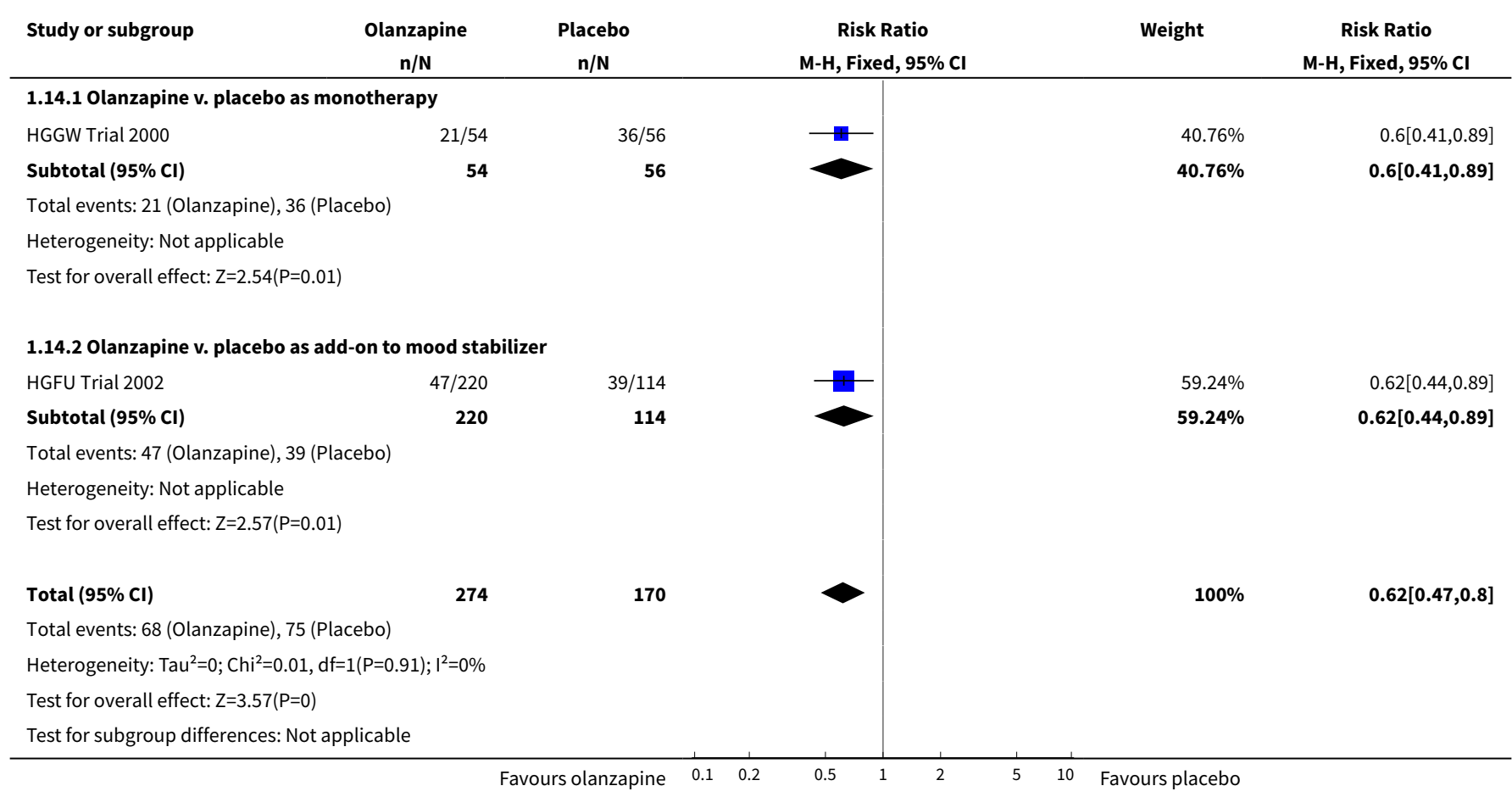


Analysis 1.15. Comparison 1 Olanzapine v placebo, Outcome 15 Failure to complete treatment.

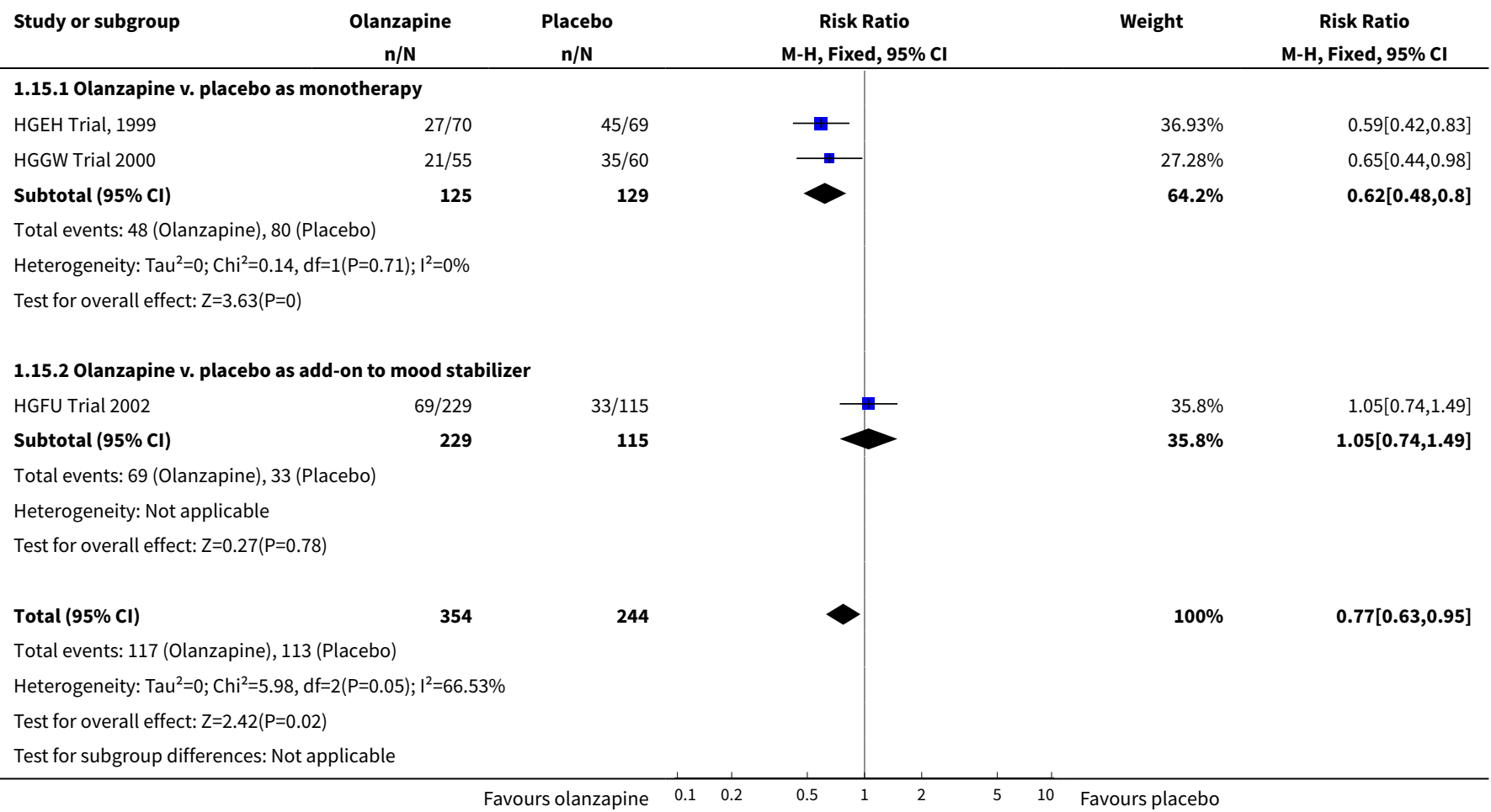

Analysis 1.16. Comparison 1 Olanzapine v placebo, Outcome 16 Treatment emergent depression.

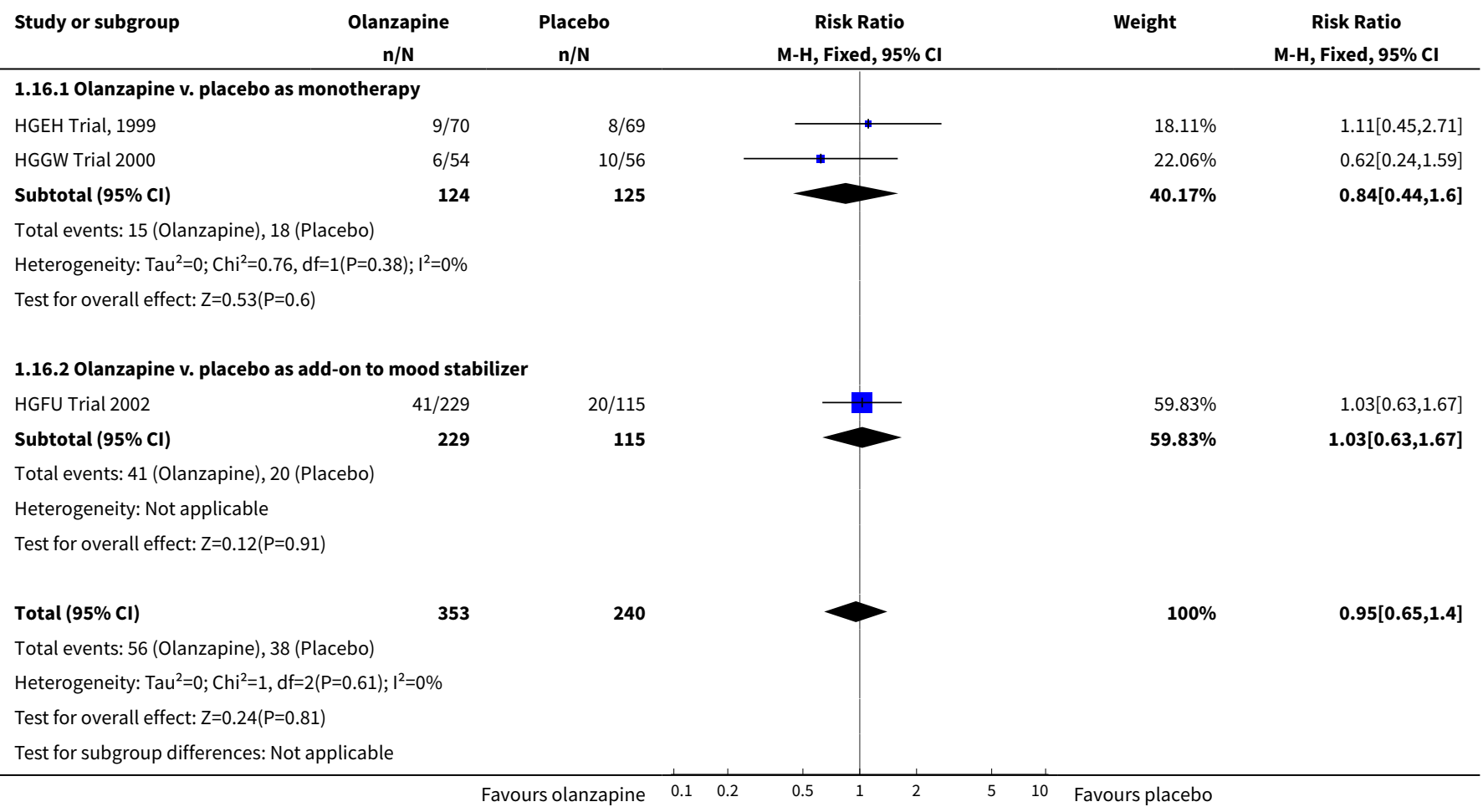


Analysis 1.17. Comparison 1 Olanzapine v placebo, Outcome 17 SAS Scale.

\begin{tabular}{|c|c|c|c|c|c|c|c|}
\hline \multirow[t]{2}{*}{ Study or subgroup } & \multicolumn{2}{|c|}{ Olanzapine } & \multicolumn{2}{|c|}{ Placebo } & \multirow{2}{*}{$\begin{array}{c}\text { Mean Difference } \\
\text { Fixed, } 95 \% \mathrm{Cl} \\
\end{array}$} & \multirow[t]{2}{*}{ Weight } & \multirow{2}{*}{$\begin{array}{c}\text { Mean Difference } \\
\text { Fixed, } 95 \% \mathrm{Cl} \\
\end{array}$} \\
\hline & $\mathbf{N}$ & $\operatorname{Mean}($ SD) & $\mathbf{N}$ & $\operatorname{Mean}(\mathrm{SD})$ & & & \\
\hline \multicolumn{8}{|c|}{ 1.17.1 Olanzapine v. placebo as monotherapy } \\
\hline HGEH Trial, 1999 & 68 & $-0.1(2.1)$ & 63 & $0.1(1.9)$ & $\#$ & $36.82 \%$ & $-0.2[-0.89,0.49]$ \\
\hline HGGW Trial 2000 & 54 & $-0.3(1.2)$ & 56 & $0.1(1.6)$ & + & $63.18 \%$ & $-0.4[-0.92,0.12]$ \\
\hline Subtotal ${ }^{\star \star \star}$ & 122 & & 119 & & $\bullet$ & $100 \%$ & $-0.33[-0.74,0.09]$ \\
\hline \multicolumn{8}{|c|}{ Heterogeneity: $\operatorname{Tau}^{2}=0 ; \mathrm{Chi}^{2}=0.21, \mathrm{df}=1(\mathrm{P}=0.65) ; \mathrm{I}^{2}=0 \%$} \\
\hline \multicolumn{8}{|c|}{ Test for overall effect: $\mathrm{Z}=1.54(\mathrm{P}=0.12)$} \\
\hline Total $\star \star \star$ & 122 & & 119 & & $\bullet$ & $100 \%$ & $-0.33[-0.74,0.09]$ \\
\hline \multicolumn{8}{|c|}{ Heterogeneity: $\operatorname{Tau}^{2}=0 ; \mathrm{Chi}^{2}=0.21, \mathrm{df}=1(\mathrm{P}=0.65) ; \mathrm{I}^{2}=0 \%$} \\
\hline Test for overall effec & & & & & & & \\
\hline
\end{tabular}

Analysis 1.18. Comparison 1 Olanzapine v placebo, Outcome 18 Barnes Akathisia Scale.

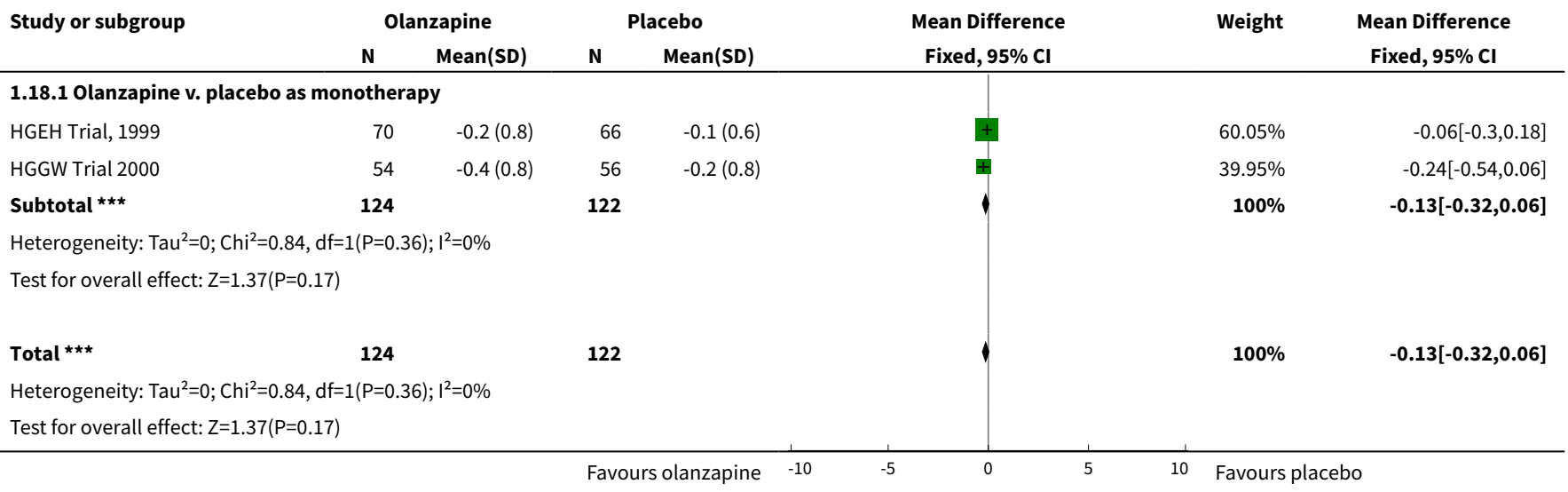

Analysis 1.19. Comparison 1 Olanzapine v placebo, Outcome 19 AIMS.

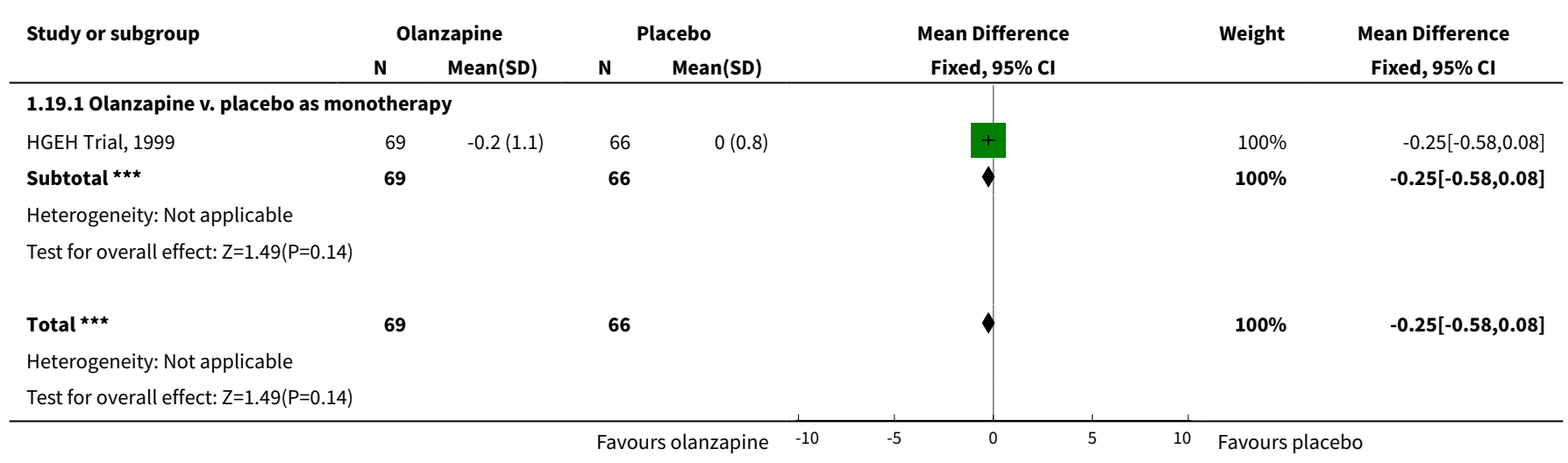


Analysis 1.20. Comparison 1 Olanzapine v placebo, Outcome 20 Weight Gain (continuous data).

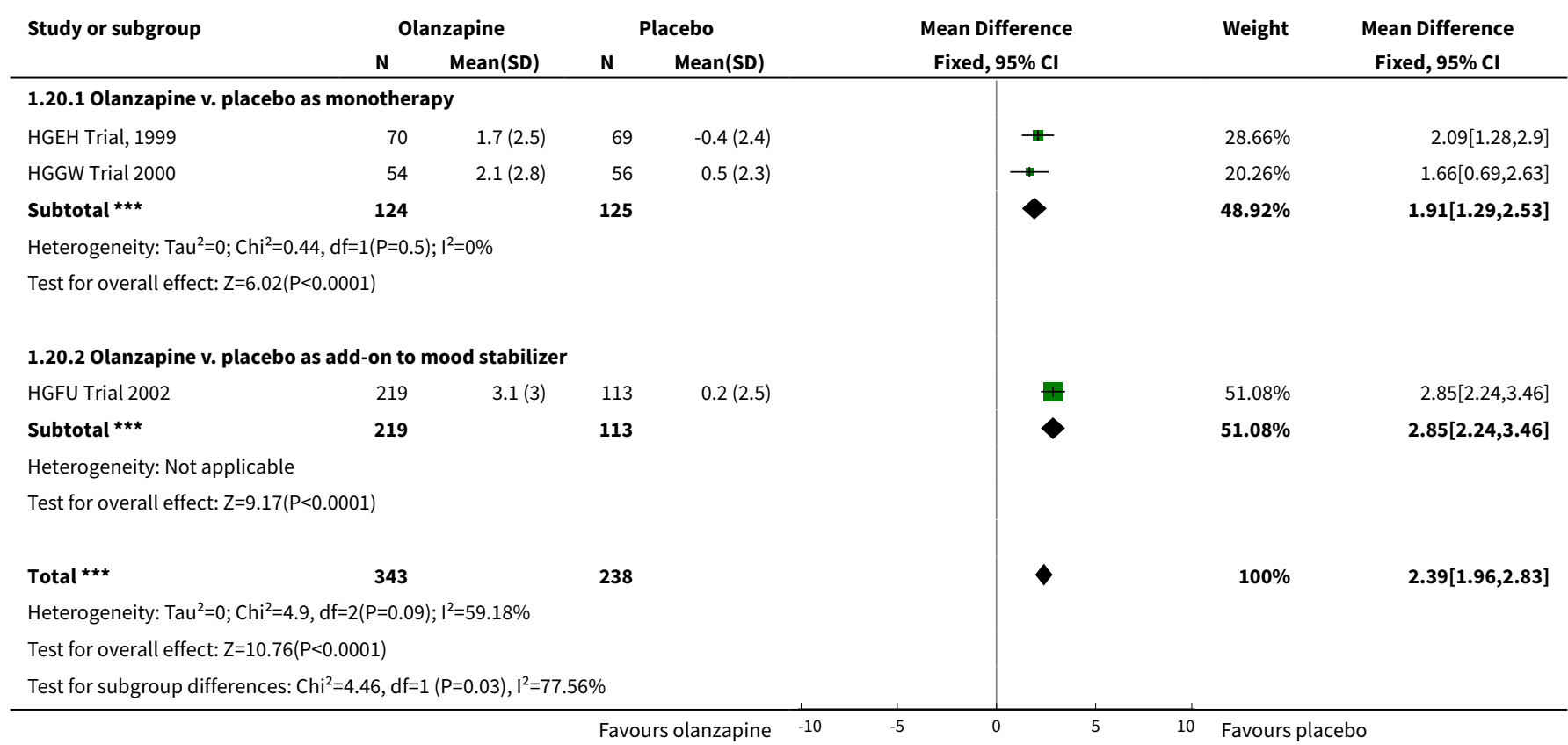

Analysis 1.21. Comparison 1 Olanzapine v placebo, Outcome 21 Somnolence.

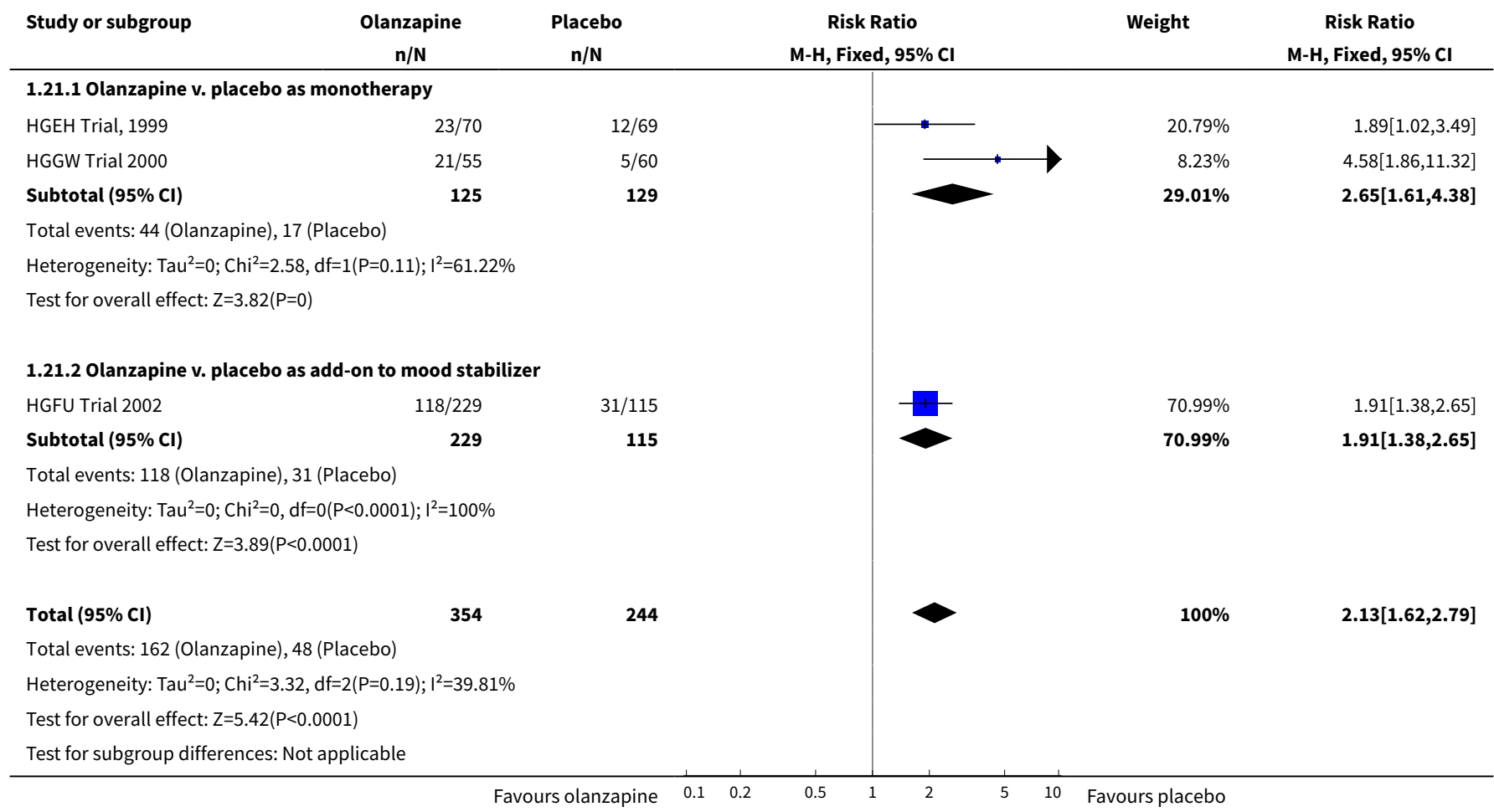


Analysis 1.22. Comparison 1 Olanzapine v placebo, Outcome 22 Dry Mouth.

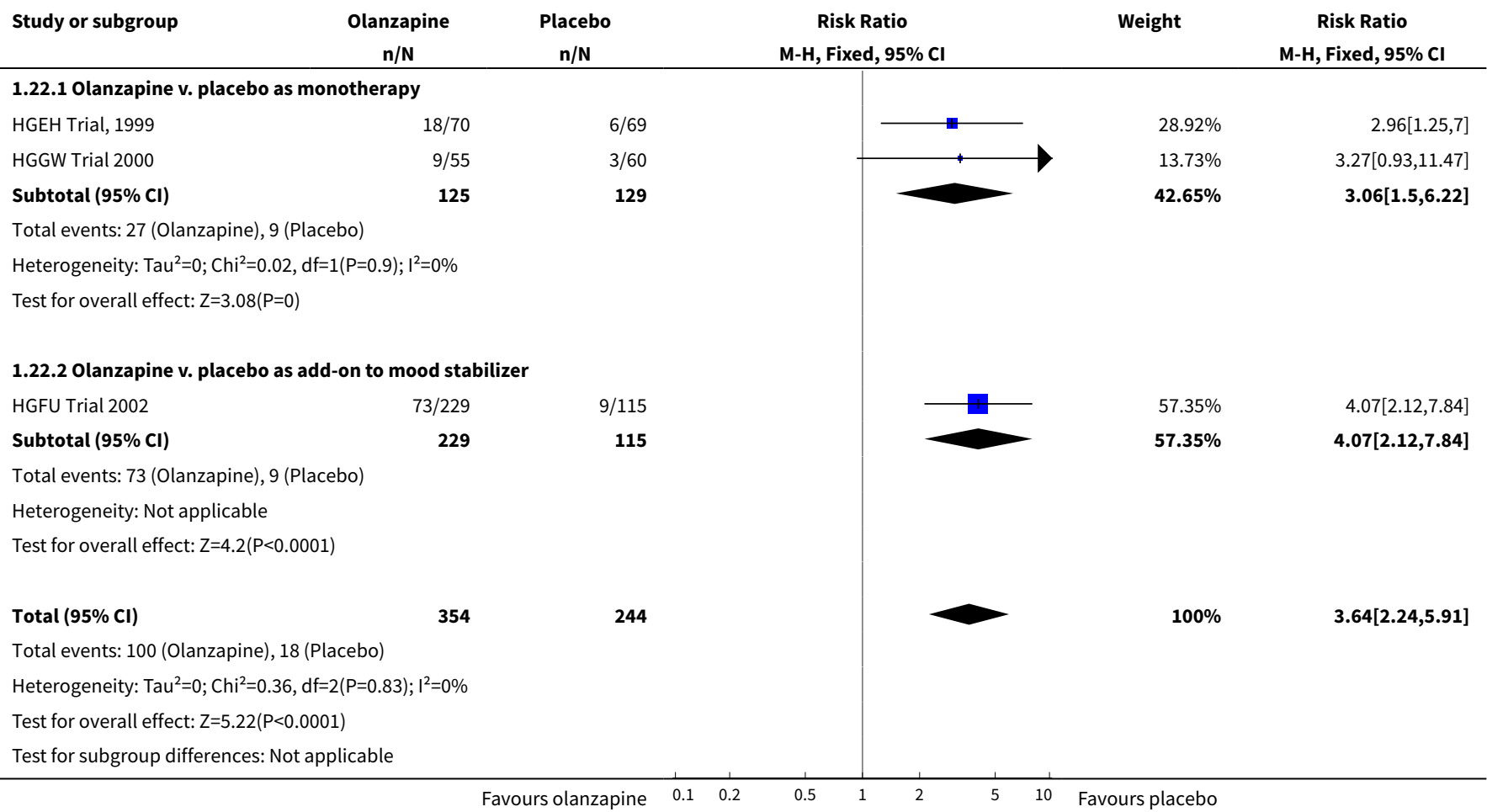

Analysis 1.23. Comparison 1 Olanzapine v placebo, Outcome 23 Dizziness.

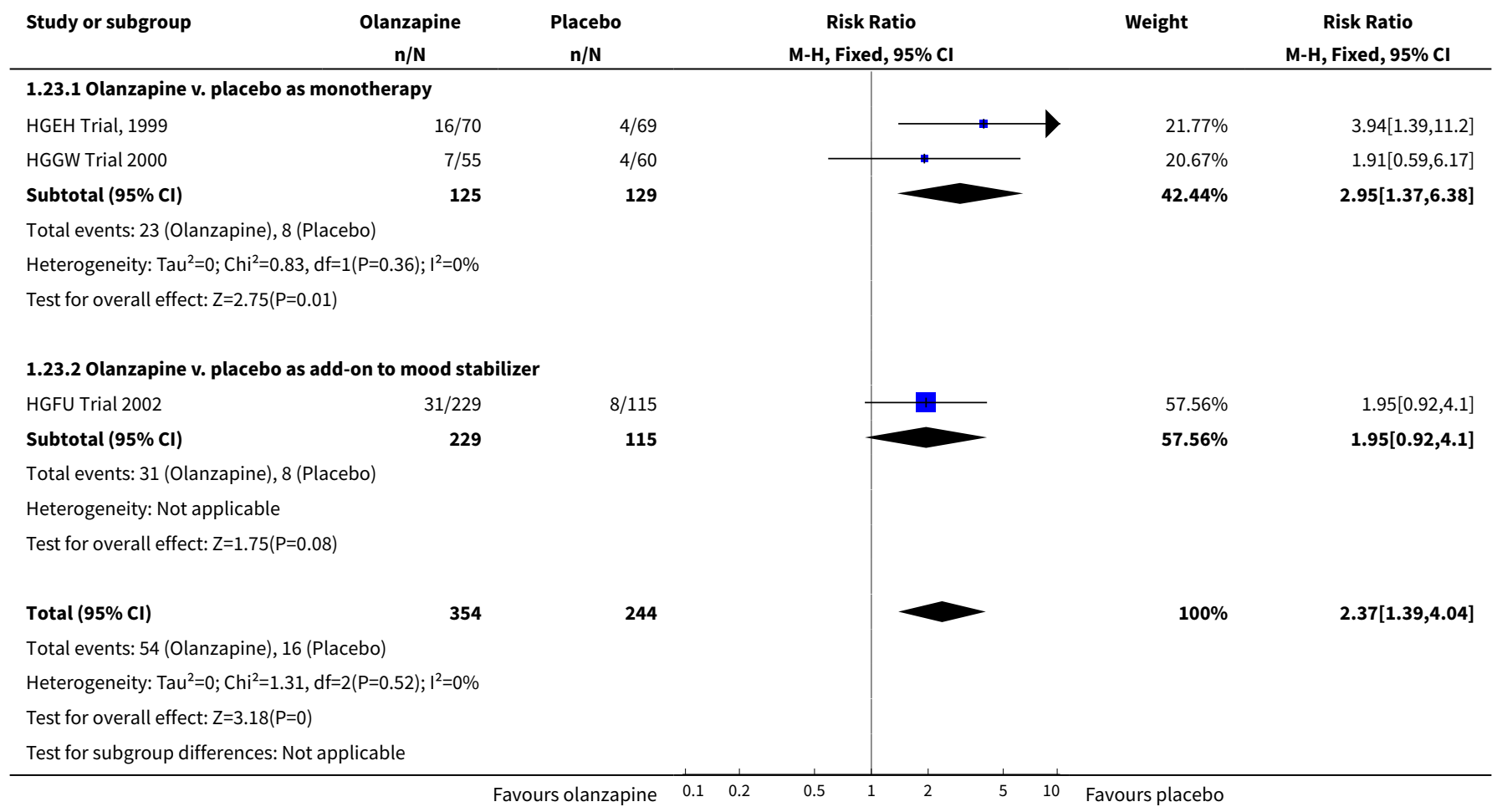


Analysis 1.24. Comparison 1 Olanzapine v placebo, Outcome 24 Agitation.

\begin{tabular}{|c|c|c|c|c|c|}
\hline Study or subgroup & $\begin{array}{c}\text { Olanzapine } \\
n / N\end{array}$ & $\begin{array}{c}\text { Placebo } \\
\mathrm{n} / \mathrm{N}\end{array}$ & $\begin{array}{c}\text { Risk Ratio } \\
\text { M-H, Fixed, } 95 \% \mathrm{Cl}\end{array}$ & Weight & $\begin{array}{c}\text { Risk Ratio } \\
\text { M-H, Fixed, } 95 \% \mathrm{Cl} \\
\end{array}$ \\
\hline \multicolumn{6}{|c|}{ 1.24.1 Olanzapine v. placebo as monotherapy } \\
\hline HGEH Trial, 1999 & $13 / 70$ & $16 / 69$ & $\mathbf{m}$ & $52.9 \%$ & $0.8[0.42,1.54]$ \\
\hline HGGW Trial 2000 & $5 / 55$ & $15 / 60$ & - & $47.1 \%$ & $0.36[0.14,0.93]$ \\
\hline Subtotal $(95 \% \mathrm{Cl})$ & 125 & 129 & & $100 \%$ & $0.59[0.35,1.01]$ \\
\hline \multicolumn{6}{|c|}{ Total events: 18 (Olanzapine), 31 (Placebo) } \\
\hline \multicolumn{6}{|c|}{ Heterogeneity: Tau $^{2}=0 ; \mathrm{Chi}^{2}=1.84, \mathrm{df}=1(\mathrm{P}=0.17) ; \mathrm{I}^{2}=45.77 \%$} \\
\hline \multicolumn{6}{|c|}{ Test for overall effect: $Z=1.92(P=0.05)$} \\
\hline Total $(95 \% \mathrm{Cl})$ & 125 & 129 & & $100 \%$ & $0.59[0.35,1.01]$ \\
\hline \multicolumn{6}{|c|}{ Total events: 18 (Olanzapine), 31 (Placebo) } \\
\hline \multicolumn{6}{|c|}{ Heterogeneity: Tau $^{2}=0 ; \mathrm{Chi}^{2}=1.84, \mathrm{df}=1(\mathrm{P}=0.17) ; I^{2}=45.77 \%$} \\
\hline Test for overall effect & & & & & \\
\hline
\end{tabular}

Analysis 1.25. Comparison 1 Olanzapine v placebo, Outcome 25 Asthenia.

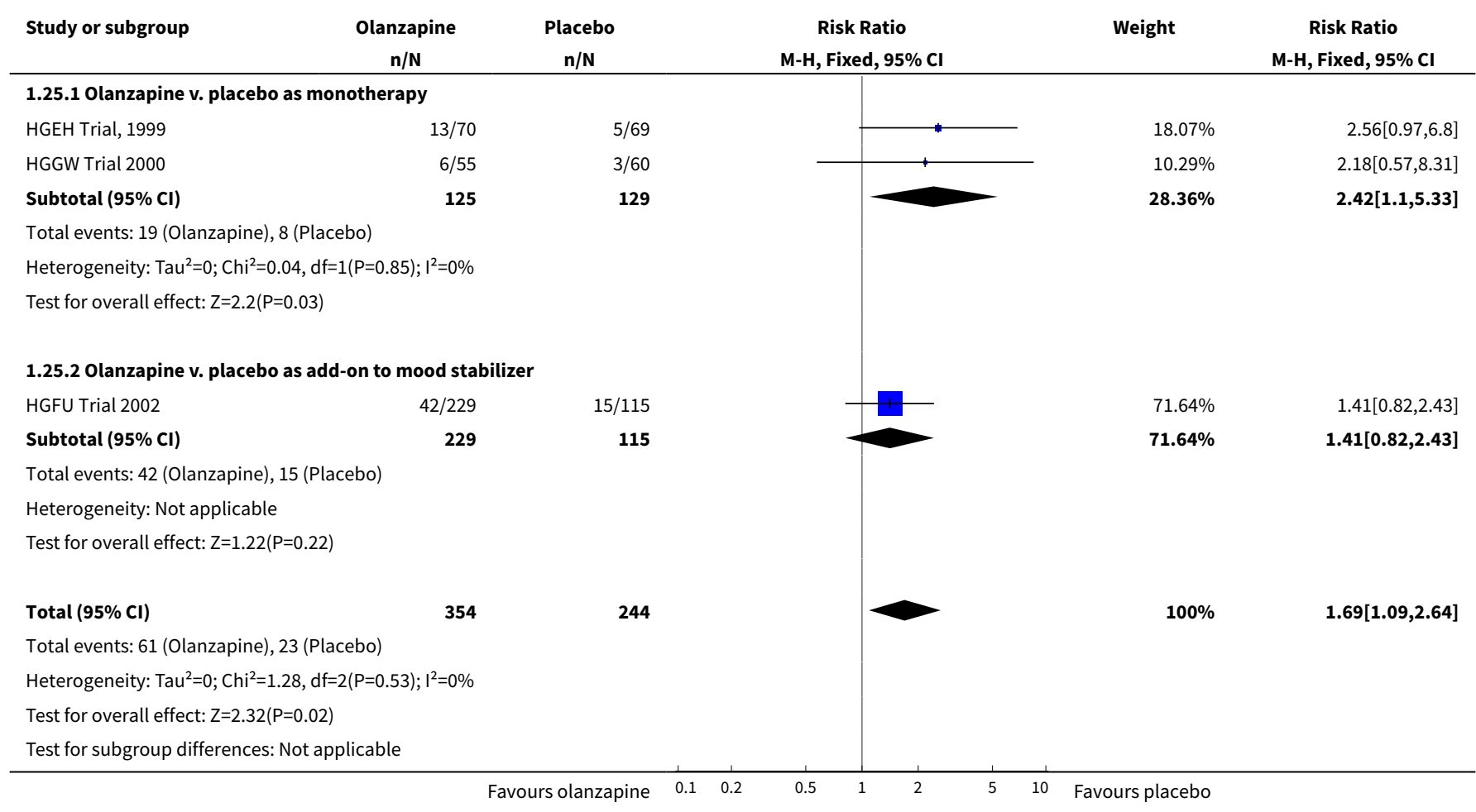


Analysis 1.26. Comparison 1 Olanzapine v placebo, Outcome 26 Headache.

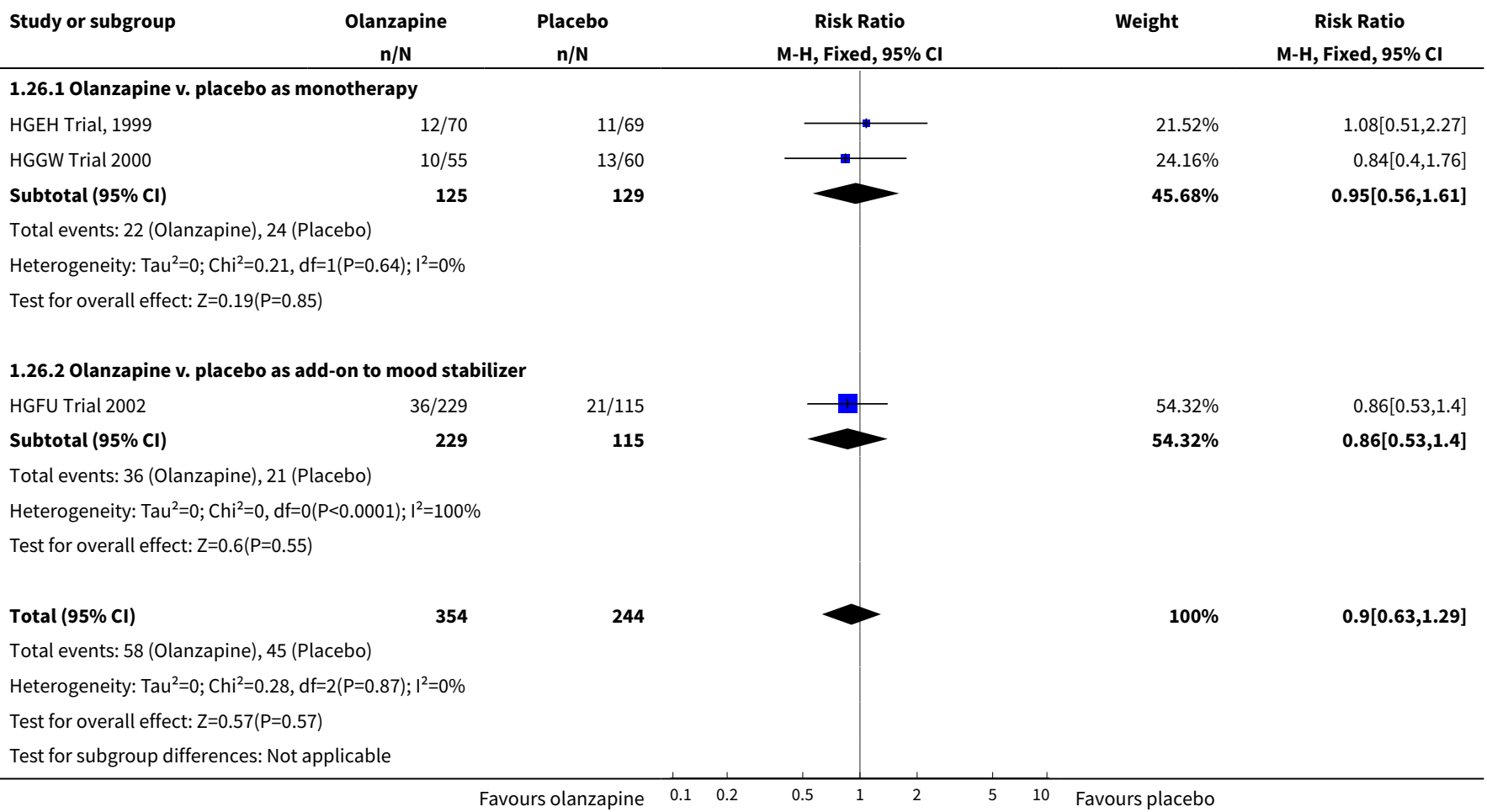

Analysis 1.27. Comparison 1 Olanzapine v placebo, Outcome 27 Anxiety.

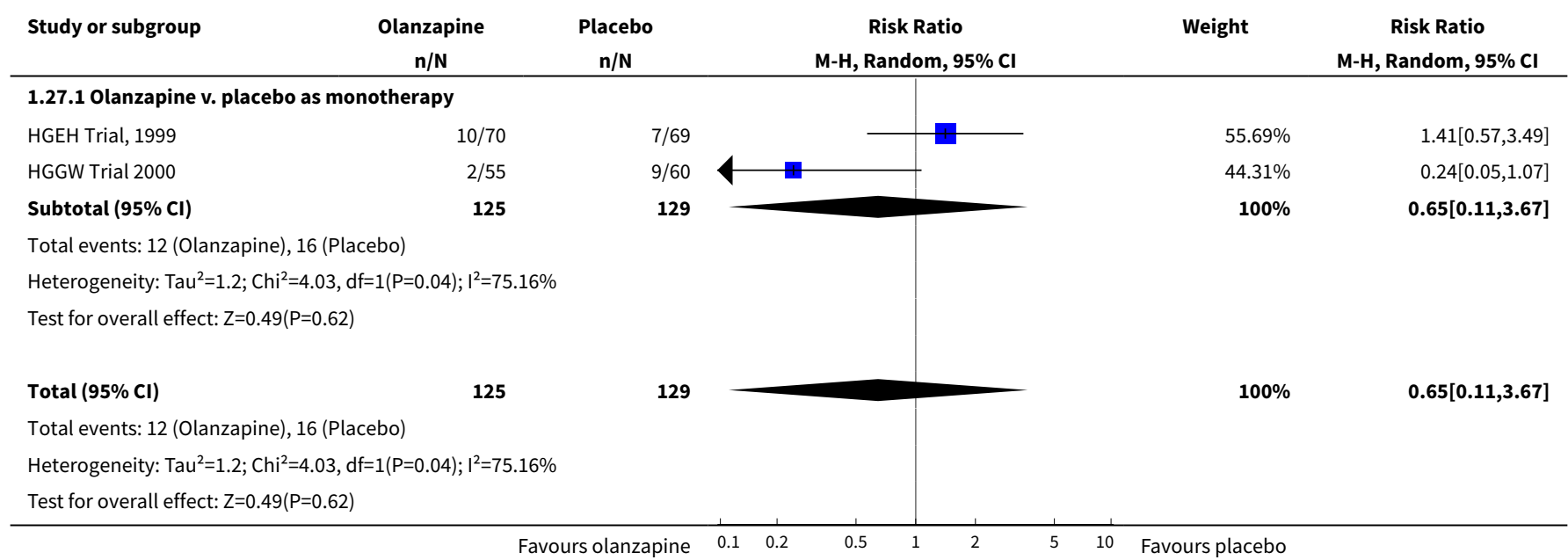

Analysis 1.28. Comparison 1 Olanzapine v placebo, Outcome 28 Constipation.

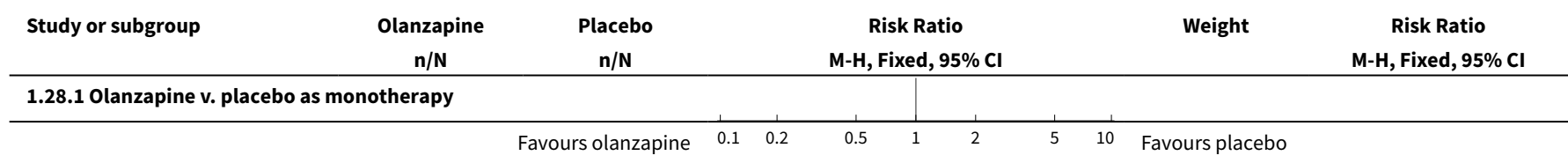




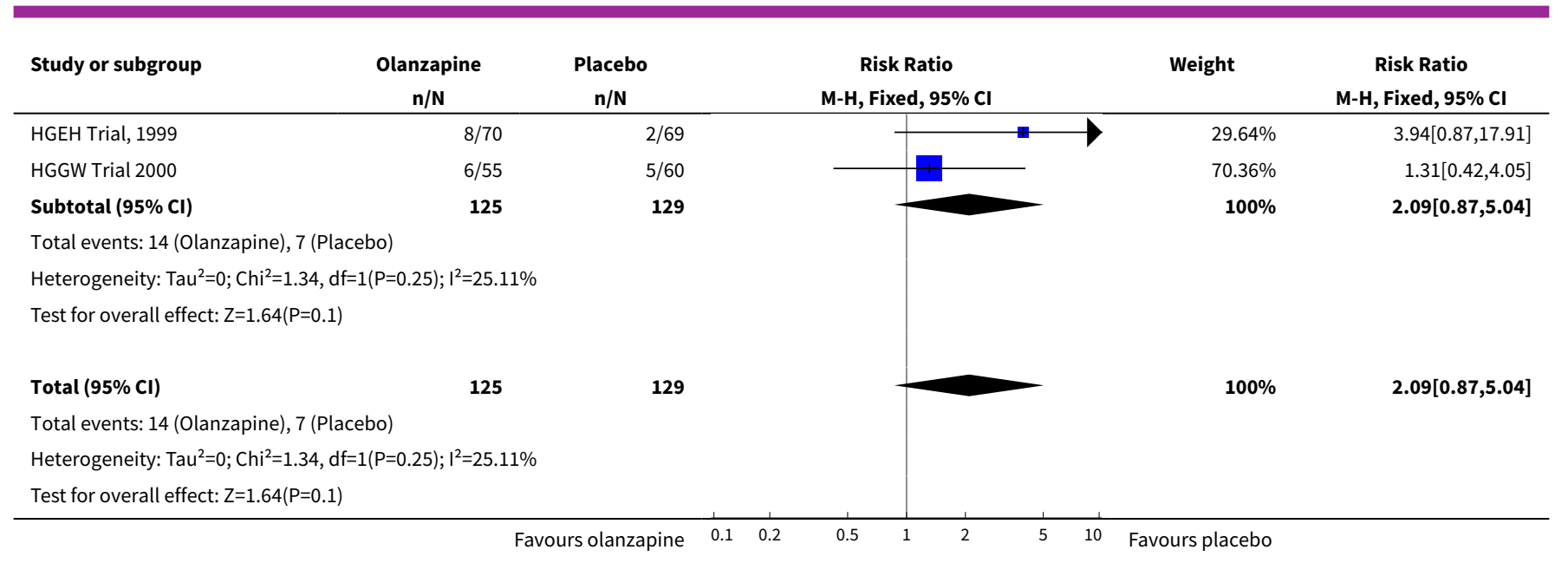

Analysis 1.29. Comparison 1 Olanzapine v placebo, Outcome 29 Pain.

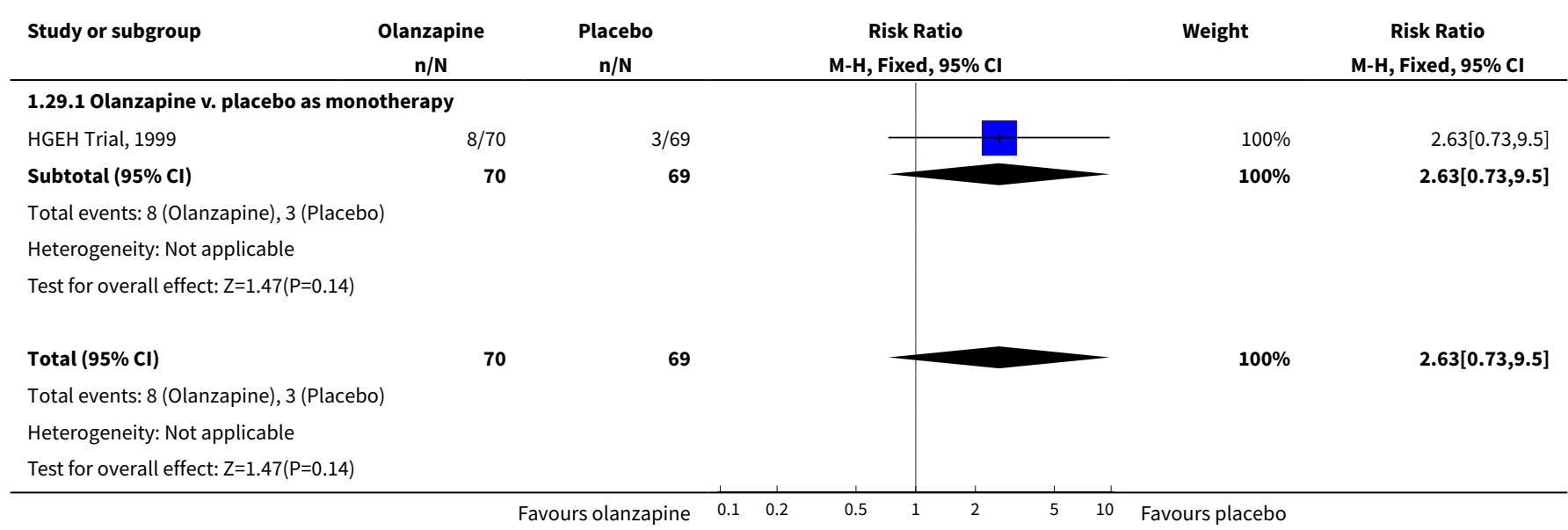

Analysis 1.30. Comparison 1 Olanzapine v placebo, Outcome 30 Hostility.

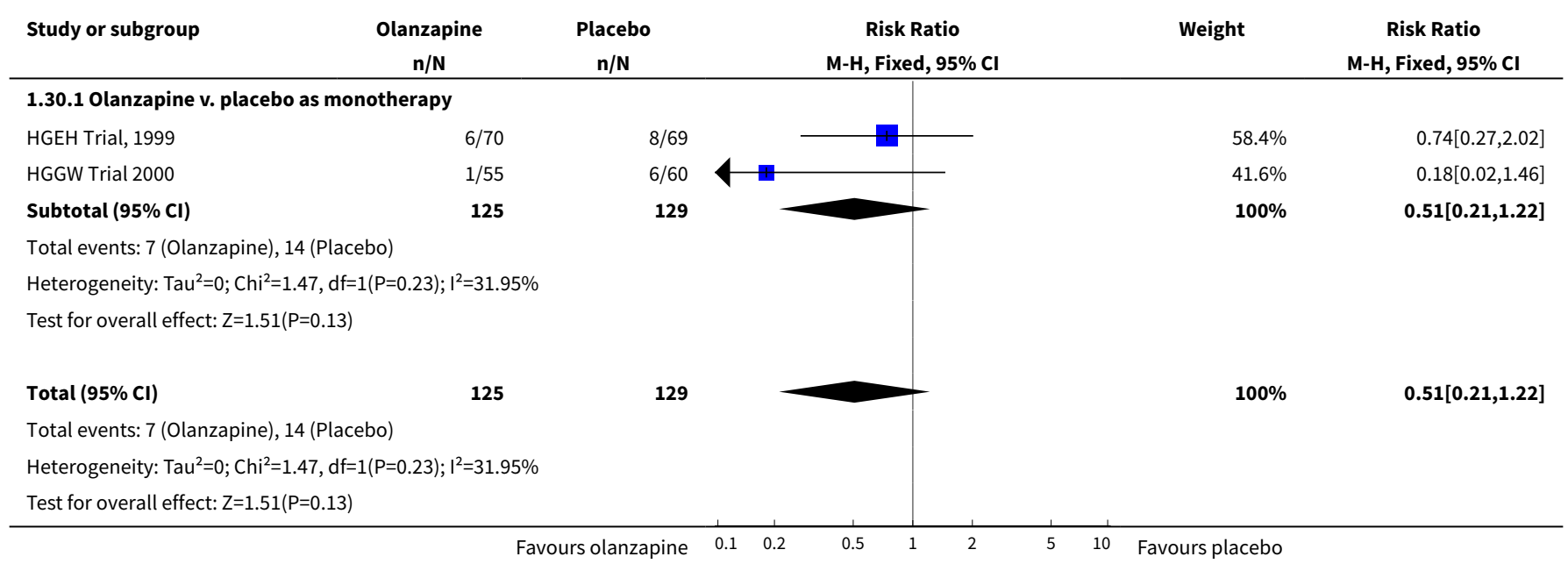


Analysis 1.31. Comparison 1 Olanzapine v placebo, Outcome 31 Nervousness.

\begin{tabular}{|c|c|c|c|c|c|}
\hline Study or subgroup & $\begin{array}{c}\text { Olanzapine } \\
n / N\end{array}$ & $\begin{array}{c}\text { Placebo } \\
\mathrm{n} / \mathrm{N}\end{array}$ & $\begin{array}{c}\text { Risk Ratio } \\
\text { M-H, Fixed, } 95 \% \mathrm{Cl}\end{array}$ & Weight & $\begin{array}{c}\text { Risk Ratio } \\
\text { M-H, Fixed, } 95 \% \mathrm{Cl} \\
\end{array}$ \\
\hline \multicolumn{6}{|c|}{ 1.31.1 Olanzapine v. placebo as monotherapy } \\
\hline HGEH Trial, 1999 & $6 / 70$ & $9 / 69$ & & $20.99 \%$ & $0.66[0.25,1.75]$ \\
\hline HGGW Trial 2000 & $5 / 55$ & $12 / 60$ & $\rightarrow$ & $26.58 \%$ & $0.45[0.17,1.21]$ \\
\hline Subtotal $(95 \% \mathrm{Cl})$ & 125 & 129 & & $47.58 \%$ & $0.54[0.27,1.08]$ \\
\hline \multicolumn{6}{|c|}{ Total events: 11 (Olanzapine), 21 (Placebo) } \\
\hline \multicolumn{6}{|c|}{ Heterogeneity: $\mathrm{Tau}^{2}=0 ; \mathrm{Chi}^{2}=0.27, \mathrm{df}=1(\mathrm{P}=0.6) ; \mathrm{I}^{2}=0 \%$} \\
\hline \multicolumn{6}{|c|}{ Test for overall effect: $Z=1.73(P=0.08)$} \\
\hline \multicolumn{6}{|c|}{ 1.31.2 Olanzapine v. placebo as add-on to mood stabilizer } \\
\hline HGFU Trial 2002 & $24 / 229$ & $17 / 115$ & & $52.42 \%$ & $0.71[0.4,1.27]$ \\
\hline Subtotal $(95 \% \mathrm{Cl})$ & 229 & 115 & & $52.42 \%$ & $0.71[0.4,1.27]$ \\
\hline \multicolumn{6}{|c|}{ Total events: 24 (Olanzapine), 17 (Placebo) } \\
\hline \multicolumn{6}{|c|}{ Heterogeneity: $\operatorname{Tau}^{2}=0 ; \mathrm{Chi}^{2}=0, \mathrm{df}=0(\mathrm{P}<0.0001) ; \mathrm{I}^{2}=100 \%$} \\
\hline \multicolumn{6}{|c|}{ Test for overall effect: $Z=1.16(P=0.24)$} \\
\hline Total $(95 \% \mathrm{Cl})$ & 354 & 244 & & $100 \%$ & $0.63[0.4,0.98]$ \\
\hline \multicolumn{6}{|c|}{ Total events: 35 (Olanzapine), 38 (Placebo) } \\
\hline \multicolumn{6}{|c|}{ Heterogeneity: $\operatorname{Tau}^{2}=0 ; \mathrm{Chi}^{2}=0.6, \mathrm{df}=2(\mathrm{P}=0.74) ; 1^{2}=0 \%$} \\
\hline \multicolumn{6}{|c|}{ Test for overall effect: $\mathrm{Z}=2.04(\mathrm{P}=0.04)$} \\
\hline Test for subgroup dif & licable & & & & \\
\hline
\end{tabular}

Analysis 1.32. Comparison 1 Olanzapine v placebo, Outcome 32 Personality Disorder.

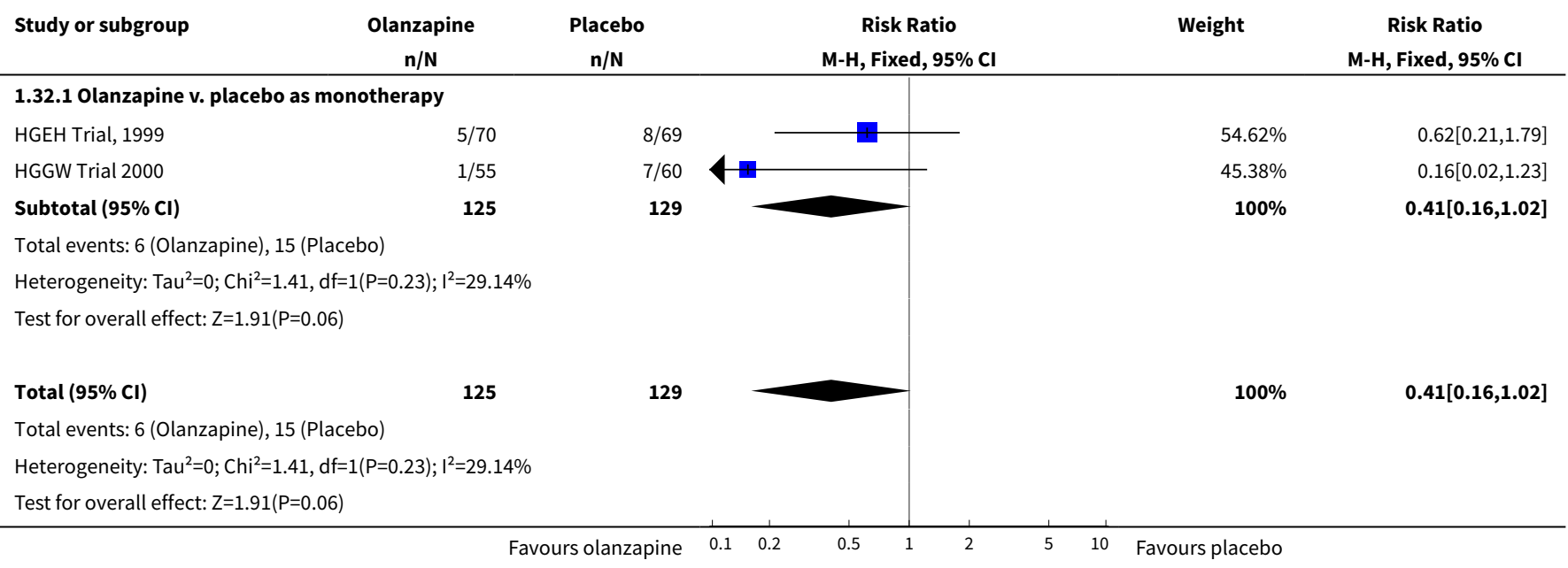


Analysis 1.33. Comparison 1 Olanzapine v placebo, Outcome 33 Weight Gain (dichotomous data).

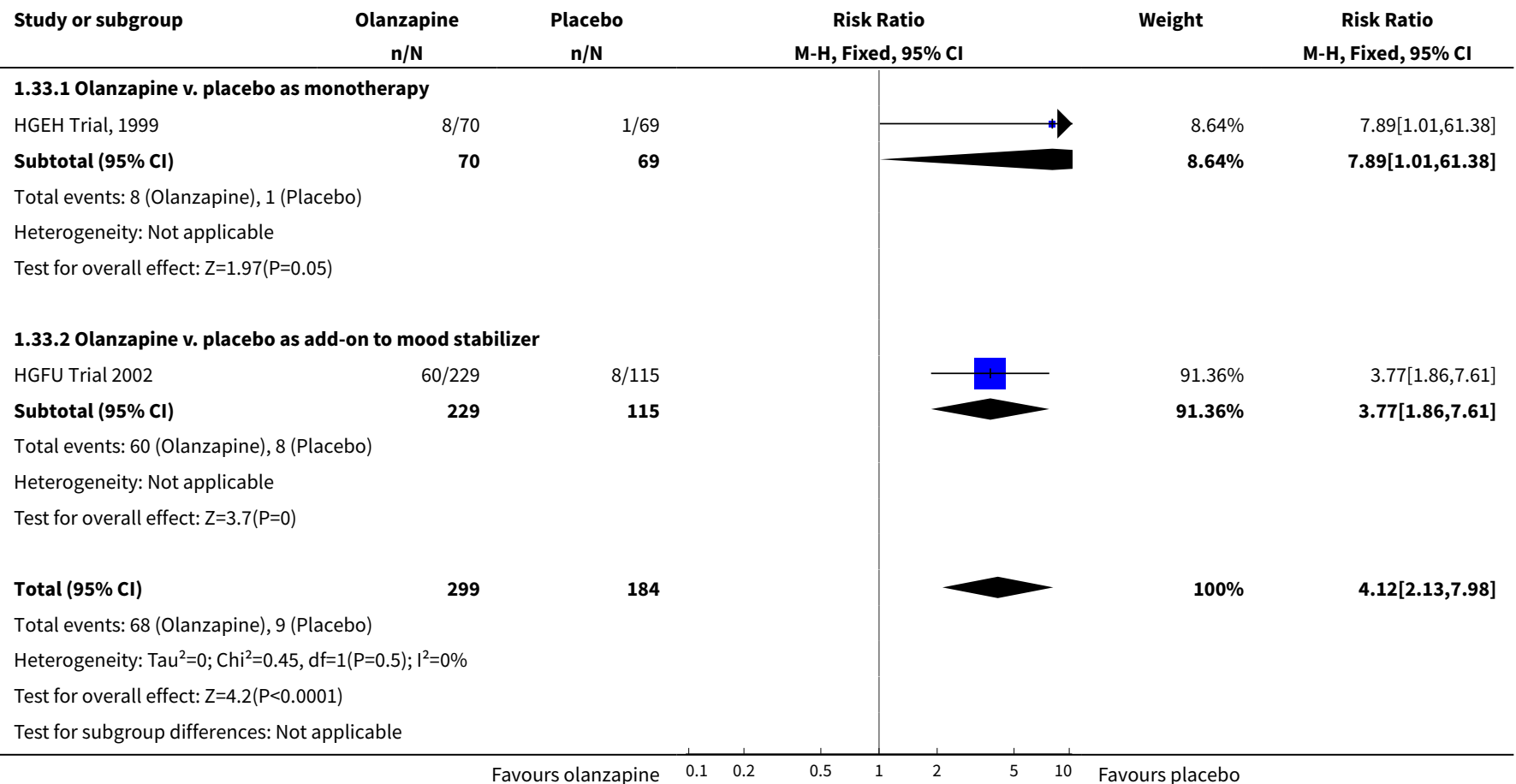

Analysis 1.34. Comparison 1 Olanzapine v placebo, Outcome 34 Increased ALT/SGPT.

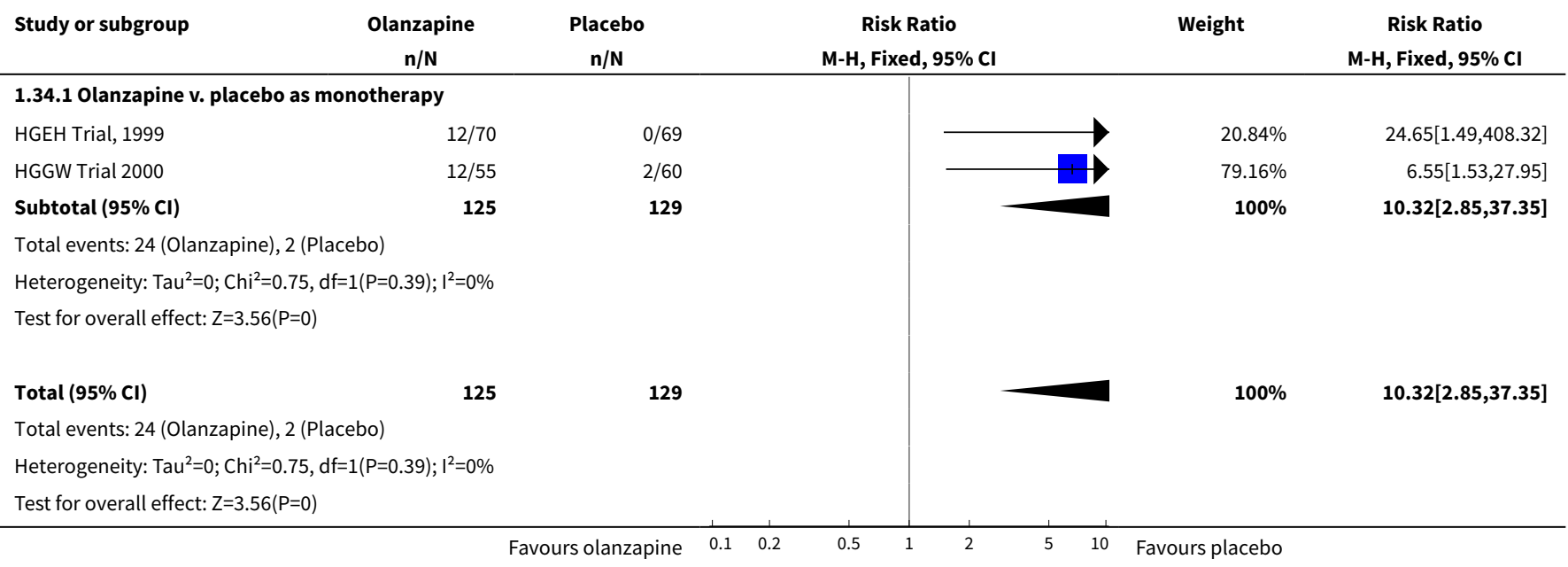

Analysis 1.35. Comparison 1 Olanzapine v placebo, Outcome 35 Dyspepsia.

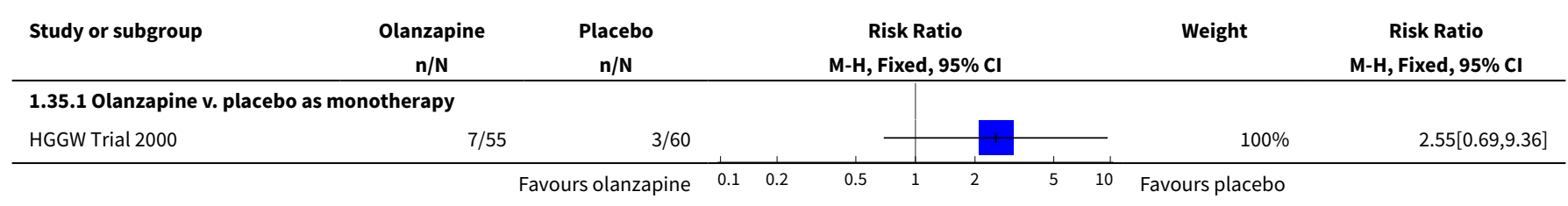




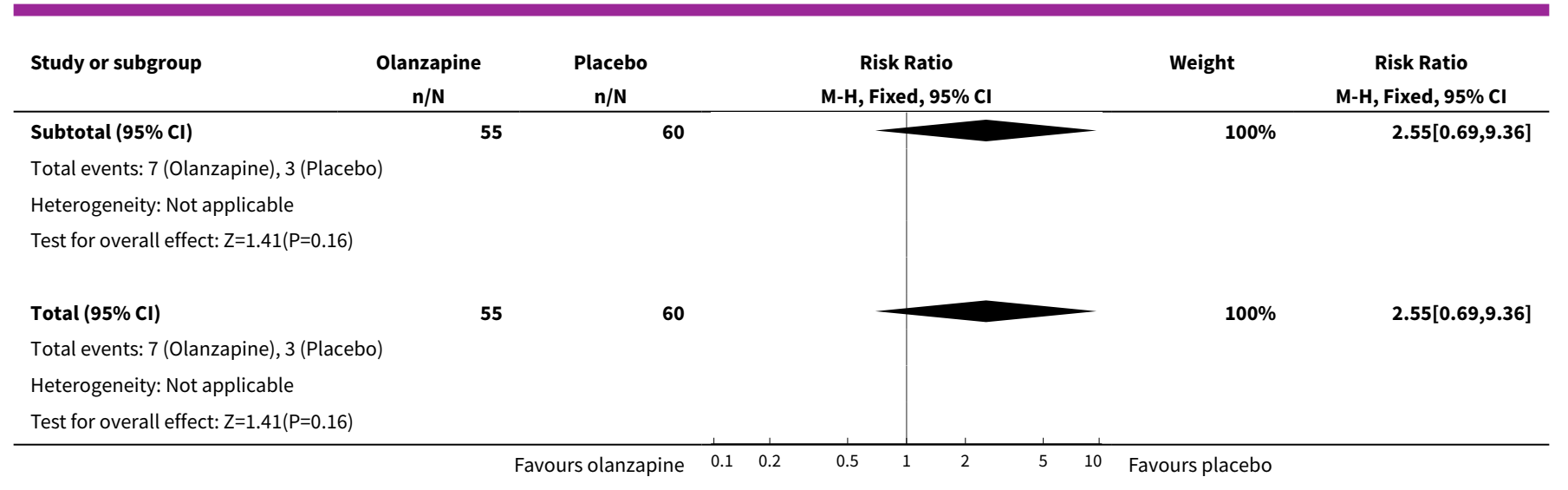

\section{Analysis 1.36. Comparison 1 Olanzapine v placebo, Outcome 36 Mean change in supine systolic blood pressure.}

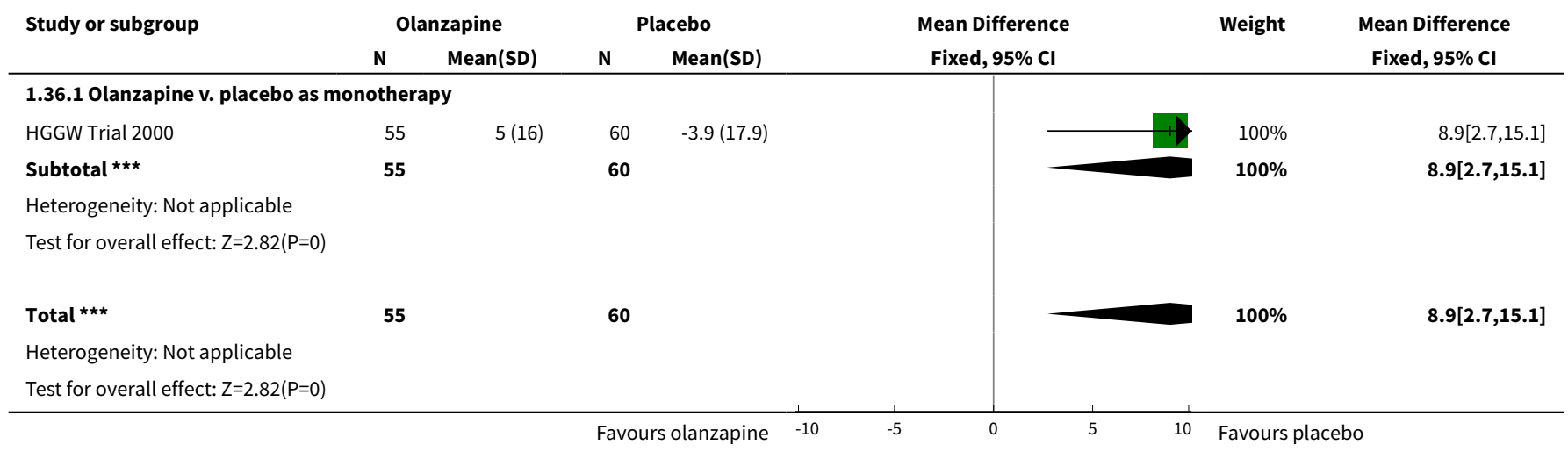

Analysis 1.37. Comparison 1 Olanzapine v placebo, Outcome 37 Increased AST.

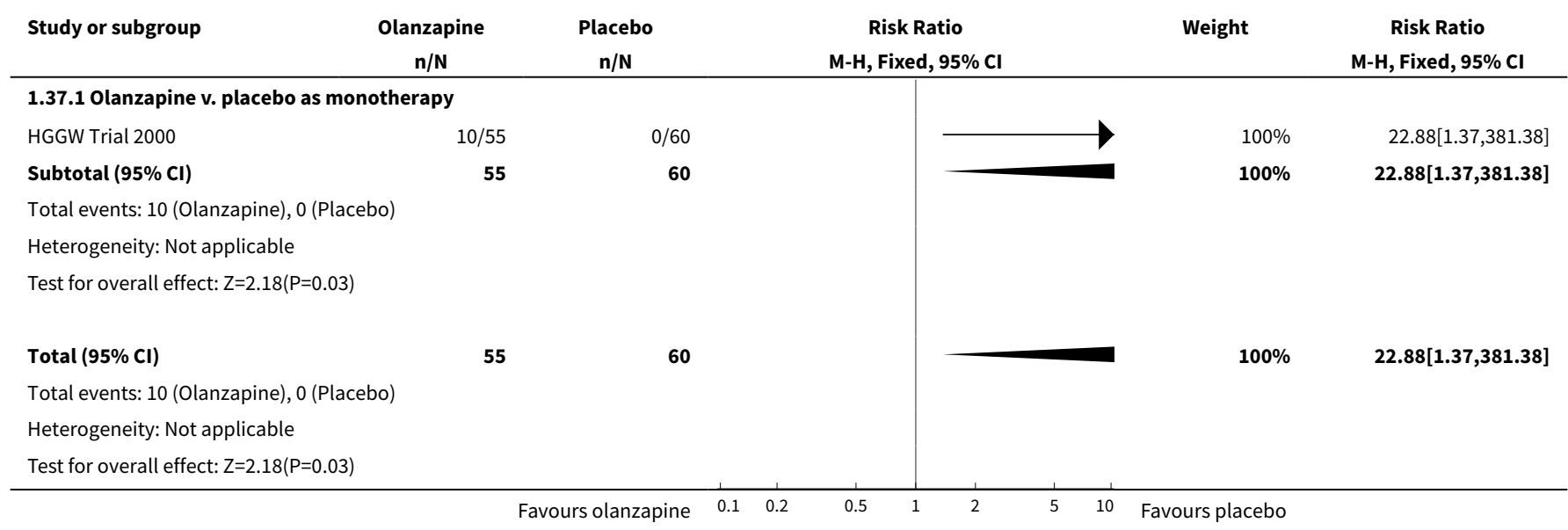


Analysis 1.38. Comparison 1 Olanzapine v placebo, Outcome 38 ECG abnormality.

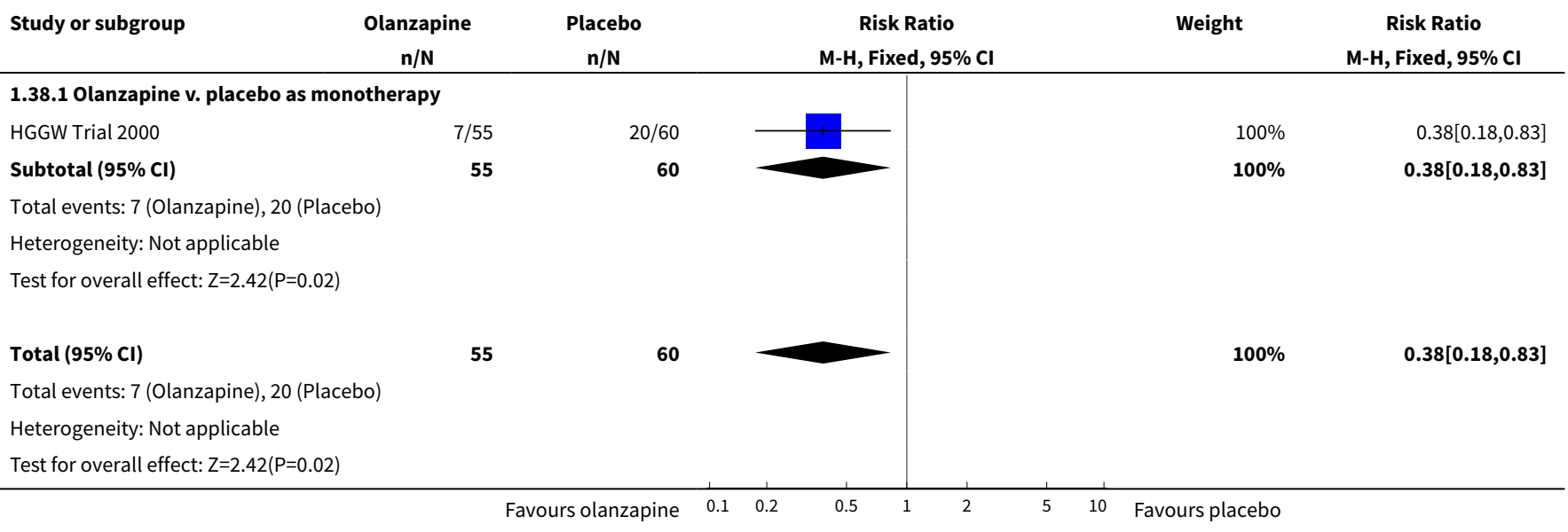

Analysis 1.39. Comparison 1 Olanzapine v placebo, Outcome 39 Corrected $Q T$ interval prolongation.

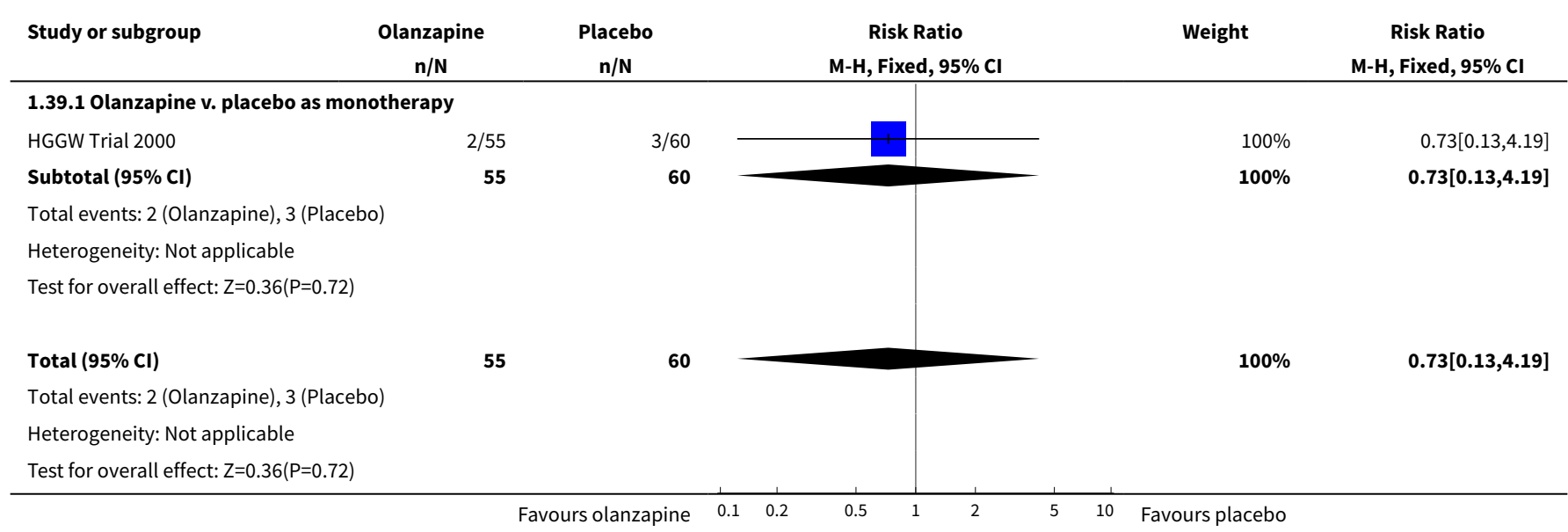

Analysis 1.40. Comparison 1 Olanzapine v placebo, Outcome 40 Prolactin elevation.

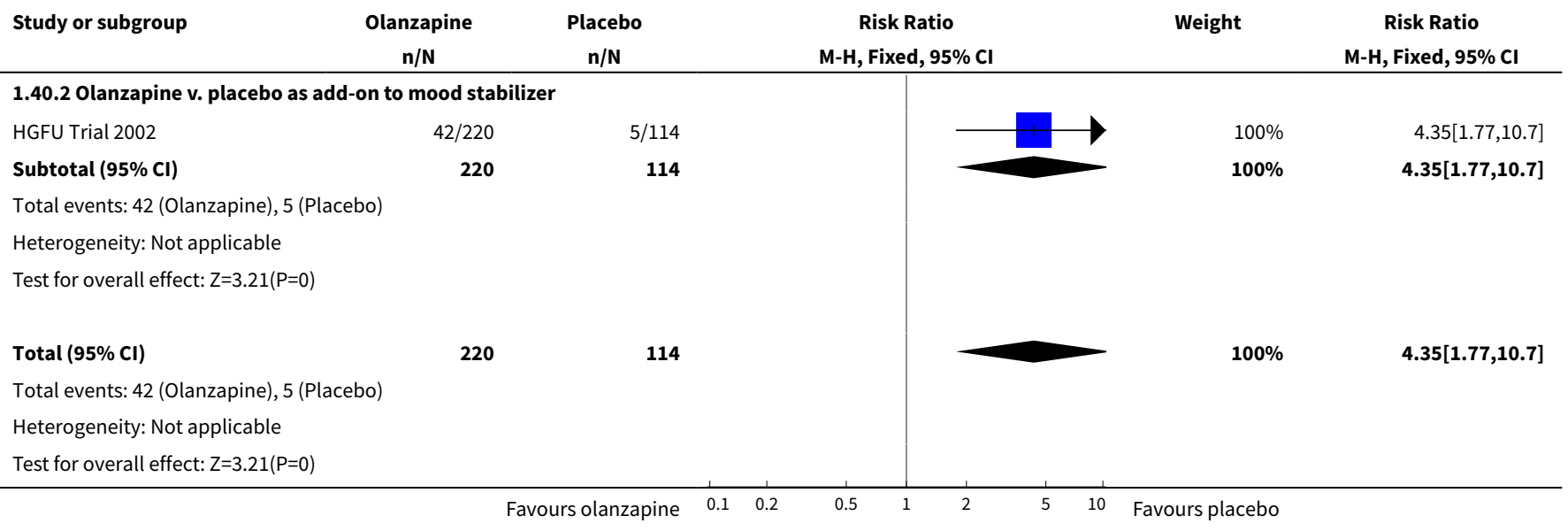


Analysis 1.41. Comparison 1 Olanzapine v placebo, Outcome 41 Increased Appetite.

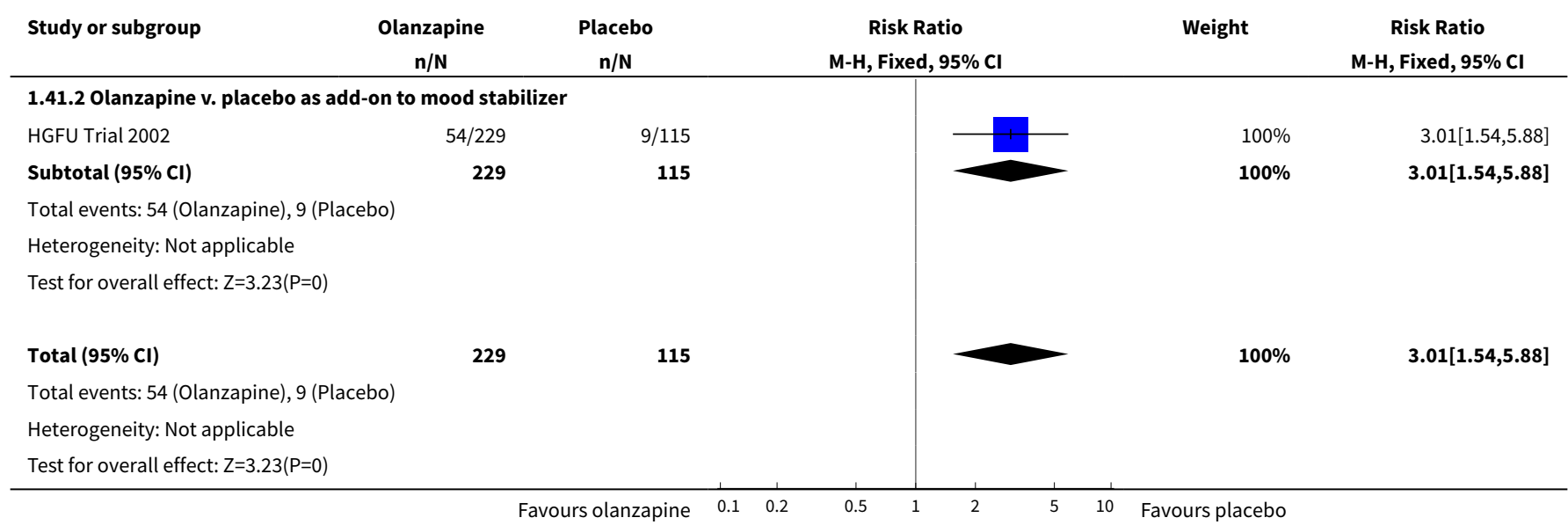

Analysis 1.42. Comparison 1 Olanzapine v placebo, Outcome 42 Tremor.

\begin{tabular}{|c|c|c|c|c|c|}
\hline Study or subgroup & $\begin{array}{c}\text { Olanzapine } \\
\mathrm{n} / \mathrm{N}\end{array}$ & $\begin{array}{c}\text { Placebo } \\
\mathrm{n} / \mathrm{N}\end{array}$ & $\begin{array}{c}\text { Risk Ratio } \\
\text { M-H, Fixed, } 95 \% \mathrm{Cl} \\
\end{array}$ & Weight & $\begin{array}{c}\text { Risk Ratio } \\
\text { M-H, Fixed, } 95 \% \mathrm{Cl} \\
\end{array}$ \\
\hline \multicolumn{6}{|c|}{ 1.42.2 Olanzapine v. placebo as add-on to mood stabilizer } \\
\hline HGFU Trial 2002 & $53 / 229$ & $15 / 115$ & & $100 \%$ & $1.77[1.05,3.01]$ \\
\hline Subtotal $(95 \% \mathrm{Cl})$ & 229 & 115 & & $100 \%$ & $1.77[1.05,3.01]$ \\
\hline \multicolumn{6}{|c|}{ Total events: 53 (Olanzapine), 15 (Placebo) } \\
\hline \multicolumn{6}{|c|}{ Heterogeneity: Not applicable } \\
\hline \multicolumn{6}{|c|}{ Test for overall effect: $Z=2.13(P=0.03)$} \\
\hline Total $(95 \% \mathrm{Cl})$ & 229 & 115 & & $100 \%$ & $1.77[1.05,3.01]$ \\
\hline \multicolumn{6}{|c|}{ Total events: 53 (Olanzapine), 15 (Placebo) } \\
\hline \multicolumn{6}{|c|}{ Heterogeneity: Not applicable } \\
\hline Test for overall effect & & & & & \\
\hline
\end{tabular}

Analysis 1.43. Comparison 1 Olanzapine v placebo, Outcome 43 Diarrhoea.

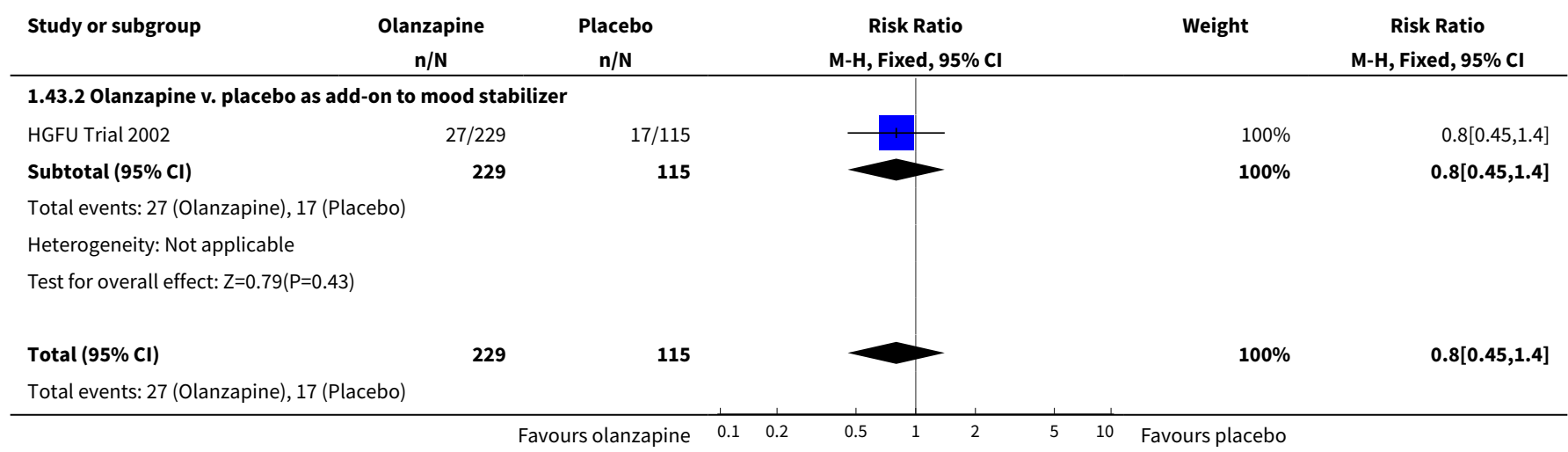




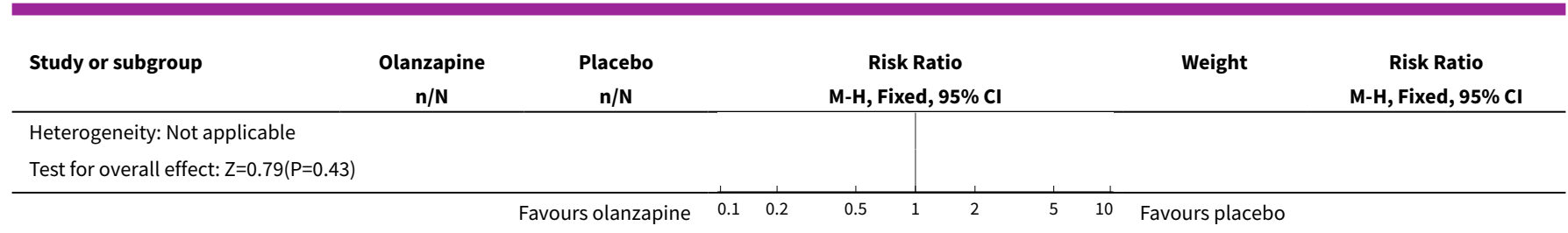

\section{Analysis 1.44. Comparison 1 Olanzapine v placebo, Outcome 44 Mean change in 21-item HAMD - depressed participants.}

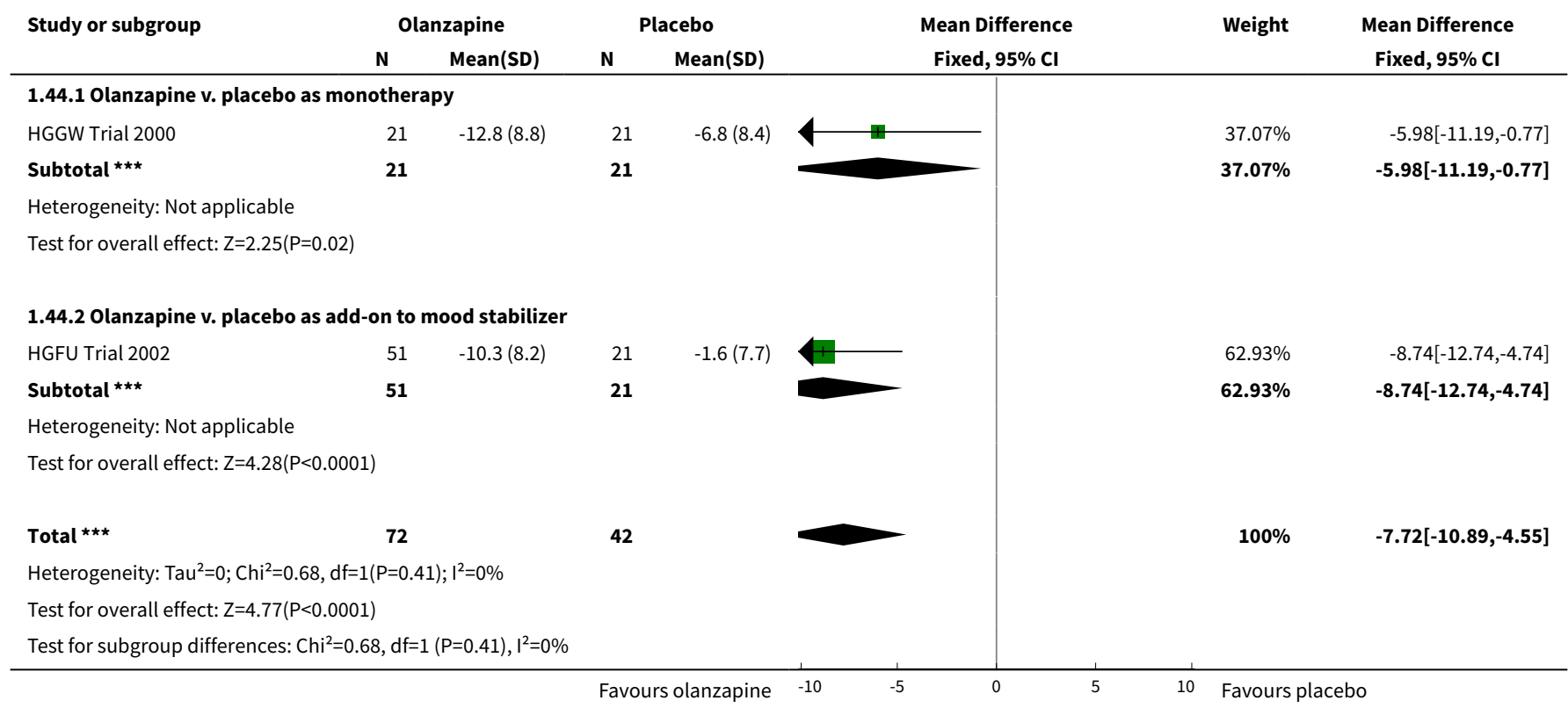

Analysis 1.45. Comparison 1 Olanzapine v placebo, Outcome 45 Thirst.

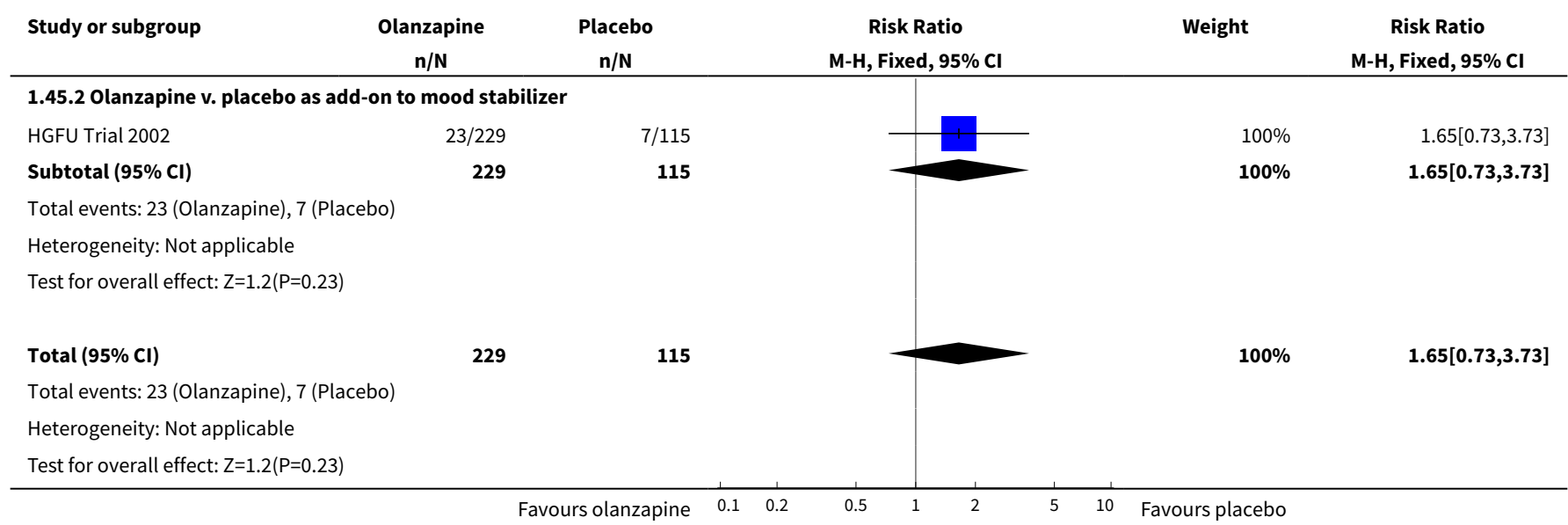


Analysis 1.46. Comparison 1 Olanzapine v placebo, Outcome 46 Speech Disorder.

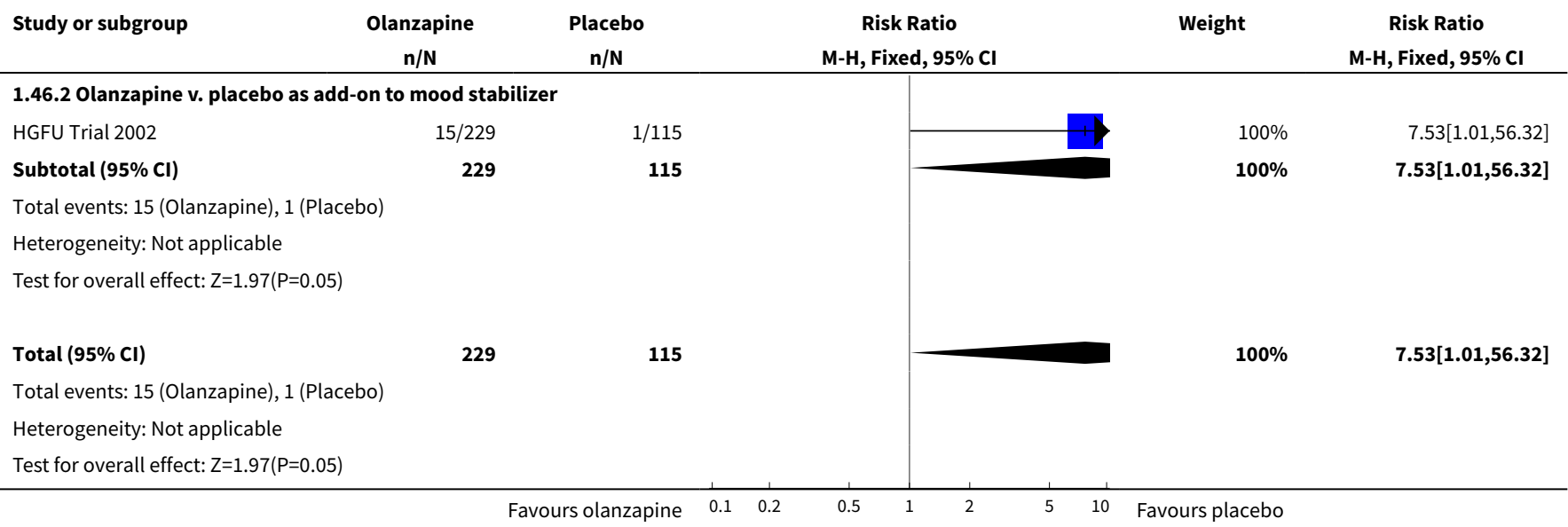

Analysis 1.47. Comparison 1 Olanzapine v placebo, Outcome 47 Mean change in YMRS for patients not experiencing psychotic symptoms.

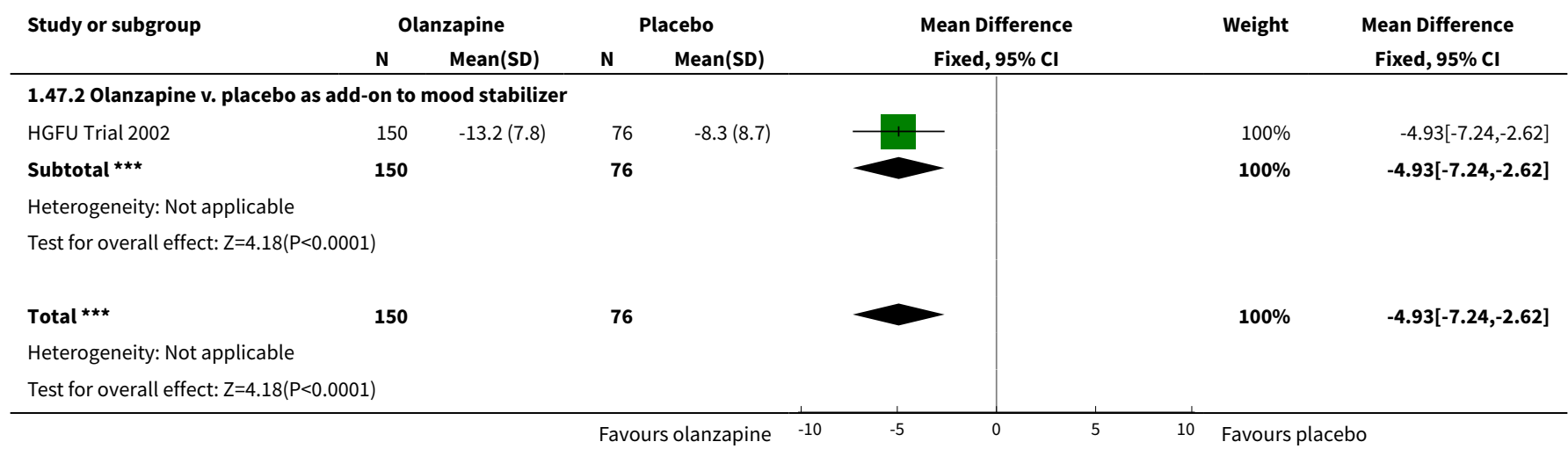

Analysis 1.48. Comparison 1 Olanzapine v placebo, Outcome 48 Mean change in YMRS according to mood stabiliser.

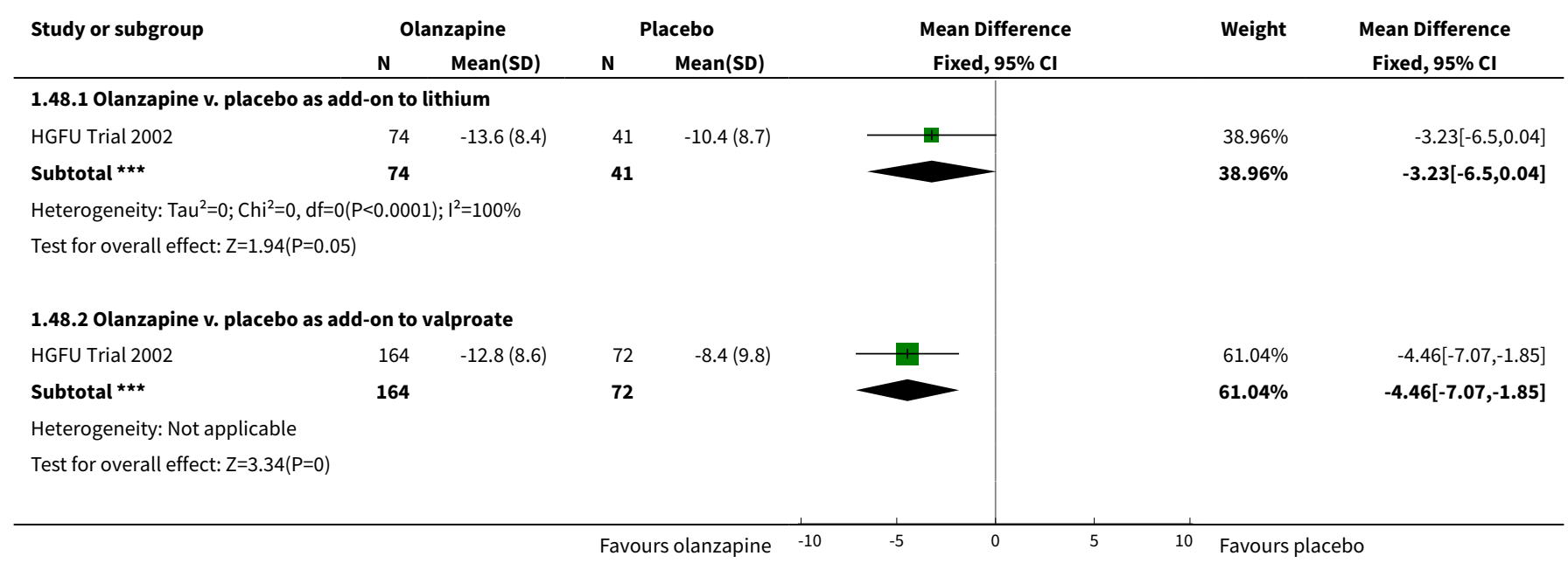




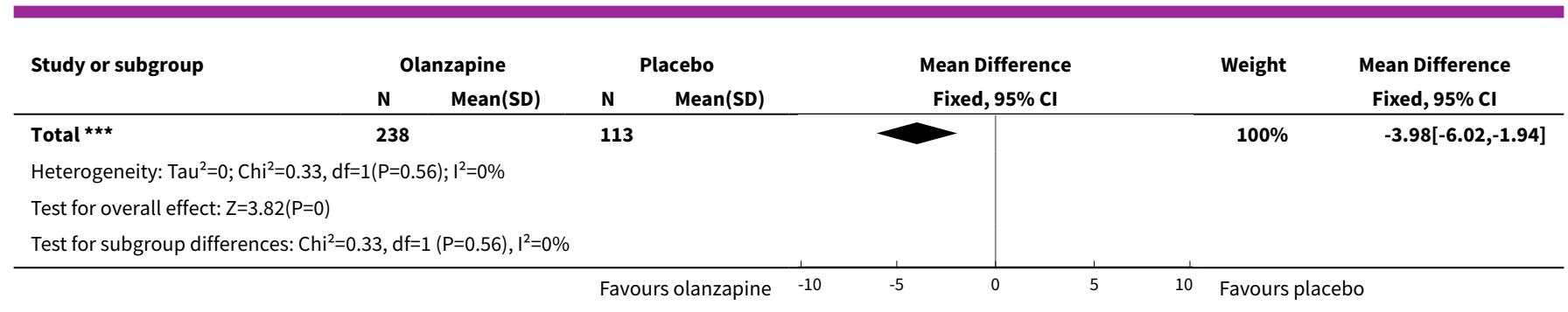

\section{Comparison 2. Olanzapine $\mathbf{v}$ mood stabiliser}

\begin{tabular}{|c|c|c|c|c|}
\hline Outcome or subgroup title & No. of studies & $\begin{array}{l}\text { No. of partici- } \\
\text { pants }\end{array}$ & Statistical method & Effect size \\
\hline 1 Mean change in MRS & 2 & 363 & $\begin{array}{l}\text { Std. Mean Difference (IV, Fixed, } \\
95 \% \mathrm{Cl} \text { ) }\end{array}$ & $-0.29[-0.50,-0.08]$ \\
\hline 1.1 Olanzapine v divalproex & 2 & 363 & $\begin{array}{l}\text { Std. Mean Difference (IV, Fixed, } \\
95 \% \mathrm{CI} \text { ) }\end{array}$ & $-0.29[-0.50,-0.08]$ \\
\hline 2 Failure to respond - YMRS & 1 & 251 & Risk Ratio (M-H, Fixed, 95\% Cl) & $0.78[0.61,0.99]$ \\
\hline 2.1 Olanzapine v divalproex & 1 & 251 & Risk Ratio (M-H, Fixed, 95\% Cl) & $0.78[0.61,0.99]$ \\
\hline $\begin{array}{l}3 \text { Failure to achieve remis- } \\
\text { sion }\end{array}$ & 1 & 251 & Risk Ratio (M-H, Fixed, 95\% Cl) & $0.79[0.64,0.97]$ \\
\hline 3.1 Olanzapine v divalproex & 1 & 251 & Risk Ratio (M-H, Fixed, 95\% Cl) & $0.79[0.64,0.97]$ \\
\hline $\begin{array}{l}4 \text { Mean Change in } 21 \text {-item } \\
\text { HAMD - all participants }\end{array}$ & 2 & 355 & Mean Difference (IV, Fixed, 95\% CI) & $-1.01[-2.43,0.41]$ \\
\hline 4.1 Olanzapine v divalproex & 2 & 355 & Mean Difference (IV, Fixed, 95\% CI) & $-1.01[-2.43,0.41]$ \\
\hline $\begin{array}{l}5 \text { Failure to respond - YMRS } \\
\text { (excluding early withdrawals) }\end{array}$ & 1 & 248 & Risk Ratio (M-H, Fixed, 95\% Cl) & $0.79[0.62,1.01]$ \\
\hline 5.1 Olanzapine v divalproex & 1 & 248 & Risk Ratio (M-H, Fixed, 95\% Cl) & $0.79[0.62,1.01]$ \\
\hline $\begin{array}{l}6 \text { Failure to achieve remis- } \\
\text { sion (excluding early with- } \\
\text { drawals) }\end{array}$ & 1 & 248 & Risk Ratio (M-H, Fixed, 95\% Cl) & $0.80[0.65,0.99]$ \\
\hline 6.1 Olanzapine v divalproex & 1 & 248 & Risk Ratio (M-H, Fixed, 95\% Cl) & $0.80[0.65,0.99]$ \\
\hline $\begin{array}{l}7 \text { Mean change in MRS and } \\
\text { presence of psychotic fea- } \\
\text { tures }\end{array}$ & 1 & 251 & $\begin{array}{l}\text { Std. Mean Difference (IV, Fixed, } \\
95 \% \mathrm{Cl})\end{array}$ & $-0.33[-0.58,-0.08]$ \\
\hline $\begin{array}{l}7.1 \text { Olanzapine v divalproex } \\
\text { - patients experiencing psy- } \\
\text { chotic symptoms }\end{array}$ & 1 & 114 & $\begin{array}{l}\text { Std. Mean Difference (IV, Fixed, } \\
95 \% \mathrm{Cl})\end{array}$ & $0.01[-0.36,0.38]$ \\
\hline $\begin{array}{l}7.2 \text { Olanzapine v divalproex } \\
\text { - patients not experiencing } \\
\text { psychotic symptoms }\end{array}$ & 1 & 137 & $\begin{array}{l}\text { Std. Mean Difference (IV, Fixed, } \\
95 \% \mathrm{CI})\end{array}$ & $-0.63[-0.97,-0.28]$ \\
\hline
\end{tabular}




\begin{tabular}{|c|c|c|c|c|}
\hline Outcome or subgroup title & No. of studies & $\begin{array}{l}\text { No. of partici- } \\
\text { pants }\end{array}$ & Statistical method & Effect size \\
\hline $\begin{array}{l}8 \text { Mean change in 21-item } \\
\text { HAMD - depressed partici- } \\
\text { pants }\end{array}$ & 1 & 53 & Mean Difference (IV, Fixed, 95\% Cl) & $-2.20[-6.40,2.00]$ \\
\hline 8.1 Olanzapine v divalproex & 1 & 53 & Mean Difference (IV, Fixed, 95\% CI) & $-2.20[-6.40,2.00]$ \\
\hline $\begin{array}{l}9 \text { Failure to complete treat- } \\
\text { ment }\end{array}$ & 3 & 431 & Risk Ratio (M-H, Fixed, 95\% Cl) & $0.88[0.71,1.08]$ \\
\hline 9.1 Olanzapine v divalproex & 2 & 371 & Risk Ratio (M-H, Fixed, 95\% Cl) & $0.90[0.73,1.12]$ \\
\hline 9.2 Olanzapine v lithium & 1 & 30 & Risk Ratio (M-H, Fixed, 95\% Cl) & $0.33[0.04,2.85]$ \\
\hline 9.3 Olanzapine v lamotrigine & 1 & 30 & Risk Ratio (M-H, Fixed, 95\% Cl) & $0.5[0.05,4.94]$ \\
\hline 10 Somnolence & 2 & 371 & Risk Ratio (M-H, Fixed, 95\% Cl) & $1.80[1.32,2.46]$ \\
\hline 10.1 Olanzapine v divalproex & 2 & 371 & Risk Ratio (M-H, Fixed, 95\% Cl) & $1.80[1.32,2.46]$ \\
\hline 11 Dry mouth & 1 & 251 & Risk Ratio (M-H, Fixed, 95\% Cl) & $5.29[2.59,10.81]$ \\
\hline 11.1 Olanzapine v divalproex & 1 & 251 & Risk Ratio (M-H, Fixed, 95\% Cl) & $5.29[2.59,10.81]$ \\
\hline 12 Increased appetite & 1 & 251 & Risk Ratio (M-H, Fixed, 95\% Cl) & $5.04[1.50,16.98]$ \\
\hline 12.1 Olanzapine $v$ divalproex & 1 & 251 & Risk Ratio (M-H, Fixed, 95\% Cl) & $5.04[1.50,16.98]$ \\
\hline 13 Nausea & 1 & 251 & Risk Ratio (M-H, Fixed, 95\% Cl) & $0.36[0.20,0.65]$ \\
\hline 13.1 Olanzapine v divalproex & 1 & 251 & Risk Ratio (M-H, Fixed, 95\% Cl) & $0.36[0.20,0.65]$ \\
\hline 14 SAS Scale & 1 & 241 & Mean Difference (IV, Fixed, 95\% CI) & $0.72[0.11,1.33]$ \\
\hline 14.1 Olanzapine v divalproex & 1 & 241 & Mean Difference (IV, Fixed, 95\% Cl) & $0.72[0.11,1.33]$ \\
\hline 15 Barnes Akathisia Scale & 1 & 241 & Mean Difference (IV, Fixed, 95\% Cl) & $0.02[-0.23,0.27]$ \\
\hline 15.1 Olanzapine v divalproex & 1 & 241 & Mean Difference (IV, Fixed, 95\% CI) & $0.02[-0.23,0.27]$ \\
\hline 16 AIMS & 1 & 247 & Mean Difference (IV, Fixed, 95\% Cl) & $-0.17[-0.61,0.27]$ \\
\hline 16.1 Olanzapine v divalproex & 1 & 247 & Mean Difference (IV, Fixed, 95\% CI) & $-0.17[-0.61,0.27]$ \\
\hline $\begin{array}{l}17 \text { Weight change (continu- } \\
\text { ous data) }\end{array}$ & 2 & 366 & Mean Difference (IV, Fixed, 95\% Cl) & $1.54[1.02,2.05]$ \\
\hline 17.1 Olanzapine v divalproex & 2 & 366 & Mean Difference (IV, Fixed, 95\% CI) & $1.54[1.02,2.05]$ \\
\hline 18 Raised ALT/SGPT & 1 & 230 & Risk Ratio (M-H, Fixed, 95\% Cl) & $12.56[0.72,220.38]$ \\
\hline 18.1 Olanzapine v divalproex & 1 & 230 & Risk Ratio (M-H, Fixed, 95\% Cl) & $12.56[0.72,220.38]$ \\
\hline 19 Lowered platelet count & 1 & 227 & Risk Ratio (M-H, Fixed, 95\% Cl) & $0.05[0.00,0.87]$ \\
\hline
\end{tabular}




\begin{tabular}{|c|c|c|c|c|}
\hline Outcome or subgroup title & No. of studies & $\begin{array}{l}\text { No. of partici- } \\
\text { pants }\end{array}$ & Statistical method & Effect size \\
\hline 19.1 Olanzapine v divalproex & 1 & 227 & Risk Ratio (M-H, Fixed, 95\% Cl) & $0.05[0.00,0.87]$ \\
\hline 20 Oedema & 1 & 120 & Risk Ratio (M-H, Fixed, 95\% Cl) & $18.76[1.11,317.86]$ \\
\hline 20.1 Olanzapine v divalproex & 1 & 120 & Risk Ratio (M-H, Fixed, 95\% Cl) & $18.76[1.11,317.86]$ \\
\hline 21 Rhinitis & 1 & 120 & Risk Ratio (M-H, Fixed, 95\% Cl) & $4.42[0.98,19.96]$ \\
\hline 21.1 Olanzapine v divalproex & 1 & 120 & Risk Ratio (M-H, Fixed, 95\% Cl) & $4.42[0.98,19.96]$ \\
\hline 22 Headache & 1 & 251 & Risk Ratio (M-H, Fixed, 95\% Cl) & $0.97[0.62,1.54]$ \\
\hline 22.1 Olanzapine v divalproex & 1 & 251 & Risk Ratio (M-H, Fixed, 95\% Cl) & $0.97[0.62,1.54]$ \\
\hline 23 Asthenia & 1 & 251 & Risk Ratio (M-H, Fixed, 95\% Cl) & $1.19[0.65,2.16]$ \\
\hline 23.1 Olanzapine v divalproex & 1 & 251 & Risk Ratio (M-H, Fixed, 95\% Cl) & $1.19[0.65,2.16]$ \\
\hline 24 Dizziness & 1 & 251 & Risk Ratio (M-H, Fixed, 95\% Cl) & $1.34[0.72,2.50]$ \\
\hline 24.1 Olanzapine v divalproex & 1 & 251 & Risk Ratio (M-H, Fixed, 95\% Cl) & $1.34[0.72,2.50]$ \\
\hline 25 Constipation & 1 & 251 & Risk Ratio (M-H, Fixed, 95\% Cl) & $1.21[0.64,2.29]$ \\
\hline 25.1 Olanzapine v divalproex & 1 & 251 & Risk Ratio (M-H, Fixed, 95\% Cl) & $1.21[0.64,2.29]$ \\
\hline 26 Dyspepsia & 1 & 251 & Risk Ratio (M-H, Fixed, 95\% Cl) & $1.30[0.67,2.49]$ \\
\hline 26.1 Olanzapine v divalproex & 1 & 251 & Risk Ratio (M-H, Fixed, 95\% Cl) & $1.30[0.67,2.49]$ \\
\hline 27 Pain & 1 & 251 & Risk Ratio (M-H, Fixed, 95\% Cl) & $0.95[0.51,1.76]$ \\
\hline 27.1 Olanzapine v divalproex & 1 & 251 & Risk Ratio (M-H, Fixed, 95\% Cl) & $0.95[0.51,1.76]$ \\
\hline $\begin{array}{l}28 \text { Weight Gain (dichotomous } \\
\text { data) }\end{array}$ & 2 & 371 & Risk Ratio (M-H, Fixed, 95\% Cl) & $1.90[1.07,3.37]$ \\
\hline 28.1 Olanzapine v divalproex & 2 & 371 & Risk Ratio (M-H, Fixed, 95\% Cl) & $1.90[1.07,3.37]$ \\
\hline 29 Agitation & 1 & 251 & Risk Ratio (M-H, Fixed, 95\% Cl) & $1.01[0.50,2.03]$ \\
\hline 29.1 Olanzapine v divalproex & 1 & 251 & Risk Ratio (M-H, Fixed, 95\% Cl) & $1.01[0.50,2.03]$ \\
\hline 30 Nervouseness & 1 & 251 & Risk Ratio (M-H, Fixed, 95\% Cl) & $0.62[0.33,1.19]$ \\
\hline 30.1 Olanzapine v divalproex & 1 & 251 & Risk Ratio (M-H, Fixed, 95\% Cl) & $0.62[0.33,1.19]$ \\
\hline 31 Tremor & 1 & 251 & Risk Ratio (M-H, Fixed, 95\% Cl) & $3.02[1.00,9.12]$ \\
\hline 31.1 Olanzapine v divalproex & 1 & 251 & Risk Ratio (M-H, Fixed, 95\% Cl) & $3.02[1.00,9.12]$ \\
\hline 32 Vomiting & 1 & 251 & Risk Ratio (M-H, Fixed, 95\% Cl) & $0.56[0.27,1.16]$ \\
\hline 32.1 Olanzapine v divalproex & 1 & 251 & Risk Ratio (M-H, Fixed, 95\% Cl) & $0.56[0.27,1.16]$ \\
\hline
\end{tabular}




\begin{tabular}{llllll}
\hline Outcome or subgroup title & No. of studies & $\begin{array}{l}\text { No. of partici- } \\
\text { pants }\end{array}$ & Statistical method & Effect size \\
\hline 33 Speech Disorder & 2 & 371 & Risk Ratio (M-H, Fixed, 95\% Cl) & $10.03[1.89,53.25]$ \\
\hline 33.1 Olanzapine v divalproex & 2 & 371 & Risk Ratio (M-H, Fixed, 95\% Cl) & $10.03[1.89,53.25]$ \\
\hline 34 Neck Rigidity & 1 & 251 & Risk Ratio (M-H, Fixed, 95\% Cl) & $4.54[1.00,20.58]$ \\
\hline 34.1 Olanzapine v divalproex & 1 & 251 & Risk Ratio (M-H, Fixed, 95\% Cl) & $4.54[1.00,20.58]$ \\
\hline 35 Diarrhoea & 1 & 251 & Risk Ratio (M-H, Fixed, 95\% Cl) & $0.47[0.21,1.06]$ \\
\hline 35.1 Olanzapine v divalproex & 1 & 251 & Risk Ratio (M-H, Fixed, 95\% Cl) & $0.47[0.21,1.06]$ \\
\hline 36 Sleep disorder & 1 & 251 & Risk Ratio (M-H, Fixed, 95\% Cl) & $7.06[0.88,56.52]$ \\
\hline 36.1 Olanzapine v divalproex & 1 & 251 & Risk Ratio (M-H, Fixed, 95\% Cl) & $13.10[0.75,230.15]$ \\
\hline 37 Tongue Oedema & 1 & 251 & Risk Ratio (M-H, Fixed, 95\% Cl) & $13.10[0.75,230.15]$ \\
\hline 37.1 Olanzapine v divalproex & 1 & 251 & $7.06[0.88,56.52]$ \\
\hline
\end{tabular}

Analysis 2.1. Comparison 2 Olanzapine v mood stabiliser, Outcome 1 Mean change in MRS.

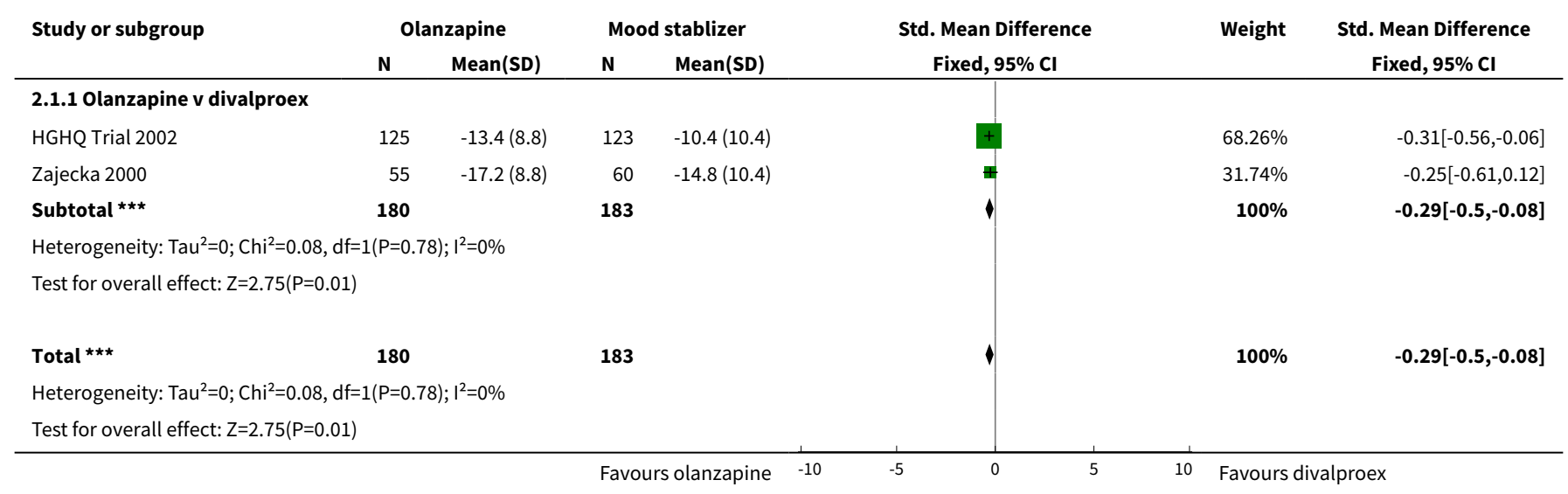

Analysis 2.2. Comparison 2 Olanzapine v mood stabiliser, Outcome 2 Failure to respond - YMRS.

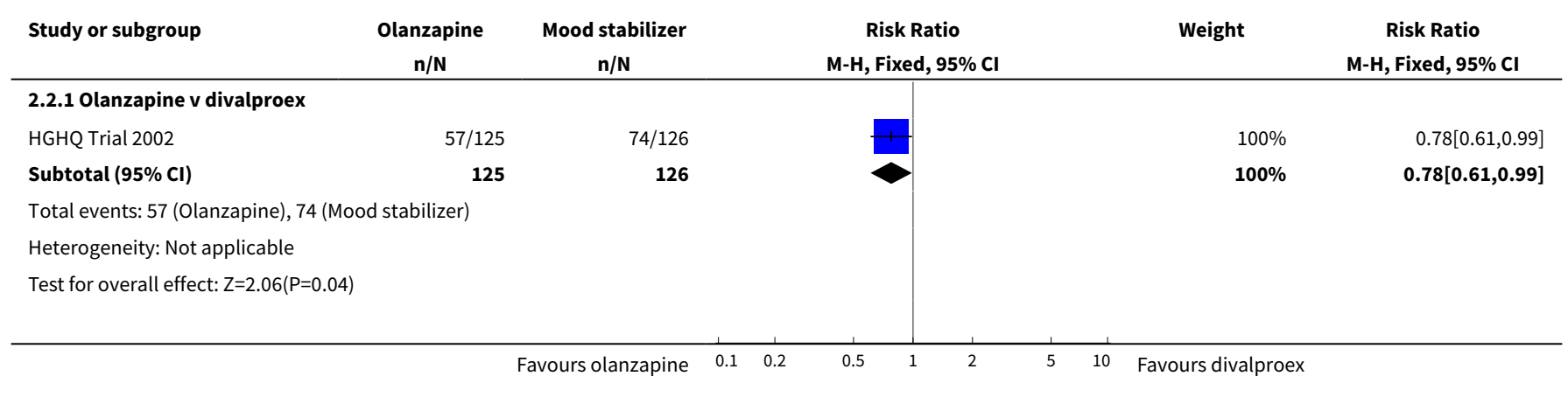




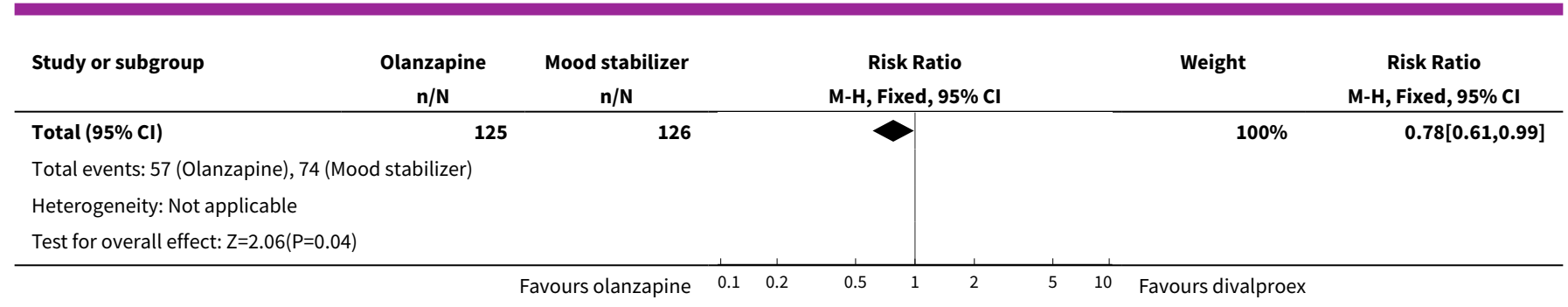

Analysis 2.3. Comparison 2 Olanzapine v mood stabiliser, Outcome 3 Failure to achieve remission.

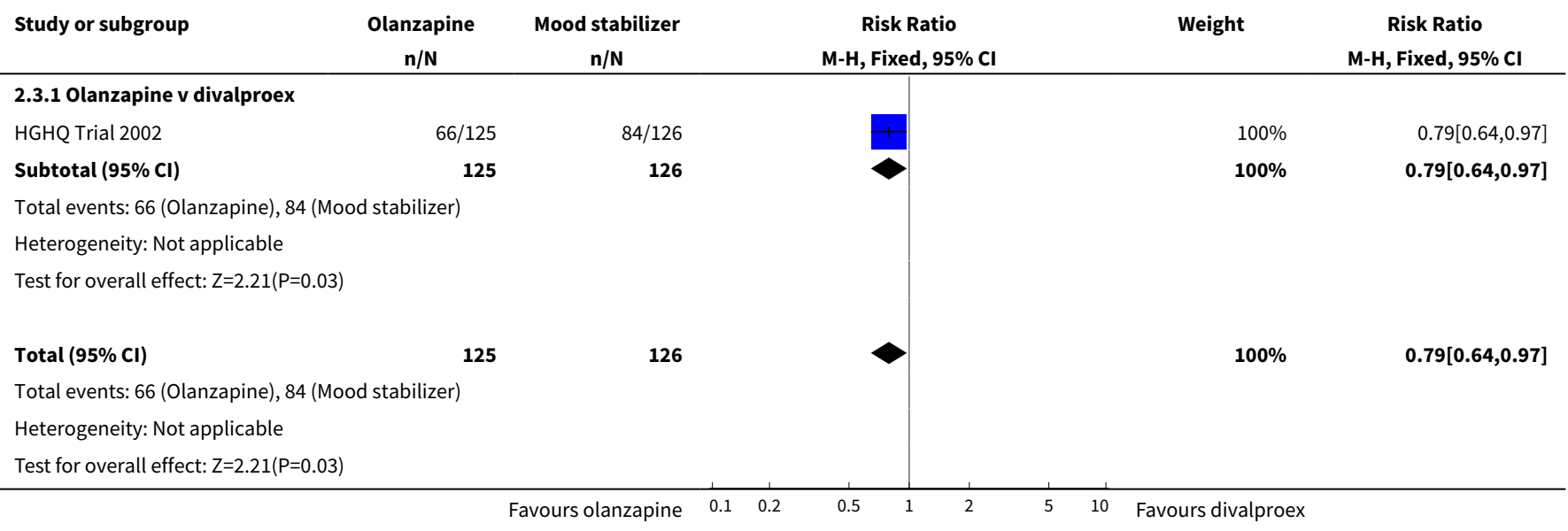

Analysis 2.4. Comparison 2 Olanzapine v mood stabiliser, Outcome 4 Mean Change in 21-item HAMD - all participants.

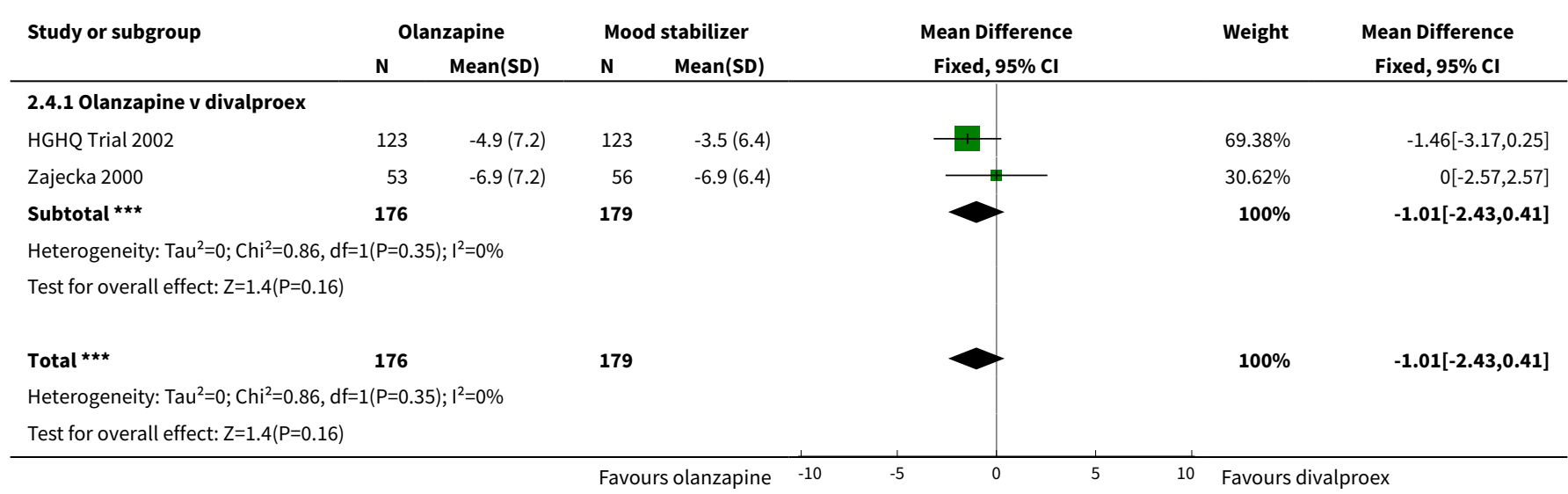


Analysis 2.5. Comparison 2 Olanzapine v mood stabiliser, Outcome 5 Failure to respond - YMRS (excluding early withdrawals).

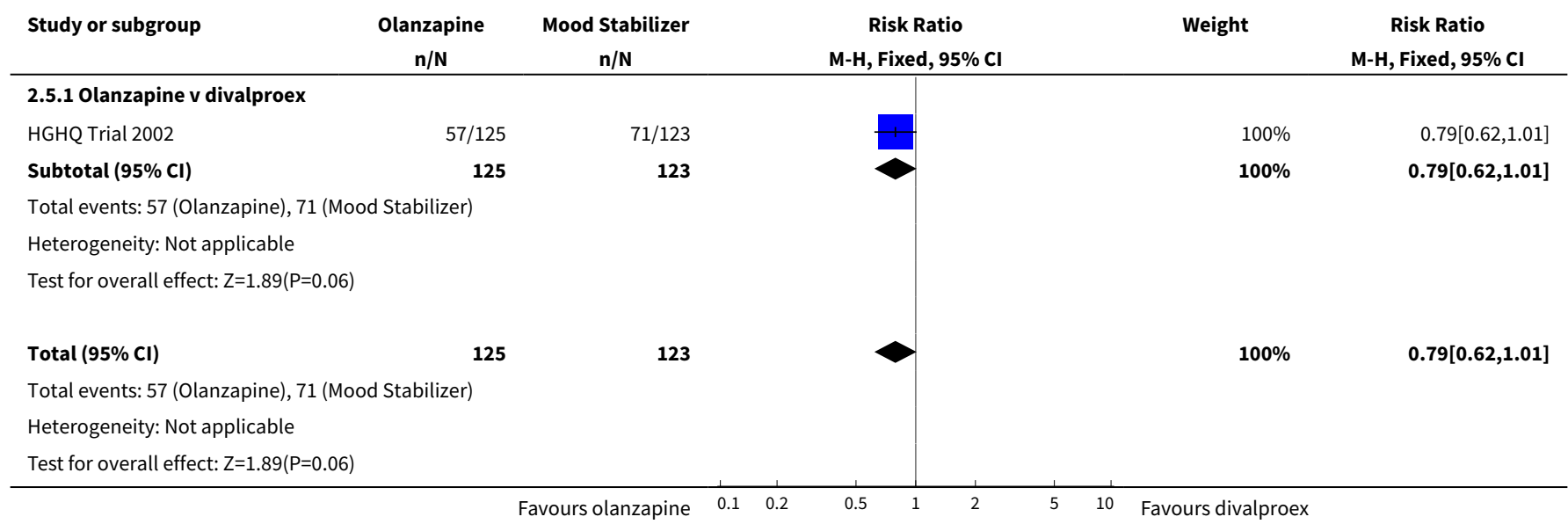

Analysis 2.6. Comparison 2 Olanzapine v mood stabiliser, Outcome 6 Failure to achieve remission (excluding early withdrawals).

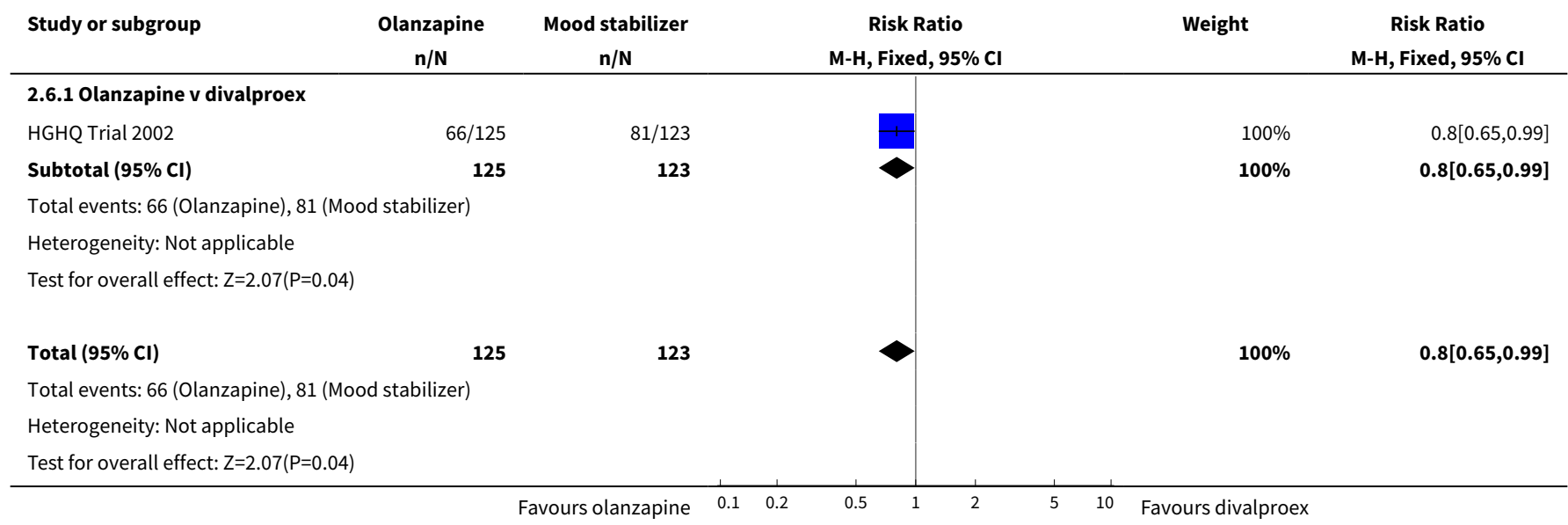

Analysis 2.7. Comparison 2 Olanzapine v mood stabiliser, Outcome 7 Mean change in MRS and presence of psychotic features.

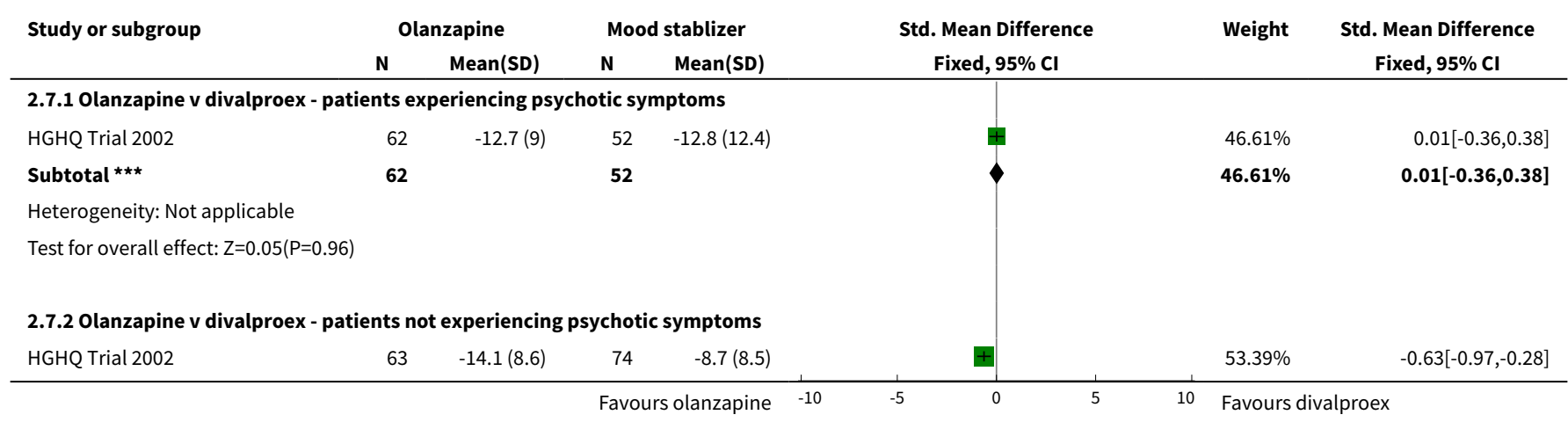




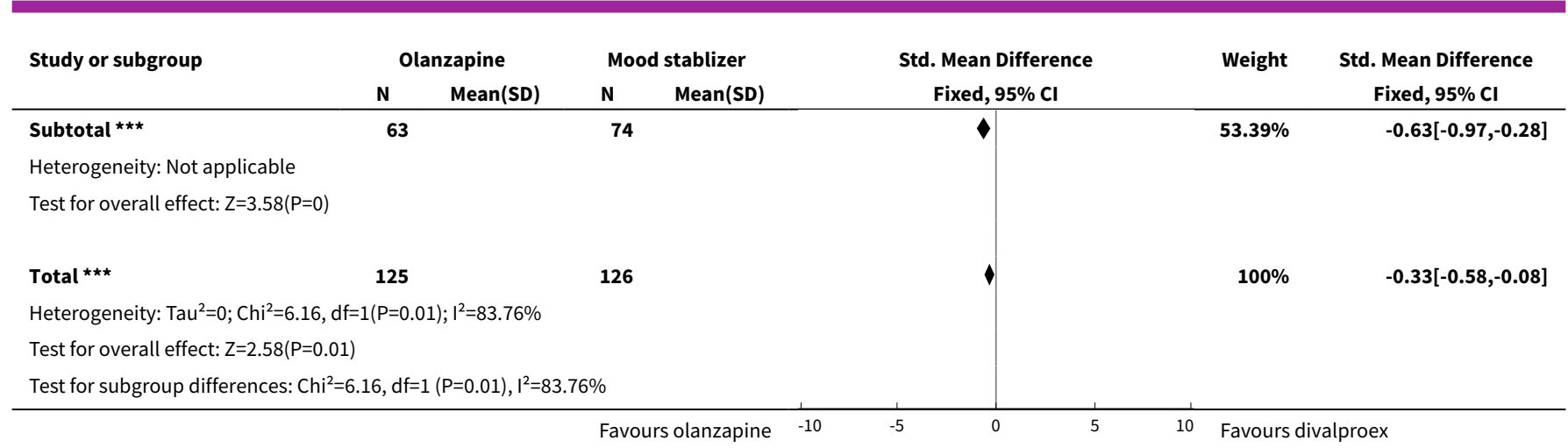

Analysis 2.8. Comparison 2 Olanzapine v mood stabiliser, Outcome 8 Mean change in 21-item HAMD - depressed participants.

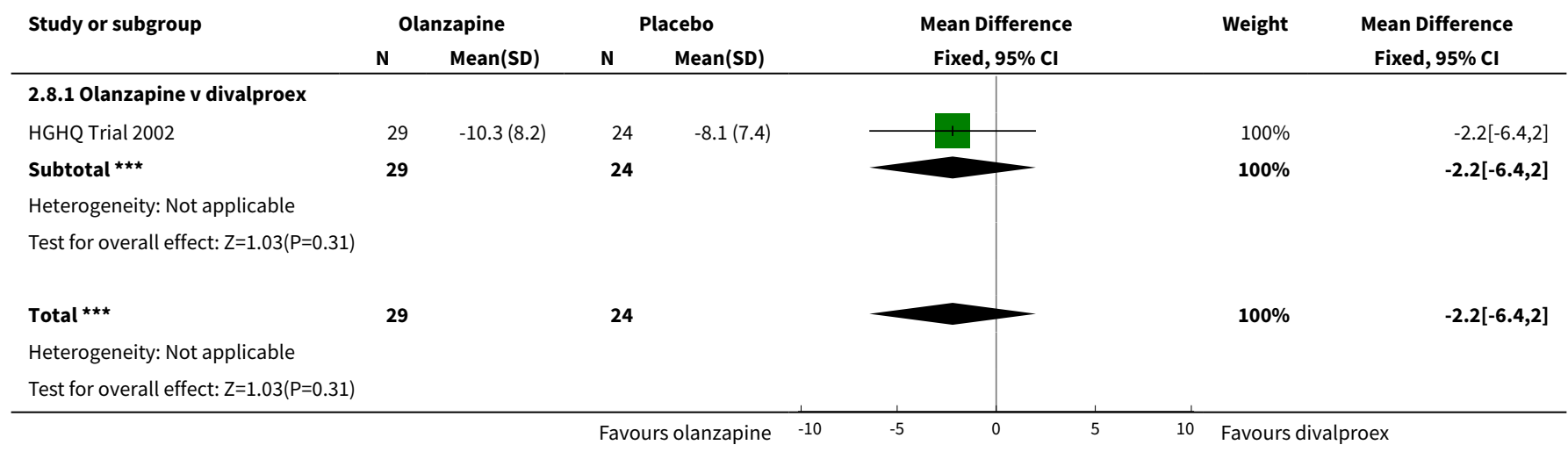

Analysis 2.9. Comparison 2 Olanzapine v mood stabiliser, Outcome 9 Failure to complete treatment.

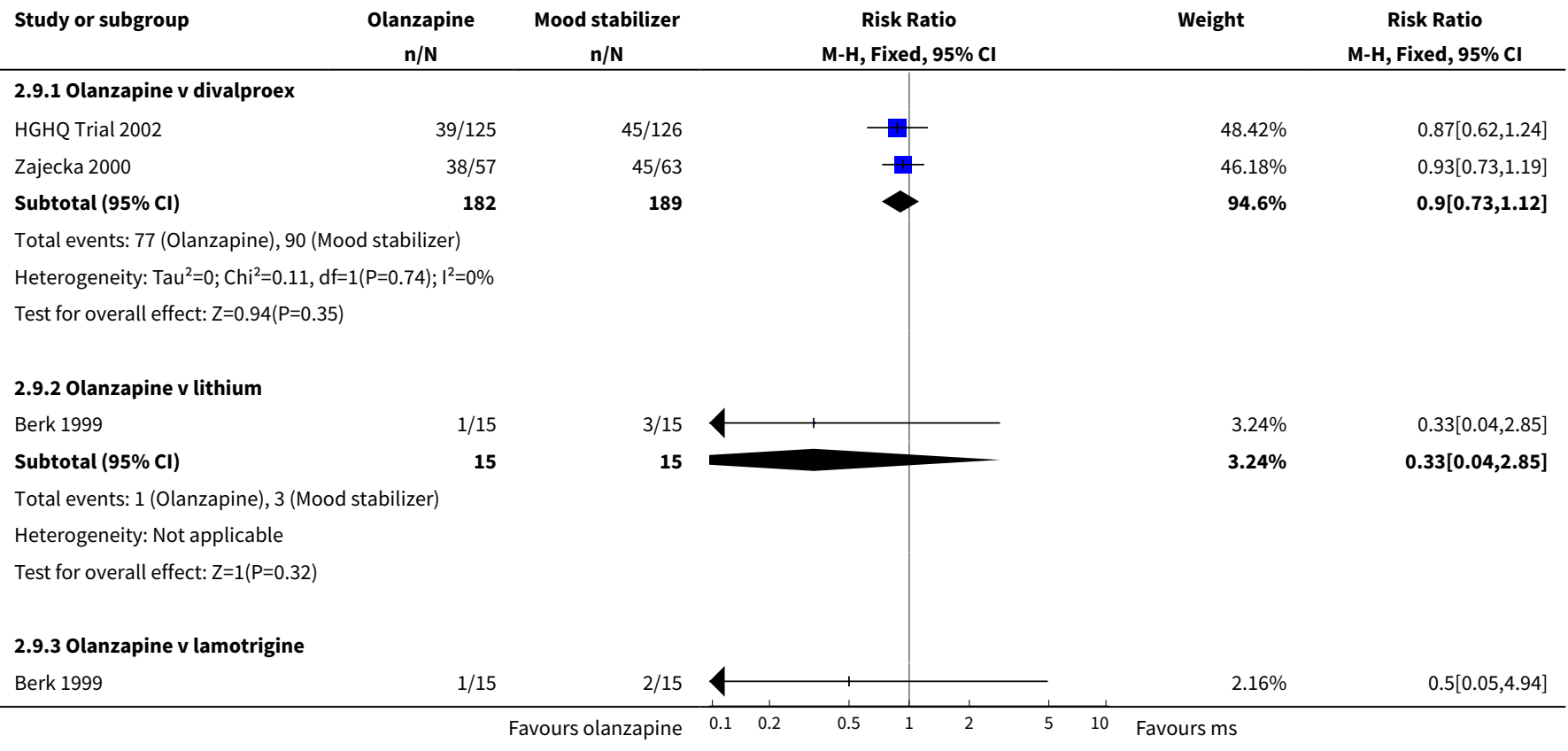




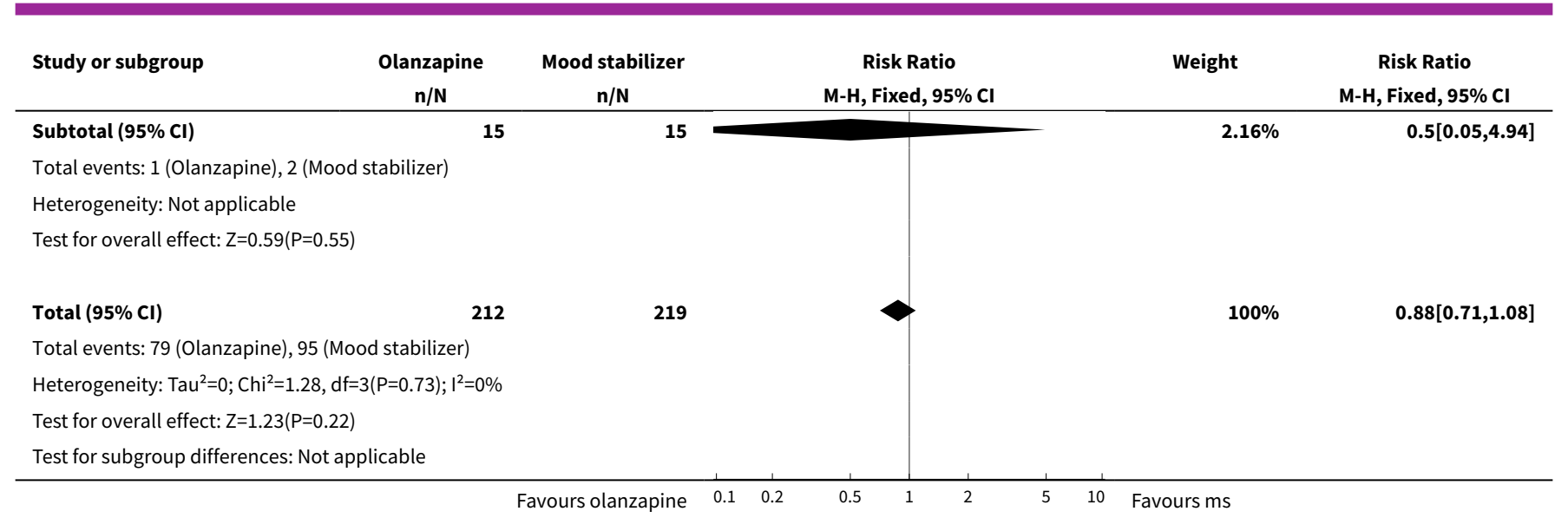

Analysis 2.10. Comparison 2 Olanzapine v mood stabiliser, Outcome 10 Somnolence.

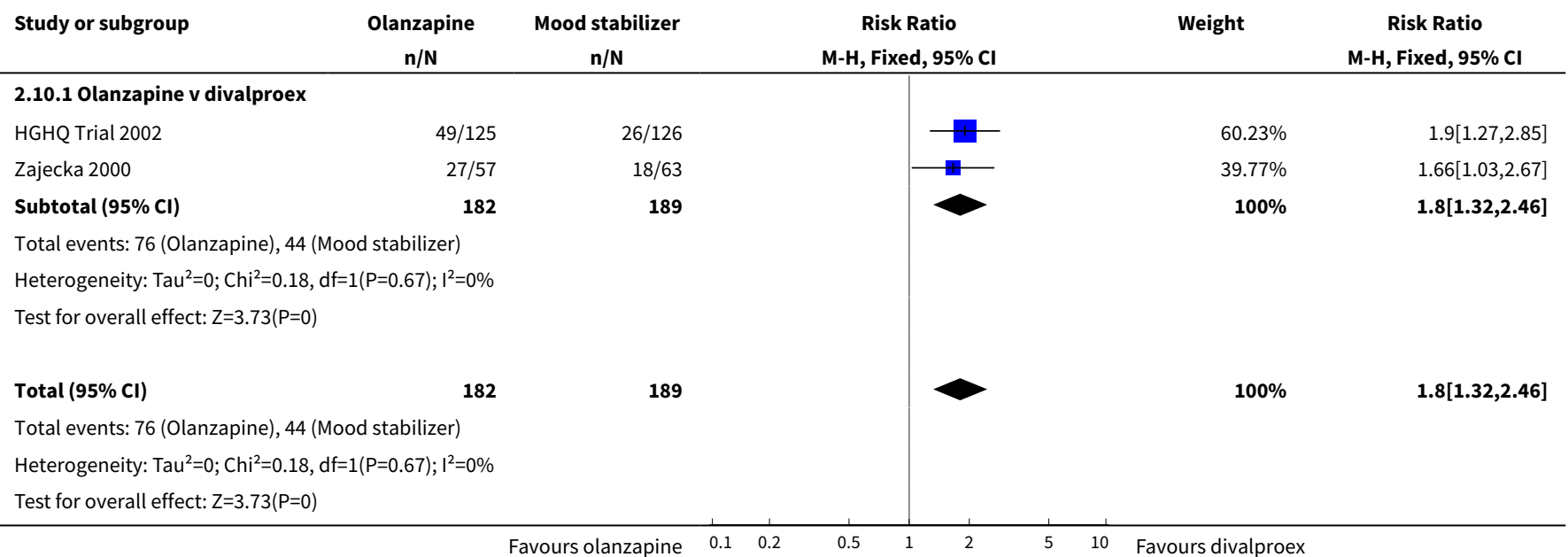

Analysis 2.11. Comparison 2 Olanzapine v mood stabiliser, Outcome 11 Dry mouth.

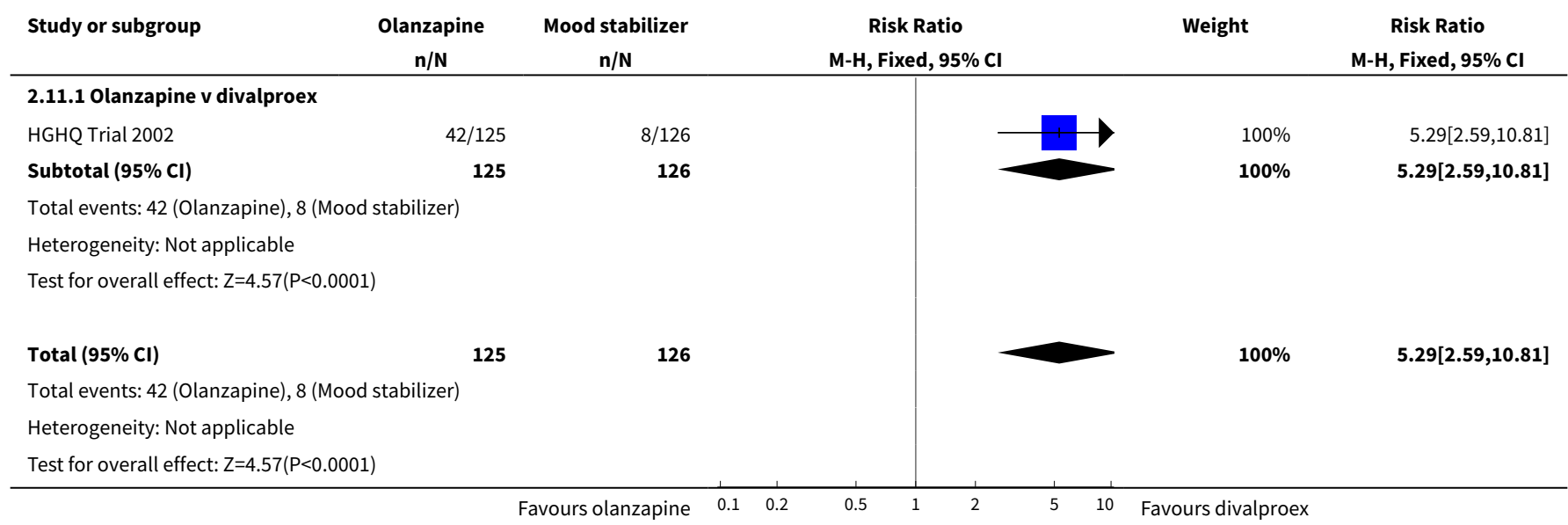


Analysis 2.12. Comparison 2 Olanzapine v mood stabiliser, Outcome 12 Increased appetite.

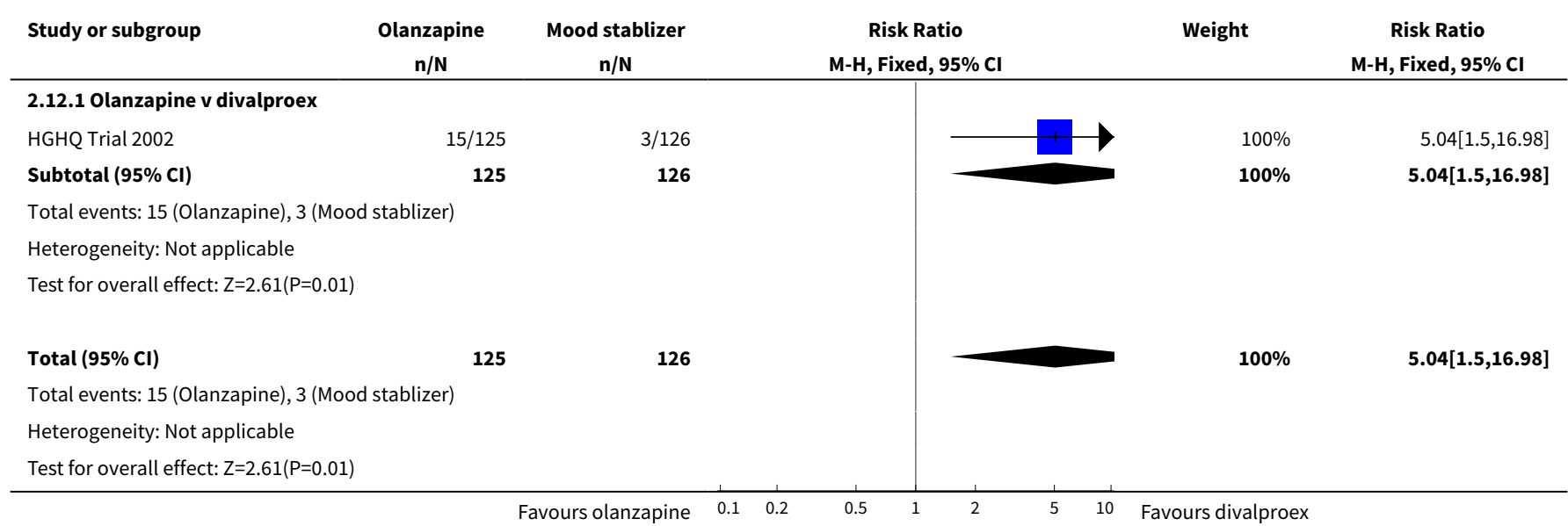

Analysis 2.13. Comparison 2 Olanzapine $\mathbf{v}$ mood stabiliser, Outcome 13 Nausea.

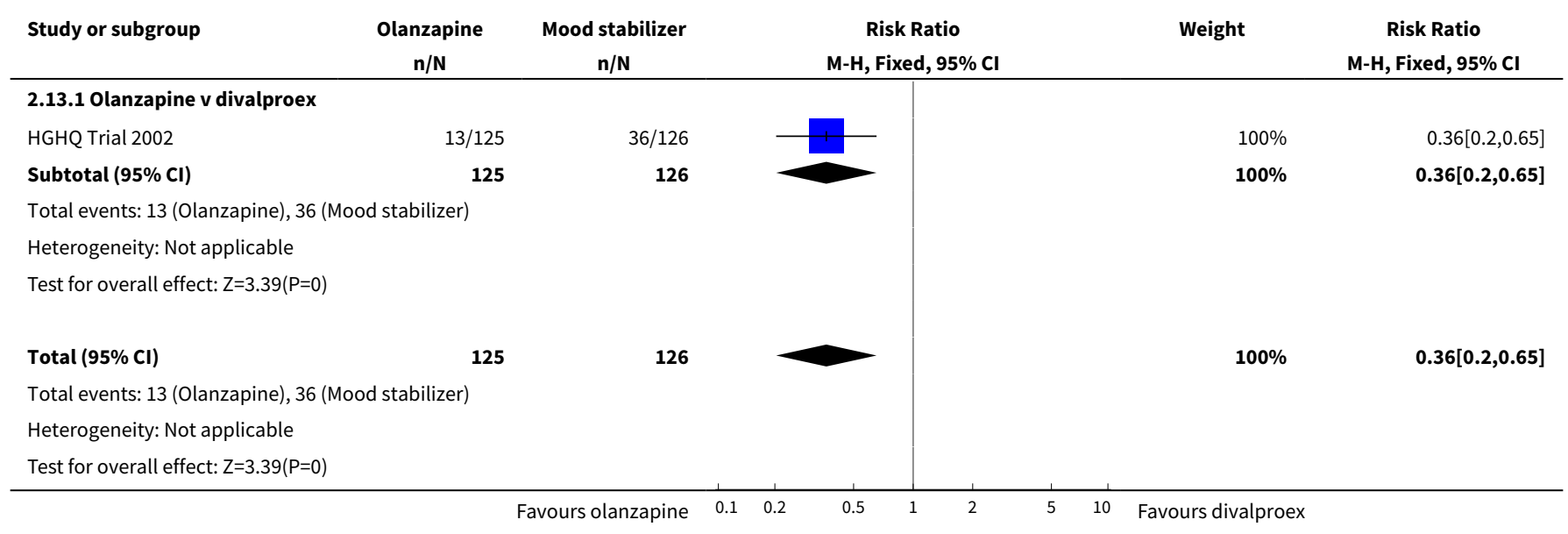

Analysis 2.14. Comparison 2 Olanzapine v mood stabiliser, Outcome 14 SAS Scale.

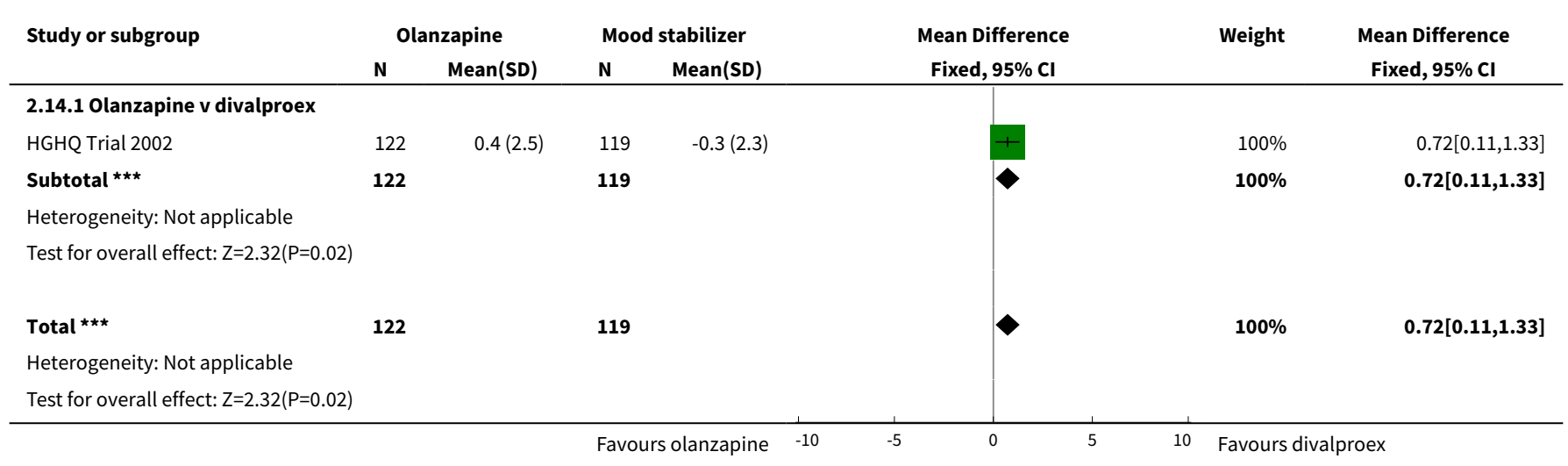


Analysis 2.15. Comparison 2 Olanzapine v mood stabiliser, Outcome 15 Barnes Akathisia Scale.

\begin{tabular}{|c|c|c|c|c|c|c|c|}
\hline \multirow[t]{2}{*}{ Study or subgroup } & \multicolumn{2}{|c|}{ Olanzapine } & \multicolumn{2}{|c|}{ Mood stabilizer } & \multirow{2}{*}{$\begin{array}{c}\text { Mean Difference } \\
\text { Fixed, } 95 \% \mathrm{Cl} \\
\end{array}$} & \multirow[t]{2}{*}{ Weight } & \multirow{2}{*}{$\begin{array}{c}\text { Mean Difference } \\
\text { Fixed, } 95 \% \mathrm{Cl} \\
\end{array}$} \\
\hline & $\mathbf{N}$ & Mean(SD) & $\mathbf{N}$ & Mean(SD) & & & \\
\hline \multicolumn{8}{|c|}{ 2.15.1 Olanzapine v divalproex } \\
\hline HGHQ Trial 2002 & 122 & $-0.2(0.9)$ & 119 & $-0.3(1)$ & & $100 \%$ & $0.02[-0.23,0.27]$ \\
\hline Subtotal $\star \star \star *$ & 122 & & 119 & & 1 & $100 \%$ & $0.02[-0.23,0.27]$ \\
\hline \multicolumn{8}{|c|}{ Heterogeneity: Not applicable } \\
\hline \multicolumn{8}{|c|}{ Test for overall effect: $Z=0.16(P=0.87)$} \\
\hline 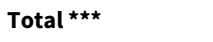 & 122 & & 119 & & 1 & $100 \%$ & $0.02[-0.23,0.27]$ \\
\hline \multicolumn{8}{|c|}{ Heterogeneity: Not applicable } \\
\hline Test for overall effec & & & & & & & \\
\hline
\end{tabular}

Analysis 2.16. Comparison 2 Olanzapine v mood stabiliser, Outcome 16 AIMS.

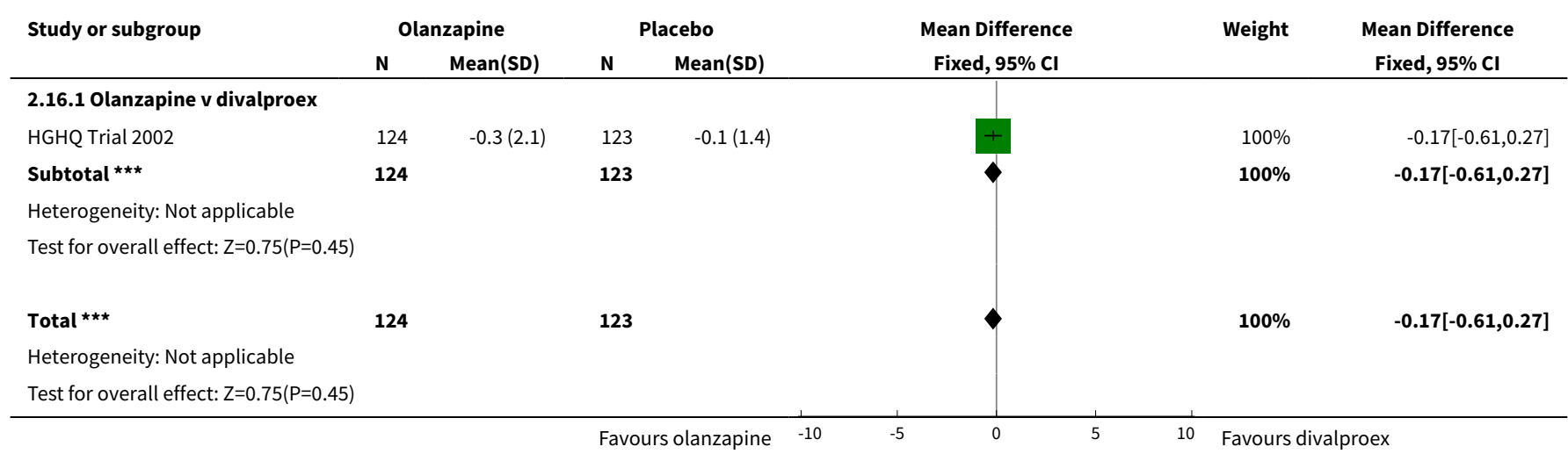

Analysis 2.17. Comparison 2 Olanzapine v mood stabiliser, Outcome 17 Weight change (continuous data).

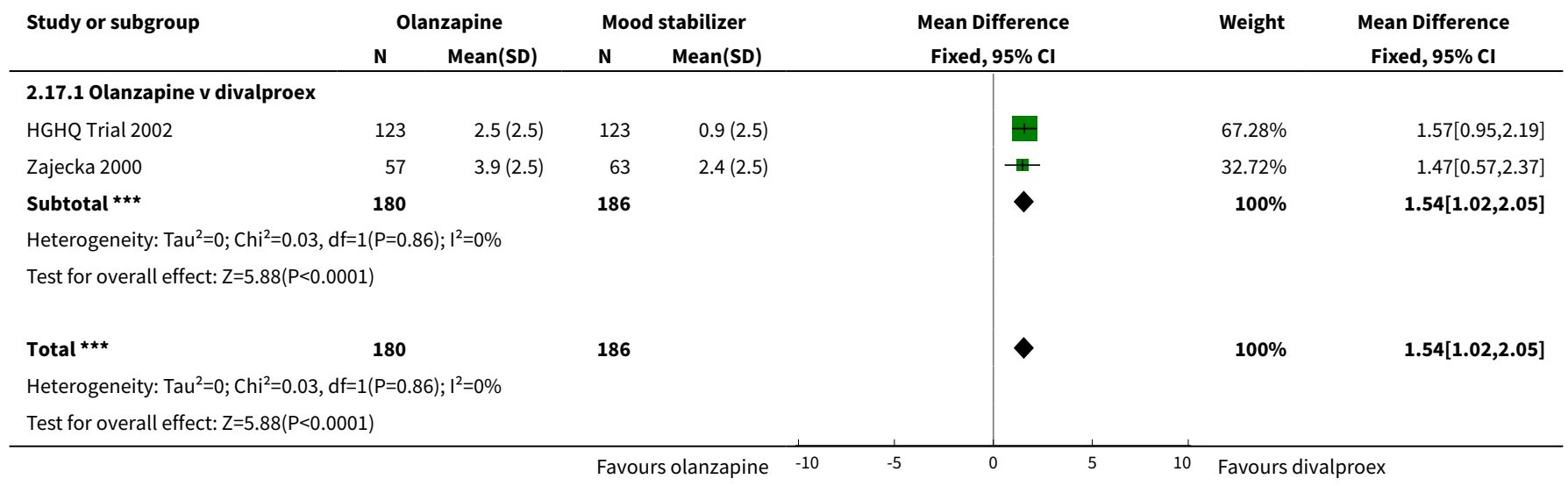


Analysis 2.18. Comparison 2 Olanzapine v mood stabiliser, Outcome 18 Raised ALT/SGPT.

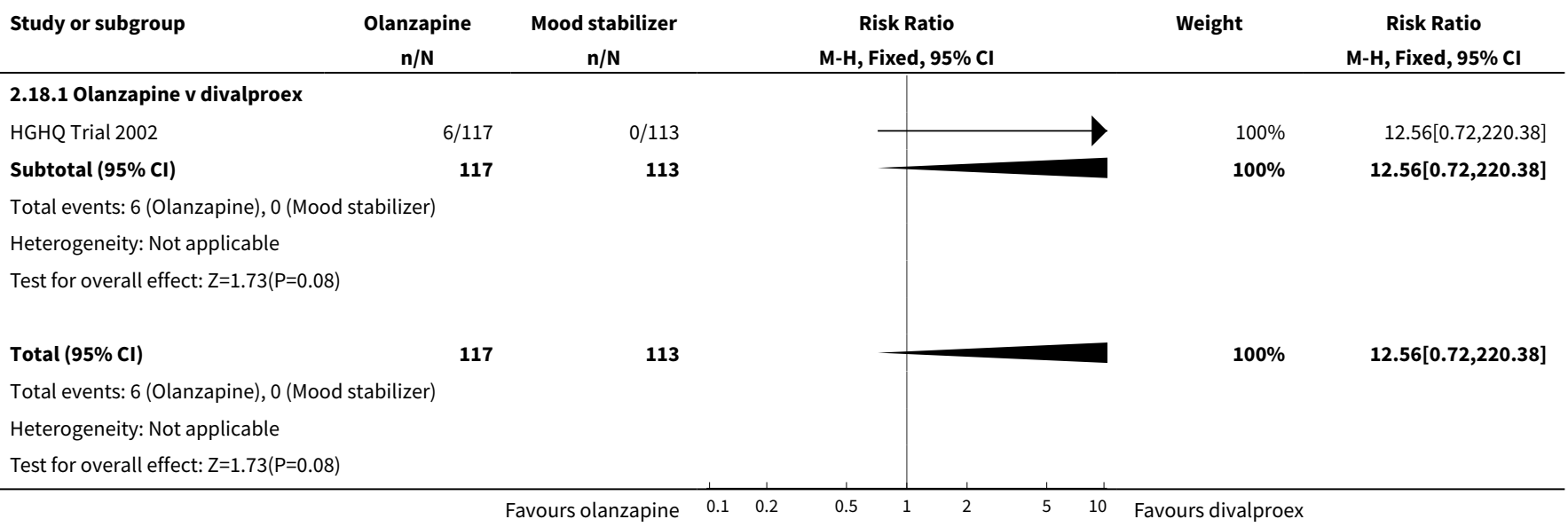

Analysis 2.19. Comparison 2 Olanzapine v mood stabiliser, Outcome 19 Lowered platelet count.

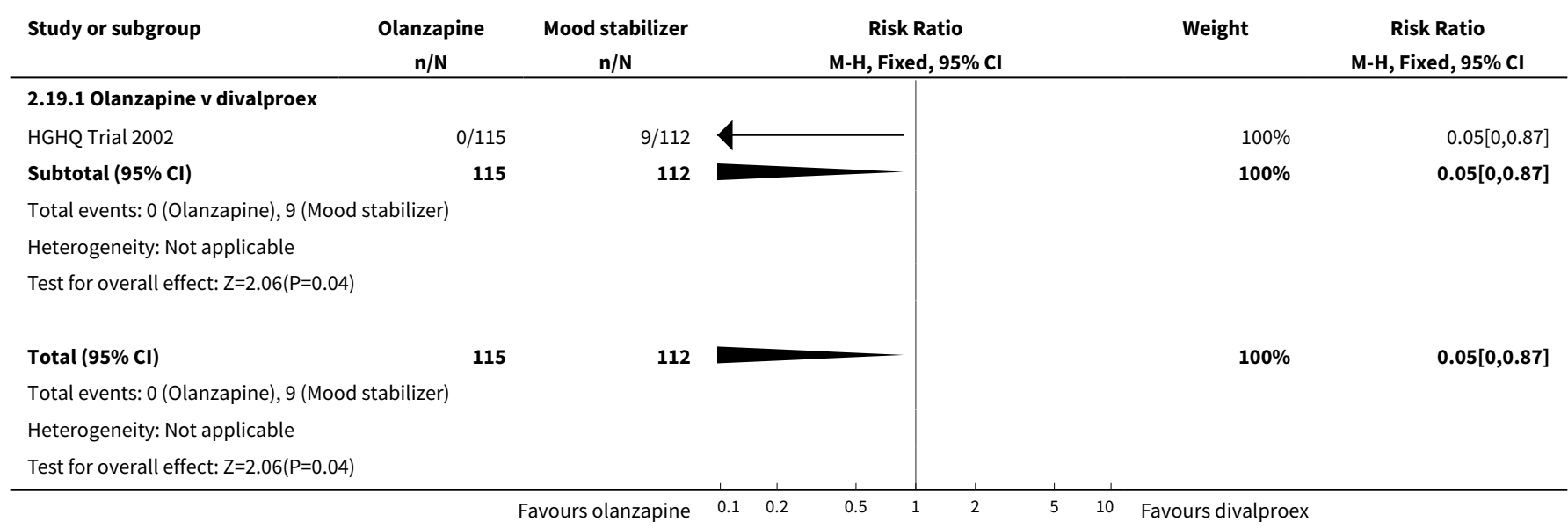

Analysis 2.20. Comparison 2 Olanzapine v mood stabiliser, Outcome 20 Oedema.

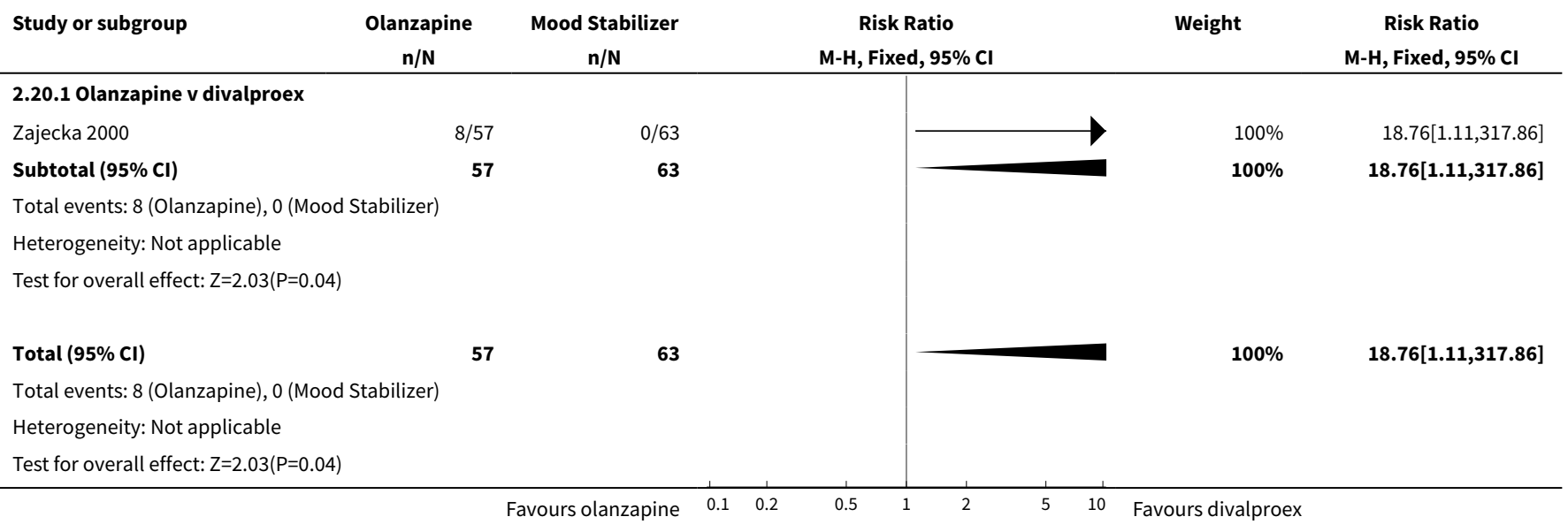


Analysis 2.21. Comparison 2 Olanzapine $v$ mood stabiliser, Outcome 21 Rhinitis.

\begin{tabular}{|c|c|c|c|c|c|}
\hline Study or subgroup & $\begin{array}{c}\text { Olanzapine } \\
n / N\end{array}$ & $\begin{array}{c}\text { Mood Stabilizer } \\
\mathrm{n} / \mathrm{N} \\
\end{array}$ & $\begin{array}{c}\text { Risk Ratio } \\
\text { M-H, Fixed, } 95 \% \mathrm{Cl} \\
\end{array}$ & Weight & $\begin{array}{c}\text { Risk Ratio } \\
\text { M-H, Fixed, } 95 \% \mathrm{Cl} \\
\end{array}$ \\
\hline \multicolumn{6}{|c|}{ 2.21.1 Olanzapine v divalproex } \\
\hline Zajecka 2000 & $8 / 57$ & $2 / 63$ & & $100 \%$ & $4.42[0.98,19.96]$ \\
\hline Subtotal $(95 \% \mathrm{Cl})$ & 57 & 63 & & $100 \%$ & $4.42[0.98,19.96]$ \\
\hline \multicolumn{6}{|c|}{ Total events: 8 (Olanzapine), 2 (Mood Stabilizer) } \\
\hline \multicolumn{6}{|c|}{ Heterogeneity: Not applicable } \\
\hline \multicolumn{6}{|c|}{ Test for overall effect: $Z=1.93(P=0.05)$} \\
\hline Total $(95 \% \mathrm{Cl})$ & 57 & 63 & & $100 \%$ & $4.42[0.98,19.96]$ \\
\hline \multicolumn{6}{|c|}{ Total events: 8 (Olanzapine), 2 (Mood Stabilizer) } \\
\hline \multicolumn{6}{|c|}{ Heterogeneity: Not applicable } \\
\hline Test for overall effec & & & & & \\
\hline
\end{tabular}

Analysis 2.22. Comparison 2 Olanzapine v mood stabiliser, Outcome 22 Headache.

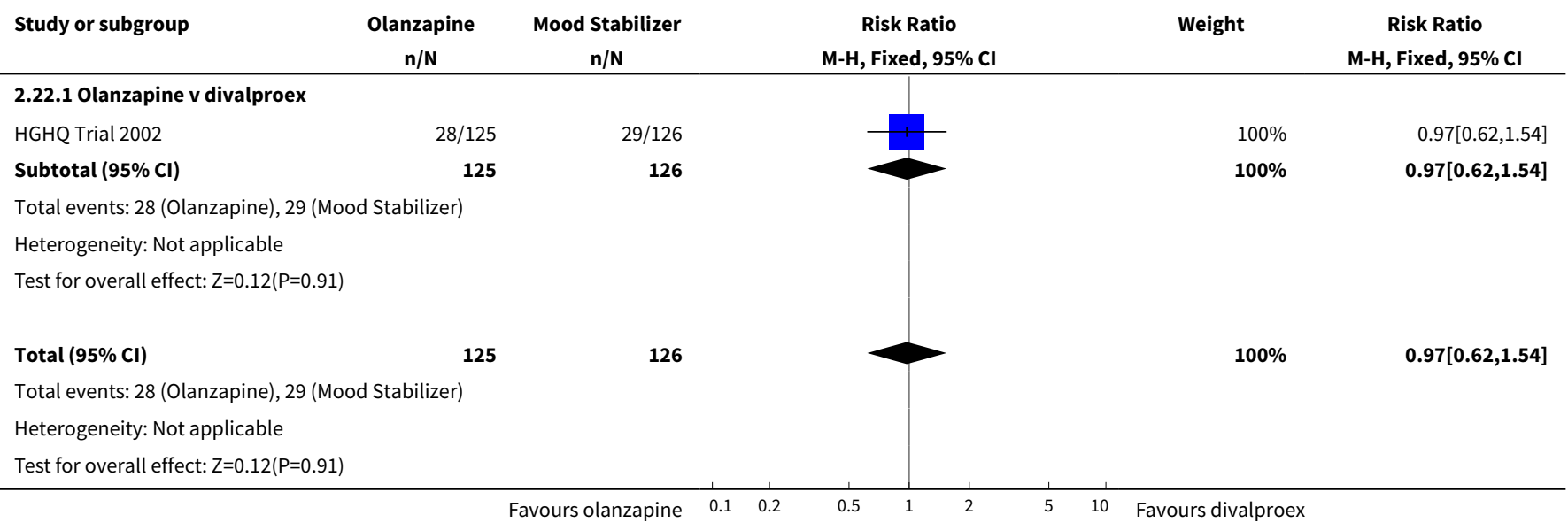

Analysis 2.23. Comparison 2 Olanzapine v mood stabiliser, Outcome 23 Asthenia.

\begin{tabular}{|c|c|c|c|c|c|}
\hline Study or subgroup & $\begin{array}{c}\text { Olanzapine } \\
n / N\end{array}$ & $\begin{array}{c}\text { Mood Stabilizer } \\
\mathrm{n} / \mathrm{N} \\
\end{array}$ & $\begin{array}{c}\text { Risk Ratio } \\
\text { M-H, Fixed, } 95 \% \mathrm{Cl}\end{array}$ & Weight & $\begin{array}{c}\text { Risk Ratio } \\
\text { M-H, Fixed, } 95 \% \mathrm{Cl}\end{array}$ \\
\hline \multicolumn{6}{|c|}{ 2.23.1 Olanzapine v divalproex } \\
\hline HGHQ Trial 2002 & $20 / 125$ & $17 / 126$ & +1 & $100 \%$ & $1.19[0.65,2.16]$ \\
\hline Subtotal $(95 \% \mathrm{Cl})$ & 125 & 126 & & $100 \%$ & $1.19[0.65,2.16]$ \\
\hline \multicolumn{6}{|c|}{ Total events: 20 (Olanzapine), 17 (Mood Stabilizer) } \\
\hline \multicolumn{6}{|c|}{ Heterogeneity: Not applicable } \\
\hline \multicolumn{6}{|c|}{ Test for overall effect: $\mathrm{Z}=0.56(\mathrm{P}=0.58)$} \\
\hline Total $(95 \% \mathrm{Cl})$ & 125 & 126 & & $100 \%$ & $1.19[0.65,2.16]$ \\
\hline Total events: 20 (Ola & d Stabilizer) & & & & \\
\hline
\end{tabular}




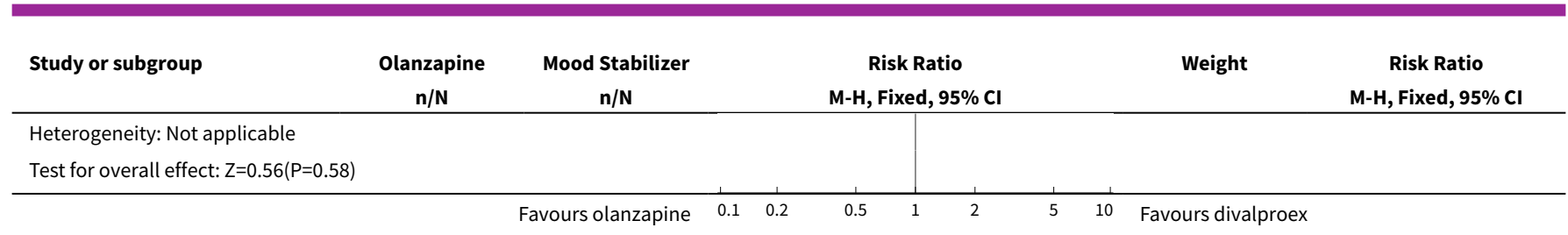

Analysis 2.24. Comparison 2 Olanzapine v mood stabiliser, Outcome 24 Dizziness.

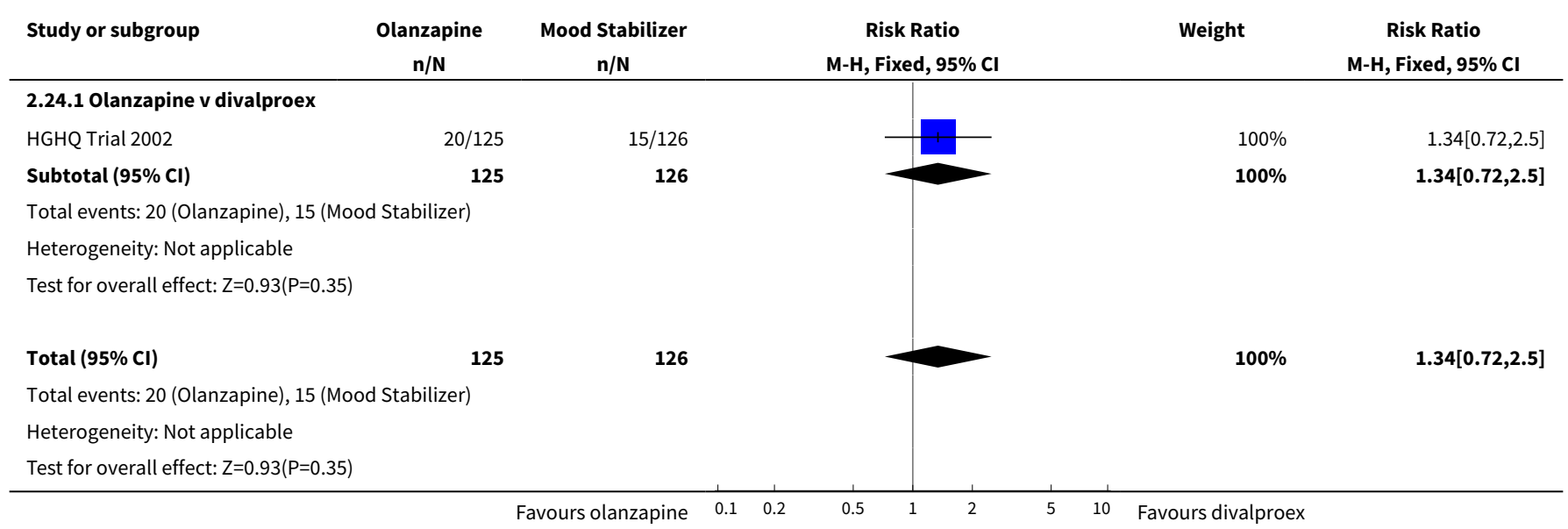

Analysis 2.25. Comparison 2 Olanzapine v mood stabiliser, Outcome 25 Constipation.

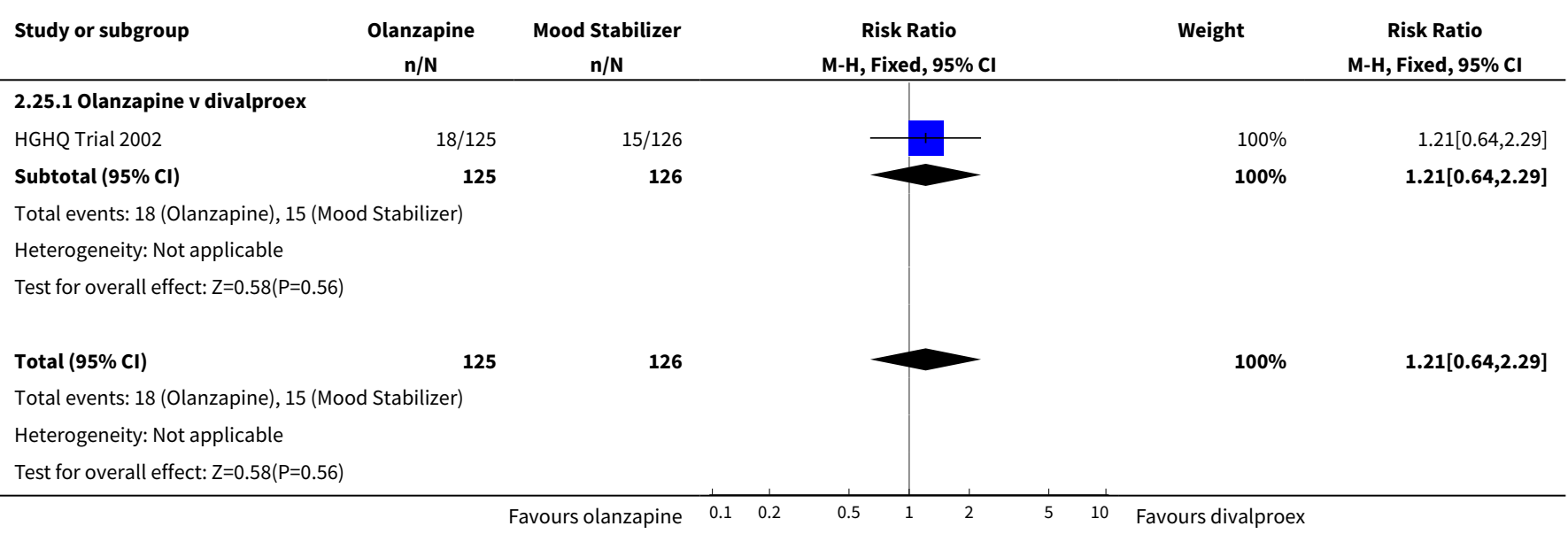

Analysis 2.26. Comparison 2 Olanzapine v mood stabiliser, Outcome 26 Dyspepsia.

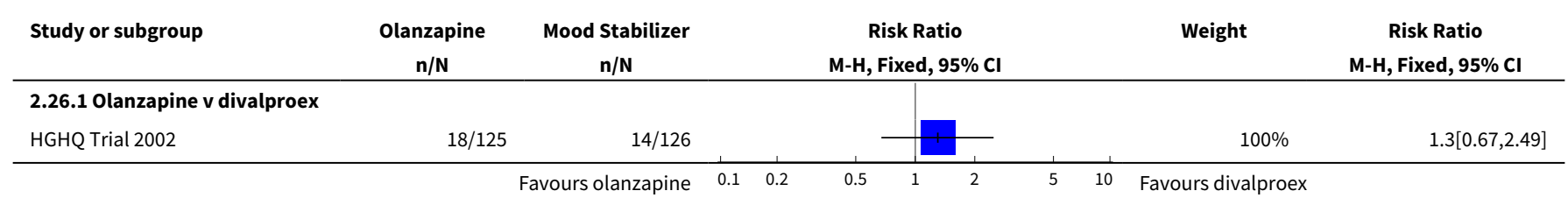




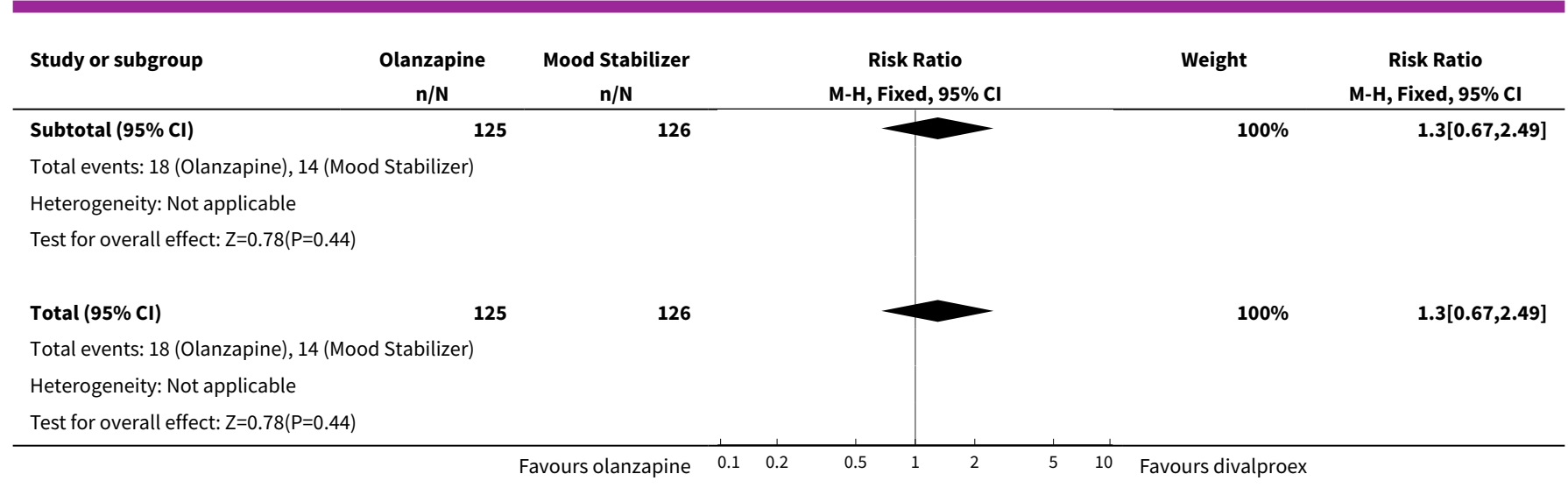

Analysis 2.27. Comparison 2 Olanzapine v mood stabiliser, Outcome 27 Pain.

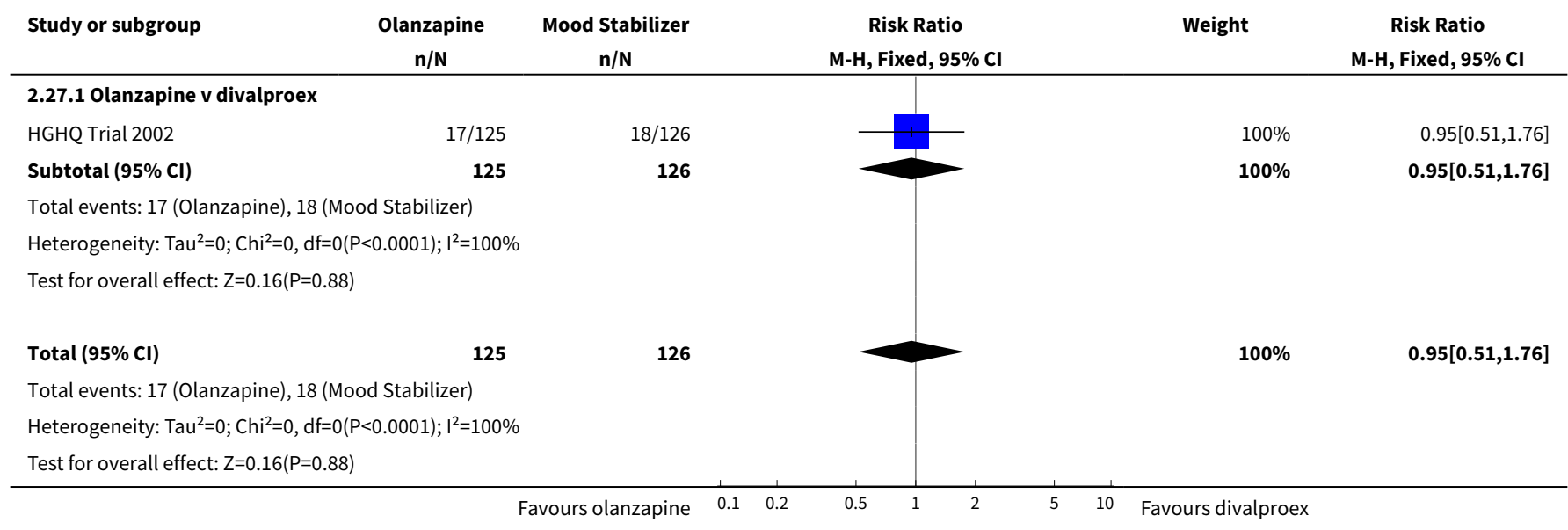

Analysis 2.28. Comparison 2 Olanzapine v mood stabiliser, Outcome 28 Weight Gain (dichotomous data).

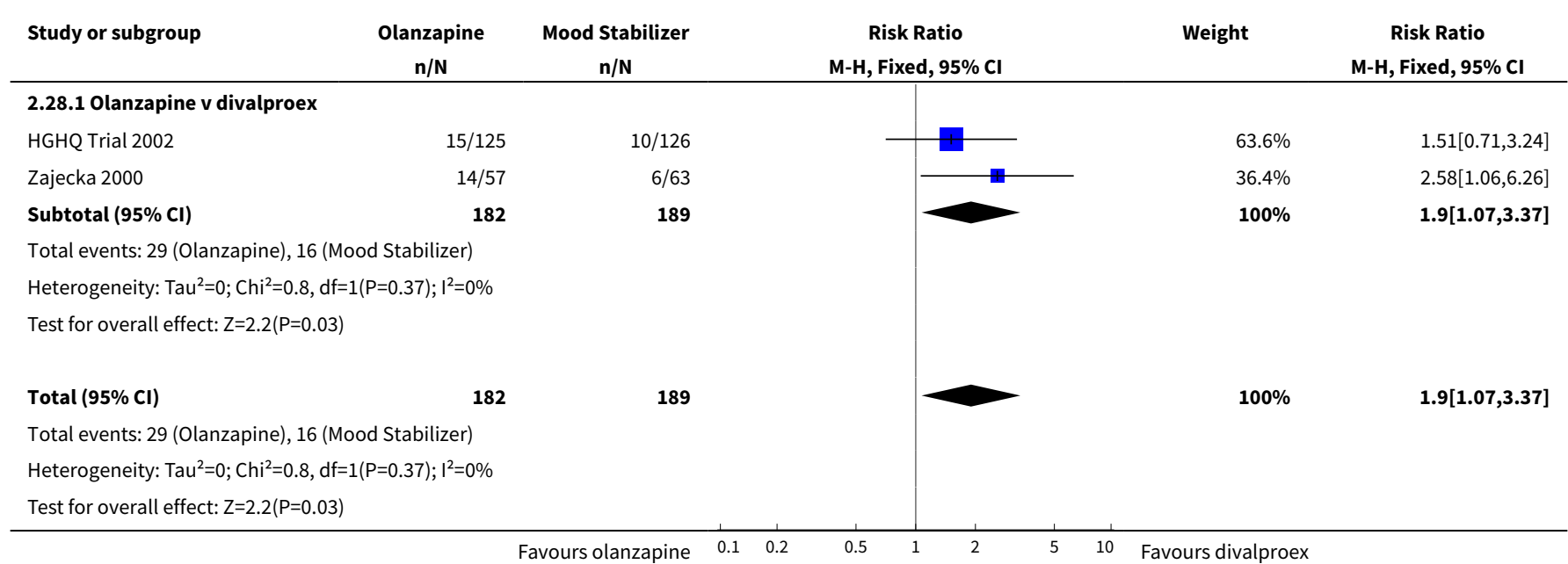


Analysis 2.29. Comparison 2 Olanzapine v mood stabiliser, Outcome 29 Agitation.

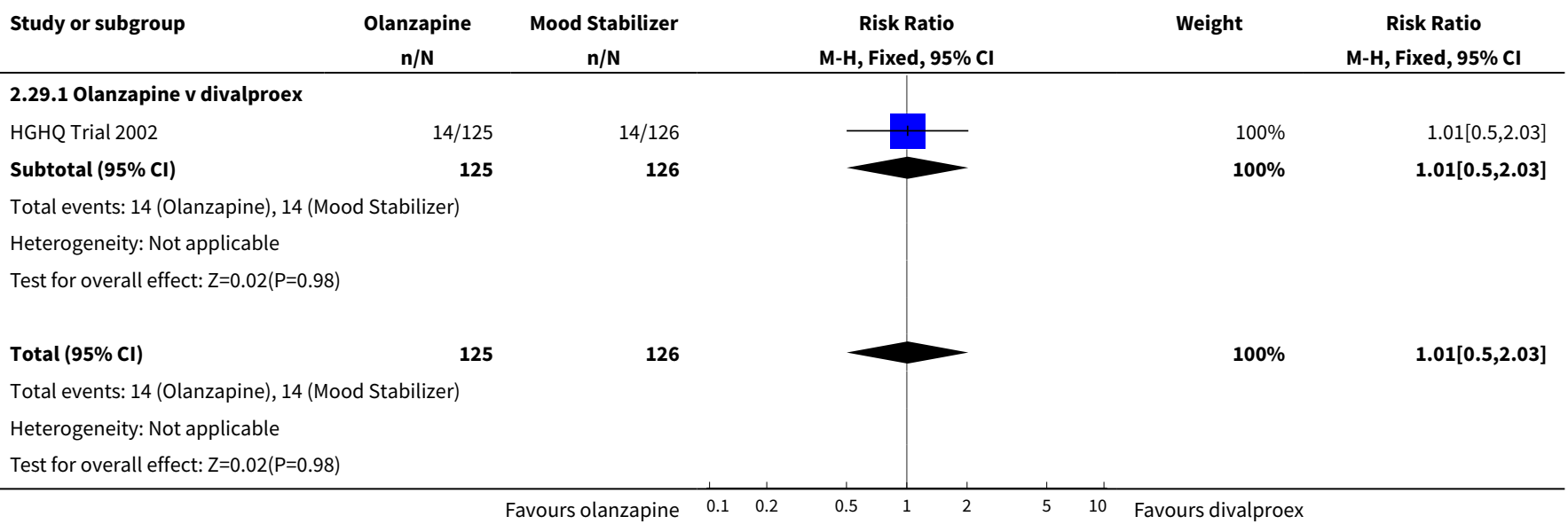

\section{Analysis 2.30. Comparison 2 Olanzapine v mood stabiliser, Outcome 30 Nervouseness.}

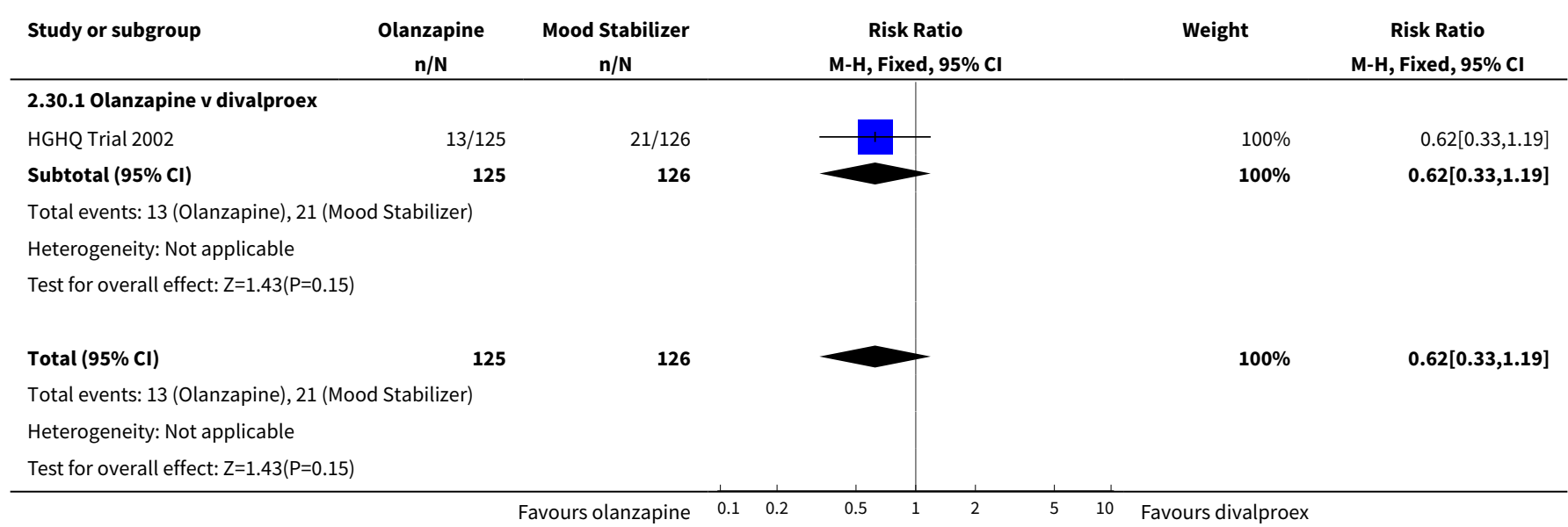

Analysis 2.31. Comparison 2 Olanzapine v mood stabiliser, Outcome 31 Tremor.

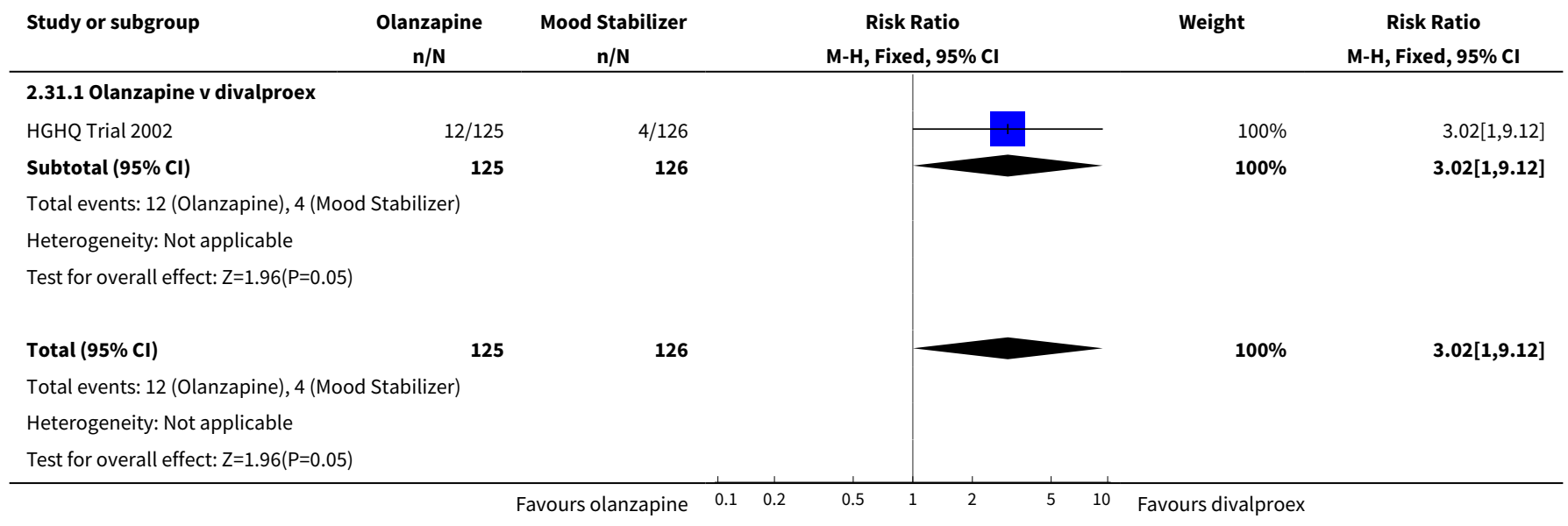


Analysis 2.32. Comparison 2 Olanzapine v mood stabiliser, Outcome 32 Vomiting.

\begin{tabular}{|c|c|c|c|c|c|}
\hline Study or subgroup & $\begin{array}{c}\text { Olanzapine } \\
n / N\end{array}$ & $\begin{array}{c}\text { Mood Stabilizer } \\
\mathrm{n} / \mathrm{N} \\
\end{array}$ & $\begin{array}{c}\text { Risk Ratio } \\
\text { M-H, Fixed, } 95 \% \mathrm{Cl} \\
\end{array}$ & Weight & $\begin{array}{c}\text { Risk Ratio } \\
\text { M-H, Fixed, } 95 \% \mathrm{Cl} \\
\end{array}$ \\
\hline \multicolumn{6}{|c|}{ 2.32.1 Olanzapine v divalproex } \\
\hline HGHQ Trial 2002 & $10 / 125$ & $18 / 126$ & & $100 \%$ & $0.56[0.27,1.16]$ \\
\hline Subtotal $(95 \% \mathrm{Cl})$ & 125 & 126 & & $100 \%$ & $0.56[0.27,1.16]$ \\
\hline \multicolumn{6}{|c|}{ Total events: 10 (Olanzapine), 18 (Mood Stabilizer) } \\
\hline \multicolumn{6}{|c|}{ Heterogeneity: Not applicable } \\
\hline \multicolumn{6}{|c|}{ Test for overall effect: $Z=1.55(P=0.12)$} \\
\hline Total $(95 \% \mathrm{Cl})$ & 125 & 126 & & $100 \%$ & $0.56[0.27,1.16]$ \\
\hline \multicolumn{6}{|c|}{ Total events: 10 (Olanzapine), 18 (Mood Stabilizer) } \\
\hline \multicolumn{6}{|c|}{ Heterogeneity: Not applicable } \\
\hline Test for overall effec & & & & & \\
\hline
\end{tabular}

Analysis 2.33. Comparison 2 Olanzapine v mood stabiliser, Outcome 33 Speech Disorder.

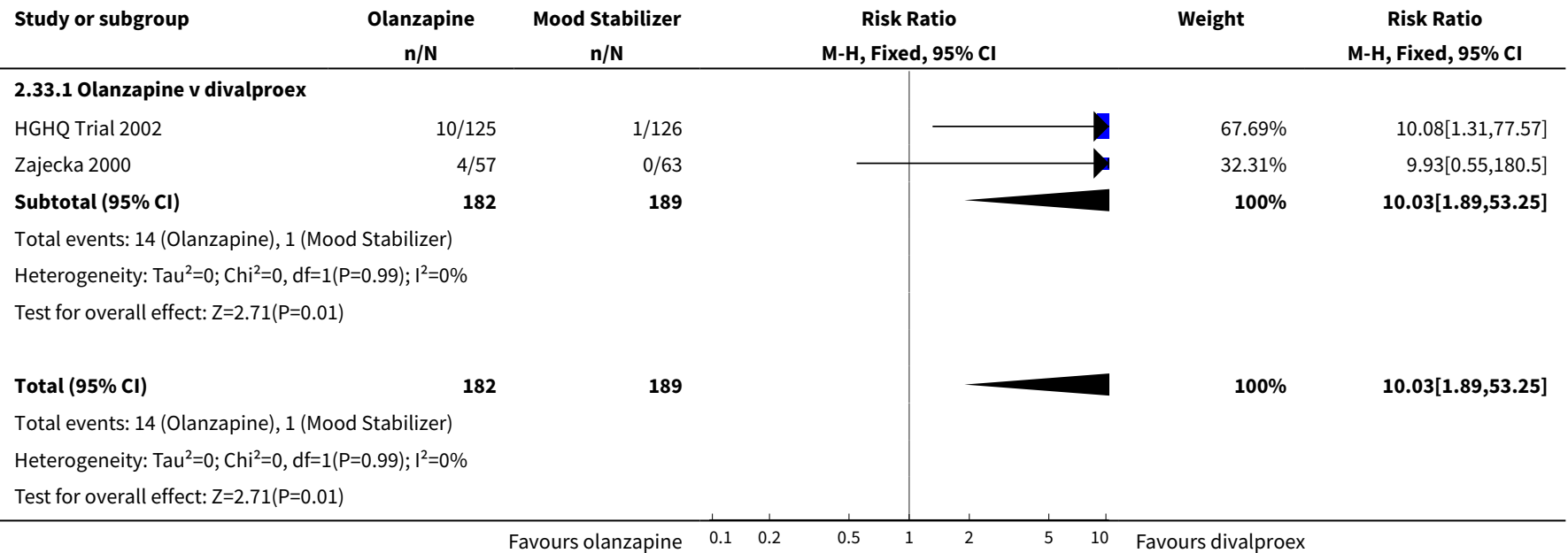

\section{Analysis 2.34. Comparison 2 Olanzapine v mood stabiliser, Outcome 34 Neck Rigidity.}

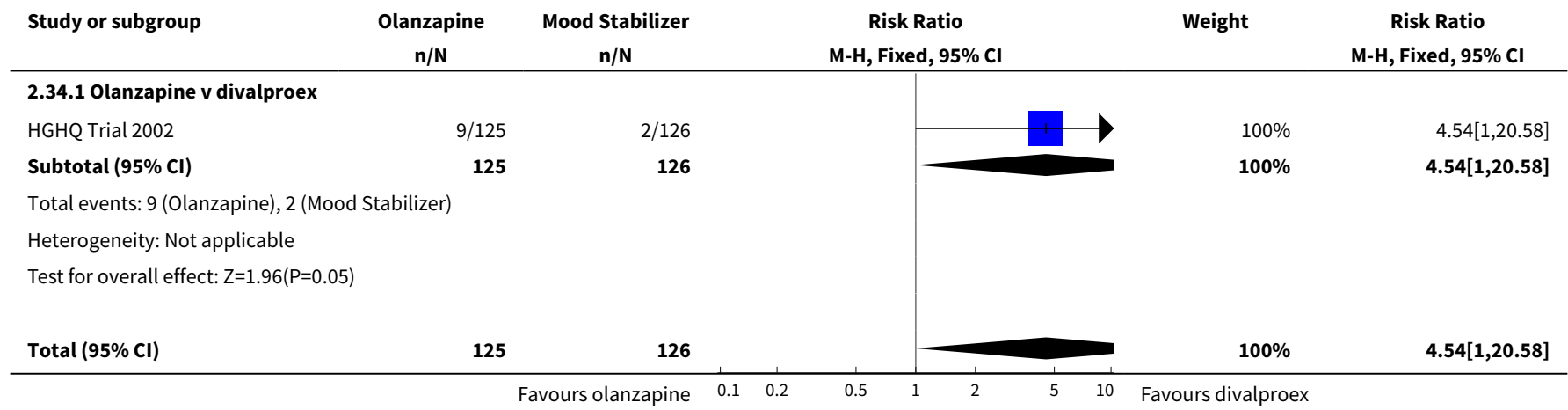




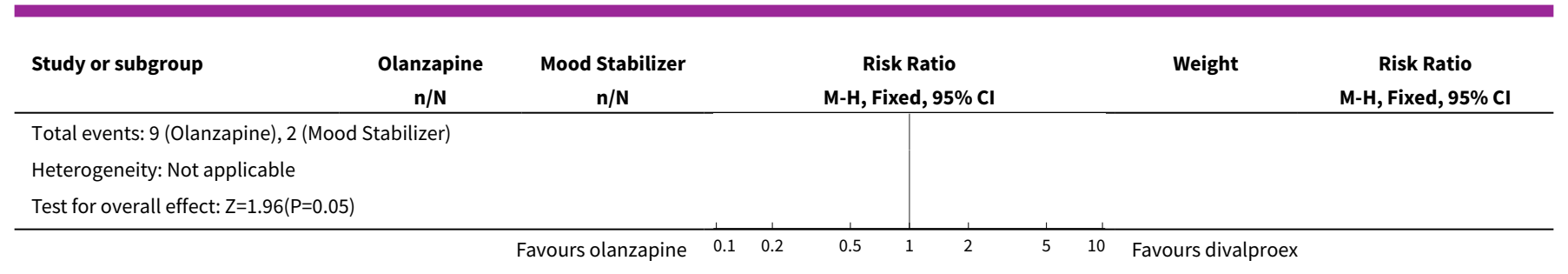

\section{Analysis 2.35. Comparison 2 Olanzapine v mood stabiliser, Outcome 35 Diarrhoea.}

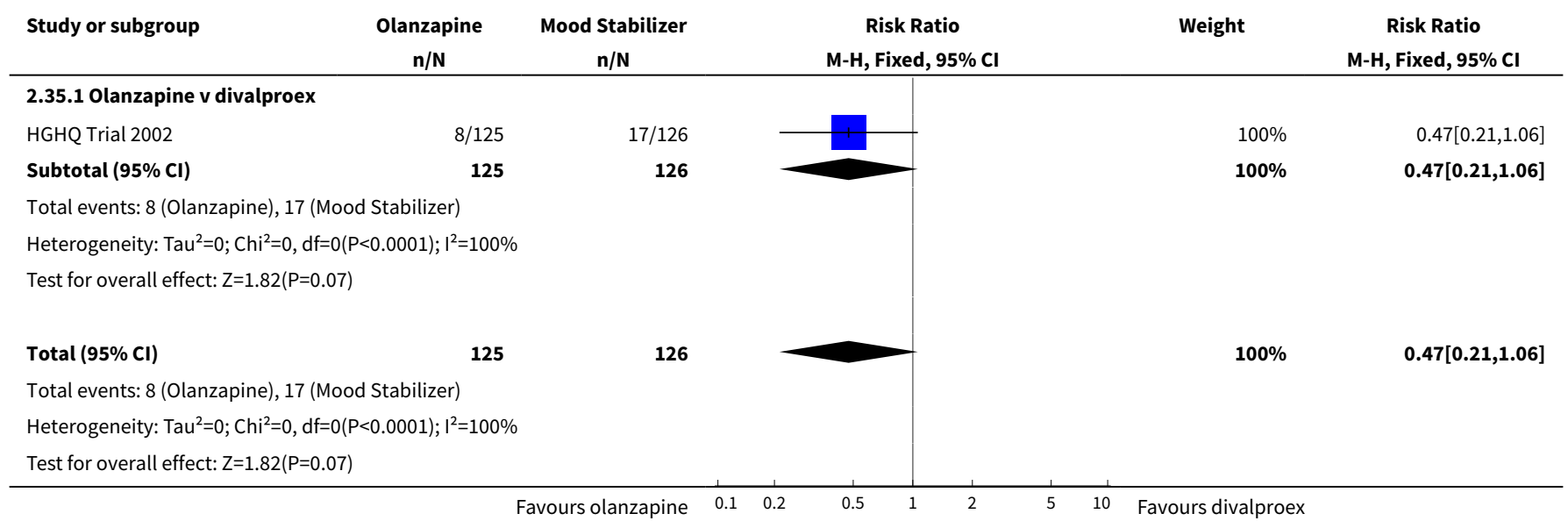

Analysis 2.36. Comparison 2 Olanzapine v mood stabiliser, Outcome 36 Sleep disorder.

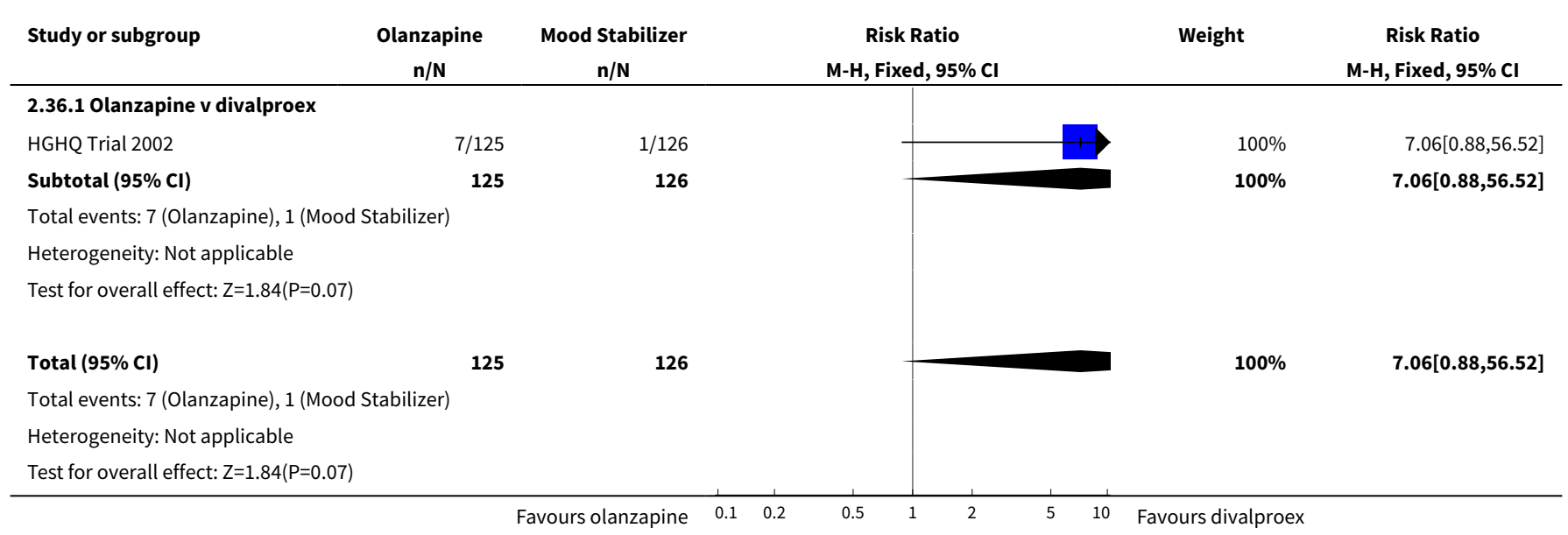

Analysis 2.37. Comparison 2 Olanzapine v mood stabiliser, Outcome 37 Tongue Oedema.

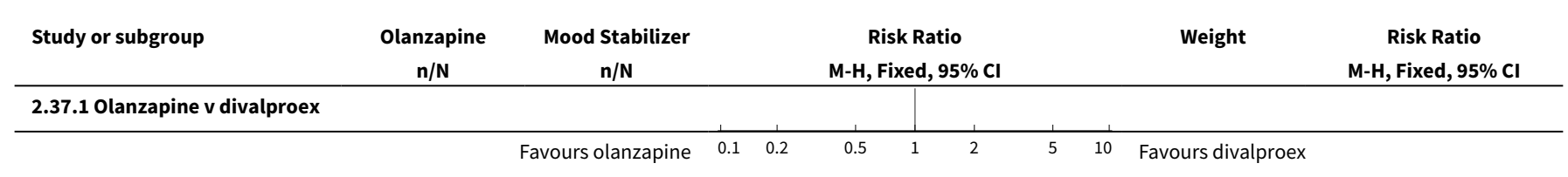




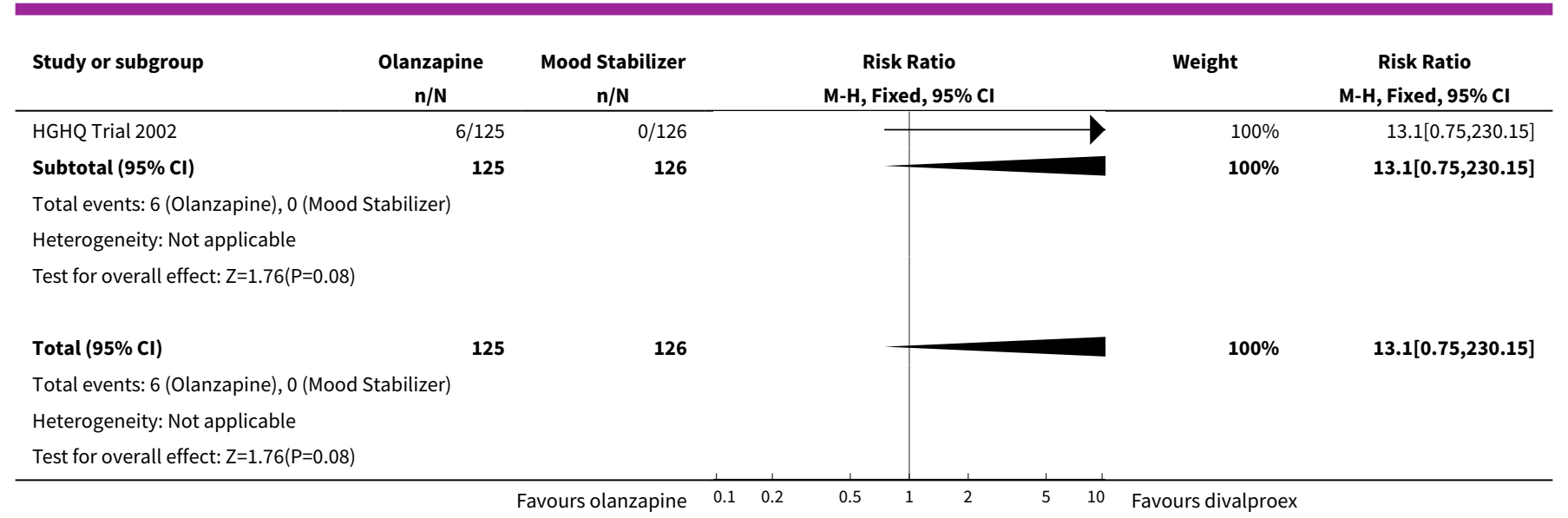

\section{Comparison 3. Olanzapine v other antipsychotic}

\begin{tabular}{|c|c|c|c|c|}
\hline Outcome or subgroup title & No. of studies & $\begin{array}{l}\text { No. of partici- } \\
\text { pants }\end{array}$ & Statistical method & Effect size \\
\hline $\begin{array}{l}1 \text { Failure to respond - (at least } \\
50 \% \text { reduction in YMRS) }\end{array}$ & 1 & 453 & Risk Ratio (M-H, Fixed, 95\% Cl) & $1.03[0.77,1.38]$ \\
\hline 1.1 Olanzapine v. haloperidol & 1 & 453 & Risk Ratio (M-H, Fixed, 95\% Cl) & $1.03[0.77,1.38]$ \\
\hline $\begin{array}{l}2 \text { Failure to achieve remission - } \\
\text { YMRS }<=12 \text { and HAMD- } 21<=8\end{array}$ & 1 & 453 & Risk Ratio (M-H, Fixed, 95\% Cl) & $0.89[0.74,1.06]$ \\
\hline 2.1 Olanzapine v. haloperidol & 1 & 453 & Risk Ratio (M-H, Fixed, 95\% Cl) & $0.89[0.74,1.06]$ \\
\hline $\begin{array}{l}3 \text { Failure to respond - excluding } \\
\text { withdrawals (at least } 50 \% \text { reduc- } \\
\text { tion in YMRS) }\end{array}$ & 1 & 444 & Risk Ratio (M-H, Fixed, 95\% Cl) & $1.07[0.79,1.46]$ \\
\hline 3.1 Olanzapine v. haloperidol & 1 & 444 & Risk Ratio (M-H, Fixed, 95\% Cl) & $1.07[0.79,1.46]$ \\
\hline $\begin{array}{l}4 \text { Failure to complete treatment } \\
\text { (acute phase) }\end{array}$ & 1 & 453 & Risk Ratio (M-H, Fixed, 95\% Cl) & $0.82[0.62,1.07]$ \\
\hline 4.1 Olanzapine v. haloperidol & 1 & 453 & Risk Ratio (M-H, Fixed, 95\% Cl) & $0.82[0.62,1.07]$ \\
\hline $\begin{array}{l}5 \text { Treatment emergent depres- } \\
\text { sion }\end{array}$ & 1 & 259 & Risk Ratio (M-H, Fixed, 95\% Cl) & $0.38[0.16,0.95]$ \\
\hline 5.1 Olanzapine v. haloperidol & 1 & 259 & Risk Ratio (M-H, Fixed, 95\% Cl) & $0.38[0.16,0.95]$ \\
\hline 6 Insomnia & 1 & 453 & Risk Ratio (M-H, Fixed, 95\% Cl) & $0.78[0.47,1.28]$ \\
\hline 6.1 Olanzapine v. haloperidol & 1 & 453 & Risk Ratio (M-H, Fixed, 95\% Cl) & $0.78[0.47,1.28]$ \\
\hline 7 Somnolence & 1 & 453 & Risk Ratio (M-H, Fixed, 95\% Cl) & $1.50[0.81,2.78]$ \\
\hline 7.1 Olanzapine v. haloperidol & 1 & 453 & Risk Ratio (M-H, Fixed, 95\% Cl) & $1.50[0.81,2.78]$ \\
\hline
\end{tabular}




\begin{tabular}{|c|c|c|c|c|}
\hline Outcome or subgroup title & No. of studies & $\begin{array}{l}\text { No. of partici- } \\
\text { pants }\end{array}$ & Statistical method & Effect size \\
\hline $\begin{array}{l}8 \text { Weight Gain (dichotomous da- } \\
\text { ta) }\end{array}$ & 1 & 453 & Risk Ratio (M-H, Fixed, 95\% Cl) & $3.59[1.49,8.64]$ \\
\hline 8.1 Olanzapine v. haloperidol & 1 & 453 & Risk Ratio (M-H, Fixed, 95\% Cl) & $3.59[1.49,8.64]$ \\
\hline 9 Akathisia & 1 & 453 & Risk Ratio (M-H, Fixed, 95\% Cl) & $0.21[0.12,0.38]$ \\
\hline 9.1 Olanzapine v. haloperidol & 1 & 453 & Risk Ratio (M-H, Fixed, 95\% Cl) & $0.21[0.12,0.38]$ \\
\hline 10 Tremor & 1 & 453 & Risk Ratio (M-H, Fixed, 95\% Cl) & $0.33[0.17,0.64]$ \\
\hline 10.1 Olanzapine v. haloperidol & 1 & 453 & Risk Ratio (M-H, Fixed, 95\% Cl) & $0.33[0.17,0.64]$ \\
\hline 11 Infection & 1 & 453 & Risk Ratio (M-H, Fixed, 95\% Cl) & $9.36[1.21,72.51]$ \\
\hline 11.1 Olanzapine v. haloperidol & 1 & 453 & Risk Ratio (M-H, Fixed, 95\% Cl) & $9.36[1.21,72.51]$ \\
\hline 12 Hypertonia & 1 & 453 & Risk Ratio (M-H, Fixed, 95\% Cl) & $0.22[0.11,0.45]$ \\
\hline 12.1 Olanzapine v. haloperidol & 1 & 453 & Risk Ratio (M-H, Fixed, 95\% Cl) & $0.22[0.11,0.45]$ \\
\hline 13 Fever & 1 & 453 & Risk Ratio (M-H, Fixed, 95\% Cl) & $15.91[0.92,274.10]$ \\
\hline 13.1 Olanzapine v. haloperidol & 1 & 453 & Risk Ratio (M-H, Fixed, 95\% Cl) & $15.91[0.92,274.10]$ \\
\hline 14 EPS & 1 & 453 & Risk Ratio (M-H, Fixed, 95\% Cl) & $0.10[0.04,0.24]$ \\
\hline 14.1 Olanzapine v. haloperidol & 1 & 453 & Risk Ratio (M-H, Fixed, 95\% Cl) & $0.10[0.04,0.24]$ \\
\hline 15 Dystonia & 1 & 453 & Risk Ratio (M-H, Fixed, 95\% Cl) & $0.20[0.06,0.69]$ \\
\hline 15.1 Olanzapine v. haloperidol & 1 & 453 & Risk Ratio (M-H, Fixed, 95\% Cl) & $0.20[0.06,0.69]$ \\
\hline 16 Hypokinesia & 1 & 453 & Risk Ratio (M-H, Fixed, 95\% Cl) & $0.12[0.01,0.93]$ \\
\hline 16.1 Olanzapine v. haloperidol & 1 & 453 & Risk Ratio (M-H, Fixed, 95\% Cl) & $0.12[0.01,0.93]$ \\
\hline 17 Increased Salivation & 1 & 453 & Risk Ratio (M-H, Fixed, 95\% Cl) & $0.06[0.01,0.47]$ \\
\hline 17.1 Olanzapine v. haloperidol & 1 & 453 & Risk Ratio (M-H, Fixed, 95\% Cl) & $0.06[0.01,0.47]$ \\
\hline 18 Dyskinesia & 1 & 453 & Risk Ratio (M-H, Fixed, 95\% Cl) & $0.07[0.00,1.27]$ \\
\hline 18.1 Olanzapine v. haloperidol & 1 & 453 & Risk Ratio (M-H, Fixed, 95\% Cl) & $0.07[0.00,1.27]$ \\
\hline $\begin{array}{l}19 \text { Failure to complete treatment } \\
\text { due to adverse effects }\end{array}$ & 1 & 453 & Risk Ratio (M-H, Fixed, 95\% Cl) & $0.66[0.34,1.26]$ \\
\hline 19.1 Olanzapine v. haloperidol & 1 & 453 & Risk Ratio (M-H, Fixed, 95\% Cl) & $0.66[0.34,1.26]$ \\
\hline $\begin{array}{l}20 \text { Failure to respond - (at least } \\
70 \% \text { reduction in YMRS) }\end{array}$ & 1 & 453 & Risk Ratio (M-H, Fixed, 95\% Cl) & $1.15[0.93,1.43]$ \\
\hline 20.1 Olanzapine v. haloperidol & 1 & 453 & Risk Ratio (M-H, Fixed, 95\% Cl) & $1.15[0.93,1.43]$ \\
\hline
\end{tabular}




\begin{tabular}{|c|c|c|c|c|}
\hline Outcome or subgroup title & No. of studies & $\begin{array}{l}\text { No. of partici- } \\
\text { pants }\end{array}$ & Statistical method & Effect size \\
\hline $\begin{array}{l}21 \text { Failure to respond - excluding } \\
\text { withdrawals (at least } 70 \% \text { reduc- } \\
\text { tion in YMRS) }\end{array}$ & 1 & 444 & Risk Ratio (M-H, Fixed, 95\% Cl) & $1.18[0.95,1.48]$ \\
\hline 21.1 Olanzapine v. haloperidol & 1 & 444 & Risk Ratio (M-H, Fixed, 95\% Cl) & $1.18[0.95,1.48]$ \\
\hline $\begin{array}{l}22 \text { Failure to respond - (at least } \\
80 \% \text { reduction in YMRS) }\end{array}$ & 1 & 453 & Risk Ratio (M-H, Fixed, 95\% Cl) & $1.10[0.92,1.31]$ \\
\hline 22.1 Olanzapine v. haloperidol & 1 & 453 & Risk Ratio (M-H, Fixed, 95\% Cl) & $1.10[0.92,1.31]$ \\
\hline $\begin{array}{l}23 \text { Failure to respond - excluding } \\
\text { withdrawals (at least } 80 \% \text { reduc- } \\
\text { tion in YMRS) }\end{array}$ & 1 & 444 & Risk Ratio (M-H, Fixed, 95\% Cl) & $1.12[0.93,1.34]$ \\
\hline 23.1 Olanzapine v. haloperidol & 1 & 444 & Risk Ratio (M-H, Fixed, 95\% Cl) & $1.12[0.93,1.34]$ \\
\hline
\end{tabular}

Analysis 3.1. Comparison 3 Olanzapine $v$ other antipsychotic, Outcome 1 Failure to respond - (at least 50\% reduction in YMRS).

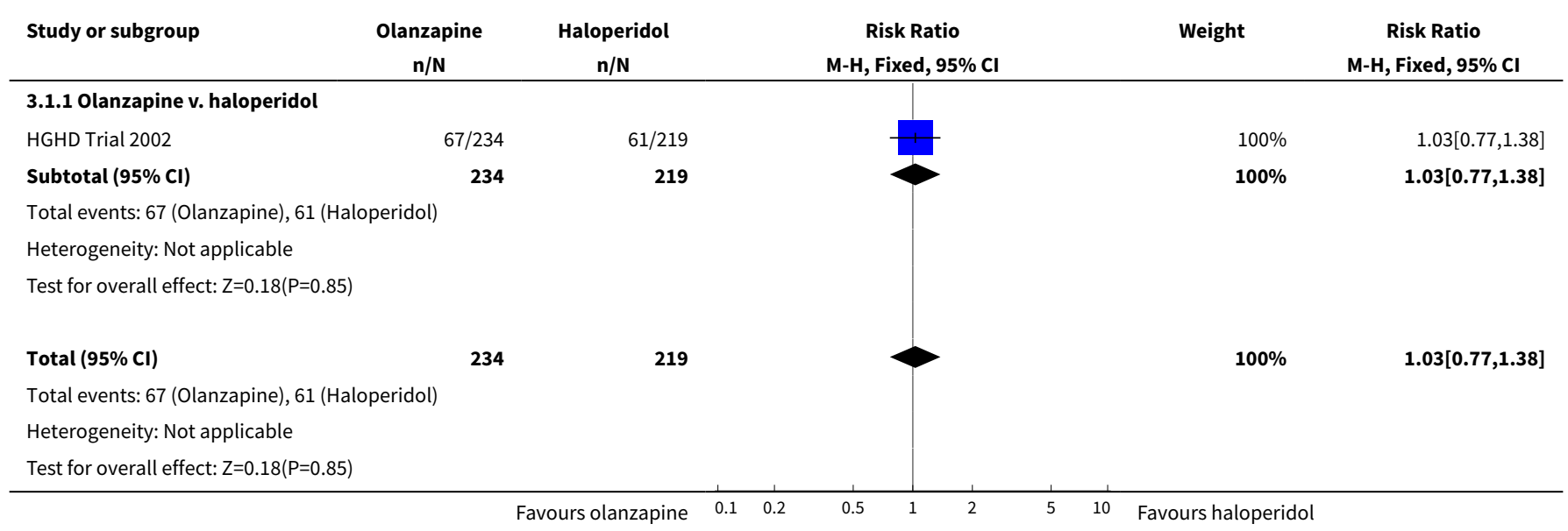

Analysis 3.2. Comparison 3 Olanzapine v other antipsychotic, Outcome 2 Failure to achieve remission - YMRS $<=12$ and HAMD-21 $<=8$.

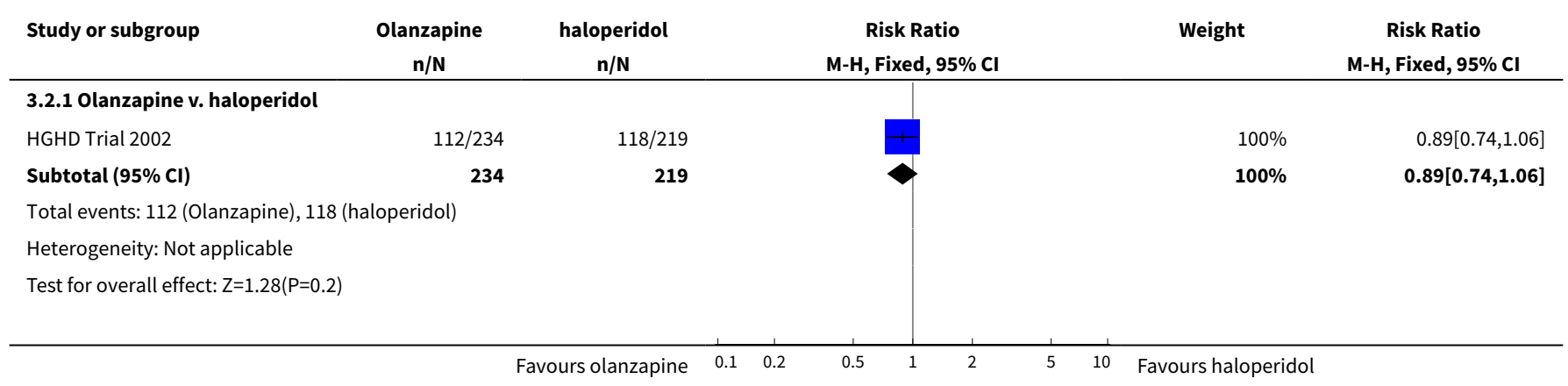




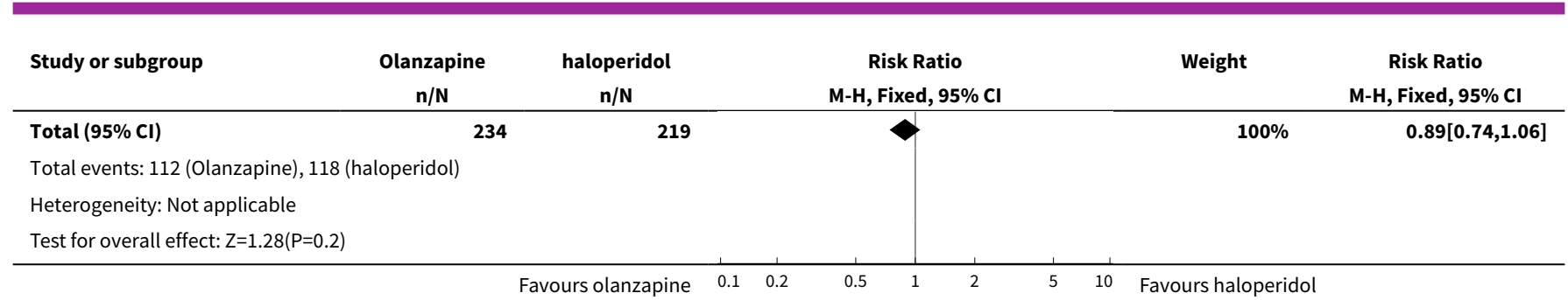

Analysis 3.3. Comparison 3 Olanzapine v other antipsychotic, Outcome 3 Failure to respond - excluding withdrawals (at least $50 \%$ reduction in YMRS).

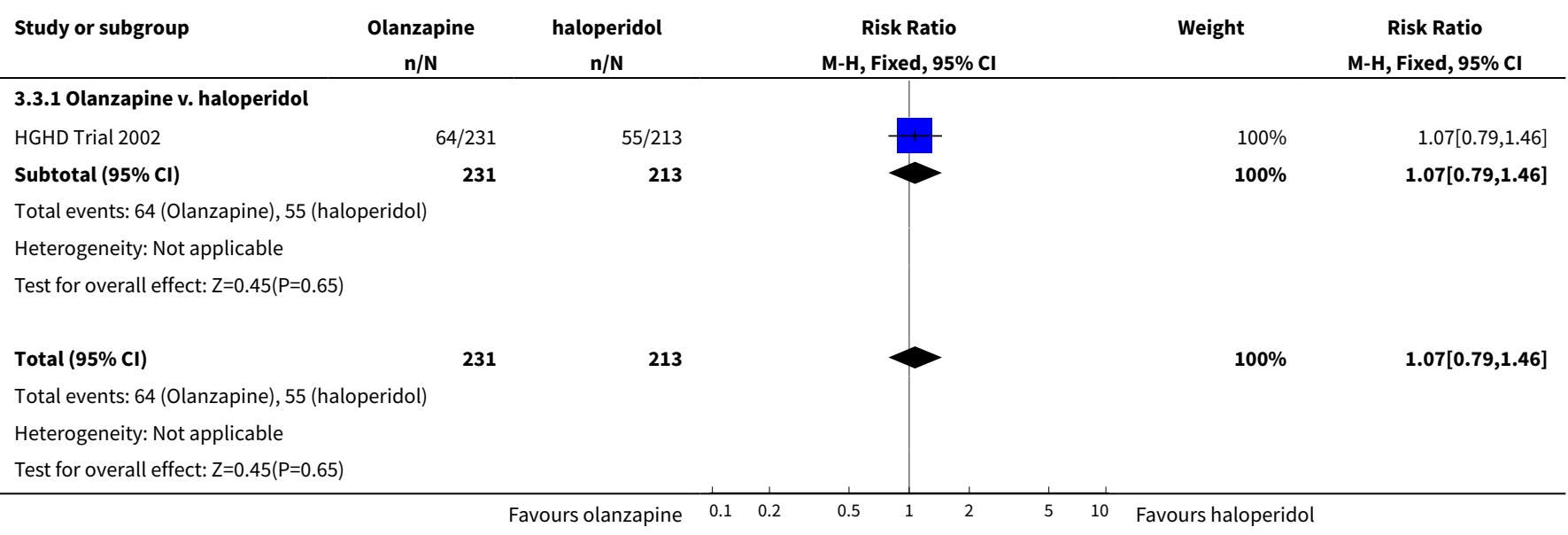

Analysis 3.4. Comparison 3 Olanzapine v other antipsychotic, Outcome 4 Failure to complete treatment (acute phase).

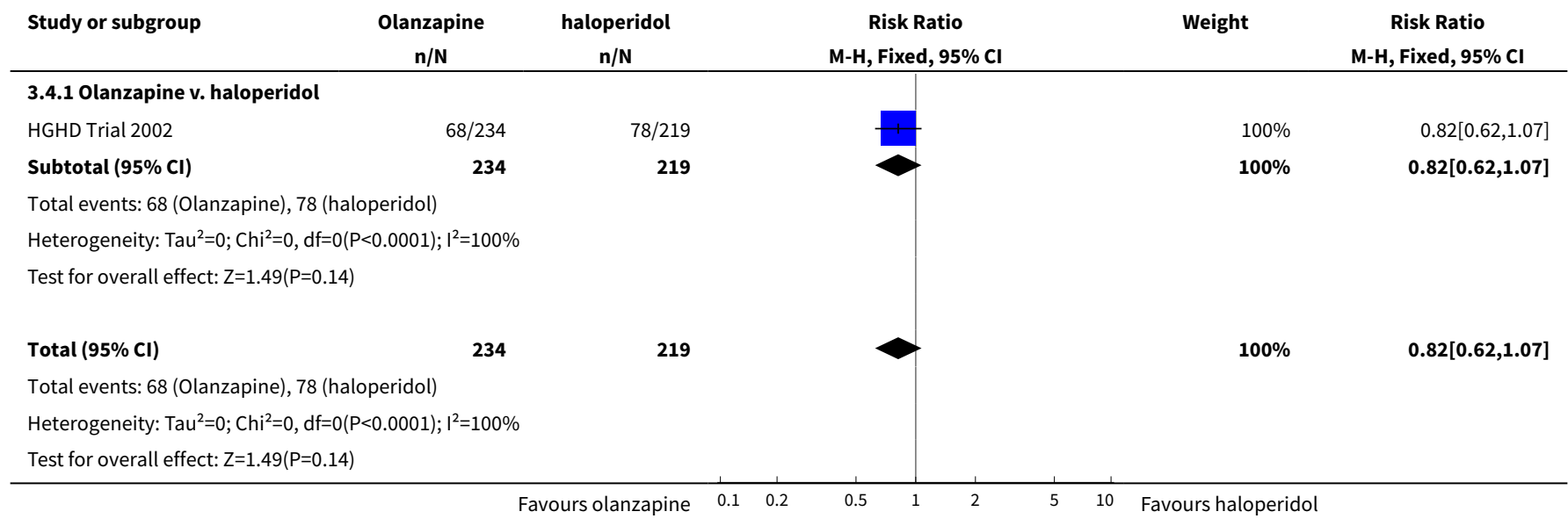


Analysis 3.5. Comparison 3 Olanzapine v other antipsychotic, Outcome 5 Treatment emergent depression.

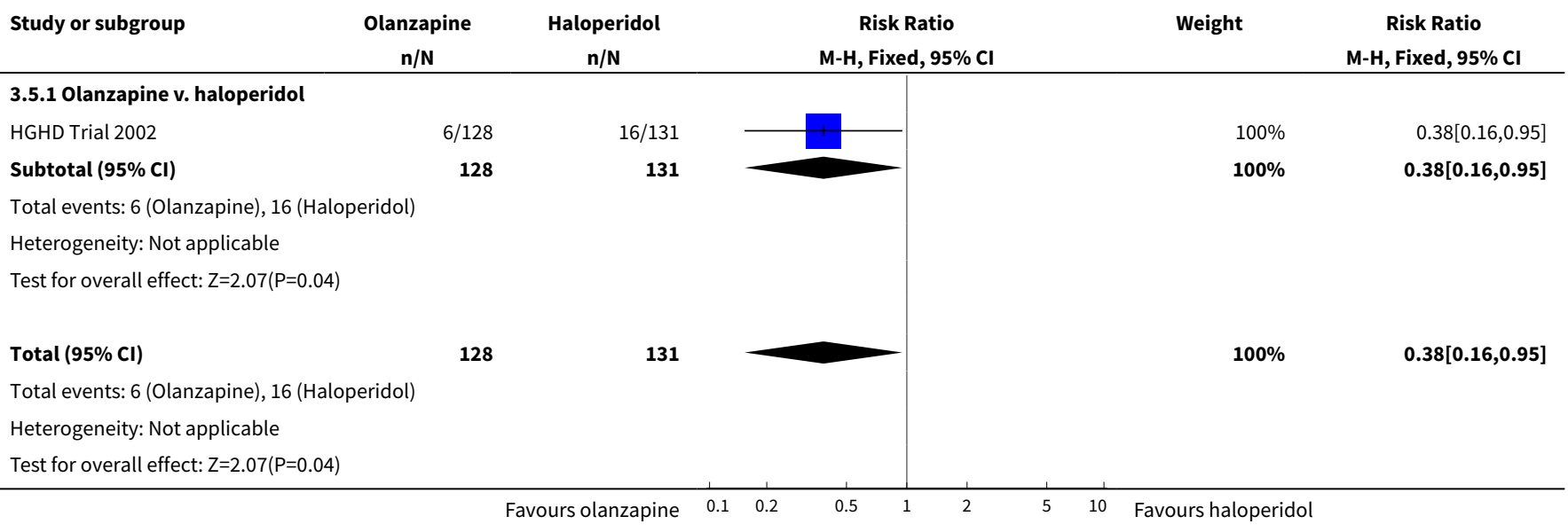

Analysis 3.6. Comparison 3 Olanzapine v other antipsychotic, Outcome 6 Insomnia.

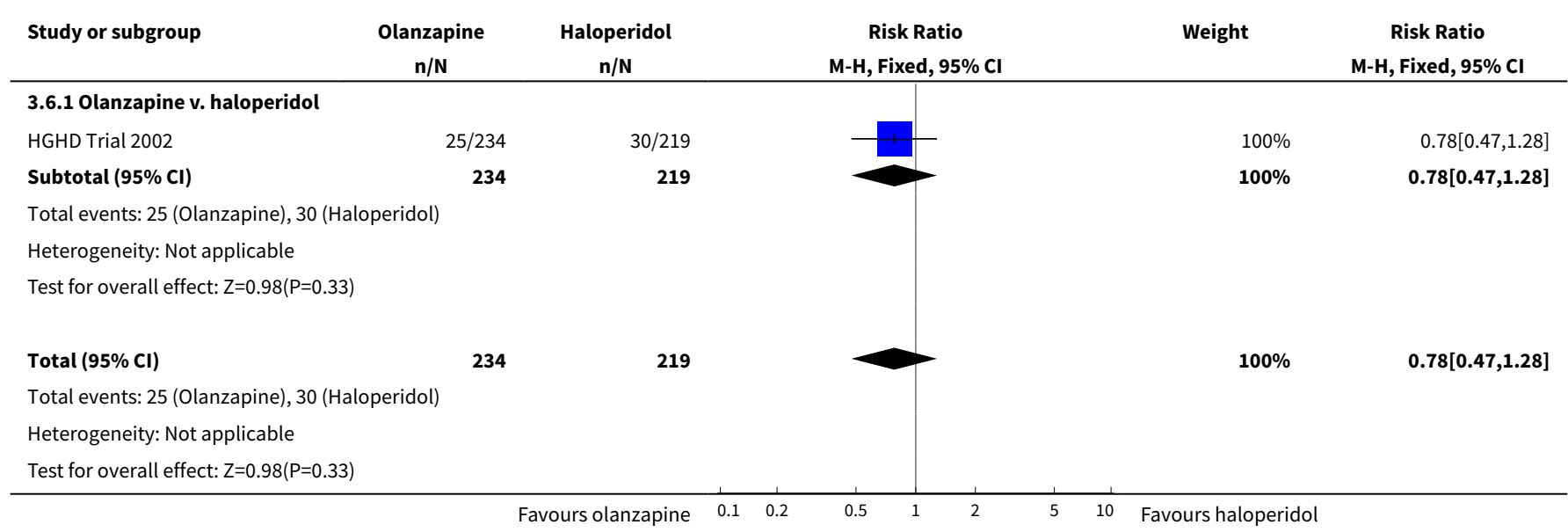

Analysis 3.7. Comparison 3 Olanzapine v other antipsychotic, Outcome 7 Somnolence.

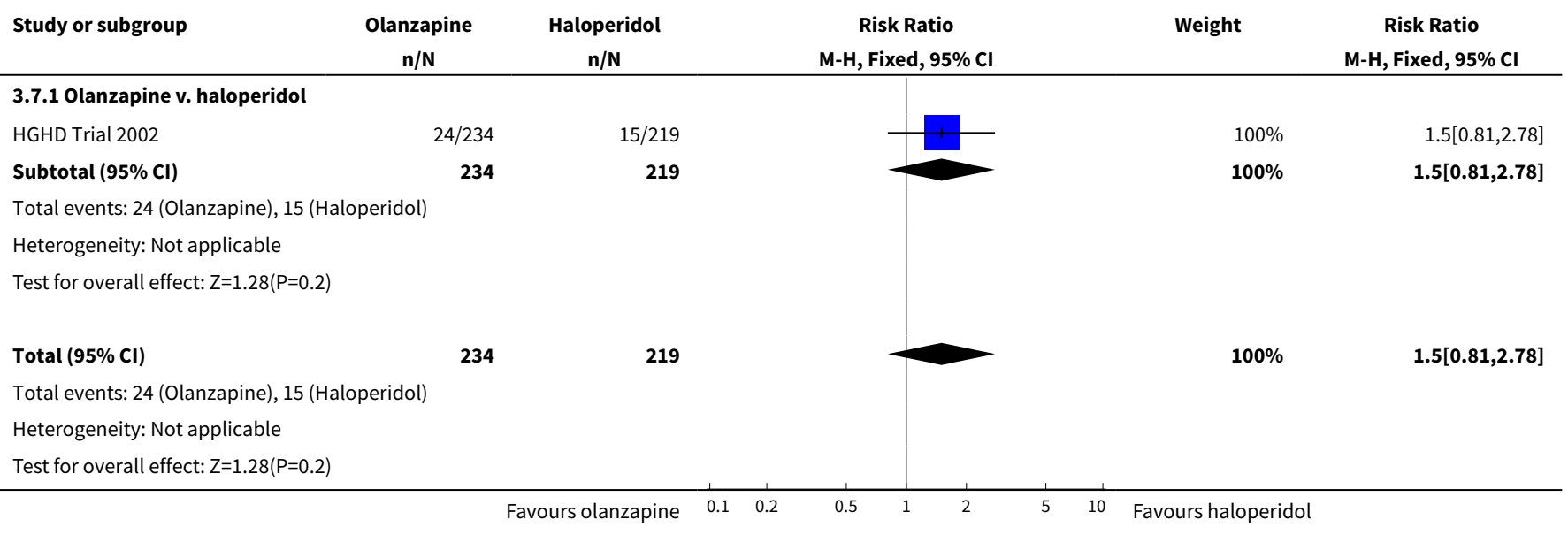


Analysis 3.8. Comparison 3 Olanzapine v other antipsychotic, Outcome 8 Weight Gain (dichotomous data).

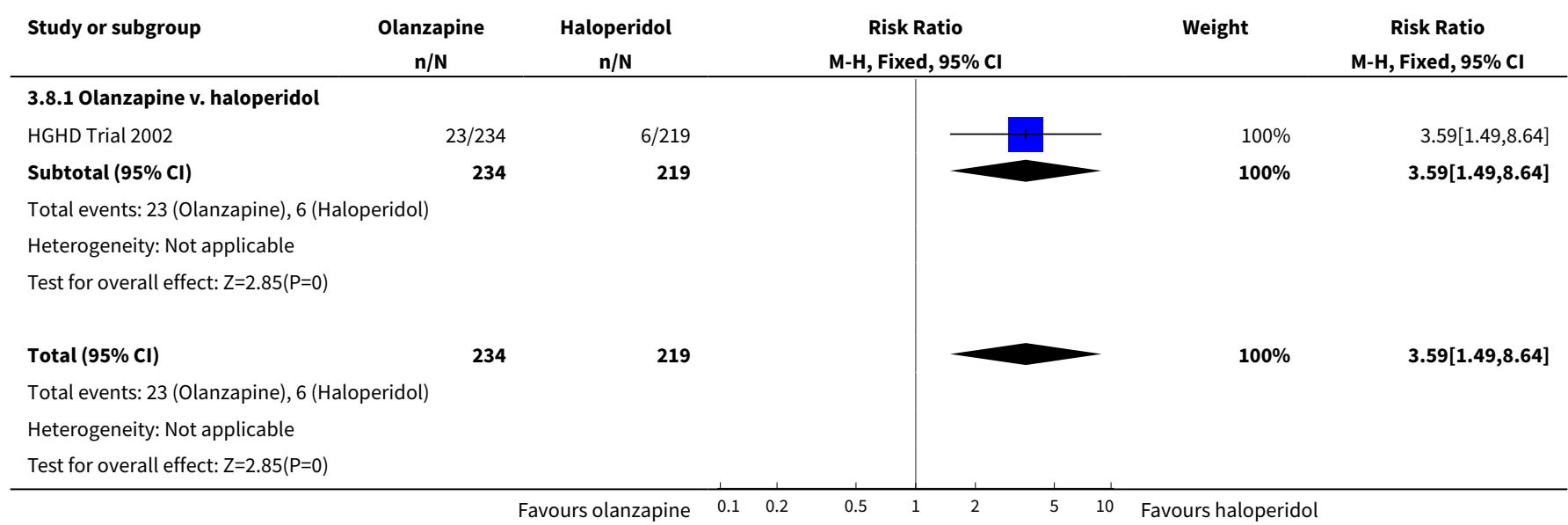

Analysis 3.9. Comparison 3 Olanzapine v other antipsychotic, Outcome 9 Akathisia.

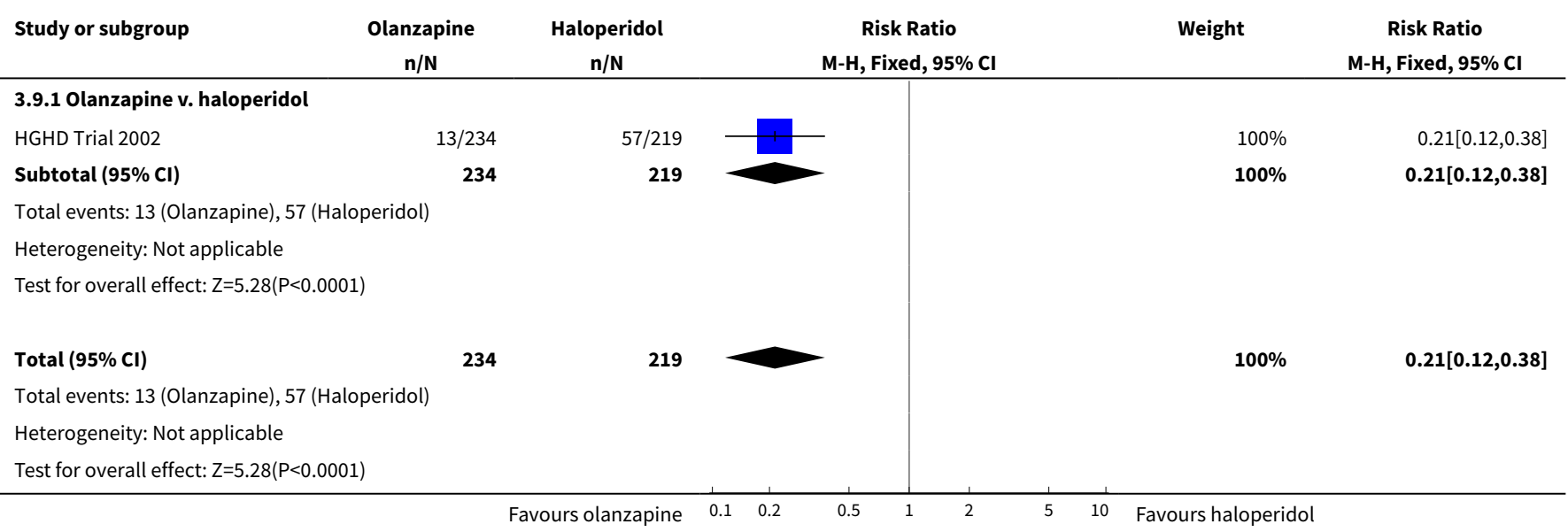

Analysis 3.10. Comparison 3 Olanzapine v other antipsychotic, Outcome 10 Tremor.

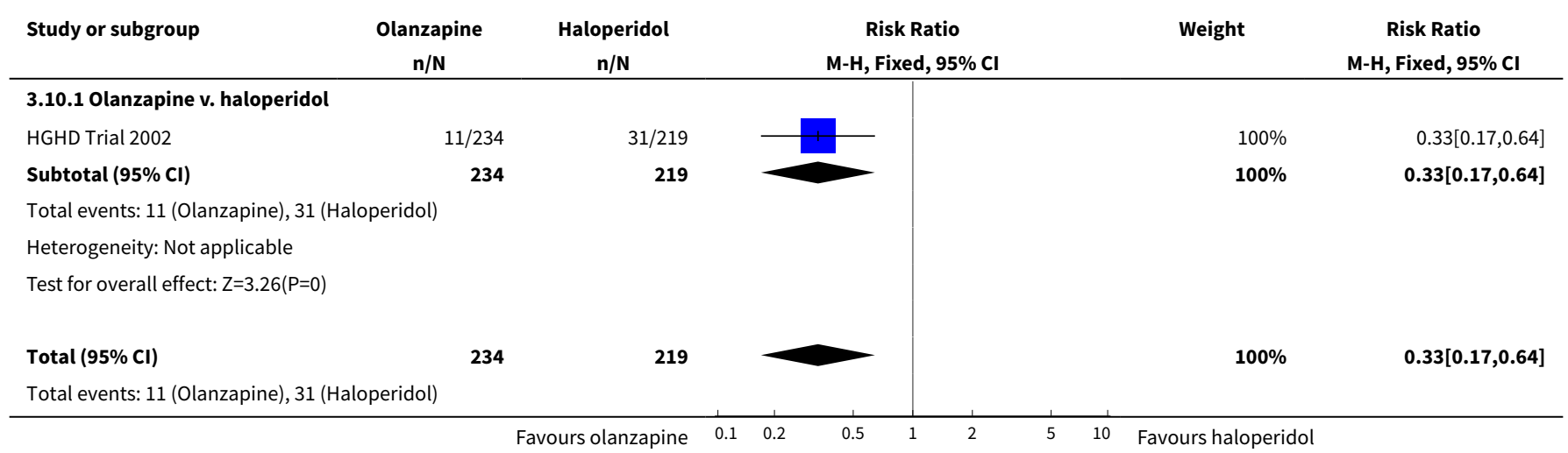




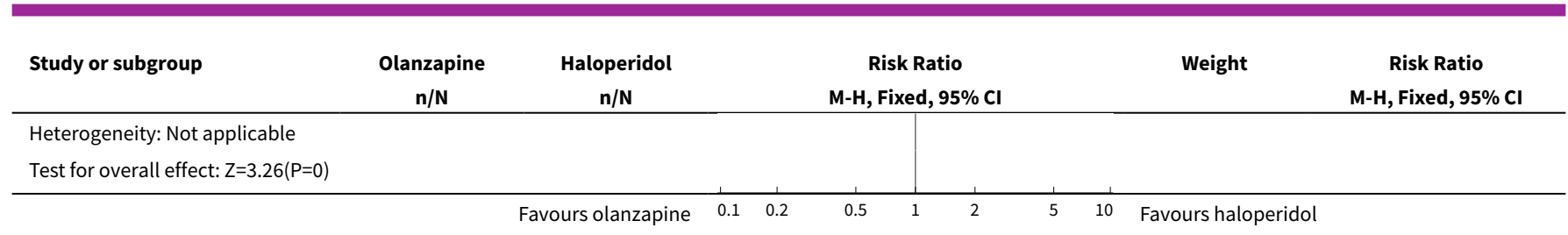

Analysis 3.11. Comparison 3 Olanzapine v other antipsychotic, Outcome 11 Infection.

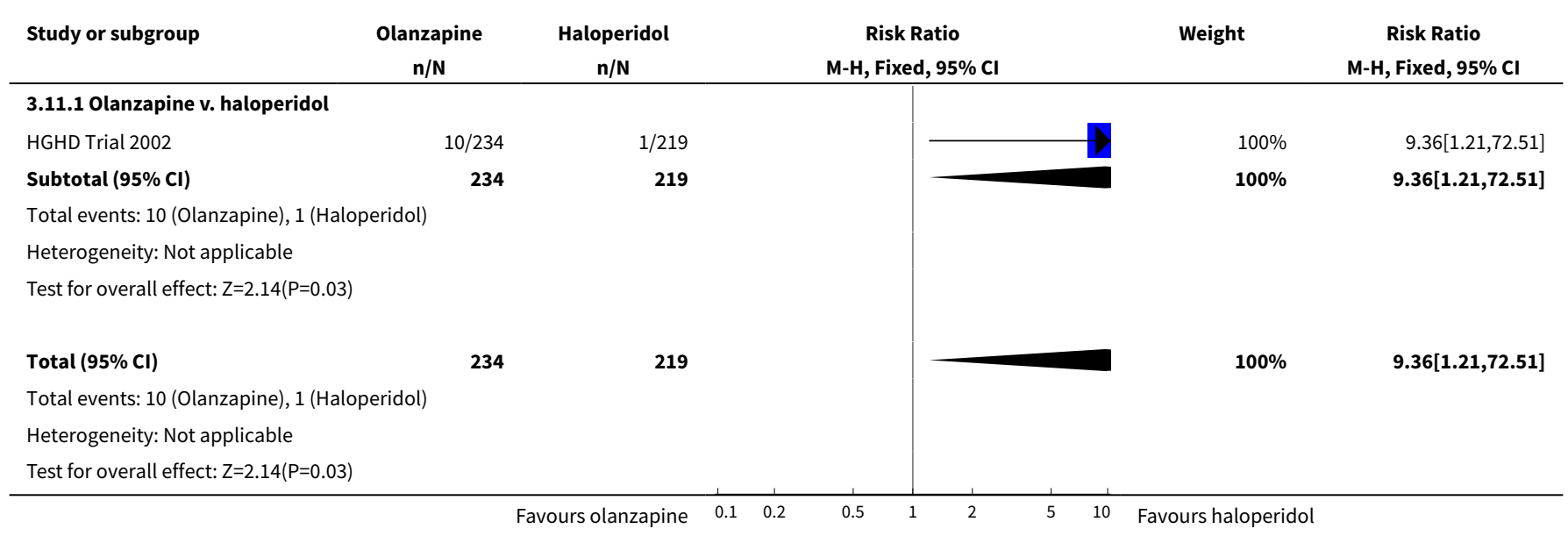

Analysis 3.12. Comparison 3 Olanzapine v other antipsychotic, Outcome 12 Hypertonia.

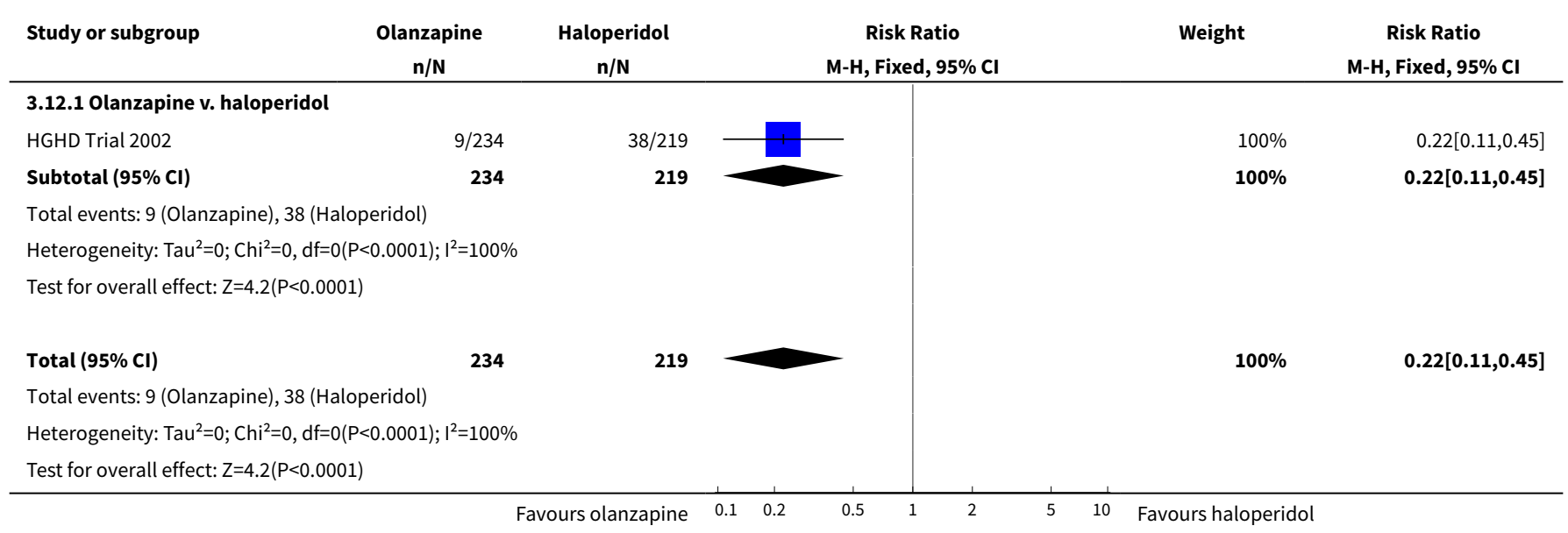

Analysis 3.13. Comparison 3 Olanzapine v other antipsychotic, Outcome 13 Fever.

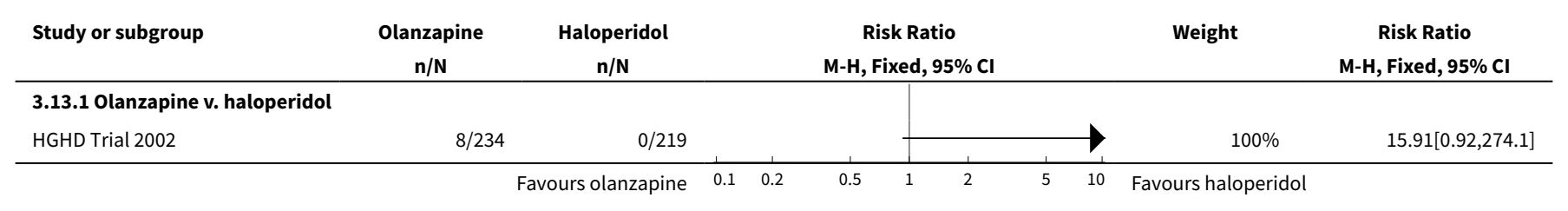




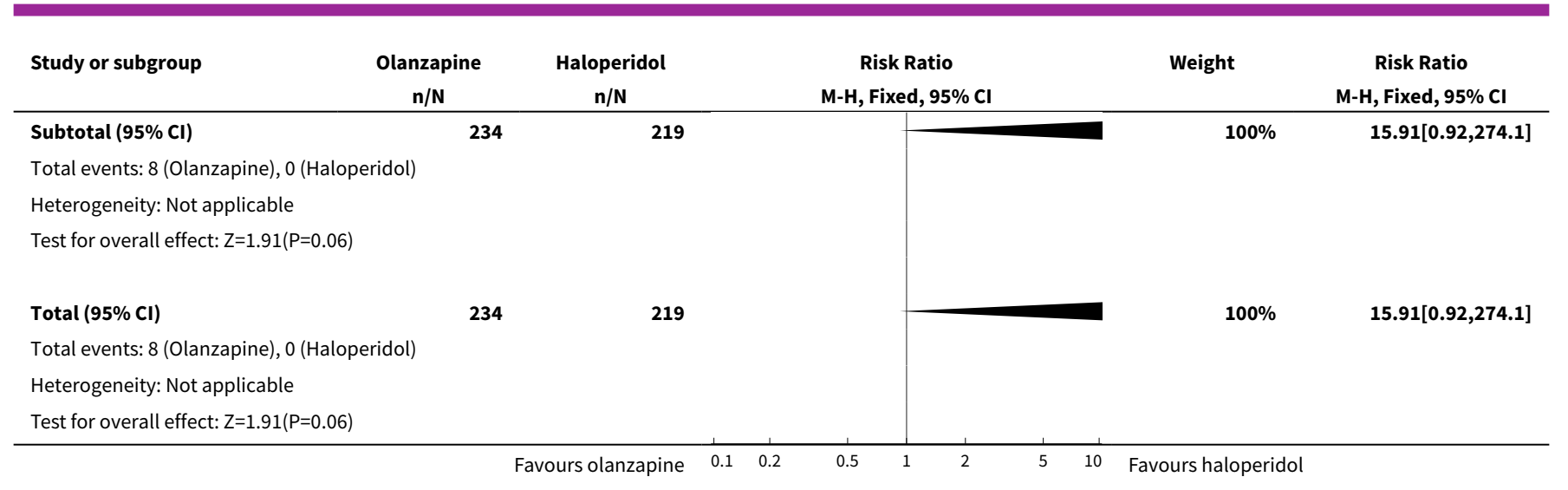

Analysis 3.14. Comparison 3 Olanzapine v other antipsychotic, Outcome 14 EPS.

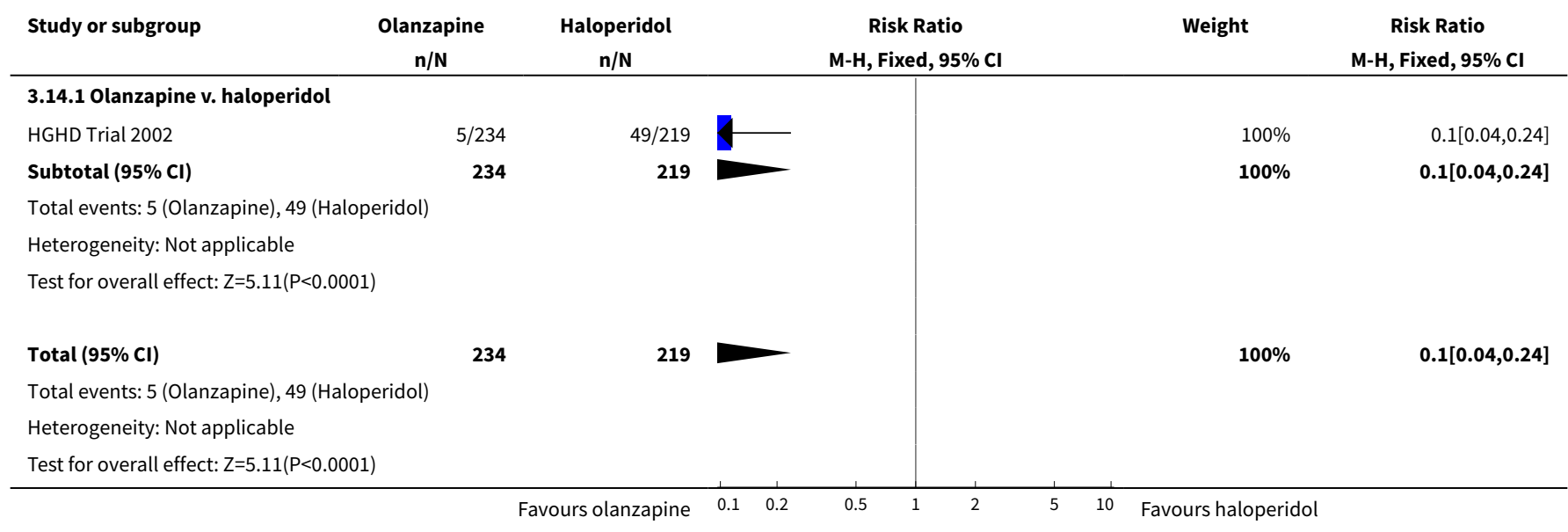

Analysis 3.15. Comparison 3 Olanzapine v other antipsychotic, Outcome 15 Dystonia.

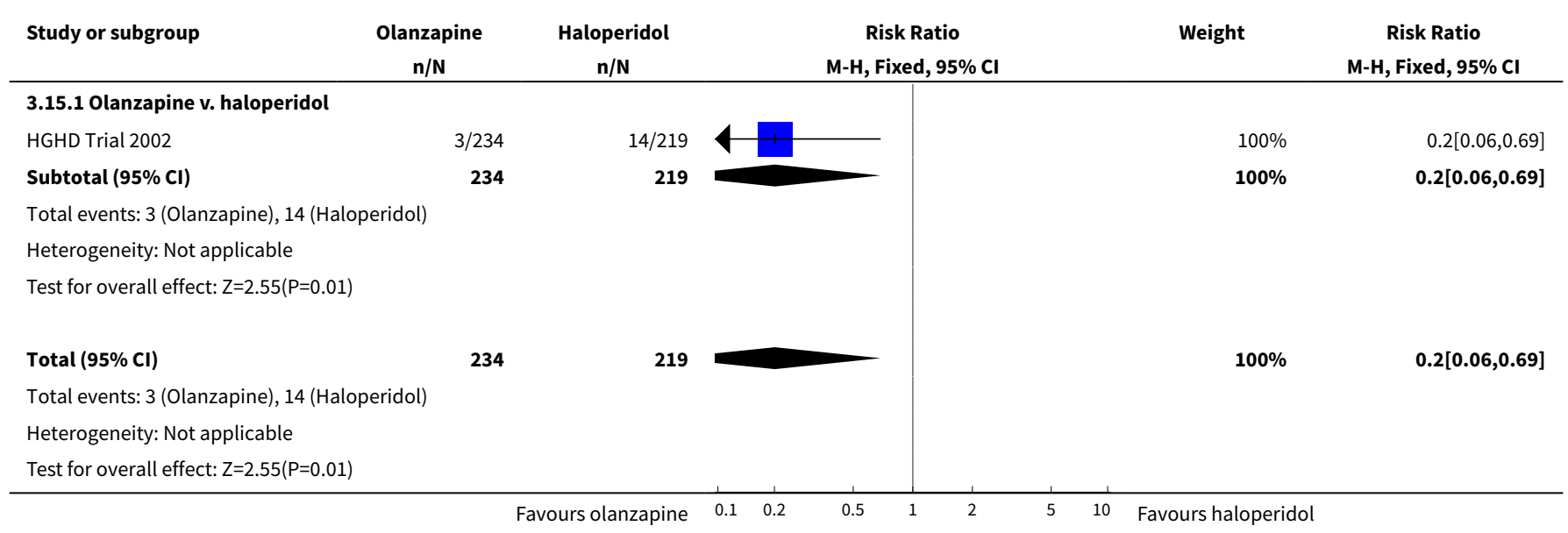


Analysis 3.16. Comparison 3 Olanzapine v other antipsychotic, Outcome 16 Hypokinesia.

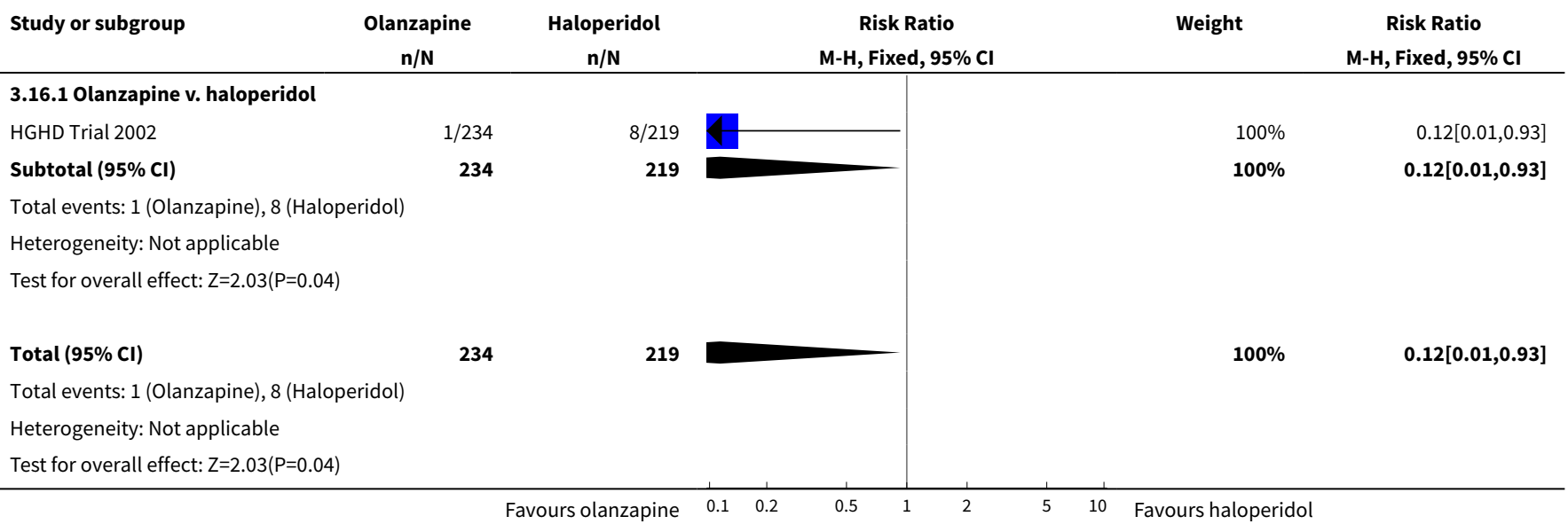

Analysis 3.17. Comparison 3 Olanzapine v other antipsychotic, Outcome 17 Increased Salivation.

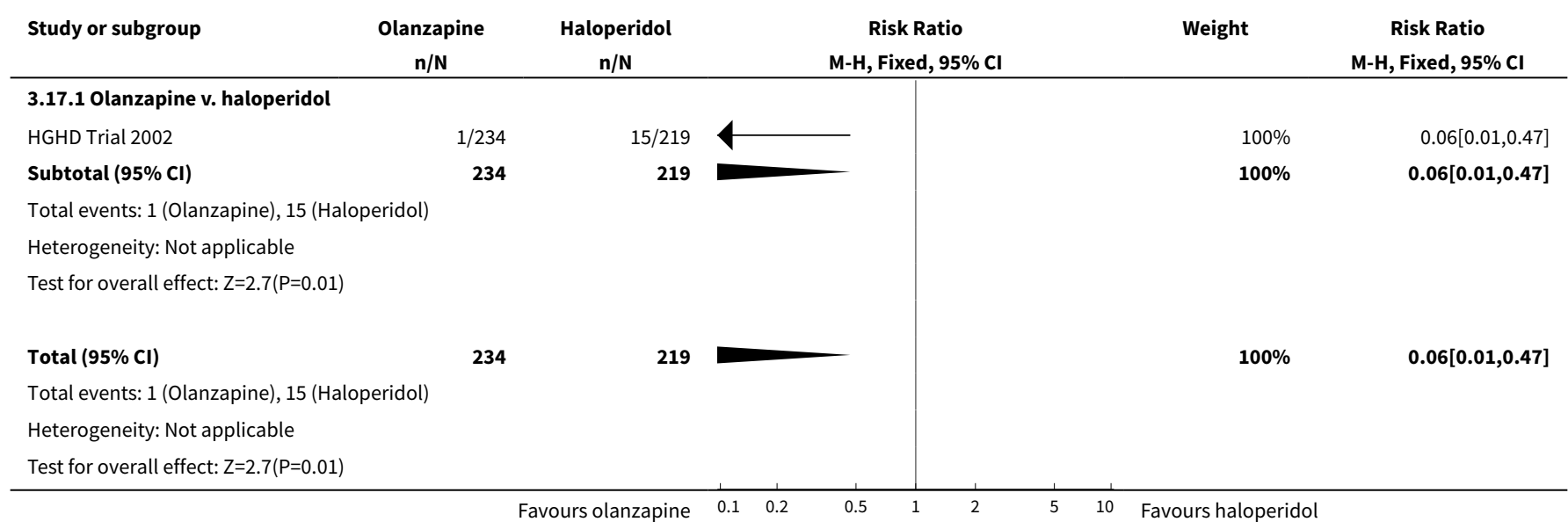

Analysis 3.18. Comparison 3 Olanzapine v other antipsychotic, Outcome 18 Dyskinesia.

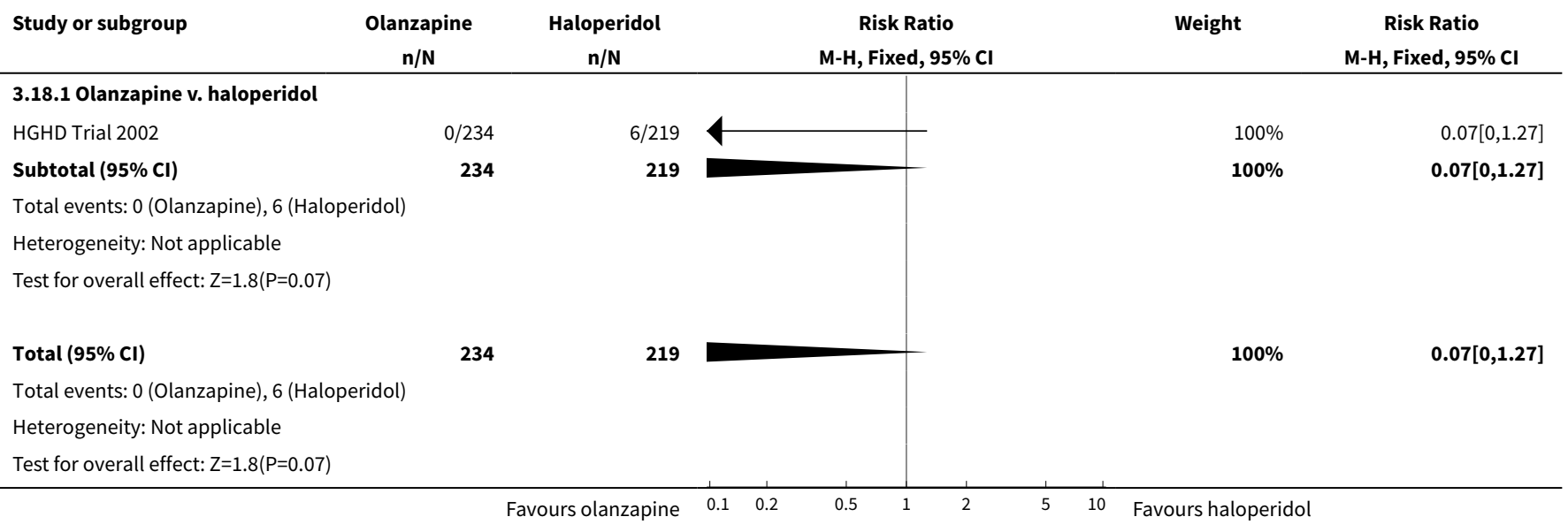


Analysis 3.19. Comparison 3 Olanzapine v other antipsychotic, Outcome 19 Failure to complete treatment due to adverse effects.

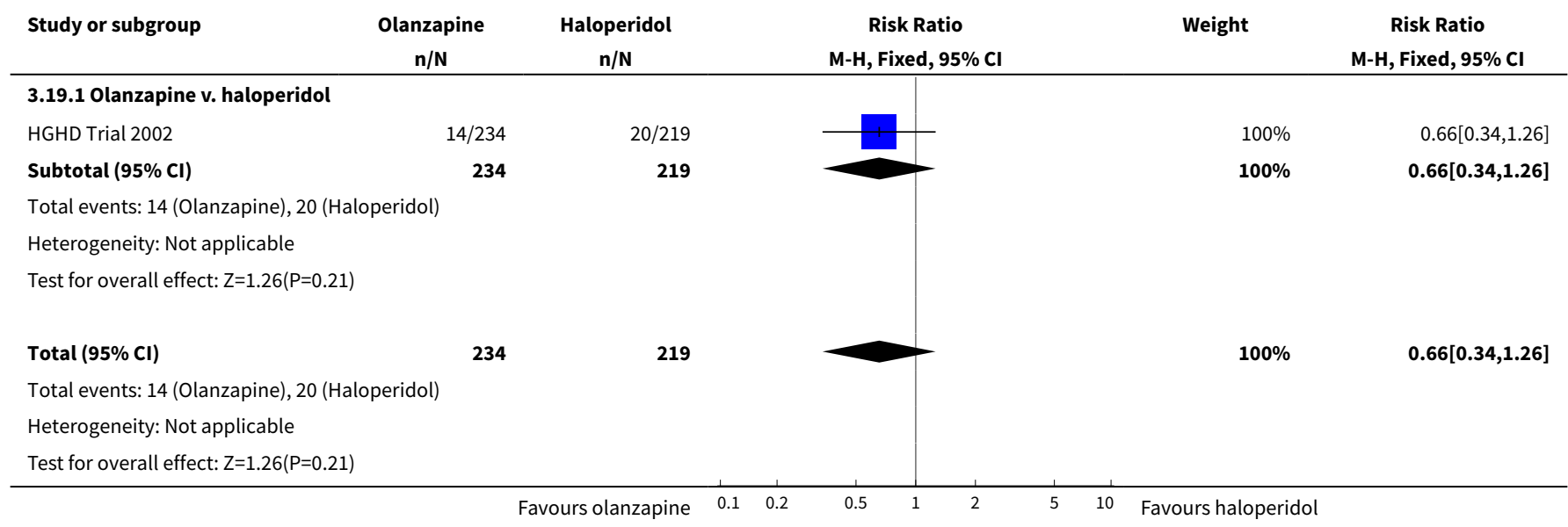

Analysis 3.20. Comparison 3 Olanzapine $v$ other antipsychotic, Outcome 20 Failure to respond - (at least 70\% reduction in YMRS).

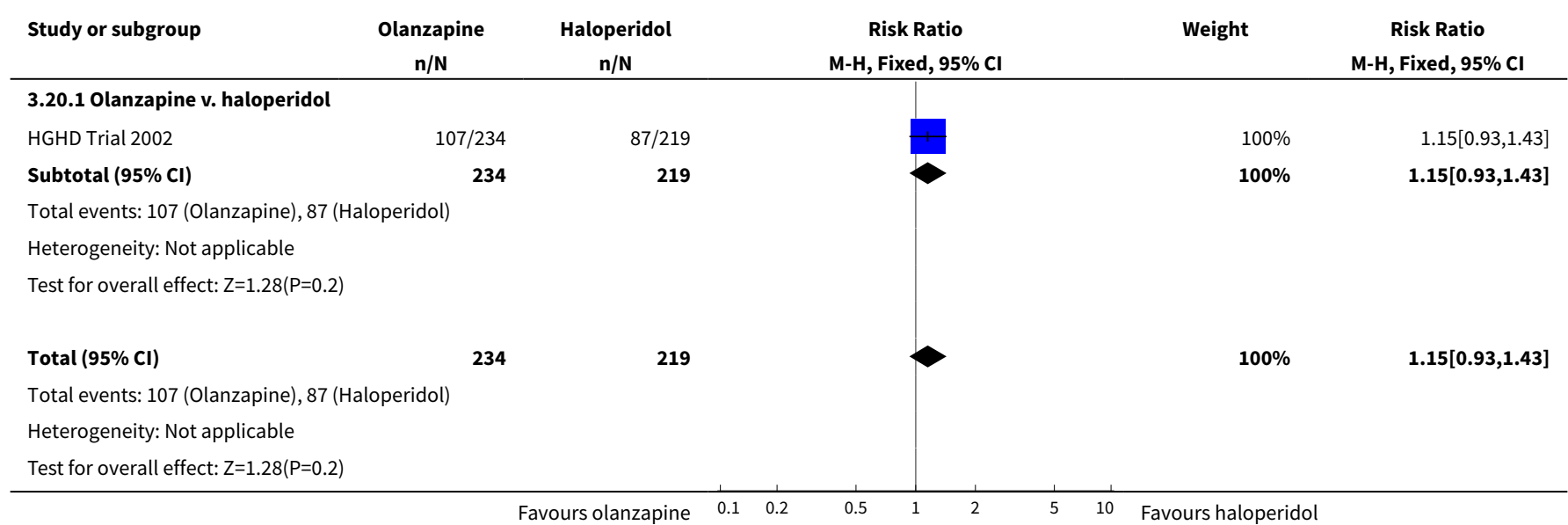

Analysis 3.21. Comparison 3 Olanzapine v other antipsychotic, Outcome 21 Failure to respond - excluding withdrawals (at least $70 \%$ reduction in YMRS).

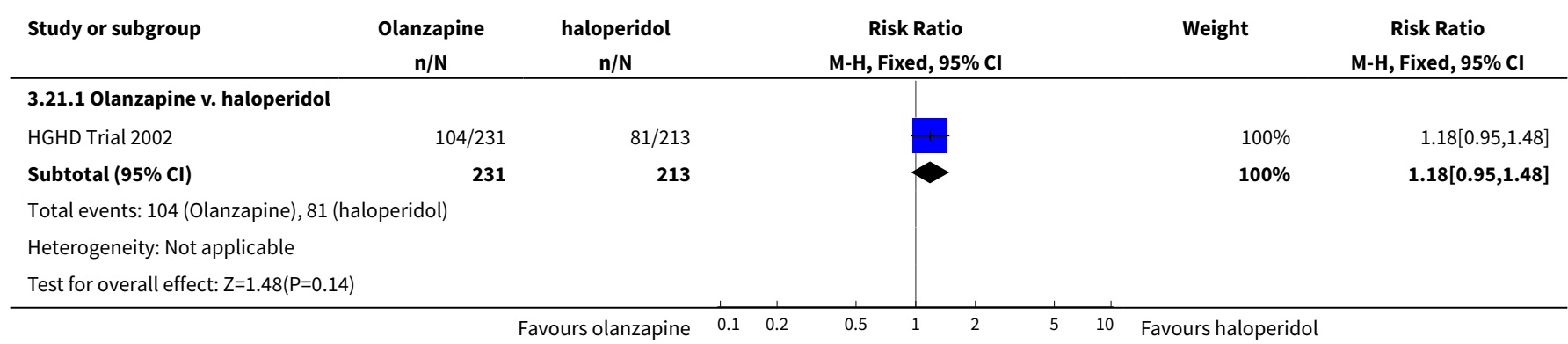




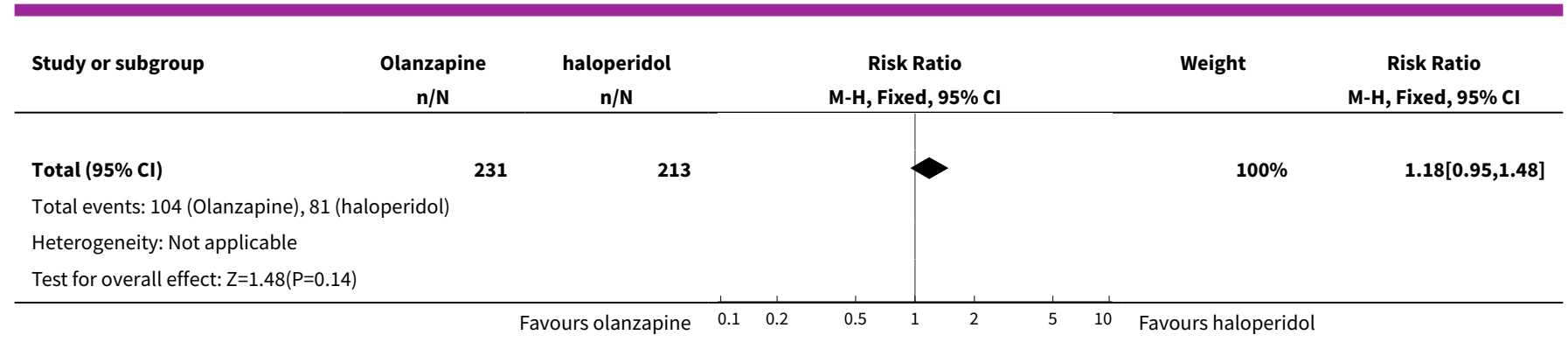

Analysis 3.22. Comparison 3 Olanzapine $v$ other antipsychotic, Outcome 22 Failure to respond - (at least $80 \%$ reduction in YMRS).

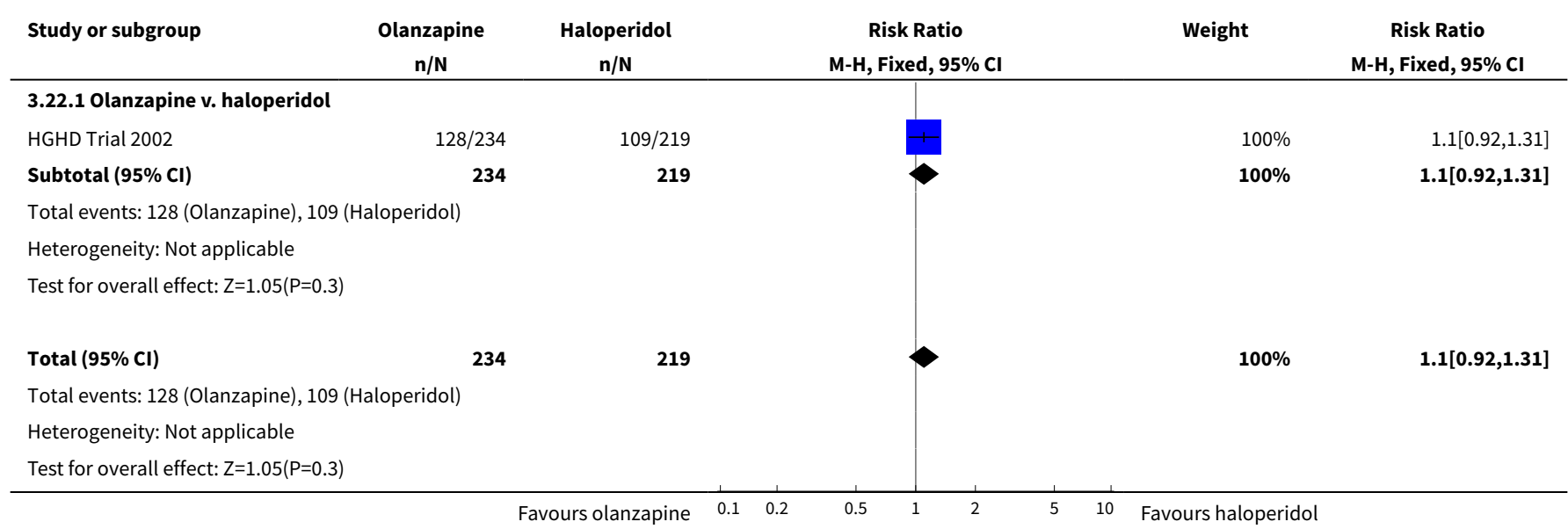

Analysis 3.23. Comparison 3 Olanzapine $v$ other antipsychotic, Outcome 23 Failure to respond - excluding withdrawals (at least $80 \%$ reduction in YMRS).

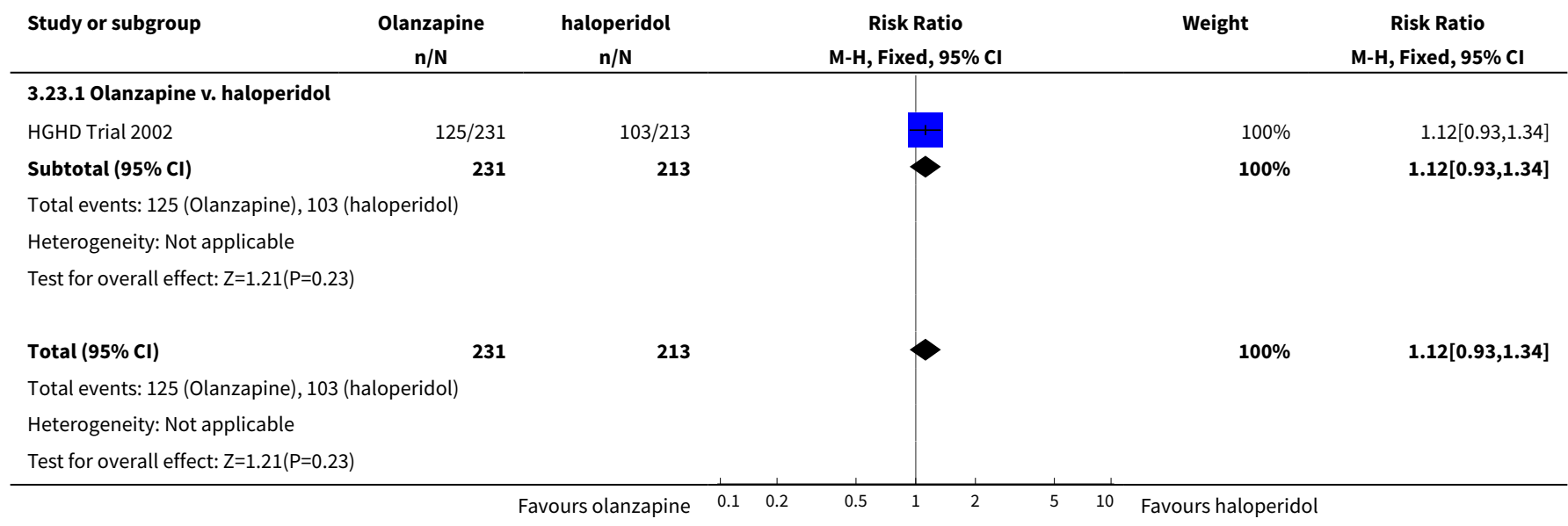




\section{FEE D B A C K}

\section{Olanzapine alone or in combination for acute mania}

\section{Summary}

This abstract is not clear, and seems to minimize or maximize various results about olanzapine. NB: I am referring only to the abstract.

High rate of failure to complete treatment needs to be in the conclusion section, not buried in the main results. One study shows a difference between olanzapine and divalproex in mania of -0.29 , barely significant, but the conclusion mentions this as the main finding. One 49 week study of olanzapine $v$ divalproex used suboptimal doses of divalproex as compared to normal doese of olanzapine ( $v$ placebo). A study showing divalproex superior to olanzapine for acute mania was not included. (Perhaps these two studies came out after the abstract). Olanzapine showed more weight gain and movement disorders (read EPS) than divalproex. These are serious problems, with long term consequences (diabetes, hyperlipidemia, EPS, etc.) "Weight gain" is not an adequate description of neuroleptic-induced adverse events. The conclusion in the abstract that olanzapine is an effective treatment for mania, and that it many be more efficatious than divalproex, is not supported by the limited data. Weight gain (without consequences) was the only adverse event mentioned in the conclusion, leaving out EPS, prolactin levels, and somnolence. There are other agents for acute mania which were not included, specifically lithium (except in combination with olanzapine). Olanzapine may be more useful for psychotic mania (or depression), where it can be used for a shorter time. This attempted review is ambitious, but with only six studies with many different aspects of the use of olanzapine, there could have been a clearer presentation, with reliance on evidence-based medicine. Although not an objective of this study, surely mention of other studies of other drugs for acute mania is required for a quality practice. Also, author involvement with the drug firm producing olanzapine needs to be noted.

I certify that I have no affiliations with or involvement in any organisation or entity with a direct financial interest in the subject matter of my criticisms.

\section{Reply}

Response to comments on:

Olanzapine alone or in combination for acute mania.

This abstract is not clear, and seems to minimize or maximize various results about olanzapine. NB: I am referring only to the abstract. High rate of failure to complete treatment needs to be in the conclusion section, not buried in the main results.

We agree that the high rates of failure to complete treatment are an important feature of the trials and limit the confidence that can be placed in the results. We do not agree, however, that this is "buried" in the results section. The conclusions are our view of the clinical bottom line and, in our opinion, are justified by the data. Conclusions are inevitably judgements - this is precisely why the objective data on trial withdrawals should be properly reported in the results section.

One study shows a difference between olanzapine and divalproex in mania of -0.29 , barely significant, but the conclusion mentions this as the main finding.

We are not sure if the comment refers to clinical or statistical significance. In terms of clinical significance, an effect size of 0.29 could be quite substantial although we have drawn attention in the review to the difficulties in interpreting the trial outcomes. The statistical imprecision of the result is described by the wide confidence interval and this reflects the uncertainty about the true difference between the treatments.

One 49 week study of olanzapine $v$ divalproex used suboptimal doses of divalproex as compared to normal doese of olanzapine ( $v$ placebo). A study showing divalproex superior to olanzapine for acute mania was not included. (Perhaps these two studies came out after the abstract).

Despite our extensive search, we did not find either of these studies. We would be delighted to examine these trials for inclusion in an updated review if the commentator could provide further details.

Olanzapine showed more weight gain and movement disorders (read EPS) than divalproex. These are serious problems, with long term consequences (diabetes, hyperlipidemia, EPS, etc.) "Weight gain" is not an adequate description of neuroleptic-induced adverse events. The potential link between weight gain and alterations in glucose metabolism is mentioned in the review. In view of recent concerns which have been expressed by regulatory authorities since the review was published, we will consider including it in the abstract when the review is updated.

The conclusion in the abstract that olanzapine is an effective treatment for mania, and that it many be more efficatious than divalproex, is not supported by the limited data.

In our opinion the data do support the superiority of olanzapine over both placebo and divalproex in reduction of manic symptoms.

Weight gain (without consequences) was the only adverse event mentioned in the conclusion, leaving out EPS, prolactin levels, and somnolence.

As above, we do not think that the conclusions section is the place to present the results. The results section of the review and abstract clearly describe all adverse events

There are other agents for acute mania which were not included, specifically lithium (except in combination with olanzapine).

The aim, as clearly described in both the peer-reviewed protocol and the review, was to review evidence for use of olanzapine not to review all treatment options in bipolar disorder.

Olanzapine may be more useful for psychotic mania (or depression), where it can be used for a shorter time. 
There was no data in the papers to support or refute this and we do not think such recommendations about subgroups of patients are justifiable at this time

This attempted review is ambitious, but with only six studies with many different aspects of the use of olanzapine, there could have been a clearer presentation, with reliance on evidence-based medicine.

We used the usual methods of systematic reviews, but we will consider how to make the review clearer when we revise it. The identification of any specific issues would be helpful.

Although not an objective of this study, surely mention of other studies of other drugs for acute mania is required for a quality practice.

Our conclusion is that "Clinicians should consider both the relative efficacy and the different incidence of specific adverse effects of available drugs". It is beyond the scope of this paper to refer to other studies.

Also, author involvement with the drug firm producing olanzapine needs to be noted.

All authors have signed the Cochrane Collaboration License for Publication and indicated that they have no conflicts of interest.

\section{Contributors}

Sender Eileen McGinn

Sender Description MPH

Sender Email qedeileen@aol.com

Sender Address 210 East 15th Street NY NY 10003

Date Received 20/08/2003 16:00:46

WHAT'S NEW

\begin{tabular}{lll}
\hline Date & Event & Description \\
\hline 3 November 2008 & Amended & Converted to new review format. \\
\hline
\end{tabular}

\section{H I S T O R Y}

Protocol first published: Issue 1, 2003

Review first published: Issue 3, 2003

\begin{tabular}{lll}
\hline Date & Event & Description \\
\hline 16 November 2002 & $\begin{array}{l}\text { New citation required and conclusions } \\
\text { have changed }\end{array}$ & Substantive amendment \\
\hline
\end{tabular}

\section{CONTRIBUTIONSOF AUTHORS}

Jennifer Rendell cowrote the protocol, identified studies, extracted data, and drafted the review.

John Geddes cowrote the protocol, extracted data, and drafted the review.

Harm Gijsman identified studies and extracted data.

Guy Goodwin commented on the protocol and text of the review.

Paul Keck commented on the protocol and text of the review.

\section{DECLARATIONSOF INTEREST}

JG has received research funding and support from Sanofi-Aventis and GlaxoSmithKline and is currently in discussion with several other companies that manufacture SSRIs about collaboration on planned independent trials and systematic reviews.

\section{SOURCES OF SUPPORT}

\section{Internal sources}

- Department of Psychiatry, University of Oxford, UK. 


\section{External sources}

- No sources of support supplied

\section{NOTES}

This review is in the process of being updated. We hope to publish the updated version in Issue 2, 2009.

\section{INDEX TERMS}

\section{Medical Subject Headings (MeSH)}

Antipsychotic Agents [ ${ }^{\star}$ therapeutic use]; Benzodiazepines; Bipolar Disorder [ ${ }^{\star}$ drug therapy]; Drug Therapy, Combination; Olanzapine; Pirenzepine [ ${ }^{*}$ analogs \& derivatives] [ ${ }^{*}$ therapeutic use]; Randomized Controlled Trials as Topic; Treatment Failure

\section{MeSH check words}

Humans 